Portland State University

PDXScholar

\title{
Biogeography, Morphology, and Systematics of the Mountain Cottontail, Sylvilagus nuttallii (Bachman, 1837), Mammalia: Lagomorpha: Leporidae
}

Johnnie H. French

Portland State University

Follow this and additional works at: https://pdxscholar.library.pdx.edu/open_access_etds

Part of the Biology Commons, and the Zoology Commons Let us know how access to this document benefits you.

\section{Recommended Citation}

French, Johnnie H., "Biogeography, Morphology, and Systematics of the Mountain Cottontail, Sylvilagus nuttallii (Bachman, 1837), Mammalia: Lagomorpha: Leporidae" (2020). Dissertations and Theses. Paper 5522.

https://doi.org/10.15760/etd.7396

This Thesis is brought to you for free and open access. It has been accepted for inclusion in Dissertations and Theses by an authorized administrator of PDXScholar. Please contact us if we can make this document more accessible: pdxscholar@pdx.edu. 
Biogeography, Morphology, and Systematics of the Mountain Cottontail, Sylvilagus nuttallii (Bachman, 1837), Mammalia:

Lagomorpha: Leporidae

$$
\text { by }
$$

Johnnie H. French

A thesis submitted in partial fulfillment of the requirements for the degree of

\author{
Master of Science \\ in \\ Biology
}

Thesis Committee:

Luis A. Ruedas, Chair

Deborah A. Duffield

Randy Zelick

Portland State University 2020 


\begin{abstract}
Widespread species often present taxonomic conundrums: are they truly a single panmictic species, or, is the widespread species in fact a polytypic species complex constituted by independently evolving, morphologically or otherwise cryptic species? One such broadly distributed taxon is Sylvilagus nuttallii, with distribution across the western United States, ranging from South Dakota to California, and from Canada to Arizona. The three subspecies constituting S. nuttallii are, however, geographically isolated and it has been hypothesized that they likely constitute independent, species level taxa. However, that study examined only two of the three holotypes, rather than broader geographic and non-geographic variation. In this study I examined the three subspecies under the framework of several distinct species concepts. I used 35 distinct cranial measurements, morphological, and dental, assessments, as well as molecular data in order to assess the taxonomic status of the subspecies in question constituting $S$. nuttallii. I collected de novo topotypic series, and examined all holotypes, as well as existing specimens in the American Museum of Natural History and Philadelphia Academy of Sciences. In addition, the effectiveness of species conservation efforts is contingent upon the understanding of its biology and evolutionary trajectory. By having a better understanding of the past, present, and hypothesized future of a species, conservation efforts may begin to mitigate the loss of biodiversity by the turn of the next century.
\end{abstract}




\section{Acknowledgements}

I would like to thank my family for their unending support and encouragement of my continued education and research. As well as, the members of my committee for their unending patience and assitance in the completion of this work. I truly appreciate the assistance and access to collections and specimens provided by the Philadelphia Academy of Sciences and the American Museum of Natural History. I would also like to thank and acknowledge the American Society of Mammalogists, the American Museum of Natural History's Theodore Roosevelt Grant, and the Forbes Lea Research fund for providing part of my research and travel expenses. Finally, I would like to thank the U.S. Fish and Wildlife Service's National Fish and Wildlife Forensics Laboratory for their continuing support of this research endeavor. 
Table of Contents

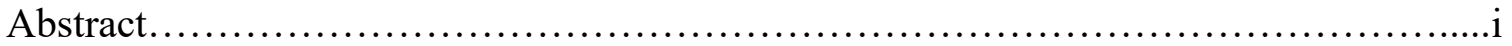

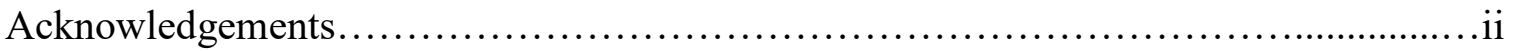

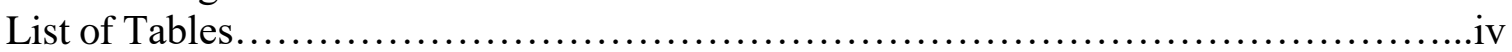

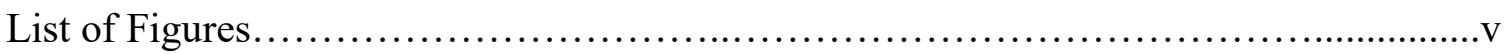

Preface...............................................................................

Chapter 1: An introduction and background of Lagomorpha (Brandt 1855), Leporidae

(Waldheim, Fischer 1817), and Sylvilagus (Gray 1867): Or, "What, if anything, is a rabbit

(Wood 1957)?"..............................................................

Chapter 2: Climate mediated ecological niche changes and shifting distribution patterns of the mountain cottontail species complex, Sylvilagus nuttallii (Bachman, 1837)................4

Chapter 3: Comparative cranial morphology and analysis of diagnostic upper and lower premolar characteristics of Sylvilagus nuttallii (Bachman, 1837) and its Subspecies......24

Chapter 4: Evolutionary relationships among the three subspecies of Sylvilagus nuttallii

(Bachman 1837) derived from genetic analysis of Cytochrome b.....................39

Chapter 5: "I have met no one who questions the existence of rabbits and hares, and I have been reluctantly forced to accept them (Wood 1957)?"...........................60

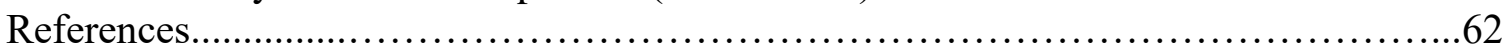

Appendix A: Ecological niche modeling data........................................ 72

Appendix B: Representative Concentration Pathway 2.6 model results .................97

Appendix C: Representative Concentration Pathway 4.5 model results ..................114

Appendix D: Representative Concentration Pathway 6.0 model results ................131

Appendix E: Representative Concentration Pathway 8.5 model results ................149

Appendix F: Model output results and figures for the Last Interglacial Period ...........166

Appendix G: Model output results and figures for the Last Glacial Maximum ..........183

Appendix H: Model output results and figures for the mid-Holocene period ...........200

Appendix I: Holotype and topotype cranial measurements ........................217 


\section{List of Tables}

Chapter 3

Table 3.1: Amount of variation accounted for during principal component analysis of Sylvilagus nuttallii skull shape and size.........................................42

Chapter 4

Table 4.1: Complete list of sequences used. Information on voucher number (whenever available), species or putative species complex, Genbank accession numbers, dataset and

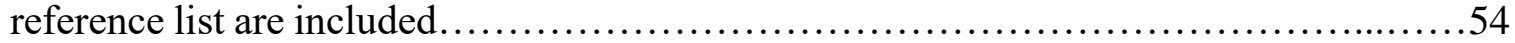

Table 4.2: Pairwise genetic divergences between groups for the cytochrome b (cytb) and $12 \mathrm{~S}$ rRNA (12S) data sets (below the diagonals), and respective standard errors (above the diagonals) 


\section{List of Figures}

Chapter 2

Figure 2.1: Current distribution map..........................................16

Figure 2.2: Last interglacial period map....................................... 17

Figure 2.3: Last glacial maximum map......................................... 18

Figure 2.4: Mid-holocene climate optimum map................................. 19

Figure 2.5: Representative Concentration Pathway 2.6 map.........................20

Figure 2.6: Representative Concentration Pathway 4.5 map...........................21

Figure 2.7: Representative Concentration Pathway 6.0 map.........................22

Figure 2.8: Representative Concentration Pathway 8.5 map........................23

\section{Chapter 3}

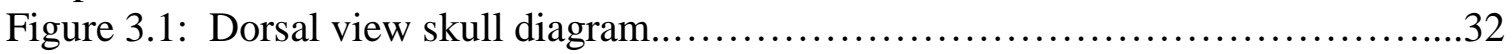

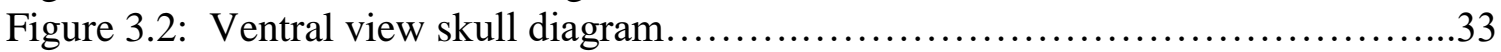

Figure 3.3: Mandibular diagram............................................. 34

Figure 3.4: Dorsal view of Sylvilagus nuttallii subspecies holotype.....................35

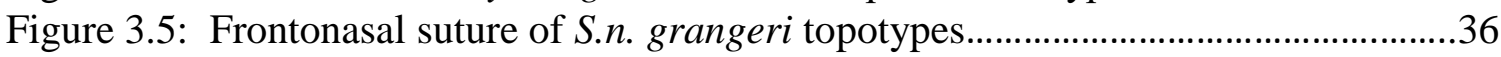

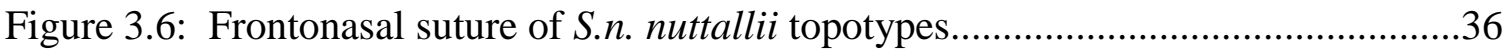

Figure 3.7: Frontonasal suture of S.n. pinetis topotypes........................... 37

Figure 3.8: Caudad view of the external occipital protuberance of S.n. granger..........37

Figure 3.9: Caudad view of the external occipital protuberance of S.n. nuttallii.........38

Figure 3.10: Caudad view of the external occipital protuberance of S.n. pinetis..........38

Figure 3.11: Ventral view of the holotypes and proposed neotype of the S. nuttallii ....39

Figure 3.12: Left lateral view of holotypes and proposed neotype of the $S$. nuttallii......39

Figure 3.13: Right lateral view of holotypes and proposed neotype of the S. nuttallii...40 Figure 3.14: Side by side comparison of the $2^{\text {nd }}$ upper pre-molar of Sylvilagus nuttallii.40 Figure 3.15: Side by side comparison of the $3^{\text {rd }}$ lower pre-molar of Sylvilagus nuttallii.41

Figure 3.16: Principal component analysis................................. 41

\section{Chapter 4}

Figure 4.1: Cytochrome $b$ phylogeny........................................ 50

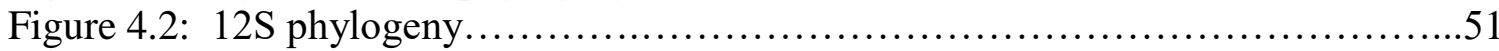

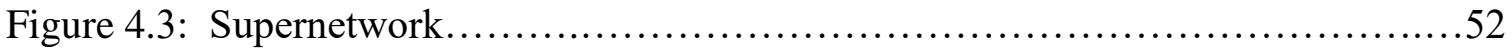

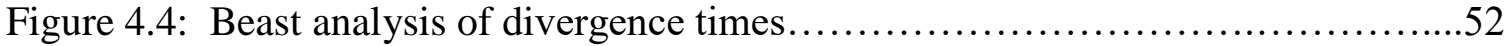

Figure 4.5: Maximum Likelihood phylogeny................................. 53 


\section{PREFACE}

This work is the culmination of a hypothesis developed more than 20 years ago from the examination of two skulls. Over the course of the following chapters, we will re-examine those holotypes as well as the third holotype of $S$. nuttallii in the species complex. In addition to the holotype specimens, we will examine all the available topotype specimens to in order to determine morphologically distinct characters that can by used in the future for identification of this cryptic species. We will also examine the shifting ranges of the three sub-species in the light of climate change from the last inter-glacial period up through the turn of next century. Finally, we will conduct genetic analysis of two mitochondrial genes from topotype specimens. Using these three methods we will test the hypothesis of conspecificity. 


\section{CHAPTER 1}

An introduction and background of Lagomorpha (Brandt 1855), Leporidae (Waldheim, Fischer 1817), and Sylvilagus (Gray 1867): Or, "What, if anything, is a rabbit (Wood 1957)?"

For most of the muddied taxonomoic history of Lagomorphs, they have been combined into an order with the Rodents. Brandt (1855) was the first to name the rabbits, hares, and pikas as Lagomorphs. It was Gidley in 1912 (Wood 1957) to formally separate them into their own Order, based primarily on dental formula, particularly the second set of incisors, as well as several skeletal structures. He also suggested an ancient origin for both orders. Albert E. Wood (1957) notes, "The two lines are independent back to the Paleocene, with no suggestion of greater affinity then than now. The similarities are of two types-those determined by the fact that both are gnawers, and those that merely indicate that both are rather primitive mammals." O'leary suggested a clade age for Lagomorpha of 53 MYA based on fossilized morphological characters. Murphy et.al. (2007) and Meredith et.al. (2011) suggest a clade age range between 71 and 94 mya. Ruedas, Mora, Lanier (2018) give an excellent account of fossil descriptions supporting this clade age. The first true Lagomorphs occured sometime before 42 mya and the divergence of the Ochotonids and Leporids which is indicated by the first occurrence of Ochotonidae in fossil record dated to $42-46$ mya (Storer 1984). The leporids diverged 13 mya (Mathee et.al. 2004). Shortly thereafter, Lepus, the true hares, diverged at 11.8 mya from the rest of the leporids (Mathee et.at. 2004). It should also be noted that this is the date when the cottontails, Sylvilagus and Brachylagus diverged on their own 
evolutionary paths with Brachylagus being at the root of the clade (Mathee et.at. 2004). True cottontails diverged from their pygmy relative $\sim 4$ mya (Mathee et.al. 2004).

Within the genus Sylvilagus, there are 18 species and many more sub-species of cottontail, many of which are under contention or have been recently revised (Ruedas et.al. 2017, Ruedas et.al. 2019). The reason for this contention is simple, they are numerous and barely diversified (Simpson 1961). Consider this: the amount of divergence between the families Ochotonidae and Leporidae is substantially less than the average mammalian family, and in fact they are so close, it could be justifiable to consider them subfamilies of a single family instead of an Order (Simpson 1961).

For more than 20 years the taxonomic status of the Sylvilagus nuttallii group has been under scrutiny (Ruedas 1998), and questions about their place among the genera have been around since Marcus Lyon reorganized the Lagomorphs in 1904. This confusion was seemingly resolved with the Magnum Opus "A Molecular Supermatrix of Rabbits and Hares Allows for the Identification of Five Intercontinental Exchanges During the Miocene" by Mathee et.al. in 2004. In the paper, they conclude S.nuttalli is most closely related to S. audubonii. However, this analysis was based solely on genetic analysis with no voucher specimen for reference. Alves and Hacklander (2008) note that the most challenging problem within Lagomorpha is defining relationships between species. They conclude the only suitable way to proceed is to use an integrated taxonomic combination of morphological and molecular data in order to place taxa in evolutionary groups. 
The Sylvilagus nuttallii group began its taxonomic history as two species and two subspecies: Lepus nuttallii (Bachman 1837), Lepus sylvaticus pinetis (Allen 1894) and Lepus sylvaticus grangeri (Allen 1894). During Nelson's revision of the Order in 1909, he classified them as one species, S. nuttallii, and three subspecies. However, even he had trouble distinguishing the slight morphological differences that have been conserved across the eons. He included five specimens of Sylivlagus floridanus in his cranial measurements of the species group, specifically, S.n.pinetis (Hoffmeister and Lee 1963). Even with this critical error, Nelson was seemingly correct in his determination that $S$. nuttallii is more closely related to $S$. floridanus than other members of the genus. Given the amount of historical and current disagreement on the taxonomic status of the Leporids, it is no wonder Albert Wood proposed his classic question "what, if anything, is a rabbit?" and went on to begrudgingly admit the existence of rabbits.

Here we present evidence of the existence of not one, but three species of rabbit using and integrative taxonomic approach based not just on morphological data, but molecular ecological data as well. With these data, we will test the hypothesis of conspecificity and make recommendations for the species complex moving forward. 


\section{CHAPTER 2}

Climate mediated ecological niche changes and spatial shifts in distribution patterns of the mountain cottontail species complex, Sylvilagus nuttallii (Bachman, 1837)

\section{ABSTRACT}

The climate envelope of a species can be described as the range of nvironmental variation within which a species can survive. A species has two options to continue its survival in the face of a changing climate: adapt or move. Where adaptation occurs on the order of thousands or millions of years, climate change can occur much more rapidly. Consider the changes that have occurred since the last interglacial period, 150,000 years before the present (B.P.). Since then, the earth has seen an ice age advance and retreat, periods of relative climatic stability, and periods of rapid warming due to anthropogenic forcing. Herein, we use maximum entropy ecological niche modeling to examine the distributional patterns of the mountain cottontail species complex, Sylvilagus nuttalli (Bachman, 1837). We begin at the last interglacial period and run models through four possible scenarios for the future distribution of the species based on the Intergovernmental Panel on Climate Change's fifth assessment report (IPCC5). We used 35 bioclimatic variables and elevation to predict past, present, and future distribution patterns based on current known occurrences. Areas of distribution range from a maximum of $1,483,125 \mathrm{~km}^{2}$ during the Holocene Climate Optimum to a minimum of $289,844 \mathrm{~km}^{2}$ during the Last Glacial Maximum climatic envelope. Predictions of future distributions based on the IPCC5 range from 1,092,656 $\mathrm{km}^{2}$ under RCP 4.5 to 779,188 
$\mathrm{km}^{2}$ under RCP 8.5 at the end of this century, showing a loss of habitat of between $15 \%$ and $40 \%$ from the $1,291,719 \mathrm{~km}^{2}$ currently occupied by the species complex.

\section{INTRODUCTION}

Elucidating the varied elements forming a species' overall distribution has long been under scrutiny by evolutionary biologists (Parmesan, 2006) and ecologists alike (Caughley et al., 1988, Lawton et al., 1994). Climate change, even small changes in temperature, has already been identified a critical element in restricting and reducing existing species' distribution, as well as shifting and shrinking of geographic ranges, depending on the tempo and magnitude of the change (Beever et al., 2011). The six warmest years on record have all occurred since 2010. Last year-2018 — ranked as the second (NASA) or third (NOAA) warmest year on record after three straight years of record temperatures between $2014-2016$. The average temperature was $0.84^{\circ} \mathrm{C}$ above normal and marked the 41 st consecutive year in which the temperature exceeded the 20th century average as computed by NOAA.

Generally, species distributions follow the principle of maximum entropy and will expand their range until conditions are no longer favorable for their survival (Jaynes, 1957). Given that climate - and in particular temperature and humidity — can limit the distribution of species, it obtains that regional climatic envelopes can then be used to predict species distributions across geologic time scales. The climate envelopes can be considered as a multivariate space whose upper and lower boundaries limit when and where a species can survive in a particular area (Polly and Eronen, 2010). Recognizing the mechanisms altering species distribution affects not only the understanding of 
population level responses but also conservation management efforts and strategies associated with the latter in order to mitigate the former (Stenseth et al., 2002, Root and Schneider, 2006).

Lagomorpha, or lagomorphs, the order of mammals consisting of rabbits, hares, and pikas, has been shown to be particularly vulnerable to climate change (Beever, et al., 2013). Within Lagomorpha, there are two extant families: Ochotonidae and Leporidae. The pika family, Ochotonidae, is constrained to high plateaus and talus fields in Asia and North America, with the caveat that they occur at lower elevations as latitude increases. Many of the species in Ochotonidae comprise restricted populations that are currently suffering from local extirpations or severe range contractions (Li and Smith, 2005; Galbreath, et al., 2009; Beever, et al., 2003; Grayson, 2005). The family Leporidae (rabbits, hares, and cottontails) has a much broader distribution and inhabits virtually every biome on the planet. In spite of this wide ranging distribution, several endemic genera and species also face extirpation or severe range shifts or contraction in the face of climate change, including Brachylagus, Bunolagus, Caprolagus, Nesolagus, Pentalagus, Pronolagus, Romerolagus, and several species in Lepus and Sylvilagus (Hoffman and Smith, 2005; Smith et al., 2018).

We examined the last 150,000 years of distributional shifts of one species of Lagomorpha: the mountain cottontail Sylvilagus nuttallii (Bachman, 1837), using ecological niche modeling. The oldest examples of modelling species distribution date to 1924, with Thomas Harvey Johnston's attempt to predict invasive species spread in Australia and Hittinka's assessment of the distribution of European species based on 
climate variables (Pearson and Dawson, 2003). The first peer reviewed niche model belongs to Nix et al.'s attempt to identify suitable habitats into which to expand cropland in Australia (Nix et al., 1977). Since then, species distribution models have become an increasingly important tool in climate change research, ecology, conservation biology, and evolution (Guisan and Thuiller, 2005). Correlative species distribution models (SDMs) are used to predict potential distributions given known occurrence data and a set of bioclimatic envelopes which limit the entropy of distribution of the species (Elith et al, 2010). Here, we use a set of 36 bioclimatic envelope layers to examine the distribution and shifting range of $S$. nuttallii. We examined five distinct time periods whose climates are hypothesized to differ, including: the Last Interglacial Period (LIG), the Last Glacial Maximum (LGM), the Holocene Climate Optimum (HCO), the current climate envelope, and the projected evelope at the end of the 21 st Century. Projections for the end of the $21^{\text {st }}$ century were based on the four representative concentration pathways outlined in the Intergovernmental Panel on Climate Change's fifth assessment report. The goal of this research was to 1) generate suitable habitat models for the $S$. nuttallii species complex; and 2) to identify climatic envelopes and environmental variables restricting species occupancy and range, thus providing a guide for conservation strategies associated with this key prey species and its predators.

\section{MATERIALS AND METHODS}

We developed the initial ecological niche models for S. nuttallii sensu lato (as currently construed) and sensu stricto (this paper), to estimate their past, present, and future distributions. The Global Biodiversity Information Facility (GBIF 2014) was used 
to retrieve known occurrence data. GBIF allows free access to records from many different natural history museum specimens worldwide. Specimen records that lacked latitude/longitude points were excluded from this assessment of distribution; because we could not physically verify the species identification of all the museum-based occurrence records, those that were known to be extralimital with respect to known current range were excluded from our data analysis. The trimmed occurrence data were then georeferenced in ArcMap 10.2 (ESRI 2013) to ensure the accuracy of recorded data and that plotted points corresponded with the original locality descriptions. Duplicate records and highly correlated environmental layer values (ENMTools 1.4.3) were removed to avoid a highly skewed output. We retrieved 35 environmental variables, 19 of which are available in WorldClim (Hijmans et al. 2005), with the remainder from CliMond (Kriticos et al. 2012), as well as elevation, the latter retrieved from Data Basin (2014). The bioclimatic layers used represent a range of climate conditions needed for species survival; bioclimatic envelope layers include a range of variables such as temperature, precipitation, isothermy, and solar radiation values. We used ArcMap 10.2 to limit variables to our defined study area. We then used MaxEnt v. 3.3.3k (Phillips et al. 2006) to run the ecological niche models in order to estimate past, present, and future, range distributions based on the existing museum data for specimens identified as S. nuttallii species or taxa subsumed therein as subspecies (Appendix A). MaxEnt models are based on the maximum-entropy principle developed by Jaynes (1957) and has proven to be an accurate and reliable method for predicting range shifts and species distributions (Rissler \& Apodaca 2007). We developed models covering three paleoclimate time periods, 
current, and future, to assess range shifts in the species. In addition, we used four scenarios for predicted global climate change from the special report on emissions developed under the Intergovernmental Panel on Climate Change's fifth assessment report (IPCC 2014) to assess potential range expansion or contraction for the individual subspecies contained in S. nuttallii. IPCC scenario 2.6 hypothesizes a mean increase of $1^{\circ} \mathrm{C}$ by $2100\left(\right.$ range $\left.0.3^{\circ}-1.7^{\circ}\right)$. IPCC scenario 4.5 hypothesizes a mean increase of $1.8^{\circ} \mathrm{C}$ by $2100\left(1.1^{\circ}-2.6^{\circ}\right)$ while scenarios 6.0 and 8.5 hypothesize mean increases of $2.2^{\circ} \mathrm{C}$ $\left(1.4^{\circ}-3.1^{\circ}\right)$ and $3.7^{\circ} \mathrm{C}\left(2.6^{\circ}-4.8^{\circ}\right)$ respectively.

The methods used to analyze the importance of the bioclimatic variables in MaxEnt are: 1) percentage contribution and permutation importance and 2) the jackknife test of variable importance. We used environmental variable contribution and jackknife test results to assess which bioclimatic layer was most important in limiting the range of S. nuttallii. Both methods use slightly different algorithms to determine variable importance. In the first test, the MaxEnt algorithm permutes values along background and training points and calculates the decrease in area under the receiver-operator curve (AUC). AUC is a measure of predictive accuracy based only on the ranking of locations and is interpreted as the probability that a presence location is ranked higher than a random point (Merow et al. 2013). The greater the decrease in value, the greater the resulting model's reliance on that bioclimatic layer. The second test uses multiple models excluding each variable in turn and creating a new model with the remaining layers. Response curves are created to show how each variable affects the outcome of the predicted range. Environmental variables that contributed less than $1 \%$ to the model 
were then excluded and the model run again, there by further restricting the model and reducing the number of variables used in subsequent analyses (Calkins et al., 2012; Kale et al., 2013).

\section{RESULTS}

We used a Maximum Entropy (MaxEnt) model, based on a data set of 36 distinct ecogeographic variables to construct a more detailed, accurate, and reliable habitat map for S. nuttallii and to predict the effects of representative IPCC concentration pathways 2.6 (Appendix B), 4.5 (Appendix C), 6.0 (Appendix D), and 8.5 (Appendix E), as well as paleoclimate data from the last interglacial (Appendix F), last glacial maximum (Appendix G), and Mid-Holocene (Appendix H) on the species' distribution. The climate model was based on climatic variables fundamental to the distribution of species (Hijmans, et al., 2008). Species Distribution Maps (SDMs) of paleoclimate matched hypothesized expansion and contraction patterns as determined based on fossil data, as well as latitudinal shifts based on warming and cooling climates over time. The predicted future distributions for $S . n$. nuttallii, S. n. pinetis and S.n. grangeri were of potential conservation concern. Our models predict a major loss of habitat and distribution across all of their currently accepted range under all four IPCC models.

\section{VARIABLE SIGNIFICANCE AND MODEL PERFORMANCE}

Our test area under curve scores were $.986, .988$ and .965 respectively for $S . n$. nuttallii, S. n. pinetis and S.n. grangeri. These figures indicate that the models resulting from our bioclimatic analysis based on museum specimen location data is robust and performed well using the selected variables. The AUC is a test of model performance and 
works on a 0 to 1 scale with 1 being a perfect prediction score and 0.5 being completely random (Phillips and Dudik, 2008). AUC values above .95 are indicative of high accuracy and are considered to be very informative (Fielding and Bell, 1997, Elith et al., 2011). The most significant variable affecting habitable ranges for $S$. n. grangeri and $S$. n. pinetis was mean diurnal temperature range; for $S$. n. nuttallii it was mean temperature of the driest quarter that was most influential, based on percent contribution and permutation importance. Models for S. $n$. grangeri indentified mean diurnal temperature range as the most important variable, followed by mean temperature of the wettest quarter, elevation, and precipitation of the warmest quarter $(53.7 \%, 20.5 \%, 15.1 \%$, and $10.8 \%$ respectively). Permutation importance matched the order of percent contribution $(43 \%, 30.8 \%, 13.6 \%$ and $12.6 \%$ respectively). In S. n. nuttallii, mean temperature of the driest quarter was the most influential in both percent contribution and permutation importance (53.2\% and $71 \%$ respectively), followed by mean temperature of the wettest quarter (25\% and 9.2\%), precipitation of the warmest quarter (18.5\% and $18.2 \%)$, and annual temperature range ( $3.3 \%$ and $1.7 \%)$. For the S. n. pinetis, mean diurnal temperature range had the highest percent contribution (45.9\%, with a permutation value of $1 \%$ ) while elevation had the highest permutation ( $48.8 \%$, percent contribution $40.1 \%$ ) followed by minimum temperature of the coldest week ( $7.8 \%$ and $40.4 \%)$, annual temperature range (3.4\% and 7.4\%), and precipitation of the warmest quarter (2.8\% and $2.5 \%)$.

The jackknife test of variable importance for the $S$. $n$. grangeri models show mean diurnal temperature range had the highest gain when used in isolation and is the 
most informative climate variable when used alone. The $S$. $n$. nuttallii model's jackknife test identified mean temperature of the driest quarter as the most influential variable when used alone and therefore the most influential variable in limiting distribution. Mean diurnal temperature range was the most informative when used alone for $S . n$. pinetis, while elevation decreased the gain the most when omitted, indicating these two variables are the most influential in restricting range for that taxon.

\section{PREDICTED HABITAT MAPS}

We generated species distribution maps for the LIG, LGM, HCO, current, and future (RCPs 2.6, 4.5, 6.0, and 8.5) distributions of S. $n$. grangeri, S. $n$. nuttallii, and S. $n$. pinetis, illustrating suitable habitat ranges ( $\geq 0.5$ probability of presence) across the western North America. Current total suitable habitat for the species complex encompasses an area of $1,291,719 \mathrm{~km}^{2}$ from southern Canada in the north to the Mogollon Rim of Arizona in the south, and from the Black Hills of South Dakota to the Cascades and Sierra Nevada mountain ranges in the west. Total suitable habitat for $S . n$.

grangeri, S. n. nuttallii, and S. n. pinetis, cover $794,937 \mathrm{~km}^{2}, 294,437 \mathrm{~km}^{2}$, and 202,343 $\mathrm{km}^{2}$ respectively. The distribution of $S . n$. grangeri covers Montana and stretches southwest to southern California; S. n. nuttallii inhabits the high deserts of the Pacific northwest east of the Cascades; the range $S$. $n$. pinetis covers the higher mountainous regions of Arizona, New Mexico, and Colorado.

During the Last Interglacial period, the $S$. nuttallii species complex had a distribution covering an area of $1,443,969 \mathrm{~km}^{2}$, with each subspecies covering an area of $962,718 \mathrm{~km}^{2}, 102,812 \mathrm{~km}^{2}, 378,437 \mathrm{~km}^{2}$ for $S$. . grangeri, S. $n$. nuttallii, and $S . n$. 
pinetis, respectively. The MaxEnt model covering the Last Glacial Maximum suggests that the species complex had its smallest distribution during that period, as well as the farthest south shift to its range. Collectively, the total suitable habitat covered less than a quarter of today's range, at just $289,843.8 \mathrm{~km}^{2}$. Distributional areas for the subspecies during the LGM were: S. $n$. grangeri, $192,178 \mathrm{~km}^{2} ;$ S. $n$. nuttallii range shifted to southern California and was reduced to $59,062 \mathrm{~km}^{2} ; S$. n. pinetis was forced south into Mexico was its range reduced to $38,062 \mathrm{~km}^{2}$, a remarkable $90 \%$ range reduction compared to the Interglacial. Suitable habitat reached its greatest extent during the Holocene Climate Optimum, during which time the range of $S$. nuttallii covered at least $1,483,125 \mathrm{~km}^{2}$. Each of the subspecies' suitable habitat areas also were reached their largest areas during that period in all the models we ran: $S$. $n$. grangeri was distributed over $917,875 \mathrm{~km}^{2} ; S$. n. nuttallii covered 255,062 $\mathrm{km}^{2}$ in the Pacific Northwest; S. $n$. pinetis stretched over $310,187 \mathrm{~km}^{2}$ of the southern Rocky Mountains.

Predictive models based on the IPPC5 RCPs 2.6, 4.5, 6.0, and 8.5, scenarios were less favorable to $S$. nuttallii. Total distributional areas for the species complex ranged from $997,500 \mathrm{~km}^{2}, 1,092,656 \mathrm{~km}^{2}$, and $874,125 \mathrm{~km}^{2}$, to $779,187 \mathrm{~km}^{2}$, respectively. Model outputs for S. $n$. grangeri show subspecies ranges of $524,281 \mathrm{~km}^{2}$ for RCP 2.6, 1,092,656 $\mathrm{km}^{2}$ for RCP 4.5, 385,000 $\mathrm{km}^{2}$ for RCP 6.0 , and 316,513 $\mathrm{km}^{2}$ for RCP 8.5 . Suitable habitat for S. $n$. nuttallii yield $238,000 \mathrm{~km}^{2}, 229,468 \mathrm{~km}^{2}, 155,968 \mathrm{~km}^{2}$, and $60,375 \mathrm{~km}^{2}$ for each scenario, respectively. Models for S. $n$. pinetis predict 245,218 km², $378,656 \mathrm{~km}^{2}, 333,156 \mathrm{~km}^{2}$, and 402,281 km². 
When considering the three sub-species combined, our modeling results indicate that 1) our model are robust and performed well with the selected variables (Fielding and Bell, 1997; Phillips and Dudik, 2008); 2) had virtually identical AUCs with our initial model; and 3) indicated a need to secure suitable habitats for conservation efforts, if not for $S$. nuttallii itself then for the predators that depend heavily on it as a food source.

\section{DISCUSSION}

Our models show clear, taxon-specific patterns of range shifts, expansions, and contractions, in response to temporal changes in climate. The models further result in identification of predictors of the relationship between bioclimatic envelopes as determinants of range predictors for a key prey species. Bioclimate features such as daytime temperature and precipitation, as well as habitat features such as elevation, are the most restrictive factors identified by our models to $S$. nuttallii, and force range shifts over time as a result of fluctuations in climate. Our modeled range shifts of the paleoclimate match fossil record data (Harris and Hearst, 1977) which lends additional credence to the validity of our methods and models for paleo-distributional modeling of S. nuttallii geographic distribution.

Models for S. $n$. grangeri suggest that taxon has a definite upper and lower limit of temperature for survival across its range. This has the effect of setting northern and southern latitudinal limits on its range. Elevation and late summer rainfall further restrict distribution. similarly, S. n. pinetis also has an upper and lower temperature limitation. However, elevation is a more important determinant of suitability for the habitat of this taxon. This suggests $S$. n. pinetis is a montane restricted taxon bounded by warm lower 
elevations and colder alpine environments. In contrast, $S$. $n$. nuttallii has its range most adversely restricted by precipitation and temperature as a function of the wet and dry seasons of the Columbia Basin and Oregon plateau.

Our models for the LIG show strict boundaries between ranges of the species complex (probability $\geq .5$ ) with virtually no overlap (i.e., parapatry), suggesting strong competitive interactions among putative subspecies. These competitive interactions at range boundaries continued until the Holocene Climate Optimum, when ranges begin to overlap in portions of the range. Following the $\mathrm{HCO}$, competition once again began to affect distribution: $S$. $n$. grangeri began losing area to $S$. $n$. nuttallii in the west and to $S$. n. pinetis in the south. Future model predictions show this trend will continue as ranges shift north due to warming climates. The magnitude of suitable habitat lost to competition and climate change depends heavily on which RCP model is used. As expected, range contraction of a lesser magnitude occurs under scenario 2.6 and progressively worsens through scenario 8.5. These competitive interaction at the boundaries among the $S$. nuttallii species complex have to date not been examined and should be considered an area in need of further research using field observational data, finer scale species distribution models, and additional bioclimatic envelope layers. The specimen-based ecological niche models resulted in hypotheses of distributions for each of the subspecies currently contained in Sylvilagus nuttallii that suggests temporally extensive spatial segregation among the subspecies. While some degree of spatial overlap between $S . n$. grangeri and S. $n$. nuttallii is exhibited in certain of the temporally bounded models (for example, Last Interglacial; Mid-Holocene), S. $n$. pinetis appear to 
be spatially discriminated from the former subspecies in all time periods explored by our models. Given the consequent potential lack of exchange of genetic material among the subspecies currently contained in S. nuttallii, this in turn suggests that the hypothesis of conspecificity among the putative subspecies may be compromised.

Figure 2.1

Current distribution of the Sylvilagus nuttallii species complex across the western U.S. S.n. nuttallii is shown in blue, S.n. grangeri is shown in orange, and S.n. pinetis is in green.

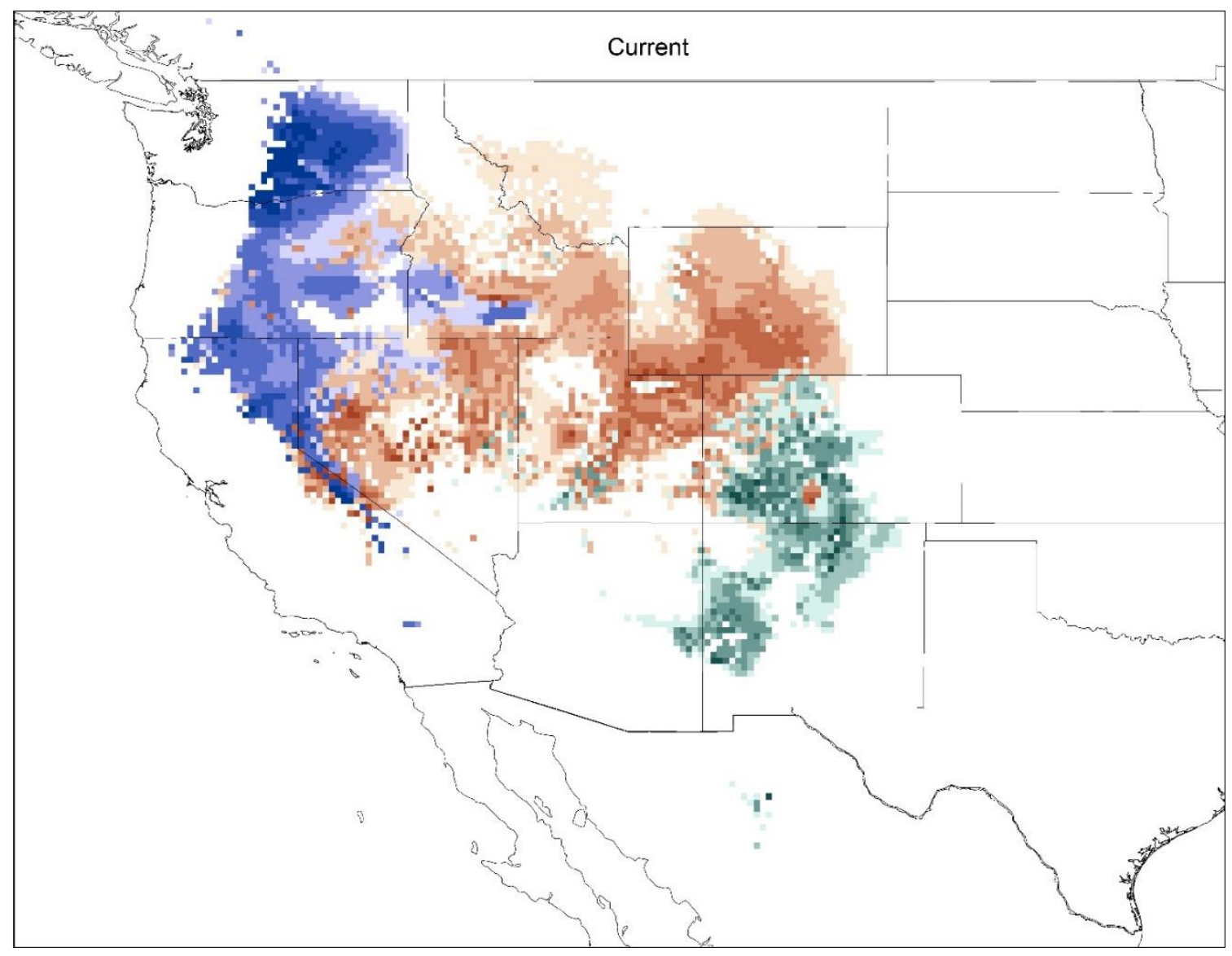


Figure 2.2

Distribution of the Sylvilagus nuttallii species complex during the Last Interglacial Period of the Western U.S. approximately 150,000 years ago.

S.n. nuttallii is shown in blue, S.n. grangeri is shown in orange, and S.n. pinetis is in green.

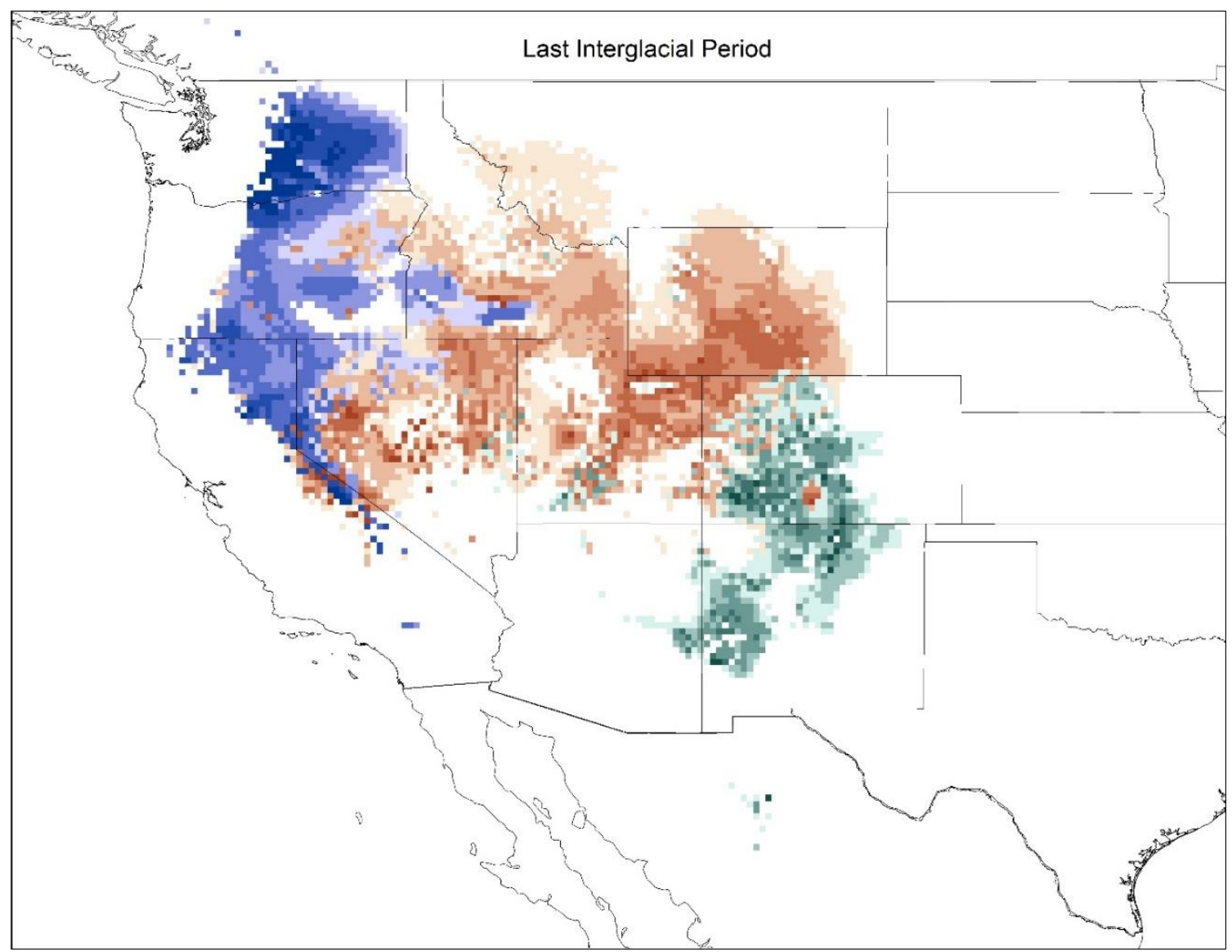


Figure 2.3

Distribution of the Sylvilagus nuttallii species complex during the Last Glacial Maximum approximately 12,000 years ago.

S.n. nuttallii is shown in blue, S.n. grangeri is shown in orange, and S.n. pinetis is in green.

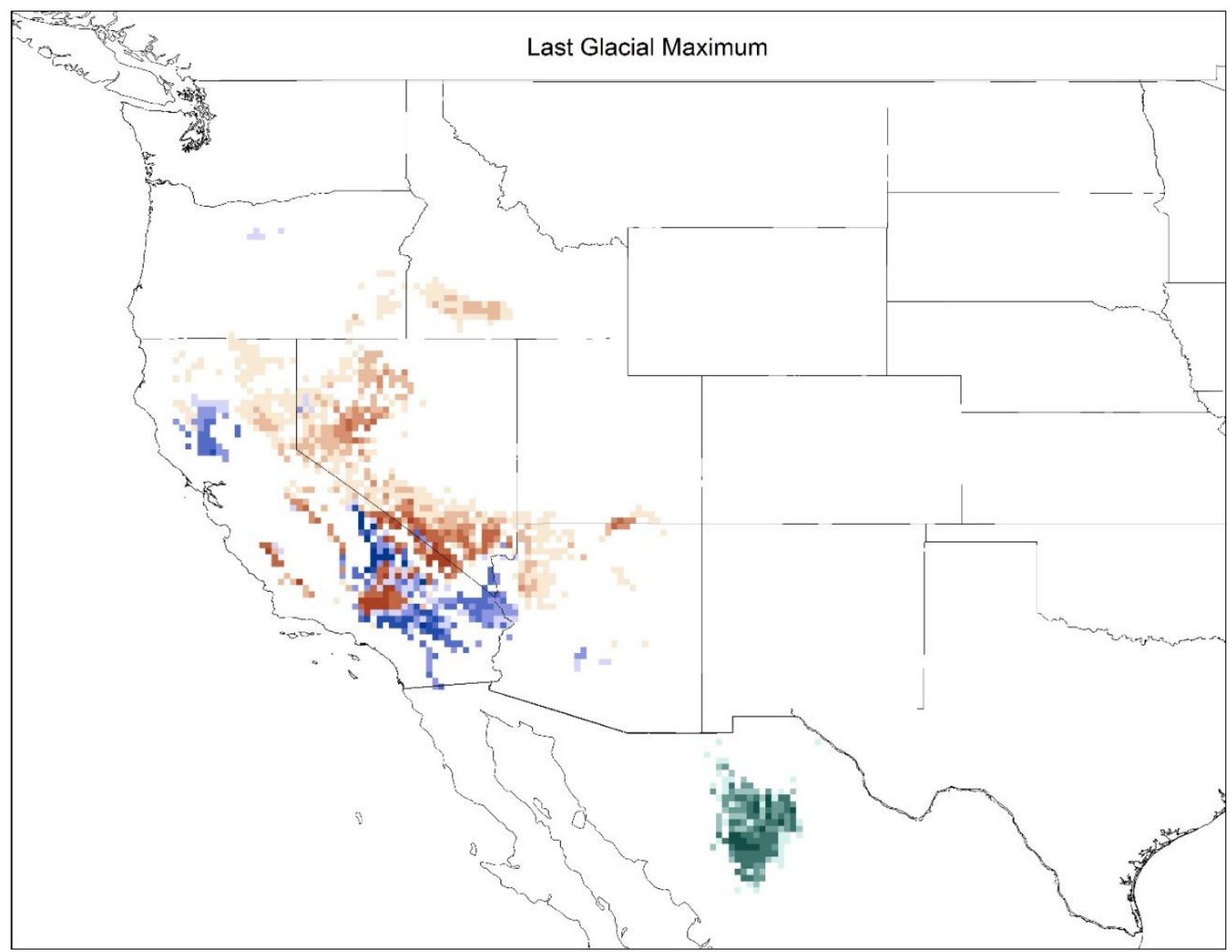


Figure 2.4

Distribution of the Sylvilagus nuttallii species complex during the Mid-Holocene Climate Optimum of the Western U.S. approximately 6,000 years ago.

S.n. nuttallii is shown in blue, S.n. grangeri is shown in orange, and S.n. pinetis is in green.

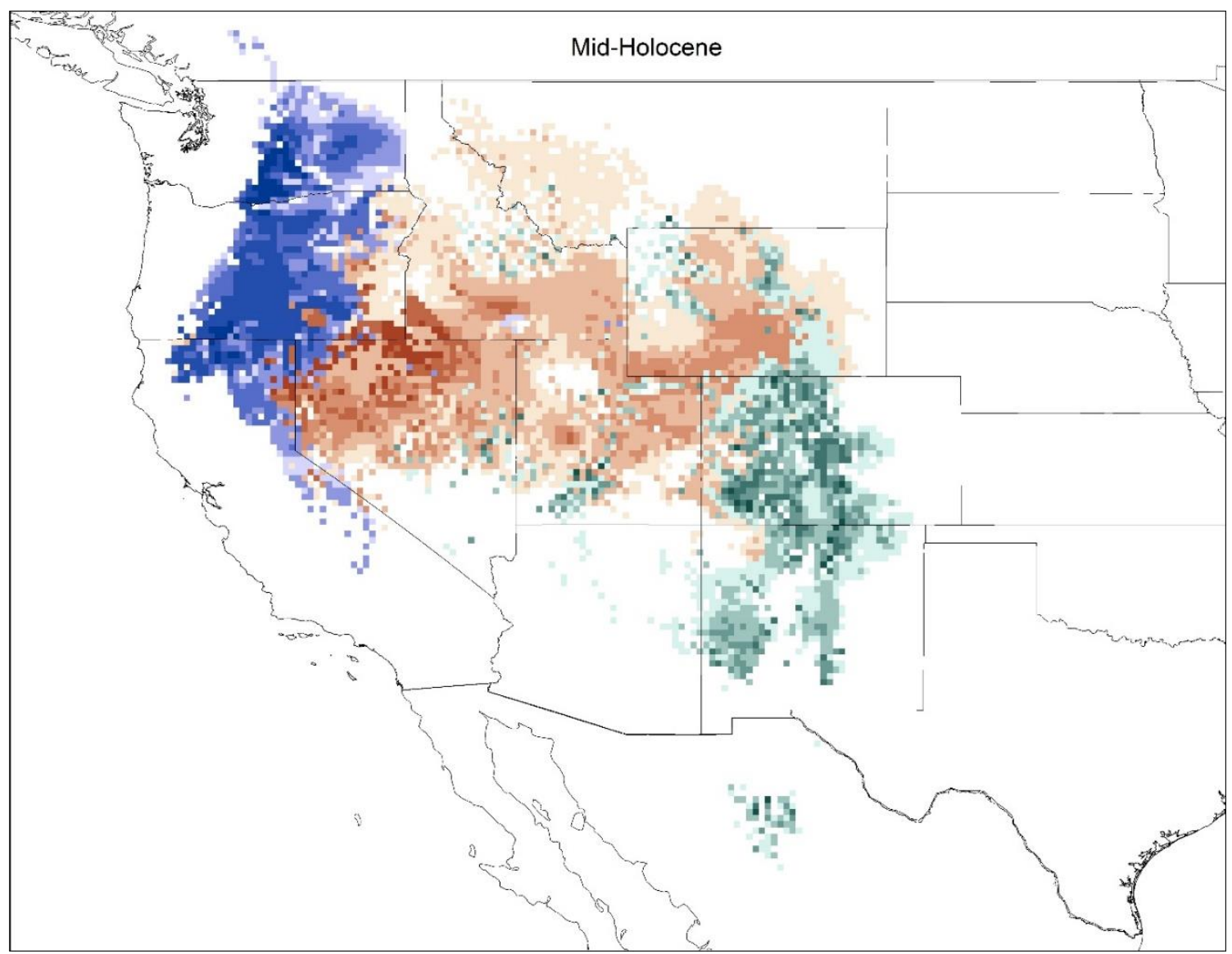


Figure 2.5

Distribution of the Sylvilagus nuttallii species complex under Representative

Concentration Pathway 2.6. IPCC scenario 2.6 predicts a mean increase of $1^{\circ} \mathrm{C}$ by 2100 (range $\left.0.3^{\circ}-1.7^{\circ}\right)$

S.n. nuttallii is shown in blue, S.n. grangeri is shown in orange, and S.n. pinetis is in green.

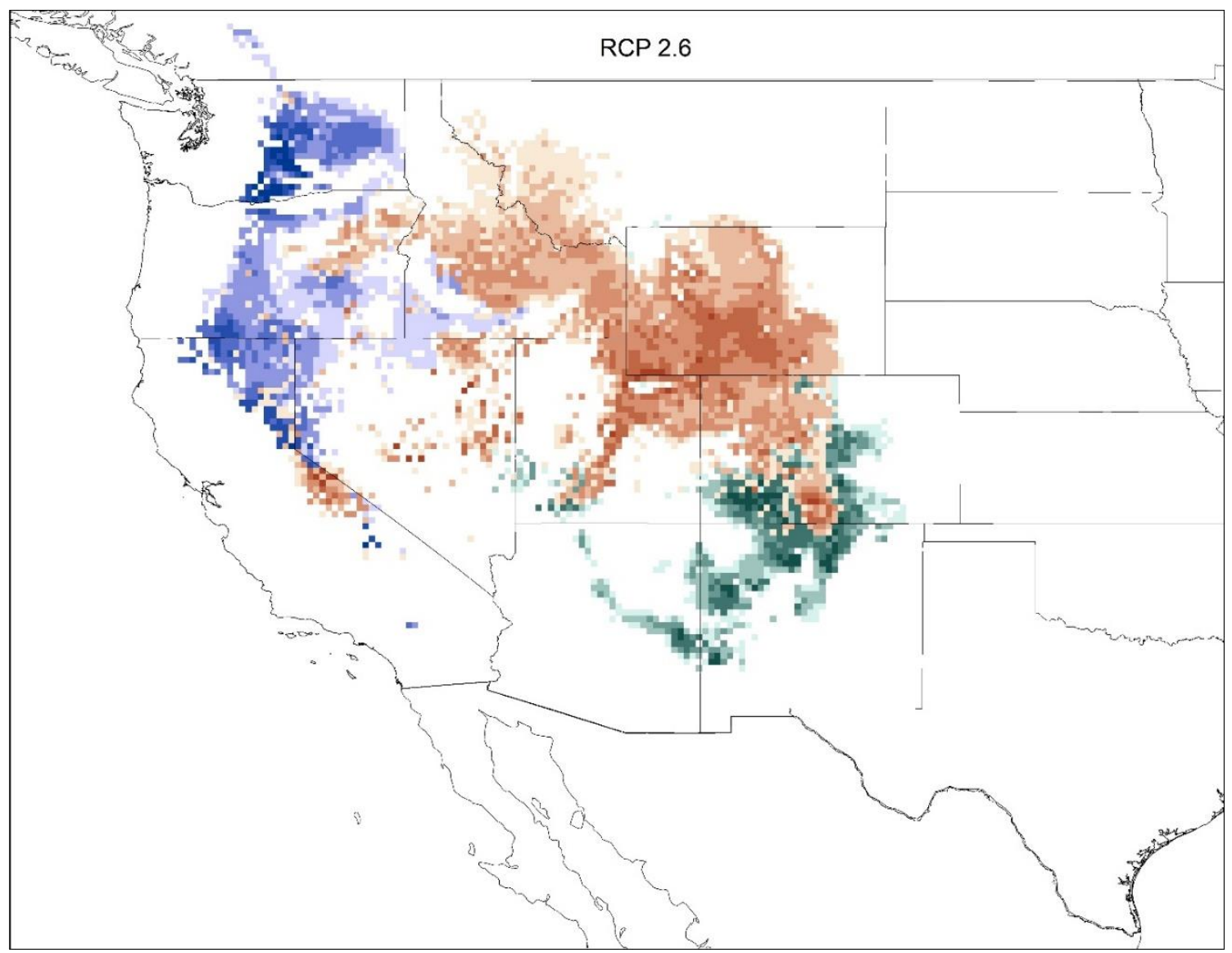


Figure 2.6

Distribution of the Sylvilagus nuttallii species complex under Representative Concentration Pathway 4.5. IPCC scenario 4.5 predicts a mean increase of $1.8^{\circ} \mathrm{C}$ by $2100\left(1.1^{\circ}-2.6^{\circ}\right)$

S.n. nuttallii is shown in blue, S.n. grangeri is shown in orange, and S.n. pinetis is in green.

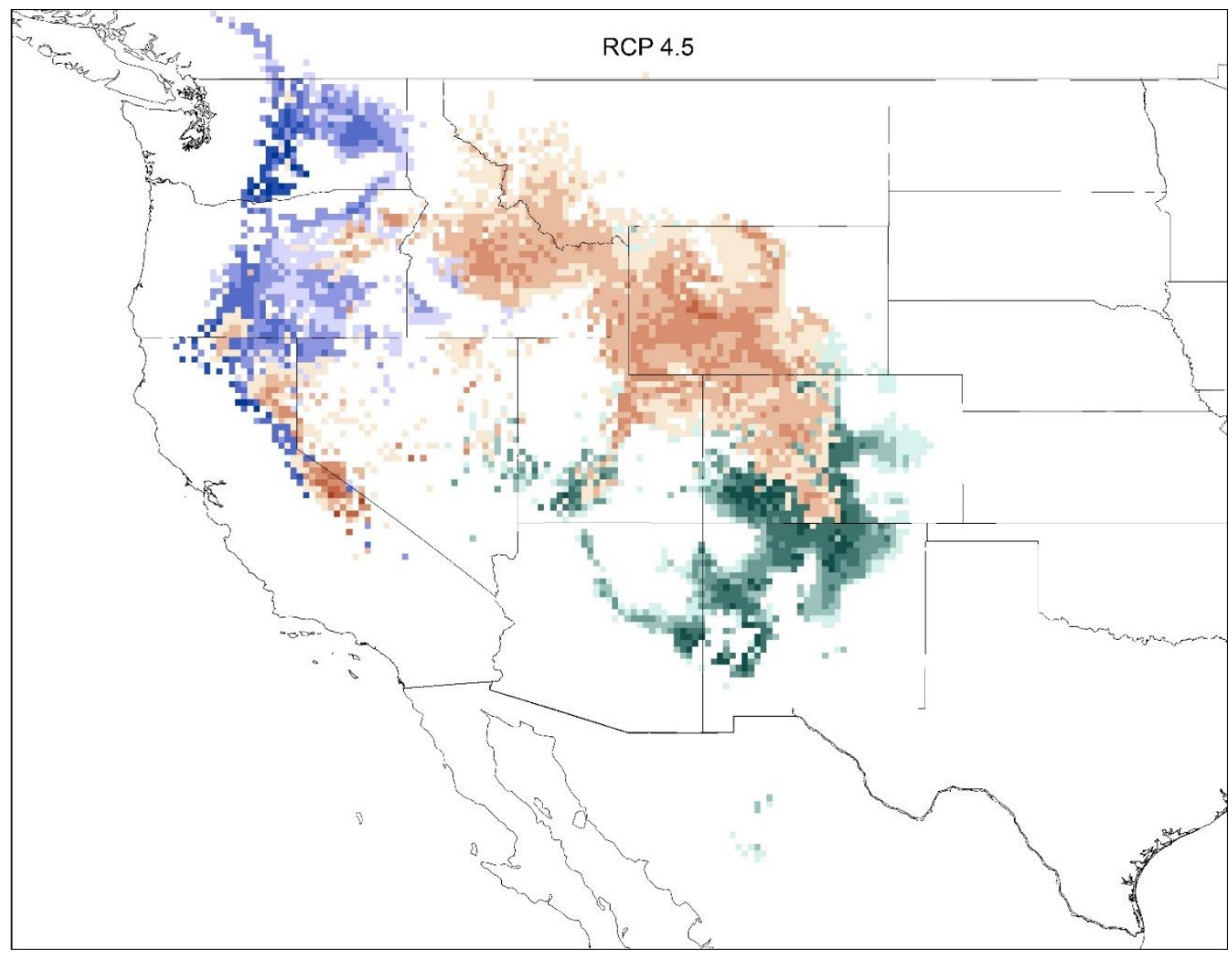


Figure 2.7

Distribution of the Sylvilagus nuttallii species complex under Representative

Concentration Pathway 6.0 which hypothesizes a mean increase of $2.2^{\circ} \mathrm{C}\left(1.4^{\circ}-3.1^{\circ}\right)$ by 2100.

S.n. nuttallii is shown in blue, S.n. grangeri is shown in orange, and S.n. pinetis is in green.

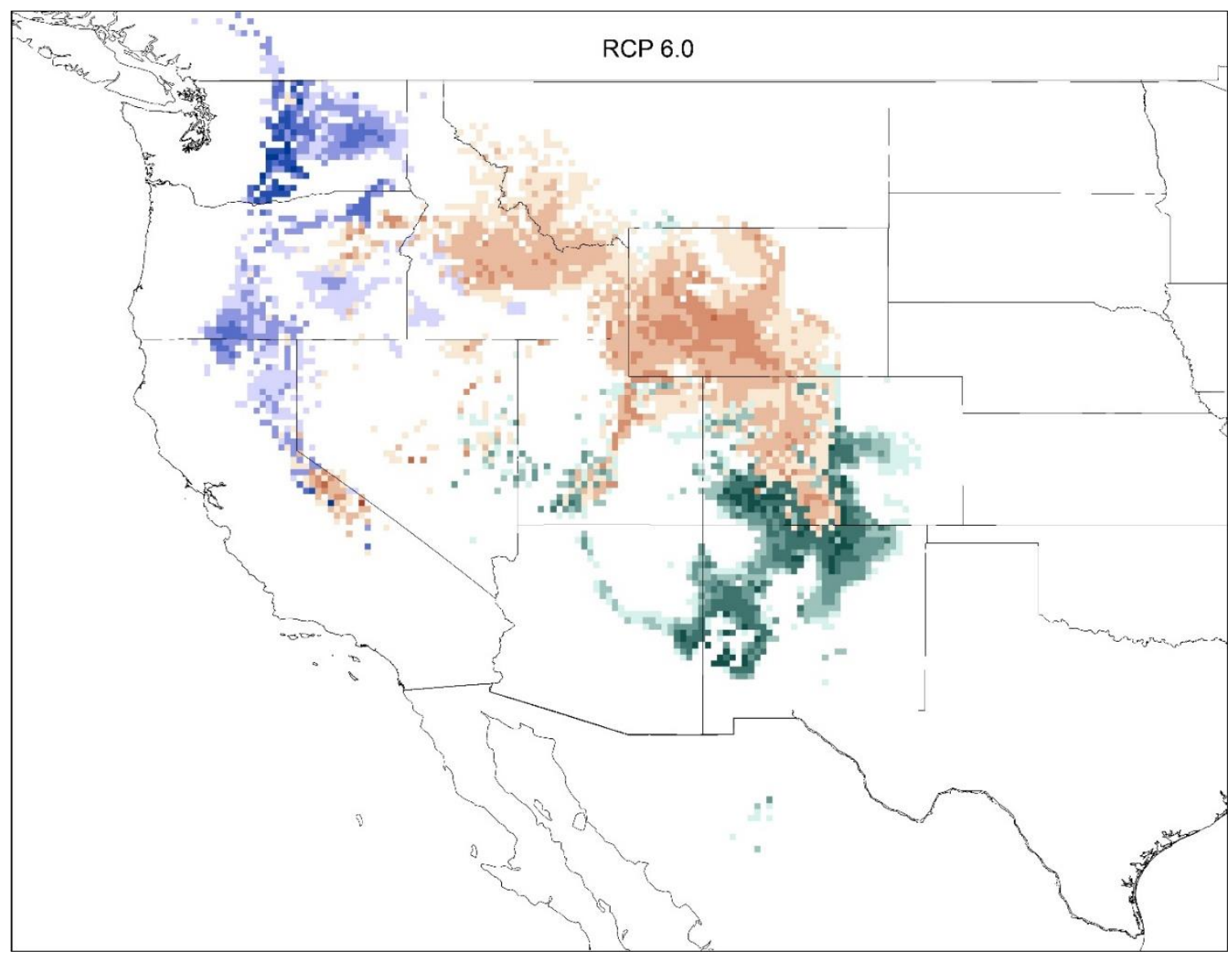


Figure 2.8

Distribution of the Sylvilagus nuttallii species complex under Representative

Concentration Pathway 8.5 which predicts a rise in temperatures of $3.7^{\circ} \mathrm{C}\left(2.6^{\circ}-4.8^{\circ}\right)$ by 2100.

S.n. nuttallii is shown in blue, S.n. grangeri is shown in orange, and S.n. pinetis is in green.

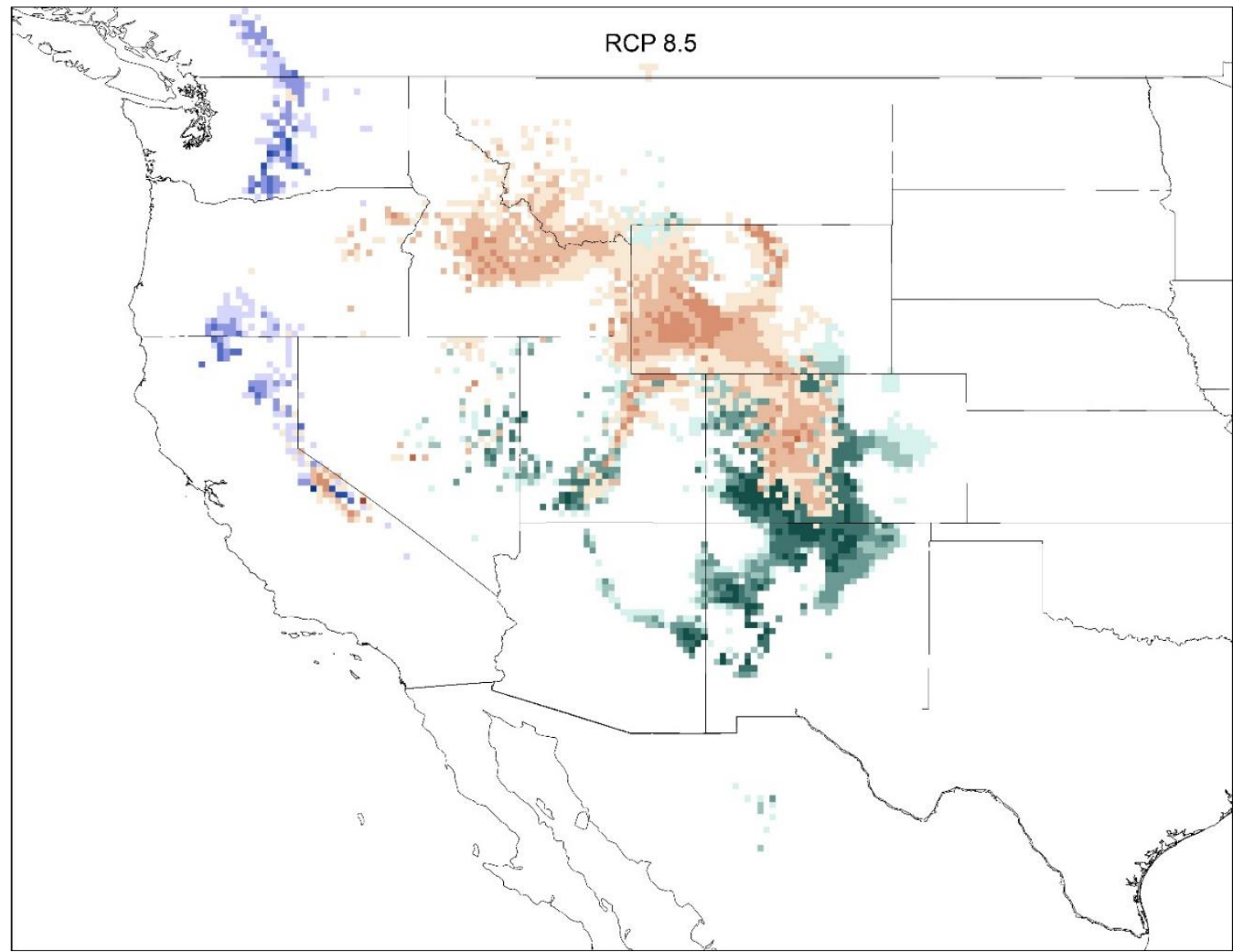




\title{
CHAPTER 3
}

Comparative cranial and dental morphology, with an analysis of diagnostic upper and lower premolar characteristics, of Sylvilagus nuttallii (Bachman, 1837) and its subspecies

\begin{abstract}
We examined 35 mensural cranial measurements, and four discrete cranial characters, as well as diagnostic characters of the second upper and third lower premolars in taxa comprising the Sylvilagus nuttallii (Bachman, 1837) species complex. We analyzed the holotypes and topotypical specimens, describe discrete characters, and provide an analysis of morphological variation across the species complex. Cranial morphology of Lagomorpha (rabbits, hares, and pikas) is highly conserved across extant taxa, and has been for most of the 40 million years of evolutionary history of the Order. Notwithstanding, it is the most important tool used in species differentiation. Mandibular measurements and premolar enamel ridge characters are described and used to discriminate among closely related taxa in both extinct and extant species. Mensural characteristics, cranial morphology, and odontological analysis of premolar characters definitively identify the three subspecies of $S$. nuttallii as distinct.
\end{abstract}




\section{INTRODUCTION}

Early descriptions of Leporids were often vague and were based on general descriptions of size, locality, and external morphology; there were few if any notes on skull descriptions (Bailey, 1905). Taxonomic decisions were often assigned solely based on the locality and coloration of pelage (Cornalia, 1849[1850]; Thomas 1911). The first attempts at estimating a phylogeny of Lagomorpha were made by Dawson (1958) and Hibbard (1963) using dental morphology. Both authors found that the lower $3^{\text {rd }}$ premolar (p3) and upper $2^{\text {nd }}$ premolar (P2) were the most taxonomically and phylogenetically informative and character rich features when comparing or differentiating among species. Indeed, Hibbard (1963) traced the evolution of dental characters to the upper Pliocene Epoch and the now extinct $\uparrow$ Nekrolagus progressus. Ancestral characters such as the trigonid and talonid basins can be found as far back as the Oligocene Palaeolagus, 20 million years before the emergence of Nekrolagus (Hibbard 1963).

Asher et al. (2005) and Meng et al. (2003) laid the modern framework for morphologically-based phylogeny of Stem Lagomorpha and Glires by analyzing 229 morphological characters of early lagomorphs. Asher et al. (2005) traced the appearance of Glires to the Cretaceous-Paleogene (K-Pg) Boundary. Rose et al. (2008) identified the earliest known leporids to $\sim 53$ mya in India. A molecular analysis by O'Leary et al. (2013) agreed with this date. However, other studies identify the emergence of Lagomorphs anywhere between 41 to 94.1 mya (Meredith et al. 2011, Murphy et al. 2007, Springer et al. 2003, Stucky and McKenna 1993) Asher et al. (2005) identified 92 cranial features useful in identifying Stem lagomorphs. However, many of those characters are primitive and found in nearly all placental mammals from the time period. 
John R. Wible considered 59 cranial characters in his landmark 2007 study "On the Cranial Osteology of the Lagomorpha”. In that study, Wible (2007) described character differences in depth in one species from each extant family of Lagomorpha: Ochotonidae (pikas, Ochotona princeps) and Leporidae (rabbits, hares, and cottontails, Romerolagus diazi), as well as less detailed comparisons with five extant leporids and six extinct lagomorphs or taxa from allied families. Ochotonidae and Leporidae diverged $\sim 42$ mya based on the fossil record (Storer 1984). This underscores the fact that characters within Lagomorpha are highly conserved but may be useful certainly for taxonomic identification, but also, carefully considered, for identification of species relationships in a phylogenetic framework. Here, we consider closely related sister taxa currently assigned to $S$. nuttallii, and present discrete morphological characters that can be used to distinguish among the three taxa.

Recently published works on the taxonomy of the genus Sylvilagus in South America (Ruedas et al., 2017, and Ruedas et al., 2019) have built upon the techniques developed by Hibbard and included mensural and discrete cranial characteristics along with detailed analysis of premolar dentition in order to elucidate differences among taxa similarly once considered conspecific. Those descriptions, along with molecular data (see Chapter 3) were used in an integrative framework in order to assess the taxonomic status of these taxa. Here we use the same methods and framework to assess the taxonomic status of taxa constituting the $S$. nuttallii species complex.

\section{MATERIALS AND METHODS}

Specimens examined: 
S.n.nuttalli ANSP382 (juv) (holotype), S.n.grangeri AMNH7403, S.n.grangeri

AMNH7400, S.n.grangeri AMNH9094/7402 (holotype), S.n.grangeri AMNH7399, S.n.grangeri AMNH7401 (juv), S.n.pinetis AMNH7335, S.n.pinetis AMNH125929, S.n.pinetis AMNH 9041/7336 (holotype), S.n.nuttalli AMNH40889, S.n.nuttalli

\section{AMNH33605}

Cranial morphology, features, and characters generally follow the terminology of Ruedas et al. (2017, 2019), Wible (2007), and Ruedas (1998). Dental morphology was adapted from but follows the terminology outlined in Ruedas et al. (2017), Angelone and Sesé (2009), López-Martínez et al. (2007), Wible (2007), Ruedas (1998), Dalquest et al. (1989) and Hibbard (1963). Drawings of P2 and p3 were created by tracing photographs taken with a Canon EOS 30D digital camera mated to a Canon MP-E $65 \mathrm{~mm} \mathrm{f} / 2.8$ 1-5X Macro Photo lens and tripod. While size was not ignored during our examinations, discrete characters were considered most important and informative for the purposes of this study; accordingly, photographs of teeth and skulls were re-sized to allow for a more accurate size free comparisons.

The dental characters are considered the most informative insofar as taxonomic identification and morphology-based phylogenetic analysis are concerned for Lagomorphs, and in particular, characters of the leporid is p3. Characters from this tooth have been used to good effect for systematic and taxonomic purposes (Hibbard 1963;

Dalquest 1979; Dalquest et al. 1989; Ruedas 1998; Ruedas et al. 2017, 2019). Characters considered in the analysis of $\mathrm{p} 3$ include the condition and gross morphology of anteroflexid, lingual and labial anteroconid of the anterior lobe, trigonid basin, paraflexid, 
protoflexid, metaconid, protoconid, and central angle of the anterior loph, as well as the hypoflexid, entoconid, hypoconid, and talonid basin on the caudal portion of the tooth. Also considered was the condition of the enamel in each of the previously mentioned characters. Characters, gross morphology and conditions considered in the analysis of P2 included the enamel, anterior cusp, mesoflexus, paraflexus, lagicone, postcone, mesial hypercone, hypoflexus, metaflexus, distal hypercone, poststyle, and distal hyperloph.

Cranial characters used in morphological examination are defined in, and generally follow Ruedas et al. (2017; 2019), Wible (2007), Asher et al. (2005), and Ruedas (1998); novel characters are defined below. Characters include: greatest length of skull, superior orbital length, postorbital process, antorbital process, zygomatic breadth at spine, greatest breadth of zygomatic arch, zygomatic length, dorsoventral depth of zygomatic arch, breadth of braincase, width at exoccipital bones, length of bullae, width of bullae, interorbital breadth, height of rostrum, width of rostrum, rostrocaudal length of incisive foramina, width of incisive foramina, length of palatal bridge, width of choana at first molar, breadth of alisphenoid constriction, alveolar length of maxillary tooth row, length of upper and lower diastema, length of dentary tooth row, height of mandible to p3 alveolus, height of mandible to $\mathrm{m} 3$ alveolus, breadth of mandible at articular head, breadth of mandible to masseteric line, greatest length of mandible to pterygoid tuberosity, greatest length of mandible to articular head, greatest length of nasal bones, combined width of nasals, lacrimal spine breadth, greatest height of skull from basisphenoid to frontal, and height of skull from palatal to frontal (Figures 1-4). Specimens analyzed are listed in Appendix I. 


\section{RESULTS}

The holotype of S. n. nuttallii (ANSP 382) is of a juvenile; the skin has been lightly taxidermied, with glass eyes placed in the skin. The skull is not fully cleaned and is laterally crushed, leaving the frontonasal suture disarticulated and the nasal bones elevated above the frontals. The caudal end of the skull is missing behind the parietals. The mandible is still attached to the skull with dried tissue, making examination of the dental crowns impossible. The right side of the mandible body is fractured completely through at the premolars. Because of these factors, a more meaningful comparison is to undertake a comparison among adult topotypical and other holotypes of adult specimens representing remaining taxa currently construed to be subspecies of $S$. n. nuttallii.

A notable and obvious size difference is apparent between $S$. $n$. pinetis and remaining sub-species. The southern $S$. $n$. pinetis is nearly $6 \mathrm{~mm}$ longer when comparing the greatest length of skull $(66.6 \mathrm{~mm}, v .60 .6 \mathrm{~mm}$ for $S . n$. grangeri, and $61.3 \mathrm{~mm}$ for $S$. n. nuttallii). In the dorsal view, moderate pitting is present on the frontals and parietals of $S . n$. nuttallii. In contrast, light pitting is present in a narrow band near the squamosal suture and absent on the frontals of both $S$. n. pinetis and S. $n$. grangeri (Fig. 5). The frontonasal suture of $S . n$. nuttallii forms a diamond shaped point on the caudad end. The well-defined medial and lateral angles are nearly parallel across the transverse plane. The rostral inflection extends to, or just beyond, the zygomatic process of the maxilla. In S. $n$. grangeri, the caudad end of the suture is broadly circular. The rostral inflection extends well beyond the zygomatic process. In $S . n$. pinetis the frontonasal suture extends caudally along the lateral edge before angling rostrally to the medial margin of a 
long sharp rostral inflection. As in $S$. $n$. grangeri, the rostral inflection extends well beyond the zygomatic process of the maxilla (Figs. 6-8). The external occipital protuberance (EOP) of $S . n$. nuttallii has well defined nearly $90^{\circ}$ lateral angles and runs parallel to the frontal plane to a medial crest extending toward the foramen magnum. Sylvilagus $n$. grangeri has a diamond shaped EOP with well-defined lateral angles that meet in a medial crest well below the frontal plane of the angles. Sylvilagus n. pinetis also has a medial crest which extends toward the foramen magnum; however, the EOP is broadly ovoid and lacks well defined lateral angles (Figs. 9-11). The lateral and ventral views of the skulls are similar in conformation (Figs. 12-14).

The lower third premolar (p3) is diagnostically distinct in most species of Sylvilagus; for taxa in the S. n. nuttallii species complex, this is no different. Sylvilagus n. nuttallii has enamel that rings the anterior loph from the hypoflexid to the posterior edge of the lingual anteroconid, whereas S. n. grangeri and S. n. pinetis has the entire anterior loph ringed with enamel. The rostral surface of $\mathrm{p} 3$ in $S . n$. nuttallii displays an unremarkable Sylvilagus anteroflexid and protoflexid, but lacks a paraflexid on the labial side. The central angle anterior to the hypoflexid is somewhat sharply angled. The lingual edge of the metaconid lacks enamel. Sylvilagus n. pinetis has a similar protoflexid, however, it also has a sharp, deep paraflexid and a double anteroflexid separated by a medial anteroconid that lacks enamel. The labial anteroconid is crenellated along the rostral edge. It has a well-defined central angle protruding into the hypoflexid. The entire edge of the entire anterior loph, excluding the medial anteroconid, displays enamel. In contrast, $S$. $n$. grangeri lacks an anteroflexid, displaying only a small 
invagination into the enamel. The paraflexid is large and rounded. The rostral surface of the hypoflexid, lingual to the central angle, displays strong crenellations. The metaconid, lingual anteroconid, labial anterconid and protoconid display enamel (Figure 16).

Morphological comparison of the second upper premolar (P2) reveals noticeable differences across members of the species complex. The rostral and lingual edges have well defined enamel. Sylvilagus n. pinetis lacks a mesoflexus, where it is well defined in S. $n$. nuttallii, and only a small invagination is present in $S . n$. grangeri. The paraflexus of $S . n$. grangeri has a crenellated anterior surface where it is smooth in its sister taxa (Figure 15).

Principal component analysis of cranial measurements underscores the degree of morphological variation among the taxa. Three quarters of variation is explained in the first three principal components. These provide clear, well defined separation of species (Figure 17). More than $90 \%$ of the variation was accounted for in the first five principal components. All variation was accounted for by PC8 (Table 1). 
Figure 3.1

Dorsal view of skull and the measurements taken. 1., Greatest Length of Skull, 2., Superior Orbital Length, 3., Posterior Orbital Process, 4., Anterior Orbital Process, 9., Breadth of Braincase, 13., Interorbital Breadth, 15., Width of Rostrum, 31., Length of Nasals, 32., Width of Nasals , 33., Lacrimal Spine Breadth.

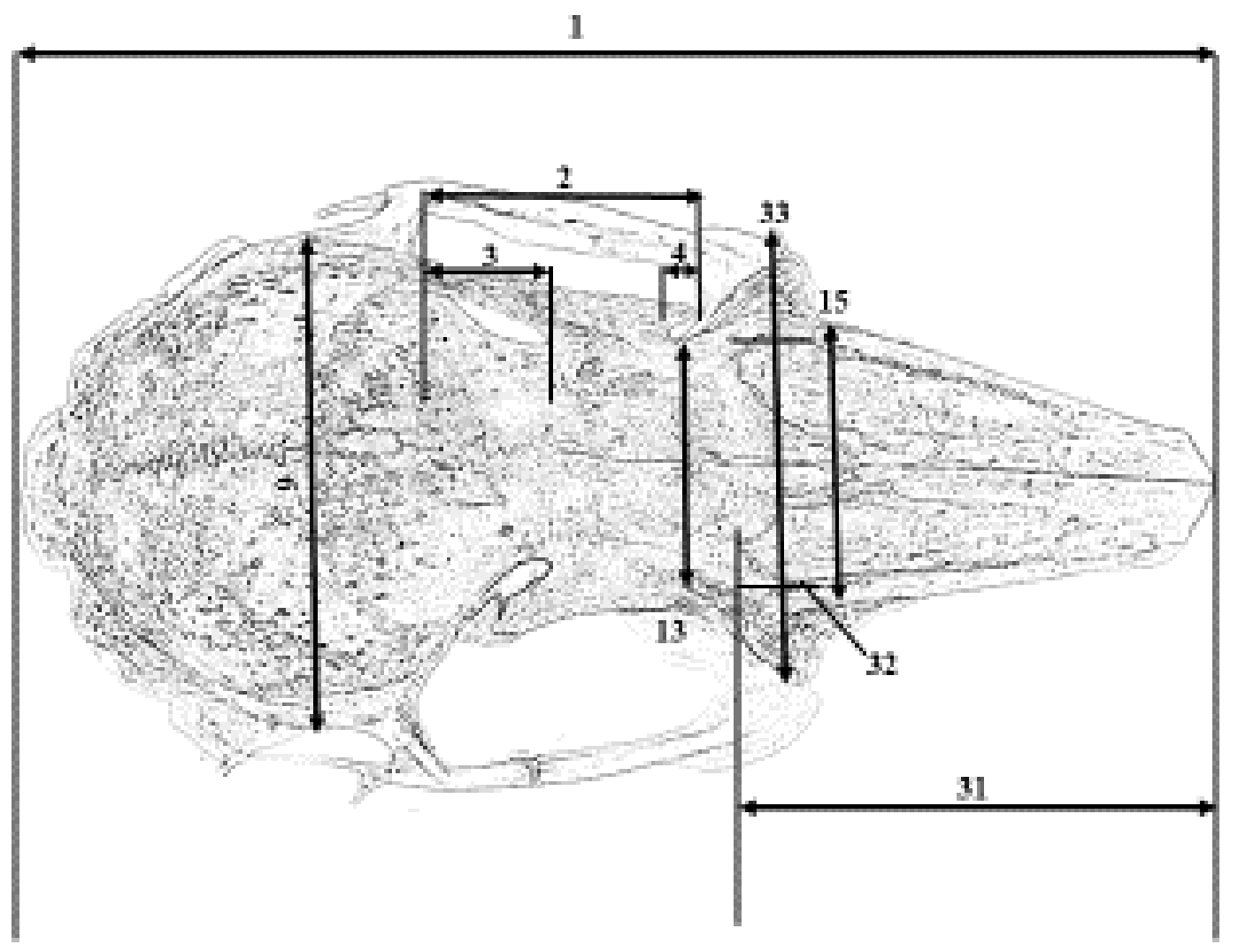


Figure 3.2

Ventral view of skull and the measurements. 5.,Zygomatic Breadth at Spine, 6., Greatest Breadth of Zygomatic, 7., Zygomatic Length, 10., Width at Exoccipital Bones, 12. , Width of Bullae 16., Rostrocaudal Length of Incisive Formina, 17., Width of Incisive Foramina, 18., Length of Palatal Bridge, 19., Width of Choana at First Molar, 20., Breadth of Alisphenoid Constriction, 21., Alveolar Length of Maxillary Tooth Row

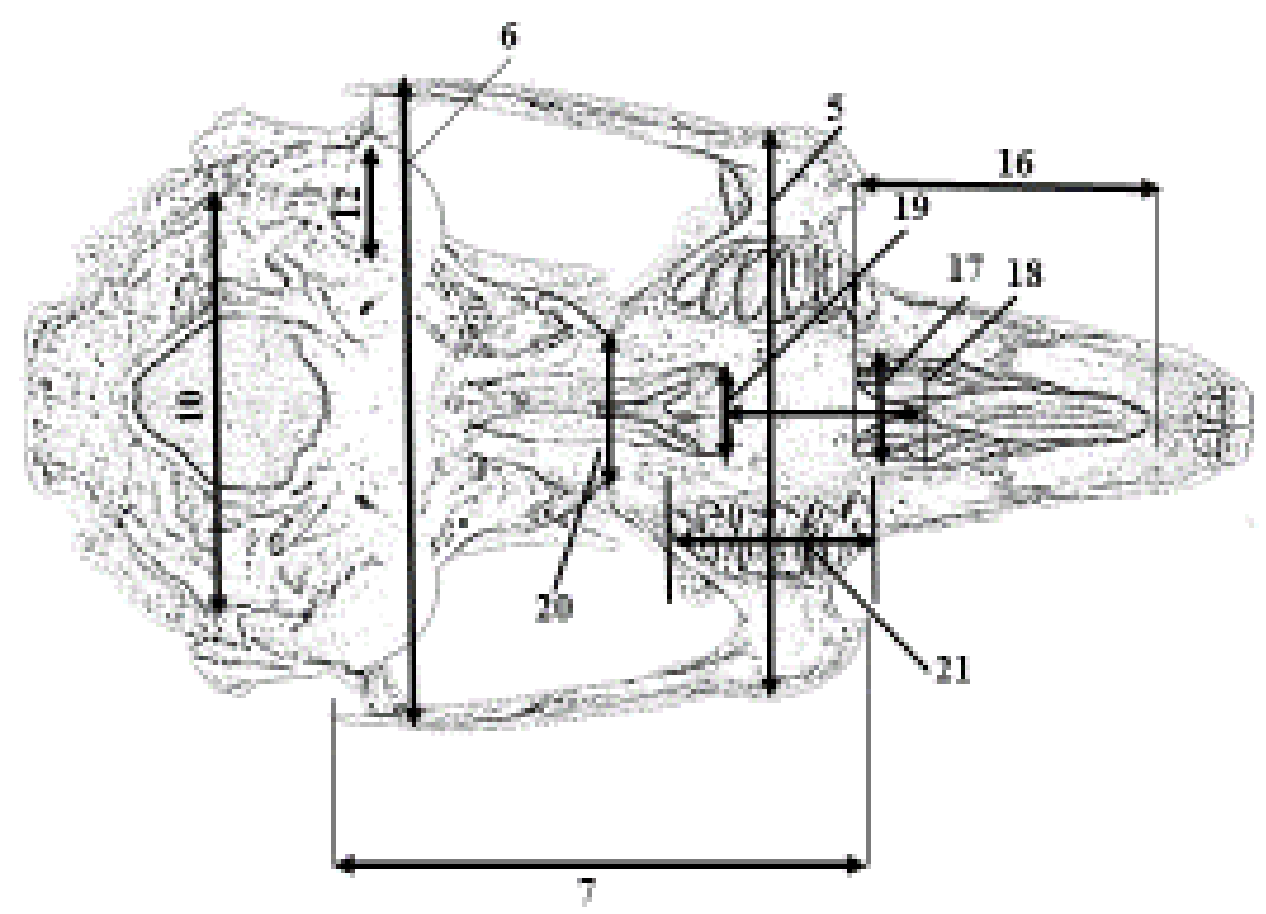


Figure 3.3

Mandibular measurements taken for principal component analysis. 23., Length of

Denterary Tooth Row, 24., Height of Mandible to p3, 25., Height of Mandible to m3, 26. , Breadth of mandible to Articular Head,

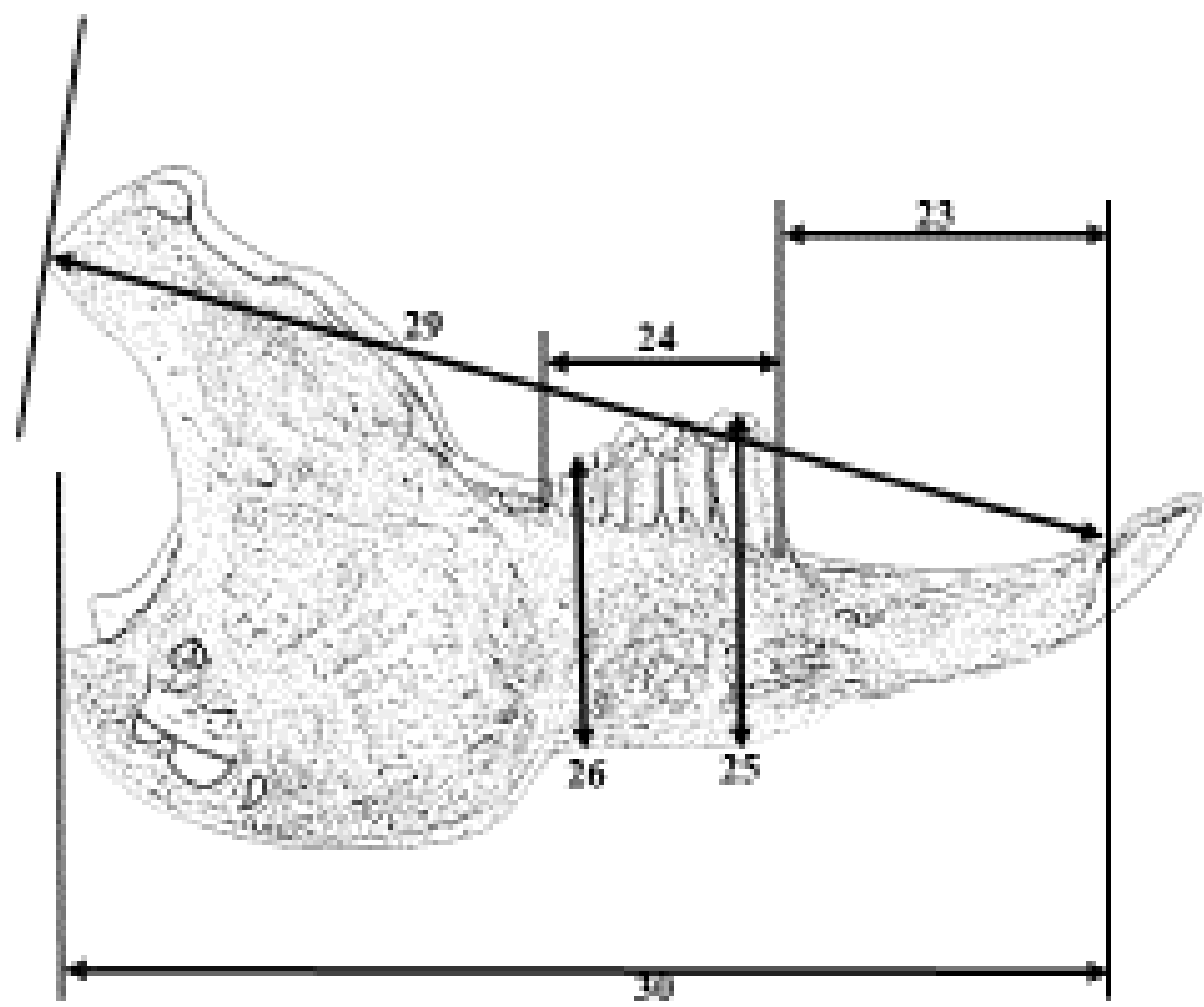


Figure 3.4

Dorsal view of Sylvilagus nuttallii subspecies holotypes and the proposed neotype. S.n. nuttallii's holotype is a juvenile.

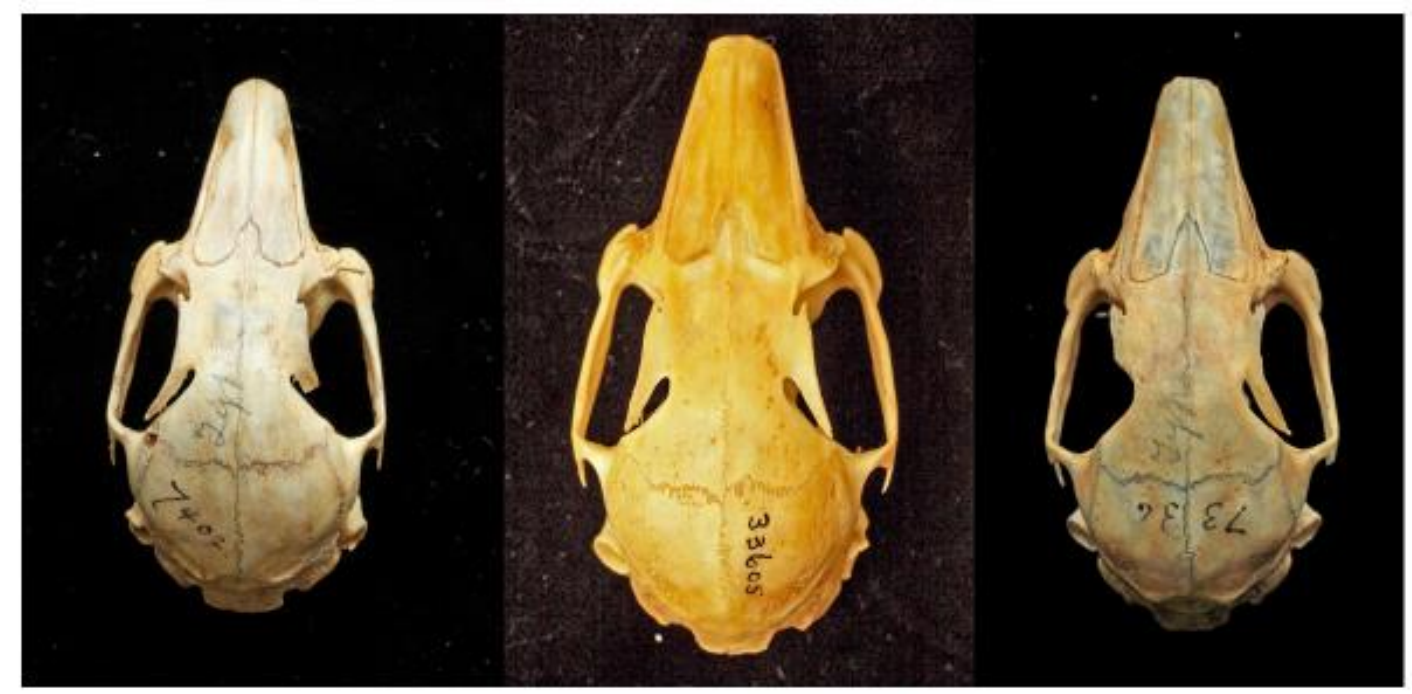


Figure 3.5

Frontonasal suture of S.n. grangeri topotypes.

Sylvilagus nuttallil grangeri frontonasal suture

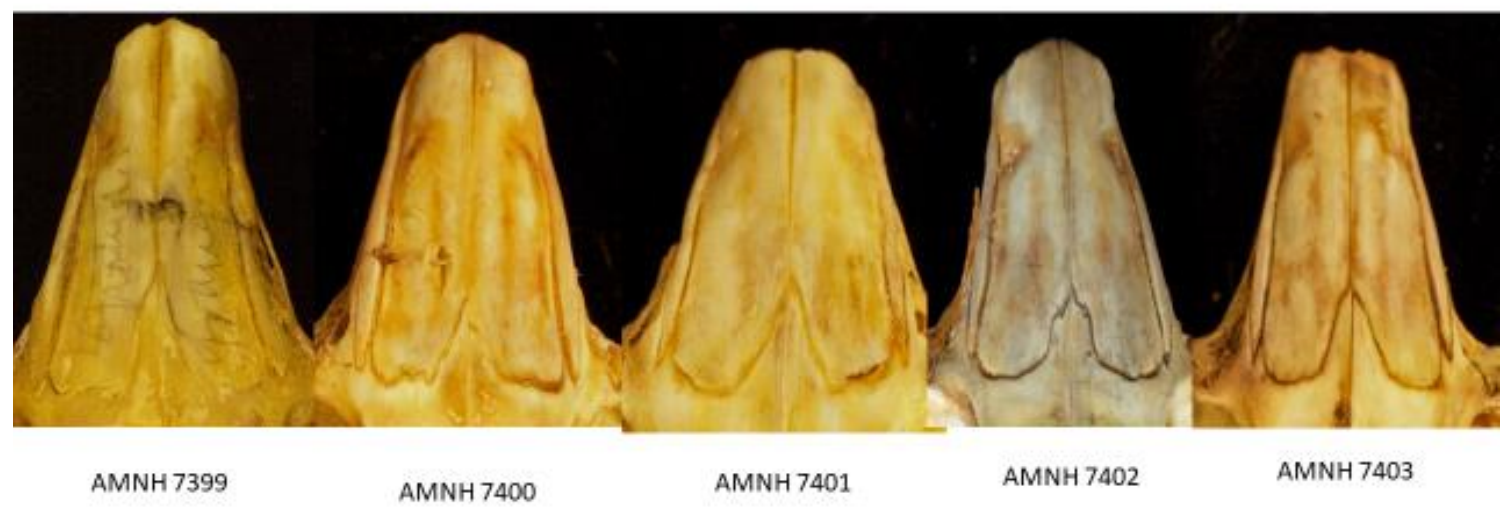

Figure 3.6

Frontonasal suture of S.n. nuttallii topotypes.

Sylvilagus nuttallii nuttallii frontonasal suture

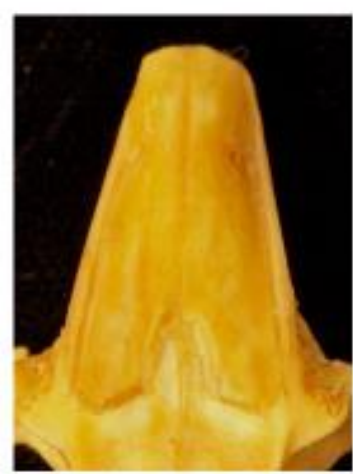

AMNH 33605

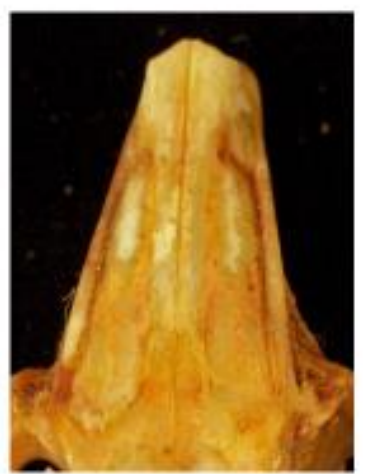

AMNH 40889 
Figure 3.7

Frontonasal suture of S.n. pinetis topotypes.

Sylvilagus nuttallii pinetis frontonasal suture

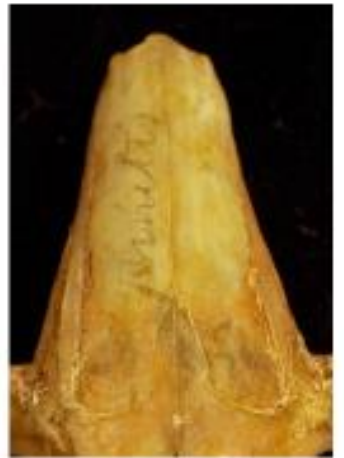

AMNH 7335

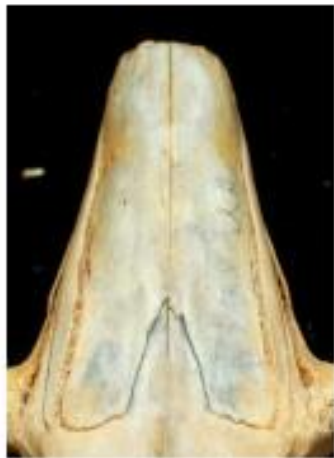

AMNH 7336

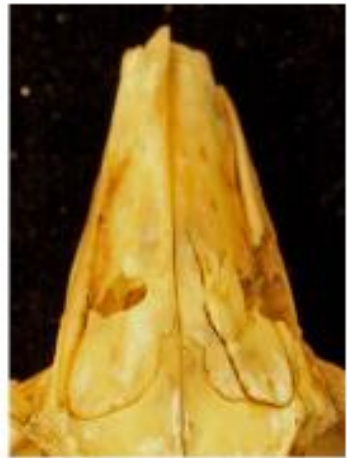

AMNH 125929

Figure 3.8

Caudad view of the external occipital protuberance found on the holotype and topotypes of S.n. grangeri.

Sylvilagus nuttallii grangeri external occipital protuberance

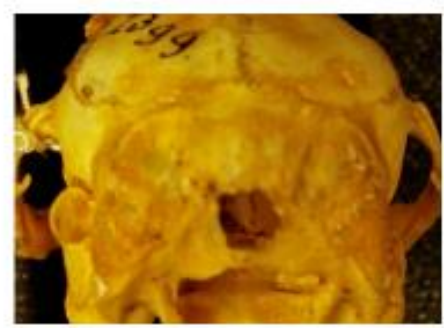

AMNH 7399

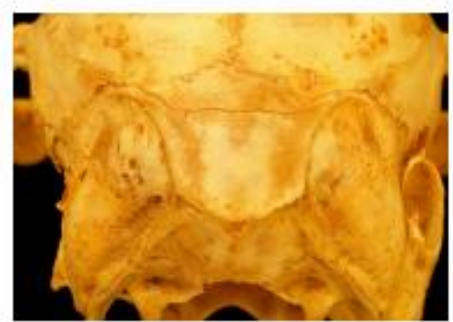

AMNH 7400

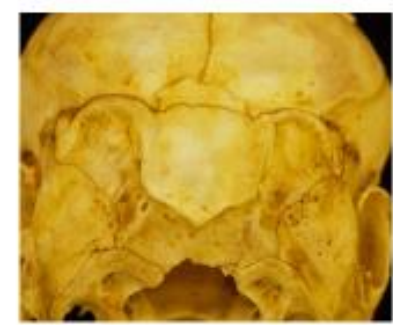

AMNH 7401

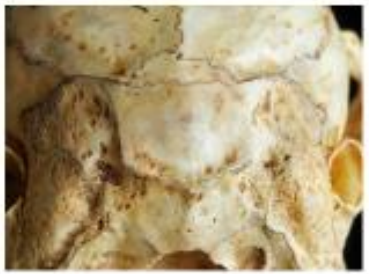

AMNH 7402

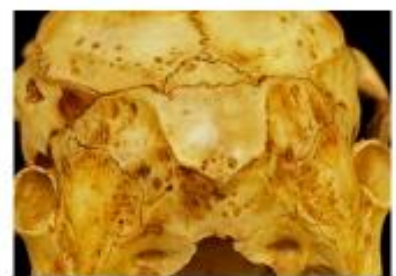

AMNH 7403 
Figure 3.9

Caudad view of the external occipital protuberance found on topotypes of S.n. nuttallii.

Sylvilagus nuttallii nuttallii external occipital protuberance

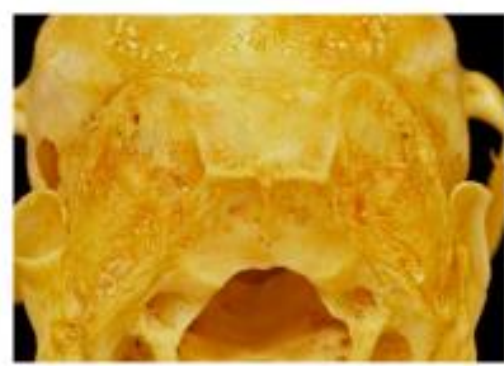

AMNH 33605

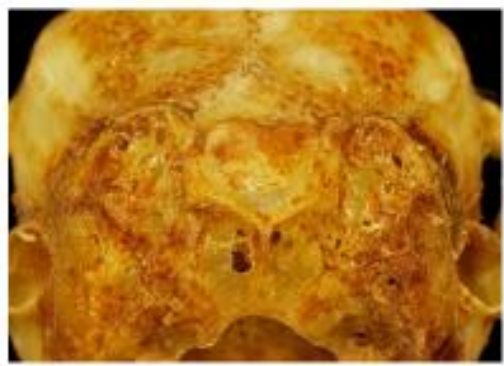

AMNH 40889

Figure 3.10

Caudad view of the external occipital protuberance found on the holotype and topotypes of S.n. pinetis.

Sylvilagus nuttallii pinetis external occipital protuberance

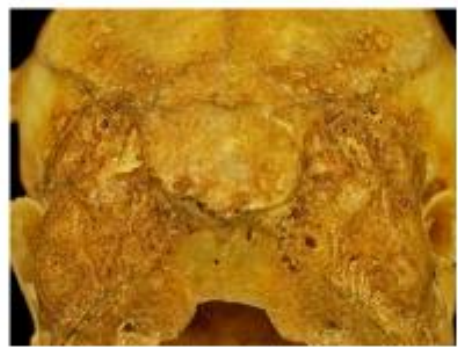

AMNH 7335

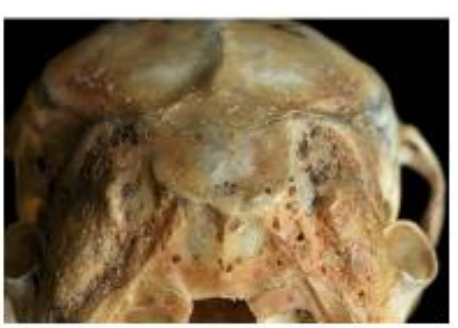

AMNH 7336

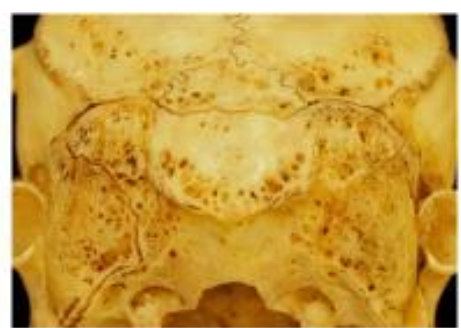

AMNH 125929 
Figure 3.11

Ventral view of the holotypes and proposed neotype of the Sylvilagus nuttallii.
S. n. grangeri
S. n. nuttallii
S. n. pinetis

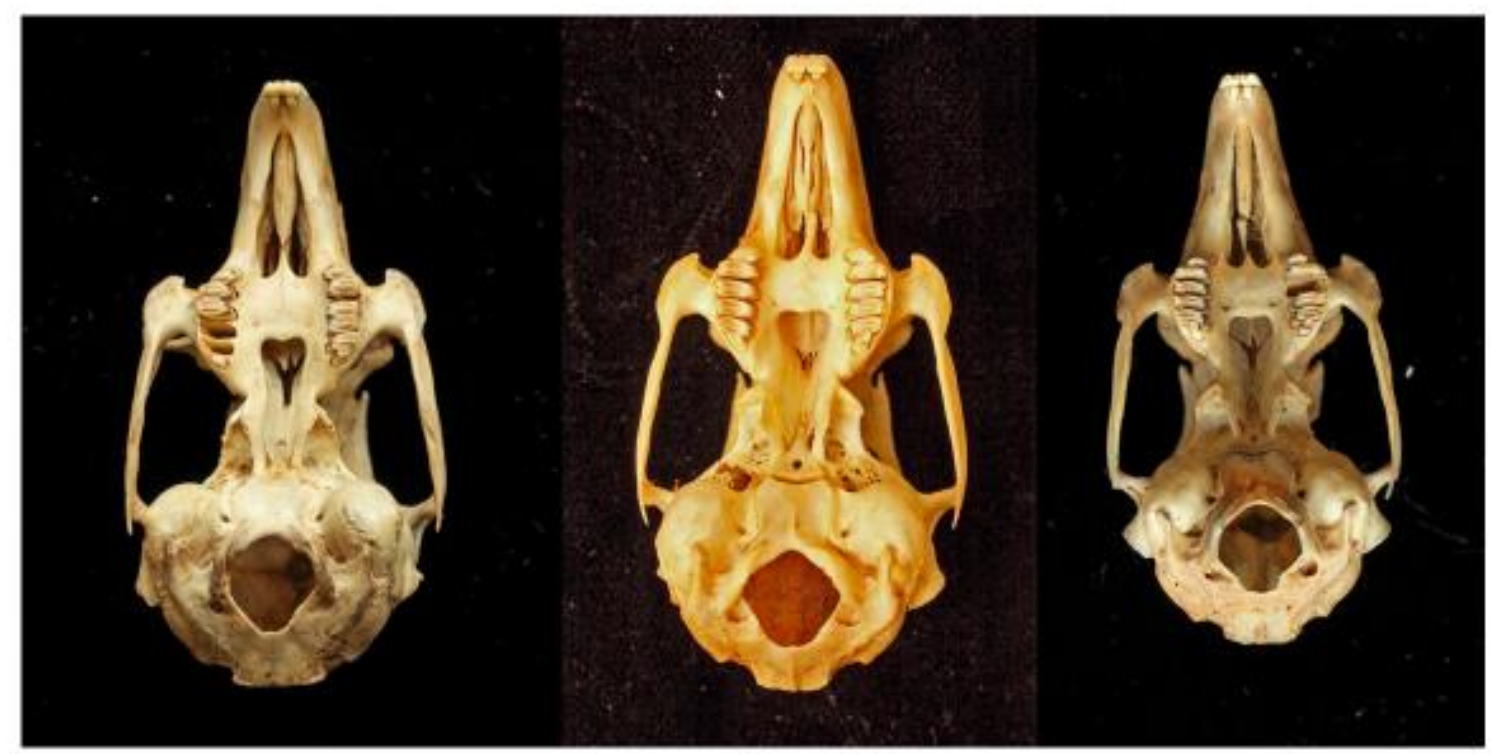

Figure 3.12

Left lateral view of the holotypes and proposed neotype of the Sylvilagus nuttallii.

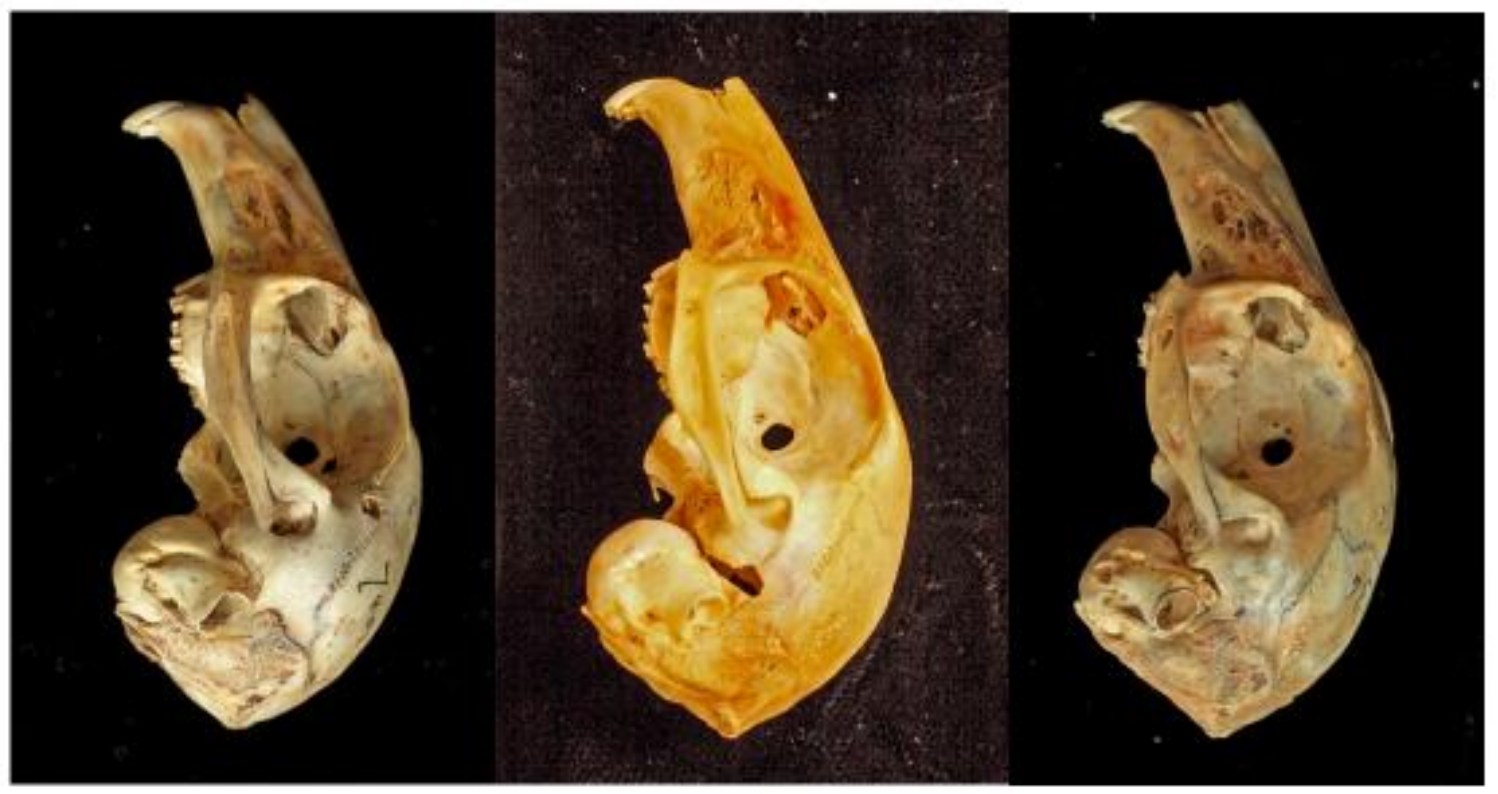


Figure 3.13

Right lateral view of the holotypes and proposed neotype of the Sylvilagus nuttallii.
S. n. grangeri
S. n. nuttallii
S. n. pinetis

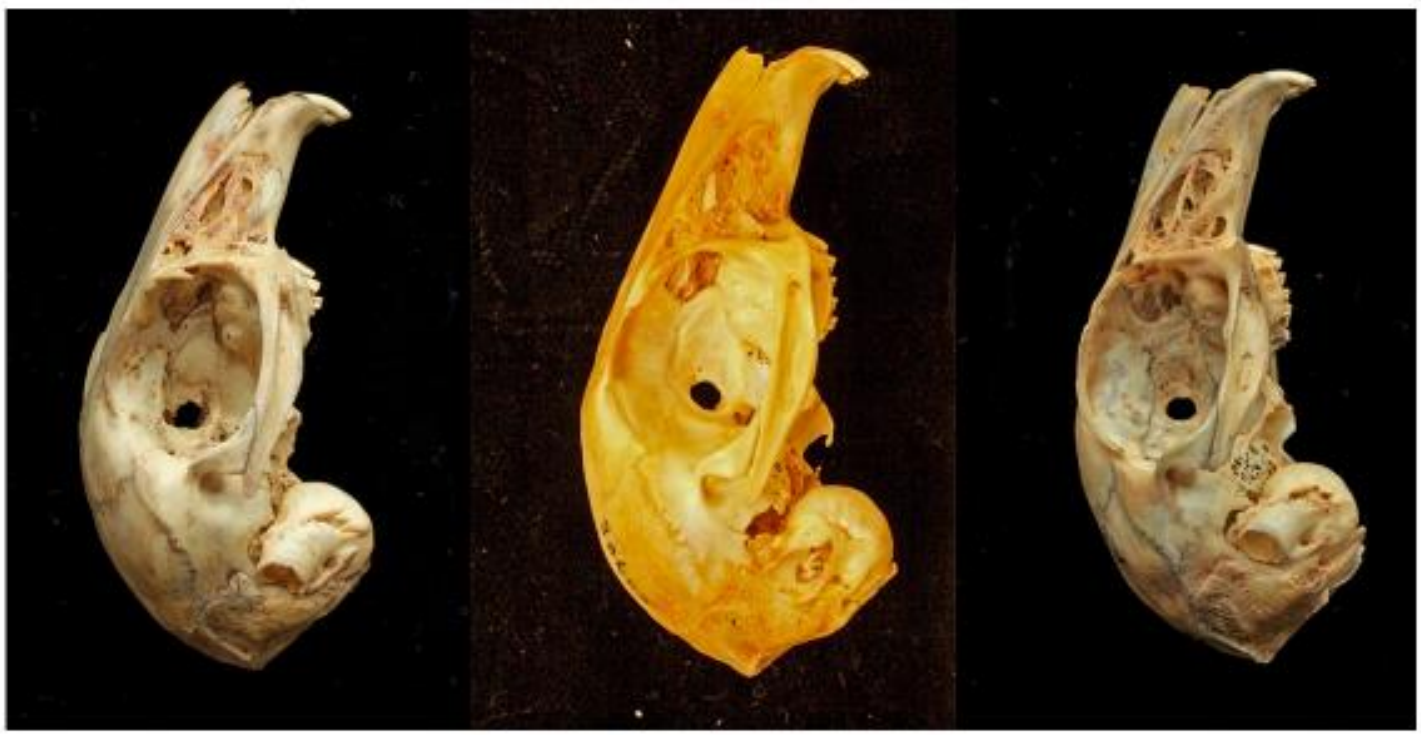

Figure 3.14

Side by side comparison of the $2^{\text {nd }}$ upper pre-molar of Sylvilagus nuttallii.

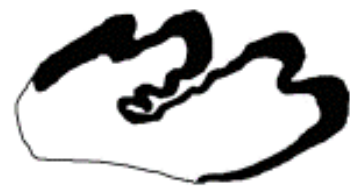

S.n. grangeri holotype AMNH 9094/7402 Female Lepus sylvaticus granger J.A. Allen 11 Aug 1894

Hill City, Custer County, SD

W.W. Granger, \# 292/1533

Bull. Am. Mus. Nat. Hist. 7: 2654 , Aug 21, 1895

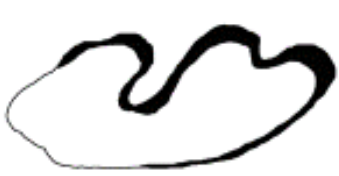

S.n. pinets holotype AMNH 9041/7336 Male Lepus sylvaticus pinetis J.A. Allen 14 Aug 1894

5 Mount Ord, White Mtns, Apache Co, AZ B.C. Condit \#2593

Bull. Am. Mus. Nat. Hist. 6: 348, Dec 7, 1894

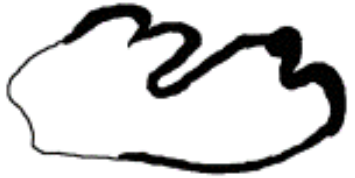

S.n. nuttallii (designated neotype) AMNH 33605 Female

Ironside, Malheur Co., Oregon 
Figure 3.15

Side by side comparison of the $3^{\text {rd }}$ lower pre-molar of Sylvilagus nuttallii.

p3 side by side comparison

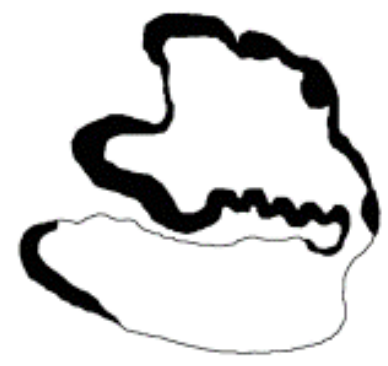

S.n. grangeri holotype AMNH 9094/7402 Female Lepus sylvaticus granger J.A. Allen 11 Aug 1894

Hill City, Custer County, SD W.W. Granger, \# 292/1533

Bull. Am. Mus. Nat. Hist. 7: 2654, Aug 21, 1895

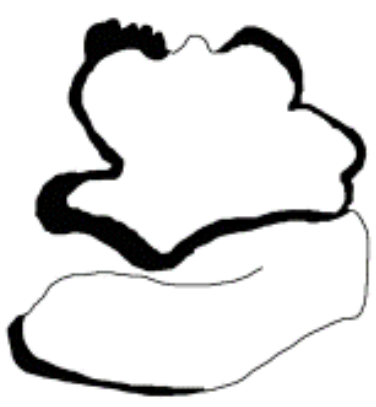

S.n. pinets holotype AMNH 9041/7336 Male Lepus sylvaticus pinetis J.A. Allen 14 Aug 1894

$S$ Mount Ord, White Mtns, Apache Co, AZ B.C. Condit $\$ 2593$ Bull. Am. Mus, Nat. Hist. 6; 348, Dec 7, 1894

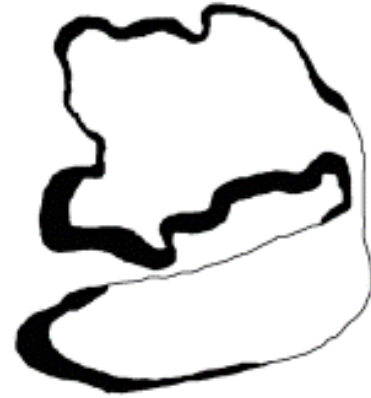

S.n. nuttallii (designated neotype) AMNH 33605 Female Ironside, Malheur Co., Oregon

Figure 3.16 Principal component analysis of holotype and topotype skull measurements of the Sylvilagus nuttallii species complex. S.n. pinetis is shown in blue, S.n. nuttallii is shown in green, and S.n. grangeri is shown in red.

Scatter plot of PC1, PC2, and $\mathrm{PC} 3$

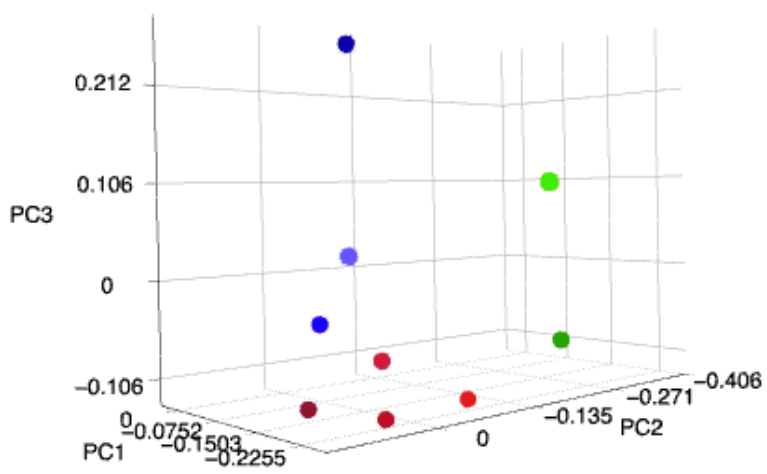

- S.n.grangeri AMNH7399 M

- S.n.grangeri AMNH9094/7402 F (holotype)

- S.n.grangeri AMNH7403 F

- S.n.grangeri AMNH7400 M

- S.n.nuttalli AMNH40889 M

- S.n.nuttalli AMNH33605 F

- S.n.pinetis AMNH 9041/7336 M (holotype)

- S.n.pinetis AMNH7335 F

- S.n.pinetis AMNH125929 F 
Table 3.1

Amount of variation accounted for during principal component analysis of Sylvilagus nuttallii skull shape and size

\begin{tabular}{|c|c|c|c|c|c|c|c|c|}
\hline & PC1 & $\mathrm{PC} 2$ & PC3 & PC4 & PC5 & PC6 & PC7 & PC8 \\
\hline & 0.53177 & 0.14180 & 0.10880 & 0.07265 & 0.05224 & 0.04281 & 0.02925 & 0.02065 \\
\hline ndi & 5 & 5 & 6 & 5 & 5 & 3 & 1 & 2 \\
\hline ulati & 0.53177 & 0.67357 & 0.78238 & & 0.90728 & 0.95009 & 0.97934 & \\
\hline & 5 & 9 & 5 & 0.85504 & 4 & 7 & 8 & 1 \\
\hline
\end{tabular}




\title{
Chapter 4
}

Evolutionary relationships among the three subspecies of Sylvilagus nuttallii (Bachman 1837) derived from genetic analysis of Cytochrome $b$

\begin{abstract}
Molecular phylogeny of the Sylvilagus nuttallii species complex was inferred using mitochondrial cytochrome $b$ (cyt $b$ ) gene extracted from topotype specimens to determine conspecificity of the three subspecies. When analyised alone, monophyly with well differentiated subspecies could be argued of the species complex. However, when other Sylvilagus species are included in the analysis it is clear $S$. $n$. grangeri is a sister taxa of S. n. pinetis. S. n. nuttallii is basal to the sister groups of $S . n$. grangeri and $S$. $n$. pinetis. We therefore recommend excising the subspecies nomial and elevating the taxa to species status.
\end{abstract}




\section{INTRODUCTION}

The term "genetic" been used since the early 1830's as a descriptive term for the origins of a species (Bateson 2002). The concept of genetics as a realm of biological sciences traces its origin to the well-known studies of Gregor Mendel and his pea plants, which led to the lost, then found Laws of Mendelian Inheritance (Butler 2010). William Bateson, a champion of Mendel's work, used the term genetics as a noun in 1905 giving us the form we know today (Bateson 2002). Simpson in 1943 and Dobzhansky in 1950 began laying the ground work for what would become the genetic species concept. It wasn't until 1957 that the idea of a genetic species concept was proposed and described as a species being nothing more than a field for the exchange of genetic material and the recombination of genes (Carson 1957). Since then a contentious debate has ensued (Mayr 1959, 1963, 1981, 1992, Dobzhanksy 1970, Coyne et al. 1988, Chandler and Gromko 1989, Masters and Spencer 1989, Mallet 1995, Bradley and Baker 2001, Baker and Bradley 2006) on how to define it, its tempo and mode, the underlying processes, speciation mechanisms and more.

With the publication of Bradley and Baker's "A Test of the Genetic Species Concept: Cytochrome- $b$ Sequences and Mammals" mammalogists finally had a concept that was workable, understandable, and could be applied across the board to differentiate between closely related species using genetic sequencing. In 2006 Baker and Bradley followed up their hallmark work with a proposed definition and explaination of the genetic species concept that is used today. In that work, they recognize the importance of vouchered museum specimens and the morphological value they hold. They conclude 
there is substantial evidence supporting more than 2000 morphologically cryptic mammalian species worldwide. According to latest estimates, there are only 6399 extant mammal species (Burgin et al. 2018). Given those numbers, nearly a third of all extant mammals are yet to be described. Here we present data on three proposed species that fall into the morphologically cryptic $30 \%$ category.

\section{MATERIALS AND METHODS}

Tissue samples were collected from topotype specimens over the course of two field seasons. Field locations in Oregon were centered on 44.90, -117.26 and 43.58, 118.26. The South Dakota location was centered on 44.18, -103.26. The Arizona field sites were centered on $35.05,-111.40$ and $34.09,-109.52$. DNA was extracted using a Qiagen DNeasy Blood and Tissue kit using the manufacturer's recommendations. We used Cyt-B1F (5'-CAT CGT TGT TTT CAA CTA TAA GAA CC-3`) and Cyt-B5R (5'GGC CAG GGT AAT GAA TTA TAC TAC T-3`) as primers for PCR amplification. Life technologies Taq PCR DNA polymerase PCR kit was used for PCR preparation. Final product for PCR was 2.5uL buffer, $1 \mathrm{uL} \mathrm{MgCl2,} 0.5 \mathrm{uL}$ Cyt-B1F, 0.5uL Cyt-b5R, 1 $\mathrm{uL}$ dNTPs, and $0.2 \mathrm{uL}$ taq with a total volumne of $25 \mathrm{uL}$. PCR cycling protocol was as follows: $94^{\circ} \mathrm{C}$ for 3 minutes, followed by 40 cycles of $94^{\circ} \mathrm{C}$ for 45 seconds, $52^{\circ} \mathrm{C}$ for 30 seconds, and $72^{\circ} \mathrm{C}$ for 90 seconds, and finished at $72^{\circ} \mathrm{C}$ for 10 minutes. All PCR products were purified using a QIAquick PCR purification kit.

\section{Maximum likelihood analyses}

Sequencing was performed by Oregon Health Sciences University's sequencing laboratory using their protocols. Sequence alignments were conducted using Clustal X, version 2.0 (Larkin et al. 2007) using default values. Final alignments were adjusted 
using Mesquite 3.02 (Maddison and Maddison 2015). Maximum likelihood (ML) analysis of the cytb gene was conducted using RAxML 8.2.4 (Stamatakis 2014). We performed 1000 replicate ML searches to assess clade confidence with 1000 bootstrap pseudoreplicates. Phylogenetic analysis was rooted using the Sylvilagus sister taxon Brachylagus idahoensis (Mathee et al. 2004)

\section{Phylogenetic analyses}

Cytochrome b (cytb) and 12S rRNA (12S) sequences were, respectively, aligned with other sequences available in the Genbank in Clustal W implemented in Bioedit v.7 (Thompson et al. 1994; Hall et al. 2011). Since most Sylvilagus specimens already sequenced had only one or the other fragment available, three sets of data were analyzed to a better level of comprehension for the phylogenetic relationships of the new data and other Sylvilagus representatives: cytb; $12 \mathrm{~S}$ and cytb+12S (Table 1). Sequences for other leporids, Ochotona princeps and Tamias striatus were added as outgroup for the phylogenetic analyses (Table 1). For each dataset, the best-fitted partition set and respective models of substitution were chosen by PartitionFinder (Lanfear et al. 2012), using the Bayesian Information Criterion (BIC). Cytb was divided in three partitions, with the following models of evolution $-\mathrm{K} 80+\mathrm{I}+\mathrm{G}$; $\mathrm{HKY}+\mathrm{I}+\mathrm{G}$ and $\mathrm{GTR}+\mathrm{G}$; and $12 \mathrm{~S}$ data set most likely evolved under a GTR $+\mathrm{I}+\mathrm{G}$ model; both for the single locus and multilocus data sets.

MRBAYES v. 3.2.5 (Huelsenbeck and Ronquist 2001; Ronquist et al. 2012) was used to infer the phylogenetic relationships for both cytb and $12 \mathrm{~S}$ data sets, running 1.2 and 1.0 million generations, respectively. For visualization purposes, neighbor joining trees for subsets of cytb and $12 \mathrm{~S}$ datasets, comprising only S. nuttallii, S. audubonii, $S$. 
floridanus and S. robustus sequences, were combined in a supernetwork after 1000 runs in SplitsTree v. 4.14.6 (Huson et al. 2004; Huson and Bryant 2006).

BEAST v.2.4.7 (Bouckaert et al. 2014) was used to estimate divergence times using the cytb+12S dataset. Following the review by Ruedas et al. (2017), two calibration points were used. The diversification of Sylvilagus was set at $4 \pm 1$ million years ago (MYA; $\mathrm{M}=1.4$ and $\mathrm{S}=0.1)$ and for Lepus at $4.5 \pm 1 \mathrm{MYA}(\mathrm{M}=1.5$ and $\mathrm{S}=0.1)$. After initial runs to allow for tuning of the run operators (Drummond and Rambaut 2007; Bouckaert et al. 2014), a run of $10^{9}$ generations was obtained based on an uncorrelated lognormal relaxed clock model (Drummond and Rambaut 2007) and a calibrated Yule model as priors. Clock models were linked, and clock rates were estimated based on the calibration points set and a gamma distribution with $\alpha=0.001$ and $\beta=1000$ was set as prior distribution for the overall clock model. This analysis was run in the CIPRES Science Gateway v. 3.3 (http://www.phylo.org). TreeAnnotator, part of the BEAST package, was used to summarize the resulting trees and target the maximum clade credibility tree. Final trees from MrBAYES and BEAST were visualized in FigTree, v. 1.4.2 (https://github.com/rambaut/figtree/).

\section{Genetic distances}

Pairwise genetic distances were calculated in MEGA v. 10.0.5 (Kumar et al. 2018), comparing the new DNA sequences for putative S. nuttallii nuttallii (01 and 03), S. $n$. grangeri (05 and 06) and S. n. pineti (07) and sequences for representatives of the following species: S. nuttalli (putatively from the same species), S. audubonii (closely related with S. nuttallii, both likely comprising complex of species; Ruedas et al. 2017; 
Silva et al. 2019), S. floridanus and S. robustus (according to the phylogenetic analyses here performed, these two species seem to be the most closely related taxa to the new samples; Fig. 1-3). A Kimura 2-parameter model (Kimura 1980) was considered and all positions containing gaps and missing data were excluded from the analysis.

\section{RESULTS}

\section{Phylogenetic analyses}

As expected given the different composition of both datasets, cytb and $12 \mathrm{~S}$ recovered slightly different phylogenetic relationships for the new DNA sequences and other, previously sequenced Sylvilagus species (Fig. 1 and 2, respectively). However, in both phylogenetic inferences, new sequences from the same putative $S$. nuttallii subspecies grouped together, but far from other sequences for this species and S. audubonii. This is best visualized in the supernetwork (Fig. 3). According to the split time estimates, the clade represented by the new sequences diverged about 1.34 Million years ago (C. I. 0.59-1.53), but the support given to the relationship between $S$. floridanus and samples 05 and 06 corresponded only to a posterior probability (PP) of 0.33 , similar to the support for this group being sister to 01 and 03 ( $\mathrm{PP}=0.32$ ) (Fig. 4). Nonetheless, the clade formed by $S$. floridanus and the new sequences had high support $(\mathrm{PP}=1)$. This time estimates are however just tentative, since $S$. robustus could not be included, but seems to be closely related to the new samples (Fig. 1).

\section{Genetic distances}

For both cytb and $12 \mathrm{~S}$ datasets, the highest genetic distances were obtained between groups including the new DNA sequences and those comprising sequences available in 
the GenBank for S. nuttalli and S. audubonii as depicted in bold in Table 2. Yet, depending on the dataset and group, the groups of new sequences were more similar to each other or to sequences for S. floridanus or S. robustus.

\section{DISCUSSION}

Our genetic analyses strongly support the conclusions based on morphological assessments of three distinct albeit cryptic species. The samples of genetic material we collected could only be $S$. nuttallii subspecies based on the locations and elevations of the sample sites. No other Sylvilagus species occurs in sympatry at these localities. Very few sequence data exist for S. nuttallii. Those that do, e.g. in Matthee et.al., may be misidentified and actually represent $S$. audubonii. Our analysis shows $S$. $n$. grangeri is sister to $\{S$. floridanus, $S$. robustus $\}$, in a clade also including $S$. $n$. pinetis, while $S$. $n$. nuttallii is basal to three previously indicated taxa. In each of the analyses, the species complex was much more closely related to each other or to S. robustus and S. floridanus than to $S$. audubonii clearly represented by the supernetwork, which lends credence to the idea of currently available samples being previously mis-identified.

According to Mathee et. al. basal Sylvilagus diverged approximately 4 million years ago. Our analysis indicate that the taxa currently hypothesized to constitute the $S$. nuttallii species complex have been on separate genetic pathways for approximately 1.34 million years. Our $12 S$ tree shows a clade more closely related to $S$. floridanus than to $S$. audubonii or currently available sequences presumed to be. The maximum likelihood analysis of cytb clearly shows $S$. $n$. grangeri and $S$. n. robustus are a closely related clade and sister to $S$. $n$. pinetis. Sylvilagus $n$. nuttallii is basal to those two groups. Given this 
taxonomic arrangement, we must falsify the hypothesis of one species of $S$. nuttallii

containing three subspecies.

Figure 4.1

Cytochrome-b phylogeny developed from the topotype specimens collected during this study.

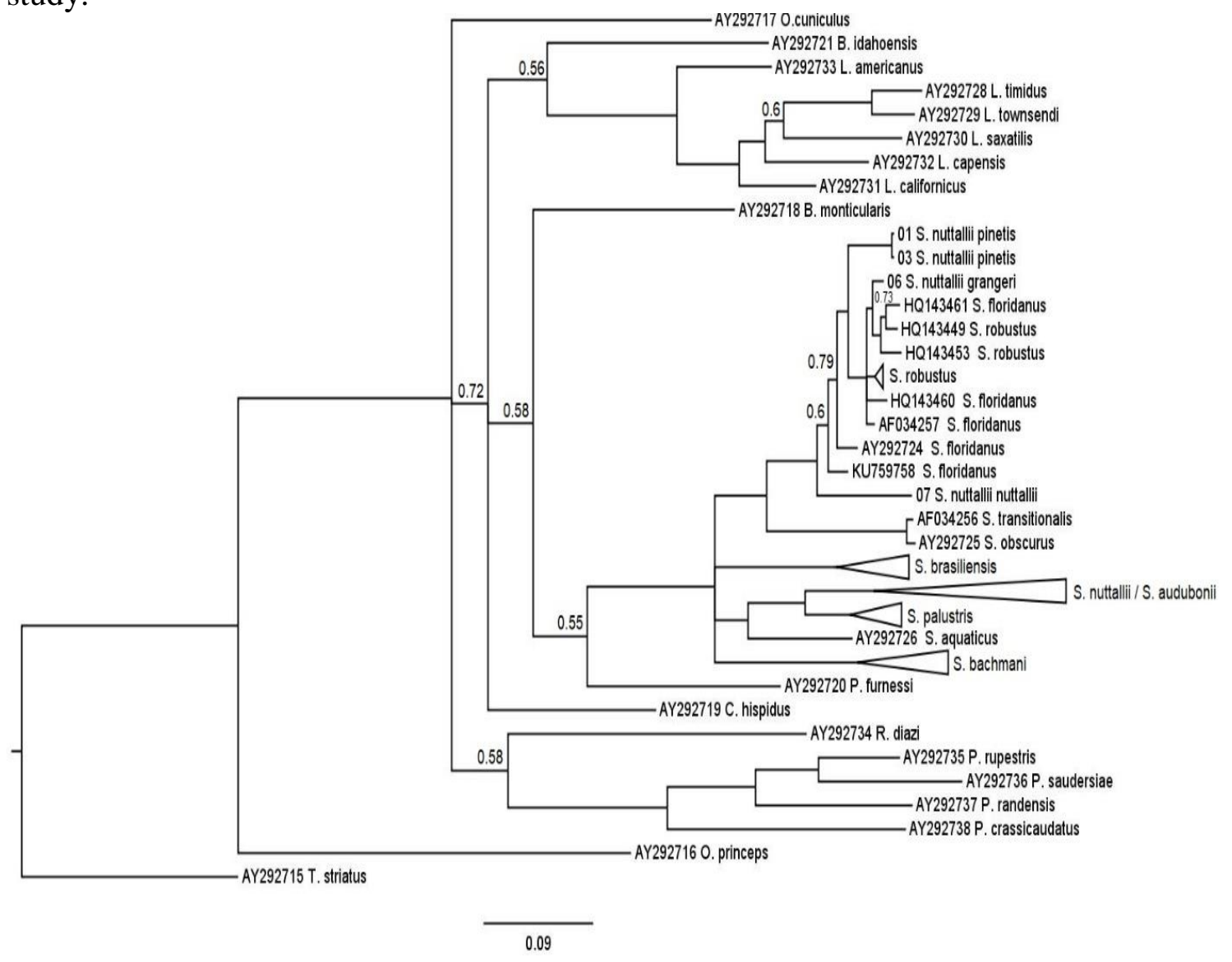


Figure 4.2

Ribosome 12S phylogeny derived from the sequencing and analysis of newly collected topotype specimens.

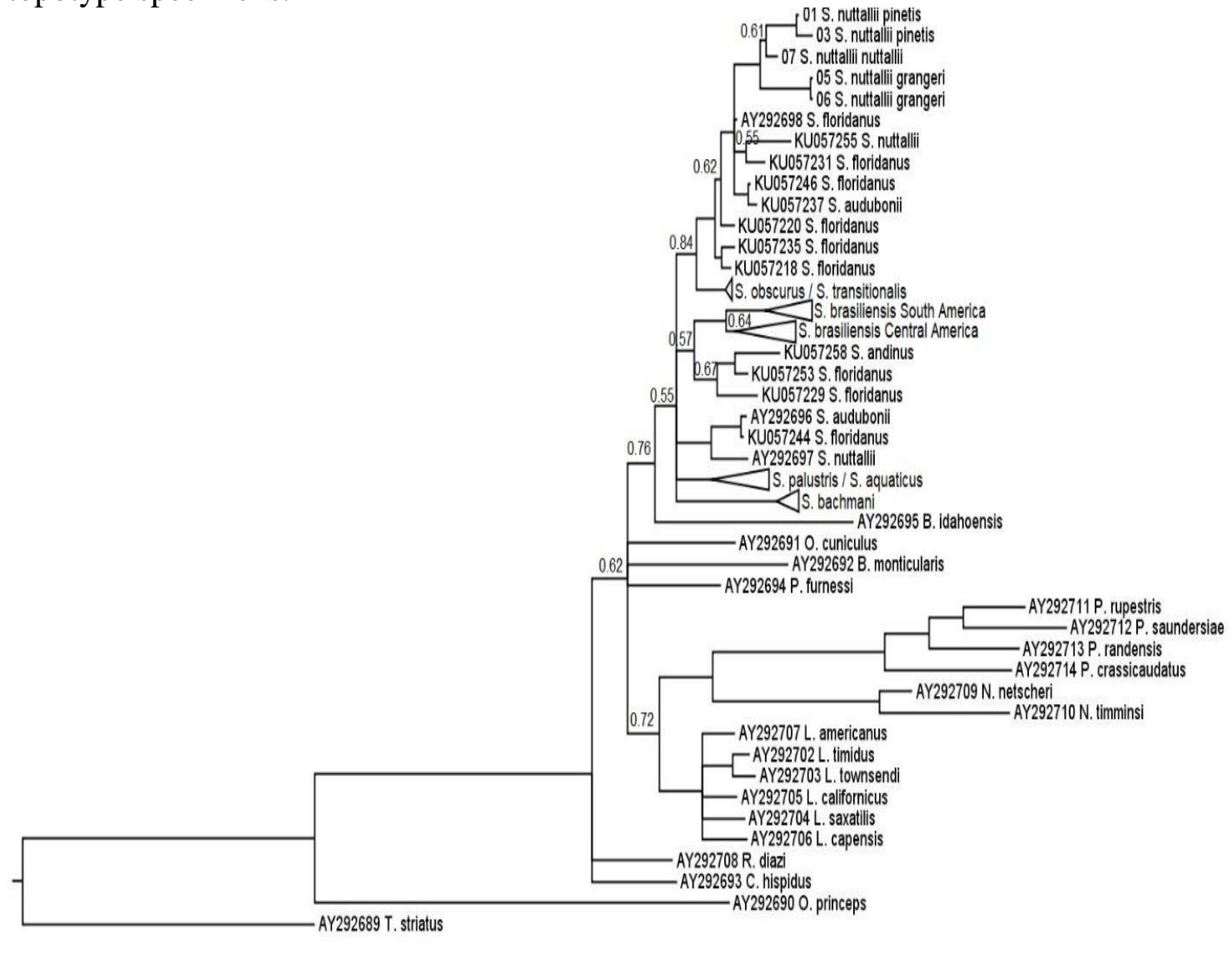


Figure 4.3

This supernetwork shows our new sequences from the $S$. nuttallii subspecies grouped together, but far from other sequences for this species and S. audubonii.

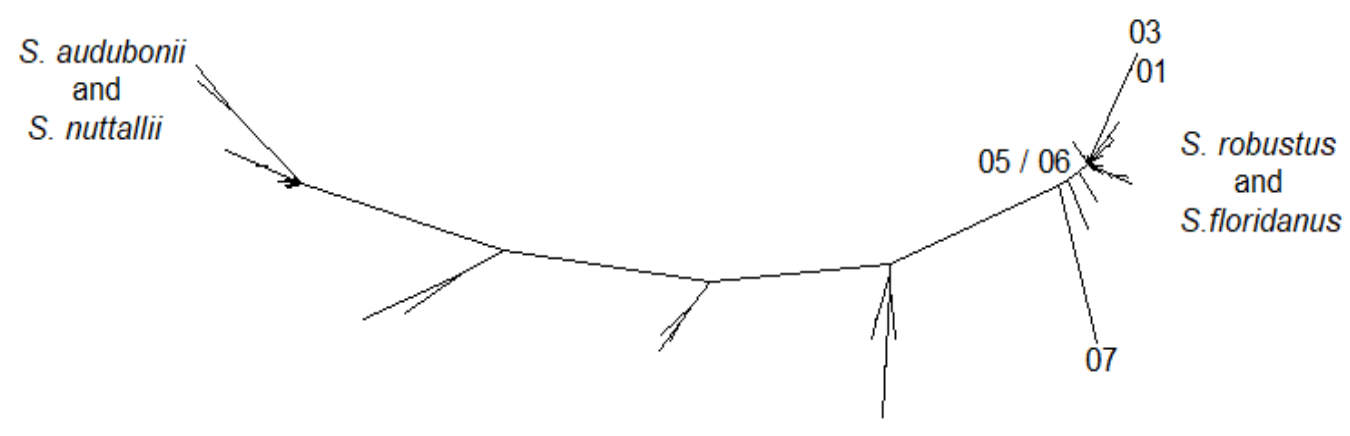

S. $f$ I

Figure 4.4

The clade represented by the new sequences diverged about 1.34 Million years ago (95\% C. I. 0.59-1.53), according to the split time estimates.

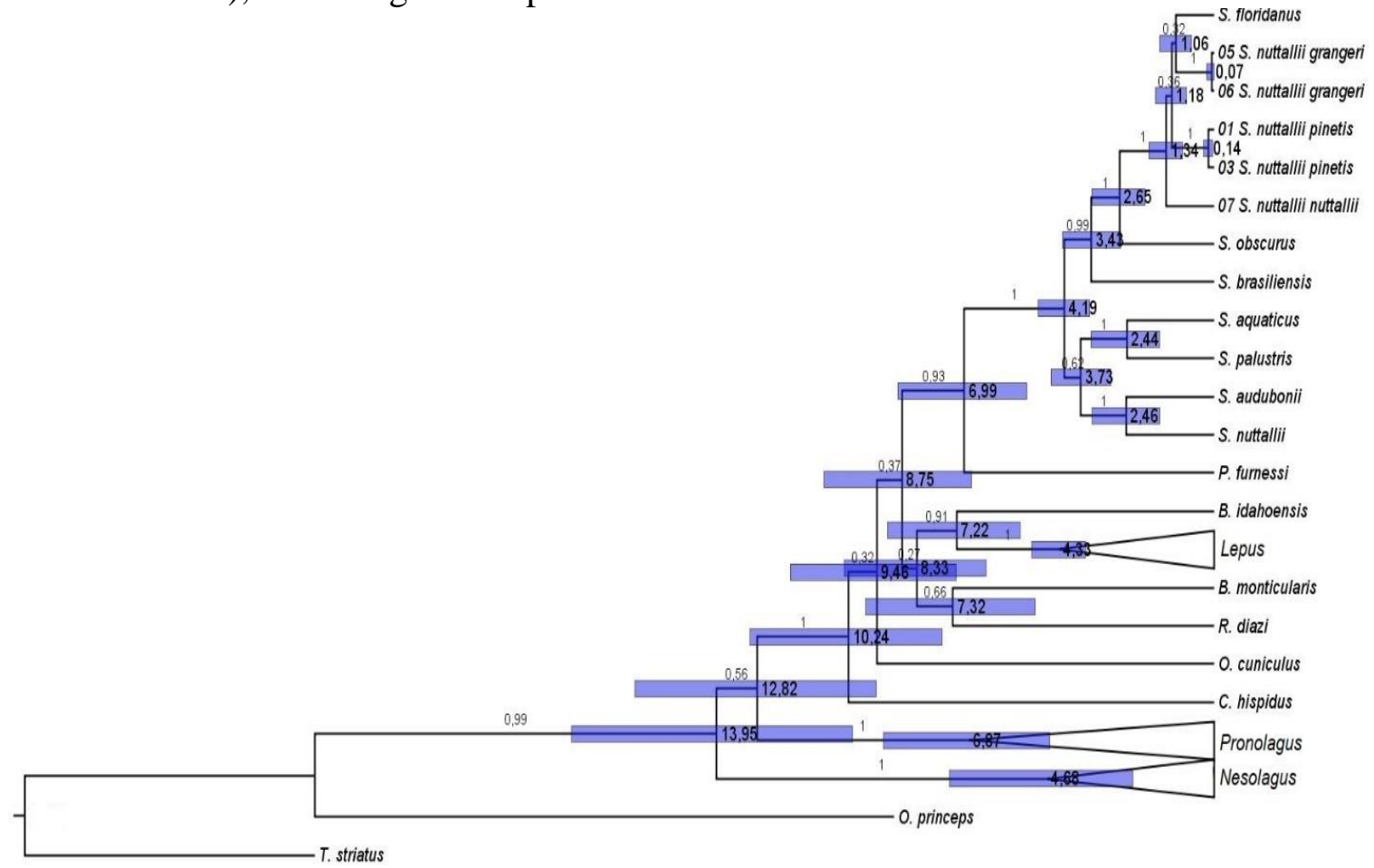


Figure 4.5

Maximum likelihood analysis showing the close relationship of S.n. grangeri and S.robustus.

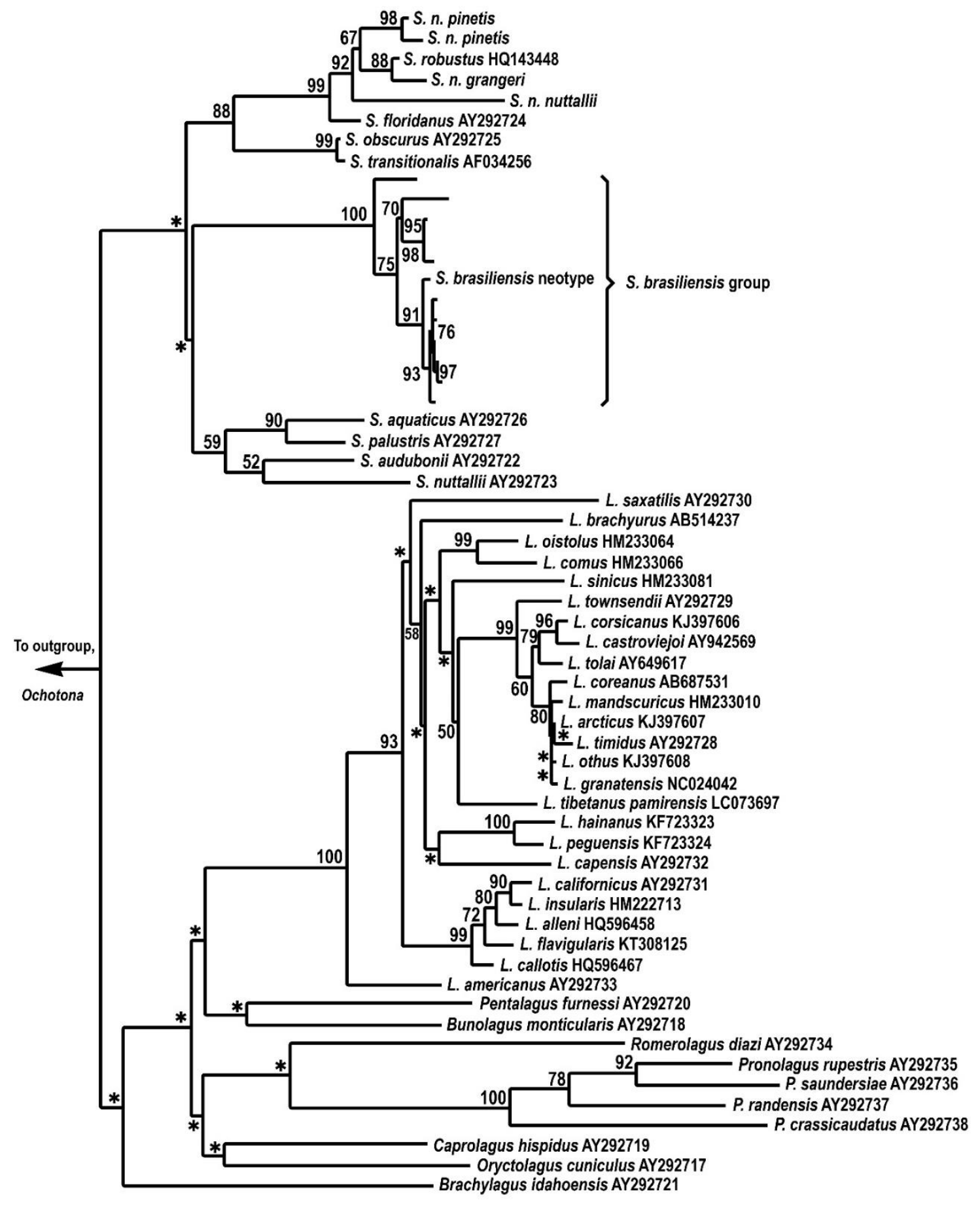


Table 4.1

Complete list of sequences used. Information on voucher number (whenever available), species or putative species complex, Genbank accession numbers, dataset and reference list are included.

\begin{tabular}{|c|c|c|c|c|c|c|}
\hline \multirow[t]{2}{*}{ Voucher } & \multirow{2}{*}{$\begin{array}{l}\text { Species / } \\
\text { Complex }\end{array}$} & \multirow{2}{*}{$\begin{array}{c}\text { MrBAYES } \\
\text { Fig.1 } \\
\text { CYTB }\end{array}$} & \multirow{2}{*}{$\begin{array}{c}\text { MrBAYES } \\
\text { Fig.2 } \\
12 S\end{array}$} & \multicolumn{2}{|c|}{$\begin{array}{l}\text { BEAST } \\
\text { Fig. } 4\end{array}$} & \multirow[t]{2}{*}{ Reference } \\
\hline & & & & CYTB & $12 \mathrm{~S}$ & \\
\hline 01 & $\begin{array}{l}\text { S. nuttallii } \\
\text { pinetis }\end{array}$ & ok & ok & ok & ok & This study \\
\hline 03 & S. n. pinetis & ok & ok & ok & ok & This study \\
\hline 05 & $\begin{array}{l}S . n . \\
\text { grangeri }\end{array}$ & & ok & & ok & This study \\
\hline 06 & $\begin{array}{l}\text { S. } n . \\
\text { grangeri }\end{array}$ & ok & ok & ok & ok & This study \\
\hline \multirow[t]{3}{*}{07} & $\begin{array}{l}\text { S. } n . \\
\text { nuttallii }\end{array}$ & ok & ok & ok & ok & This study \\
\hline & $\begin{array}{l}\text { S. } n . \\
\text { nuttallii }\end{array}$ & AY292723 & AY292697 & $\begin{array}{c}\text { AY292 } \\
723\end{array}$ & $\begin{array}{c}\text { AY292 } \\
697\end{array}$ & Matthee et al. 2004 \\
\hline & S. audubonii & AY292722 & AY292696 & $\begin{array}{l}\text { AY292 } \\
722\end{array}$ & $\begin{array}{c}\text { AY292 } \\
696\end{array}$ & Matthee et al. 2004 \\
\hline 14513 & S. audubonii & KU759759 & & & & $\begin{array}{c}\text { Álvarez-Castañeda and } \\
\text { Lorenzo } 2017\end{array}$ \\
\hline ASK7391 & S. audubonii & HQ143463 & & & & Nalls et al. 2012 \\
\hline $\begin{array}{l}\text { MSB262 } \\
536\end{array}$ & S. audubonii & KC661076 & & & & Dickerman et al. 2013 \\
\hline $\begin{array}{l}\text { MSB858 } \\
\quad 44\end{array}$ & S. audubonii & JQ965153 & & & & Dickerman et al. 2013 \\
\hline \multirow[t]{2}{*}{$\begin{array}{c}\text { BYU162 } \\
54\end{array}$} & S. audubonii & HQ596488 & & & & Ramírez-Silva et al. 2010 \\
\hline & S. aquaticus & AY292726 & AY292700 & $\begin{array}{c}\text { AY292 } \\
726\end{array}$ & $\begin{array}{c}\text { AY292 } \\
700\end{array}$ & Matthee et al. 2004 \\
\hline $\begin{array}{l}\text { MVZ218 } \\
243\end{array}$ & S. bachmani & KU759757 & & & & $\begin{array}{l}\text { Álvarez-Castañeda and } \\
\text { Lorenzo } 2017\end{array}$ \\
\hline $\begin{array}{l}\text { MVZ218 } \\
031\end{array}$ & S. bachmani & KU759756 & & & & $\begin{array}{l}\text { Álvarez-Castañeda and } \\
\text { Lorenzo } 2017\end{array}$ \\
\hline $\begin{array}{l}\text { MVZ218 } \\
018\end{array}$ & S. bachmani & KU759755 & & & & $\begin{array}{l}\text { Álvarez-Castañeda and } \\
\text { Lorenzo } 2017\end{array}$ \\
\hline $\begin{array}{l}\text { MVZ206 } \\
869\end{array}$ & S. bachmani & KU759753 & & & & $\begin{array}{l}\text { Álvarez-Castañeda and } \\
\text { Lorenzo } 2017\end{array}$ \\
\hline $\begin{array}{l}\text { MVZ208 } \\
257\end{array}$ & S. bachmani & KU759752 & & & & $\begin{array}{l}\text { Álvarez-Castañeda and } \\
\text { Lorenzo } 2017\end{array}$ \\
\hline $\begin{array}{l}\text { MVZ202 } \\
\quad 374\end{array}$ & S. bachmani & KU759751 & & & & $\begin{array}{l}\text { Álvarez-Castañeda and } \\
\text { Lorenzo } 2017\end{array}$ \\
\hline 16458 & S. bachmani & KU759750 & & & & $\begin{array}{l}\text { Álvarez-Castañeda and } \\
\text { Lorenzo } 2017\end{array}$ \\
\hline 16457 & S. bachmani & KU759749 & & & & $\begin{array}{l}\text { Álvarez-Castañeda and } \\
\text { Lorenzo } 2017\end{array}$ \\
\hline 15982 & S. bachmani & KU759748 & & & & $\begin{array}{l}\text { Álvarez-Castañeda and } \\
\text { Lorenzo } 2017\end{array}$ \\
\hline
\end{tabular}




\begin{tabular}{|c|c|c|c|c|c|c|}
\hline 15932 & S. bachmani & KU759747 & & & & $\begin{array}{l}\text { Álvarez-Castañeda and } \\
\text { Lorenzo } 2017\end{array}$ \\
\hline 15931 & S. bachmani & KU759746 & & & & $\begin{array}{l}\text { Álvarez-Castañeda and } \\
\text { Lorenzo } 2017\end{array}$ \\
\hline 15930 & S. bachmani & KU759745 & & & & $\begin{array}{l}\text { Álvarez-Castañeda and } \\
\text { Lorenzo } 2017\end{array}$ \\
\hline 15929 & S. bachmani & KU759744 & & & & $\begin{array}{c}\text { Álvarez-Castañeda and } \\
\text { Lorenzo } 2017\end{array}$ \\
\hline 15928 & S. bachmani & KU759743 & & & & $\begin{array}{l}\text { Álvarez-Castañeda and } \\
\text { Lorenzo } 2017\end{array}$ \\
\hline 15174 & S. bachmani & KU759742 & & & & $\begin{array}{l}\text { Álvarez-Castañeda and } \\
\text { Lorenzo } 2017\end{array}$ \\
\hline 15173 & S. bachmani & KU759741 & & & & $\begin{array}{l}\text { Álvarez-Castañeda and } \\
\text { Lorenzo } 2017\end{array}$ \\
\hline 15172 & S. bachmani & KU759740 & & & & $\begin{array}{l}\text { Álvarez-Castañeda and } \\
\text { Lorenzo } 2017\end{array}$ \\
\hline 15171 & S. bachmani & KU759739 & & & & $\begin{array}{l}\text { Álvarez-Castañeda and } \\
\text { Lorenzo } 2017\end{array}$ \\
\hline 15170 & S. bachmani & KU759738 & & & & $\begin{array}{l}\text { Álvarez-Castañeda and } \\
\text { Lorenzo } 2017\end{array}$ \\
\hline 15169 & S. bachmani & KU759737 & & & & $\begin{array}{l}\text { Álvarez-Castañeda and } \\
\text { Lorenzo } 2017\end{array}$ \\
\hline 15168 & S. bachmani & KU759736 & & & & $\begin{array}{c}\text { Álvarez-Castañeda and } \\
\text { Lorenzo } 2017\end{array}$ \\
\hline 15167 & S. bachmani & KU759735 & & & & $\begin{array}{l}\text { Álvarez-Castañeda and } \\
\text { Lorenzo } 2017\end{array}$ \\
\hline 13445 & S. bachmani & KU759734 & & & & $\begin{array}{l}\text { Álvarez-Castañeda and } \\
\text { Lorenzo } 2017\end{array}$ \\
\hline 13444 & S. bachmani & KU759733 & & & & $\begin{array}{l}\text { Álvarez-Castañeda and } \\
\text { Lorenzo } 2017\end{array}$ \\
\hline 4910 & S. bachmani & KU759732 & & & & $\begin{array}{c}\text { Álvarez-Castañeda and } \\
\text { Lorenzo } 2017\end{array}$ \\
\hline $\begin{array}{l}\text { UFPE174 } \\
0\end{array}$ & $\begin{array}{l}S . \\
\text { brasiliensis }\end{array}$ & MH115201 & KU057257 & $\begin{array}{c}\text { MH115 } \\
201\end{array}$ & $\begin{array}{c}\text { KU057 } \\
257\end{array}$ & $\begin{array}{c}\text { Ruedas et al. 2017; Silva } \\
\text { et al. } 2019\end{array}$ \\
\hline $\begin{array}{c}\text { DPV5358 } \\
0\end{array}$ & $\begin{array}{c}S . \\
\text { brasiliensis }\end{array}$ & MH115206 & & & & Silva et al. 2019 \\
\hline SP01 & $\begin{array}{c}S . \\
\text { brasiliensis }\end{array}$ & & MH115195 & & & Silva et al. 2019 \\
\hline LG479 & $\begin{array}{c}S . \\
\text { brasiliensis }\end{array}$ & MH115205 & MH115193 & & & Silva et al. 2019 \\
\hline M1778 & $\begin{array}{c}S . \\
\text { brasiliensis }\end{array}$ & MH115204 & MH115192 & & & Silva et al. 2019 \\
\hline M1770 & $\begin{array}{c}S . \\
\text { brasiliensis }\end{array}$ & MH115203 & MH115191 & & & Silva et al. 2019 \\
\hline M1380 & $\begin{array}{c}\text { S. } \\
\text { brasiliensis }\end{array}$ & MH115202 & MH115190 & & & Silva et al. 2019 \\
\hline RS01 & $\begin{array}{c}S . \\
\text { brasiliensis }\end{array}$ & MH115208 & & & & Silva et al. 2019 \\
\hline $\begin{array}{l}\text { MPEG45 } \\
456\end{array}$ & $\begin{array}{c}S . \\
\text { brasiliensis }\end{array}$ & MH115212 & & & & Silva et al. 2019 \\
\hline $\begin{array}{l}\text { MPEG45 } \\
\quad 455\end{array}$ & $\begin{array}{c}S . \\
\text { brasiliensis }\end{array}$ & MH115211 & & & & Silva et al. 2019 \\
\hline
\end{tabular}




\begin{tabular}{|c|c|c|c|c|c|c|}
\hline M1796 & $\begin{array}{c}S . \\
\text { brasiliensis }\end{array}$ & MH115209 & MH115197 & & & Silva et al. 2019 \\
\hline TOC013 & $\begin{array}{l}S . \\
\text { brasiliensis }\end{array}$ & & MH115198 & & & Silva et al. 2019 \\
\hline & S. floridanus & AY292724 & AY292698 & $\begin{array}{c}\text { AY292 } \\
724\end{array}$ & $\begin{array}{l}\text { AY292 } \\
698\end{array}$ & Matthee et al. 2004 \\
\hline 12554 & S. floridanus & KU759758 & & & & $\begin{array}{l}\text { Álvarez-Castañeda and } \\
\text { Lorenzo } 2017\end{array}$ \\
\hline ET462 & S. floridanus & HQ143462 & & & & Nalls et al. 2010 \\
\hline ASK4948 & S. floridanus & HQ143461 & & & & Nalls et al. 2010 \\
\hline \multirow[t]{4}{*}{ ASK4764 } & S. floridanus & HQ143460 & & & & Nalls et al. 2010 \\
\hline & S. floridanus & AF034257 & & & & Snyder \& Husband 1997 \\
\hline & S. obscurus & AY292725 & AY292699 & $\begin{array}{c}\text { AY292 } \\
725\end{array}$ & $\begin{array}{l}\text { AY292 } \\
699\end{array}$ & Matthee et al. 2004 \\
\hline & S. palustris & AY292727 & AY292701 & $\begin{array}{c}\text { AY292 } \\
727\end{array}$ & $\begin{array}{l}\text { AY292 } \\
701\end{array}$ & Matthee et al. 2004 \\
\hline Spal14 & S. palustris & JQ955720 & & & & Tursi et al. 2013 \\
\hline Spal13 & S. palustris & JQ955719 & & & & Tursi et al. 2013 \\
\hline Spal25 & S. palustris & JQ955718 & & & & Tursi et al. 2013 \\
\hline Spal11 & S. palustris & JQ955717 & & & & Tursi et al. 2013 \\
\hline Spal17 & S. palustris & JQ955716 & & & & Tursi et al. 2013 \\
\hline Spal16 & S. palustris & JQ955715 & & & & Tursi et al. 2013 \\
\hline Spal15 & S. palustris & JQ955714 & & & & Tursi et al. 2013 \\
\hline Spal12 & S. palustris & JQ955713 & & & & Tursi et al. 2013 \\
\hline Spal27 & S. palustris & JQ955712 & & & & Tursi et al. 2013 \\
\hline Spal10 & S. palustris & JQ955711 & & & & Tursi et al. 2013 \\
\hline Spal19 & S. palustris & JQ955710 & & & & Tursi et al. 2013 \\
\hline Spal5 & S. palustris & JQ955709 & & & & Tursi et al. 2013 \\
\hline Spal22 & S. palustris & JQ955708 & & & & Tursi et al. 2013 \\
\hline Spal9 & S. palustris & JQ955707 & & & & Tursi et al. 2013 \\
\hline Spal23 & S. palustris & JQ955706 & & & & Tursi et al. 2013 \\
\hline Spal8 & S. palustris & JQ955705 & & & & Tursi et al. 2013 \\
\hline Sapl1 & S. palustris & JQ955704 & & & & Tursi et al. 2013 \\
\hline Spal24 & S. palustris & JQ955703 & & & & Tursi et al. 2013 \\
\hline Spal4 & S. palustris & JQ955702 & & & & Tursi et al. 2013 \\
\hline Spal3 & S. palustris & JQ955701 & & & & Tursi et al. 2013 \\
\hline Spal6 & S. palustris & JQ955700 & & & & Tursi et al. 2013 \\
\hline Spal31 & S. palustris & JQ955699 & & & & Tursi et al. 2013 \\
\hline Spal2 & S. palustris & JQ955698 & & & & Tursi et al. 2013 \\
\hline Spal32 & S. palustris & JQ955697 & & & & Tursi et al. 2013 \\
\hline Sap17 & S. palustris & JQ955696 & & & & Tursi et al. 2013 \\
\hline Spal33 & S. palustris & JQ955695 & & & & Tursi et al. 2013 \\
\hline Spal28 & S. palustris & JQ955694 & & & & Tursi et al. 2013 \\
\hline Spal26 & S. palustris & JQ955693 & & & & Tursi et al. 2013 \\
\hline Spal20 & S. palustris & JQ955692 & & & & Tursi et al. 2013 \\
\hline Spal18 & S. palustris & JQ955691 & & & & Tursi et al. 2013 \\
\hline Spal30 & S. palustris & JQ955690 & & & & Tursi et al. 2013 \\
\hline Spal29 & S. palustris & JQ955689 & & & & Tursi et al. 2013 \\
\hline
\end{tabular}




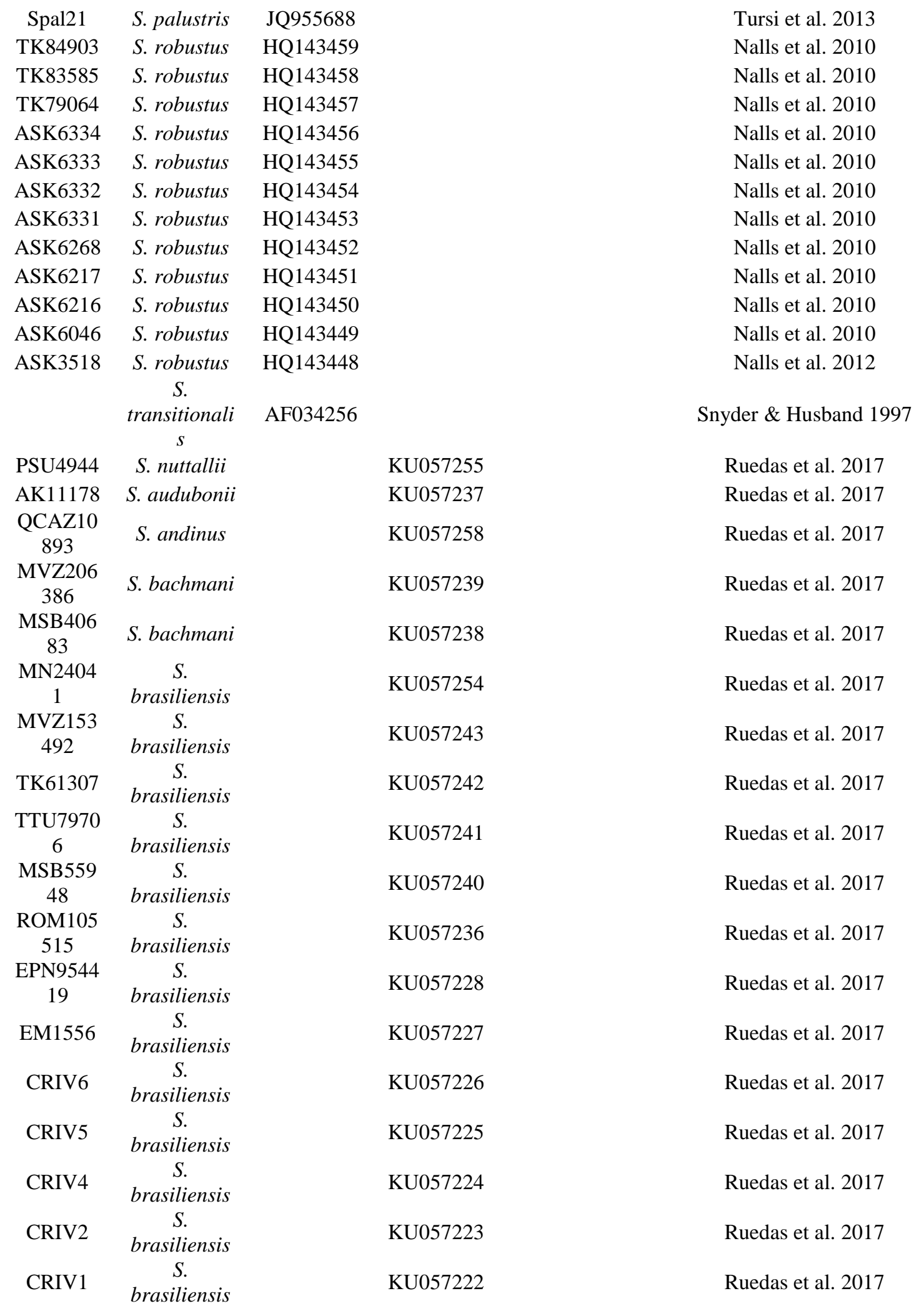




\begin{tabular}{|c|c|c|c|c|c|c|}
\hline CR1hsr & $\begin{array}{l}S . \\
\text { brasiliensis }\end{array}$ & & KU057219 & & & Ruedas et al. 2017 \\
\hline $\begin{array}{c}\text { TTU1143 } \\
74\end{array}$ & S. dicei & & KU057256 & & & Ruedas et al. 2017 \\
\hline $\begin{array}{c}\text { TK14751 } \\
8\end{array}$ & S. dicei & & KU057251 & & & Ruedas et al. 2017 \\
\hline IIBT349 & S. floridanus & & KU057253 & & & Ruedas et al. 2017 \\
\hline AK11511 & S. floridanus & & KU057246 & & & Ruedas et al. 2017 \\
\hline NP310 & S. floridanus & & KU057235 & & & Ruedas et al. 2017 \\
\hline $\begin{array}{c}\text { MVZ154 } \\
373\end{array}$ & S. floridanus & & KU057231 & & & Ruedas et al. 2017 \\
\hline hidra008 & S. floridanus & & KU057229 & & & Ruedas et al. 2017 \\
\hline CR26gpv & S. floridanus & & KU057220 & & & Ruedas et al. 2017 \\
\hline $\begin{array}{c}\mathrm{ASNHC}_{2} \\
2330\end{array}$ & S. floridanus & & KU057218 & & & Ruedas et al. 2017 \\
\hline $\begin{array}{c}\text { MSB158 } \\
807\end{array}$ & S. gabbi & & KU057233 & & & Ruedas et al. 2017 \\
\hline $\begin{array}{c}\text { MSB 158 } \\
806\end{array}$ & S. gabbi & & KU057232 & & & Ruedas et al. 2017 \\
\hline AK11516 & S. obscurus & & KU057248 & & & Ruedas et al. 2017 \\
\hline AK11529 & S. obscurus & & KU057247 & & & Ruedas et al. 2017 \\
\hline PSU4960 & $\begin{array}{c}\text { S. palustris } \\
\text { S. }\end{array}$ & & KU057249 & & & Ruedas et al. 2017 \\
\hline \multirow[t]{14}{*}{ AK11525 } & $\begin{array}{c}\text { transitionali } \\
s\end{array}$ & & KU057250 & & & Ruedas et al. 2017 \\
\hline & $\begin{array}{c}\text { B. } \\
\text { idahoensis }\end{array}$ & AY292721 & AY292695 & $\begin{array}{c}\text { AY292 } \\
721\end{array}$ & $\begin{array}{c}\text { AY292 } \\
695\end{array}$ & Matthee et al. 2004 \\
\hline & $\begin{array}{c}B . \\
\text { monticularis }\end{array}$ & AY292718 & AY292692 & $\begin{array}{c}\text { AY292 } \\
718\end{array}$ & $\begin{array}{c}\text { AY292 } \\
692\end{array}$ & Matthee et al. 2004 \\
\hline & C. hispidus & AY292719 & AY292693 & $\begin{array}{c}\text { AY292 } \\
719\end{array}$ & $\begin{array}{c}\text { AY292 } \\
693\end{array}$ & Matthee et al. 2004 \\
\hline & $\begin{array}{c}L . \\
\text { californicus }\end{array}$ & AY292731 & AY292705 & $\begin{array}{c}\text { AY292 } \\
731\end{array}$ & $\begin{array}{c}\text { AY292 } \\
705\end{array}$ & Matthee et al. 2004 \\
\hline & L. capensis & AY292732 & AY292706 & $\begin{array}{c}\text { AY292 } \\
732\end{array}$ & $\begin{array}{c}\text { AY292 } \\
706\end{array}$ & Matthee et al. 2004 \\
\hline & L. saxatilis & AY292730 & AY292704 & $\begin{array}{c}\text { AY292 } \\
730\end{array}$ & $\begin{array}{c}\text { AY292 } \\
704\end{array}$ & Matthee et al. 2004 \\
\hline & L. timidus & AY292728 & AY292702 & $\begin{array}{c}\text { AY292 } \\
728\end{array}$ & $\begin{array}{c}\text { AY292 } \\
702\end{array}$ & Matthee et al. 2004 \\
\hline & L. townsendi & AY292729 & AY292703 & $\begin{array}{c}\text { AY292 } \\
729\end{array}$ & $\begin{array}{c}\text { AY292 } \\
703\end{array}$ & Matthee et al. 2004 \\
\hline & $\begin{array}{c}\text { L.americanu } \\
s\end{array}$ & AY292733 & AY292707 & $\begin{array}{c}\text { AY292 } \\
733\end{array}$ & $\begin{array}{c}\text { AY292 } \\
707\end{array}$ & Matthee et al. 2004 \\
\hline & N. netscheri & & AY292709 & & $\begin{array}{c}\text { AY292 } \\
709\end{array}$ & Matthee et al. 2004 \\
\hline & N. timminsi & & AY292710 & & $\begin{array}{c}\text { AY292 } \\
710\end{array}$ & Matthee et al. 2004 \\
\hline & O. cuniculus & AY292717 & AY292691 & $\begin{array}{c}\text { AY292 } \\
717\end{array}$ & $\begin{array}{c}\text { AY292 } \\
691\end{array}$ & Matthee et al. 2004 \\
\hline & $\begin{array}{c}P . \\
\text { crassicaudat } \\
\text { us }\end{array}$ & AY292738 & AY292714 & $\begin{array}{c}\text { AY292 } \\
738\end{array}$ & $\begin{array}{c}\text { AY292 } \\
714\end{array}$ & Matthee et al. 2004 \\
\hline
\end{tabular}




\begin{tabular}{cccccc} 
P. furnessi & AY292720 & AY292694 & AY292 & AY292 & Matthee et al. 2004 \\
& & & 694 & \\
P. randensis & AY292737 & AY292713 & AY292 & AY292 & Matthee et al. 2004 \\
& & & 737 & 713 & \\
$\begin{array}{c}\text { P. rupestris } \\
\text { AY292735 }\end{array}$ & AY292711 & AY292 & AY292 & Matthee et al. 2004 \\
$\begin{array}{c}\text { A. } \\
\text { saundersiae }\end{array}$ & AY292736 & AY292712 & AY292 & AY292 & Matthee et al. 2004 \\
$\begin{array}{c}\text { R. diazi } \\
\text { AY }\end{array}$ & AY292734 & AY292708 & AY292 & AY292 & Matthee et al. 2004 \\
O. princeps & AY292716 & AY292690 & AY292 & AY292 & Matthee et al. 2004 \\
T. striatus & AY292715 & AY292689 & AY292 & AY290 & Matthee et al. 2004 \\
\hline
\end{tabular}

Table 4.2

Pairwise genetic divergences between groups for the cytochrome b (cytb) and 12S rRNA (12S) data sets (below the diagonals), and respective standard errors (above the diagonals).

\begin{tabular}{c|ccccccc} 
Cytb & $\begin{array}{c}\text { S.n.pine } \\
\text { stis }\end{array}$ & $\begin{array}{c}\text { S.n.grang } \\
\text { eri }\end{array}$ & $\begin{array}{c}\text { S.n.nutta } \\
\text { llii }\end{array}$ & $\begin{array}{c}\text { S.audub } \\
\text { onii }\end{array}$ & $\begin{array}{c}\text { S.florida } \\
\text { nus }\end{array}$ & $\begin{array}{c}\text { S.robus } \\
\text { tus }\end{array}$ & $\begin{array}{c}\text { S.nutta } \\
\text { llii }\end{array}$ \\
\hline $\begin{array}{c}\text { S.n.pinest } \\
\text { is }\end{array}$ & & 0.008 & 0.012 & 0.017 & 0.007 & 0.008 & 0.016 \\
$\begin{array}{c}\text { S.n.grang } \\
\text { eri }\end{array}$ & 0.039 & & 0.012 & 0.017 & 0.004 & 0.004 & 0.017 \\
$\begin{array}{c}\text { S.n.nuttal } \\
\text { lii }\end{array}$ & 0.076 & 0.076 & & 0.018 & 0.010 & 0.011 & 0.017 \\
$\begin{array}{c}\text { S.audubo } \\
\text { nii }\end{array}$ & 0.138 & 0.148 & 0.169 & & 0.016 & 0.017 & 0.010 \\
$\begin{array}{c}\text { S.florida } \\
\text { nus }\end{array}$ & 0.040 & 0.020 & 0.070 & 0.143 & & 0.003 & 0.016 \\
$\begin{array}{c}\text { S.robustu } \\
\text { s }\end{array}$ & 0.037 & 0.012 & 0.075 & 0.142 & 0.018 & & 0.016 \\
$\begin{array}{c}\text { S.nuttalli } \\
i\end{array}$ & 0.125 & 0.134 & 0.147 & 0.057 & 0.126 & 0.125 &
\end{tabular}

\begin{tabular}{|c|c|c|c|c|c|c|}
\hline $12 \mathrm{~S}$ & $\begin{array}{c}\text { S.n.pinet } \\
\text { is }\end{array}$ & $\begin{array}{c}\text { S.n.granger } \\
\text { is }\end{array}$ & $\begin{array}{c}\text { S.n.nuttall } \\
i i\end{array}$ & $\begin{array}{c}\text { S.audubon } \\
i i\end{array}$ & $\begin{array}{c}\text { S.floridan } \\
\text { us }\end{array}$ & $\begin{array}{c}\text { S.nuttall } \\
i i\end{array}$ \\
\hline S.n.pinetis & & 0.006 & 0.004 & 0.005 & 0.004 & 0.005 \\
\hline $\begin{array}{c}\text { S.n.granger } \\
\text { is }\end{array}$ & 0.027 & & 0.005 & 0.005 & 0.005 & 0.005 \\
\hline S.n.nuttallii & 0.014 & 0.017 & & 0.004 & 0.003 & 0.004 \\
\hline S.audubonii & 0.029 & 0.030 & 0.020 & & 0.004 & 0.004 \\
\hline $\begin{array}{c}\text { S.floridanu } \\
\text { s }\end{array}$ & 0.022 & 0.025 & 0.014 & 0.021 & & 0.004 \\
\hline S.nuttallii & 0.032 & 0.034 & 0.023 & 0.028 & 0.027 & \\
\hline
\end{tabular}




\section{CHAPTER 5}

"I have met no one who questions the existence of rabbits and hares, and I have been reluctantly forced to accept them" (Wood 1957).

We began this research by returning to Albert Wood's famous question from 1957

"What, if anything is a rabbit?" In that work, Wood described the basic set of characteristics defining a lagomorph, including: a dental formula of I2/1 C0/0 P2-3/2 M23/2-3; upper tooth rows farther apart than the lower; a single layer of enamel, as opposed to two in rodents; highly fenestrated rostrum; elongated incisive foramina; midline of palate extending only to P4 or M1; supra orbital processes well developed; lacking ectotympanic with bullae formed solely from ectotympanic; solid rami with no movement at symphysis; lacking an epicondylar foramen; fused tibia and fibula; fibula and calcaneum articulating with each other; caecum has a spiral valve; lacking os penis; among other characters.

With respect specifically to Sylvilagus nuttalli, Edward W. Nelson described pelage differences of the mountain cottontails in great detail in his 1909 work, The Rabbits of North America. He described color differences in fresh and worn pelage, as well as post-juvenal and juvenal coloration differences of the three putative subspecies. Most notably, $S$. $n$. pinetis is pinkish to ochraceous in color, whereas $S . n$. grangeri is a light creamy buff that is darkened by black overlaying the lighter cream; S. n. nuttalli has a similar wash of black, but it overlays a dark dull fawn color with very little distinction between the back and rump. 
Building upon the historical framework noted above, we have laid the groundwork pointing to the possibility of three distinct species being present in this taxonomic group. This work is the first to examine the species group using an integrative taxonomic approach to determine conspecificity. Each of the three taxa currently contained within $S$. nuttalli has had minimal overlap in their ranges and ecological niches since, at least, the last interglacial period. Dental examination of the lower third premolars show each group possesses unique characters not found in their subsumed putative sister taxa. Morphological examination shows distinct skull patterns unique to each taxon. These patterns, such as the exoccipital ridge, hold the same shape within the subspecies but are discretely distinct relative the other subspecies. Principal component analysis of skull measurements show clear clustering of the presumed subspecies and separation from remaining groups within the species complex. Genetic analysis of two mitochondrial genes show the presumed species group form part of different clades and more closely related to other species of Sylvilagus than to each other. In light of the foregoing, we feel the hypothesis of conspecificity in the group must be rejected based on the results of our analyses. 


\section{REFERENCES}

Allen, J.A., Price, W.W., Grangeri, W., \& Condit, B.C. (1894). Descriptions of ten new North American mammals, and remarks on others. Order of the Trustees, American Museum of Natural History.

Alves, P.C., \& Hacklander, K. (2008). Lagomorph Species: Geographical distribution and conservation status. In: Alves P.C., Ferrand, N., Hacklander, K., eds. Lagomorph biology: evolution, ecology, and conservation., Heidelberg: Springer, 395-405.

Anderson, R. P., \& Gonzalez, I. (2011). Species-specific tuning increases robustness to sampling bias in models of species distributions: An implementation with Maxent. Ecological Modelling, 222. 15. 2796-2811.

Álvarez-Castañeda ST, Lorenzo C (2017) Phylogeography and phylogeny of Lepus californicus (Lagomorpha: Leporidae) from Baja California Peninsula and adjacent islands. Biol J Linn Soc, 121:15-27.

Angelone, C., and C. Sese. (2009). New characters for species discrimination within the genus Prolagus (Ochotonidae, Lagomorpha, Mammalia). Journal of Paleontology, 83(1):80-88.

Asher, R.J., J. Meng, J.R. Wible, M.C. Mckenna, G.W. Rougier, D. Dashzeveg, And M.J. Novacek. (2005). Stem Lagomorpha and the antiquity of Glires. Science, 303:1091-1094.

Bachman, J. (1837). Observations on the Different Species of Hares (genus Lepus) Inhabitation the United States and Canada.

Baker, R.J. and Bradley, R.D., (2006) Speciation in Mammals and the Genetic Species Concept. Journal of Mammalogy, 87(4):643-662.

Bateson, P. (2002). William Bateson: a biologist ahead of his time. Journal of Genetics, 81(2), 49-58.

Bateson, W. (1909). Heredity and variation in modern lights. Pp. 85- 101 in Darwin and modern science (A. C. Seward, ed.). Cambridge University Press, Cambridge, United Kingdom.

Bouckaert R, Heled J, Kühnert D, et al (2014) BEAST 2: A software platform for Bayesian evolutionary analysis. PLoS Comput Biol, 10:e1003537 
Bradley, R.D., and Baker, R.J., (2001) A test of the Genetic Species Concept:

Cytochrome-b sequences and mammals. Journal of Mammalogy, 82(4):960-973.

Brandt, J.F. (1855). Beitrage zur nachern Kenntis der Saugethiere Russland. Memoires de l'Academie imperial des science de St. Petersbourg, 9(6): 295

Butler, John M. (2010). Fundamentals of Forensic DNA Typing. Burlington, MA: Elsevier/Academic Press, pp. 34-35.

Calkins, M. T., Beever, E. A., Boykin, K. G., Frey, J. K., \& Andersen, M. C. (2012). Notso-splendid isolation: modeling climate-mediated range collapse of a montane mammal Ochotona princeps across numerous ecoregions. Ecography, 35. 780791.

Carson, H. L. (1957). The species as a field for gene recombination. In The species problem (Vol. 50, pp. 23-38). Washington^ eD. C DC: American Association for the Advancement of Science.

Caughley, G., Grice, D., Barker, R. and Brown, B. (1988). The edge of the range. Journal of Animal Ecology, 57: 771-785.

Chandler, C. R., \& Gromko, M. H. (1989). On the relationship between species concepts and speciation processes. Systematic Biology, 38(2), 116-125.

Chapman, J. A. and J. E. C. Flux. (1990). "Rabbits, Hares and Pikas, Status Survey and Conservative Action Plan". International Union for Conservation of Nature and Natural Resources.

Connor J Burgin, J.P. Colella, P.L. Kahn, N.S. Upham. (2018). How many species of mammals are there?. Journal of Mammalogy, 99, (1), 1-14.

Cornalia, AE., (1849[1850]). Vertebratorum synopsis in Museo Mediolanense extantium; quæ per Novam Orbem Cajetanus Osculati collegit annis 1846-47-48 speciebus novis vel minus cognitis adjectis nec non descriptionibus atque iconibus illustrates. Pp. 301-315 in Esplorazione delle regioni equatoriali lungo il Napo ed il fiume delle Amazzoni: frammento di un viaggio fatto nelle due Americhe negli anni 1846-1847-1848 da Gaetano Osculati (Osculati, G.). Tip. Bernardoni. Milan, Italy.

Coyne, J. A., Orr, H. A., \& Futuyma, D. J. (1988). Do we need a new species concept?. Systematic Zoology, 37(2), 190-200.

Dawson, M. (1958). Later Tertiary Leporidae of North America. Univ. Kansas Paleont. Contr., Vertebrate, 6:1-75. 
Dalquest, W.W. (1979). Identification of genera of American rabbits of Blancan age. The Southwestern Naturalist, 24(2): 275-278.

Dalquest, W.W., F. Stangl, J.V. Grimes. (1989). The third lower premolar of the Cottontail, Genus Sylvilagus, and its value in the discrimination of three species. The American Midland Naturalist. 121: 293-301.

Dickerman RW, McNew SM, Witt CC (2013) Long-distance movement in a Dusky Great Horned Owl and limits to phylogeography for establishing provenance. West North Am Nat, 401-408.

Dobzhansky, T. (1950). Mendelian populations and their evolution. The American Naturalist, 74:312- 321.

Dobzhansky T (1970) Genetics of the evolutionary process. Columbia University Press, New York.

Drummond AJ, Rambaut A (2007) BEAST: Bayesian evolutionary analysis by sampling trees. BMC Evol Biol ,7:214 . doi: 10.1186/1471-2148-7-214

Elith, J., et. al. (2006). Novel methods improve prediction of species' distributions from occurrence data. Ecography, 29. 129-151.

Elith, J., et al., (2010). The art of modelling range-shifting species. Methods in Ecology and Evolution, 1: 330-342.

Fielding A.H., Bell J.F. (1997) A review of methods for the assessment of prediction errors in conservation presence/absence models. Environmental Conservation, 24: $38-49$.

Fisher, J. L. (2012). Shifting Prehistoric Abundances of Leporids at Five Finger Ridge, a Central Utah Archaeological Site. Western North American Naturalist, 72. 1. 6068.

Guisan, A., and W. Thuiller. (2005). Predicting species distribution: offering more than simple habitat models. Ecology Letters, 8. 993-1009.

Hall, Raymond, E. (1981). “The Mammals of North America”. A Wiley-Interscience publication.

Hall T, Ibis Biosciences, Carlsbad C (2011) BioEdit: An important software for molecular biology. GERF Bull Biosci, 2:60-61. 
Harris, A.H., and J. Hearst. (1977). Late Wisconsin mammalian fauna from dust cave, guadalupe mountains national park, Culberson County, Texas. The Southwestern Naturalist, 57 (2). 202-206.

Heikkinen, R. K. et al. (2006). Methods and uncertainties in biocli- matic envelope modelling under climate change. Prog. Phys. Geogr, 30. $751-777$.

Hibbard, C.W. (1963). The origin of the P3 pattern of Sylvilagus, Caprolagus, Oryctolagus and Lepus. J. Mammal, 44:1-15.

Hijmans, R.J., Cameron, S.E., Parra, J.L., Jones, P.G., Jarvis, A., (2005). Very high resolu- tion interpolated climate surfaces for global land areas. International Journal of Climatology, 25, 1965-1978.

Harris, Arthur, H. and Jonena Hearst. (2012). Late Wisconsin Mammalian Fauna from Dust Cave, Guadalupe Mountains National Park, Culberson County, Texas. The Southwestern Naturalist, 57. 2. 202-206.

Heikkinen, R. K., Luoto, M., Araújo, M.B., Virkkala, R., Thuiller, W. and Sykes, M.T. (2006) Methods and uncertainties in bioclimatic envelope modelling under climate change. Prog. Phys. Geog, 30:751-777.

Hoffman, R., and A. T. Smith. (2005). Order Lagomorpha. Pages 185-211 in: D. E. Wilson and D.M. Reeder, editors, Mammal Species of the World: a taxonomic and geographic reference, $3^{\text {rd }}$ ed. Johns Hopkins University Press, Baltimore, Maryland, xxxv+2142 pp. 2 vols.

Hoffmeister, D., \& Lee, M. (1963). Taxonomic Review of Cottontails, Sylvilagus floridanus and Sylvilagus nuttallii, in Arizona. The American Midland Naturalist, 70(1), 138-148.

Huelsenbeck JP, Ronquist F (2001) MRBAYES: Bayesian inference of phylogenetic trees. Bioinformatics, 17:754-755

Huson DH, Bryant D (2006) Application of phylogenetic networks in evolutionary studies. Mol Biol Evol, 23:254-267 . doi: 10.1093/molbev/msj030

Huson DH, Dezulian T, Klopper T, Steel MA (2004) Phylogenetic super-networks from partial trees. IEEE/ACM Trans Comput Biol Bioinforma, 1:151-158 . doi: 10.1109/TCBB.2004.44

Jaynes, E. T. (1957). Information Theory and Statistical Mechanics. Physical Review, Series II. 106 (4): 620-630. 
Jaynes, E. T. (1957). Information Theory and Statistical Mechanics II. Physical Review, Series II. 108 (2): 171-190.

Kale, R., Ramesh, T., Qureshi, Q., Sankar, K. (2013). Predicting the distribuition pattern of samll conarivores in response to environmental factors in the western Ghats. Plosone, 8(11): 1-13.

Kimura M (1980) A simple method for estimating evolutionary rate of base substitutions through comparative studies of nucleotide sequences. J Mol Evol, 16:111-120

Kumar S, Stecher G, Li M, et al (2018) MEGA X: Molecular evolutionary genetics analysis across computing platforms. Mol Biol Evol, 35:1547-1549 . doi: 10.1093/molbev/msy096

Knight, R.L. and Erickson, A.W. (1977) Ecological Notes on Long-Eared and Great Horned Owls along the Columbia River. The Murrelet, 58(1):2-6.

Koehler, G.M. and Hornocker, M.G., (1991) Seasonal Resource Use among Mountain Lions, Bobcats, and Coyotes. Journal of Mammalogy, 72(2): 391-396.

Kozlowski, A. J., E. M. Gese, and W. M. Arjo. (2012). Effects of Intraguild Predation: Evaluating Resource Competition Between Two Canid Species with Apparent Niche Separation. International Journal of Ecology, 2012: 1-12.

Larkin, M.A., Blackshields, G., Brown, N.P., Chenna, R., McGettigan, P.A., McWilliam, H., Valentin, F., Wallace, I.M., Wilm, A., Lopez, R., Thompson, J.D., Gibson, T.J. \& Higgins, D.G. (2007) Clustal W and Clustal X version 2.0. Bioinformatics, 23(21):2947-2948.

Lanfear R, Calcott B, Ho SYW, Guindon S (2012) PartitionFinder: Combined selection of partitioning schemes and substitution models for phylogenetic analyses. Mol Biol Evol, 29:1695-1701 . doi: 10.1093/molbev/mss020

Lawton, J.H., Nee, S., Letcher, A.J. and Harvey, P.H. (1994). Animal distributions: patterns and processes. In Large-Scale Ecology and Conservation Biology (P.J. Edwards, R.M. May and N.R. Webb, eds), pp 41-58. London: Blackwell.

Lopez-Martinez, N, A. Likius, H. T. Mackaye, P. Vignaud, and M Brunet. (2007). A new lagomorph from the Late Miocene of Chad (Central Africa). Revista Española de Paleontología, 22:1-20.

Maddison, W. P. and D.R. Maddison. (2015). Mesquite: a modular system for evolutionary analysis. Version 3.02 http://mesquiteproject.org 
Mallet, James (1995). "A species definition for the modern synthesis". Trends in Ecology \& Evolution, 10: 294-299.

Mallet, J. (2010). Why was Darwin's view of species rejected by twentieth century biologists?. Biology \& Philosophy, 25(4), 497-527.

Masters, J., \& Spencer, H. (1989). Why We Need a New Genetic Species Concept. Systematic Zoology, 38(3), 270-279. doi:10.2307/2992287

Matthee, C. A., and S. K. Davis. (2001). Molecular insights into the evolution of the family Bovidae: A nuclear DNA perspective. Mol. Biol. Evol., 18:1220-1230.

Matthee, C.A., B. J. van Vuuren, D. Bell, T.J. Robinson. (2004). A molecular supermatrix of the rabbits and hares (Leporidae) allows for the identification of five intercontinental exchanges during the Miocene. Systematic Biology, 53(3): 433-447.

Mayr E (1959) Isolation as an evolutionary factor. Proc Am Philos Soc, 103:221-230

Mayr E (1963) Animal species and evolution. Harvard University Press, Cambridge

Mayr E (1981) How I became a Darwinian. In: Mayr E, Provine WB (eds) The evolutionary synthesis. Perspectives on the unification of biology. Harvard University Press, Cambridge, pp 413-423

Mayr E (1982) The growth of biological thought. Diversity, evolution, and inheritance. Belknap, Cambridge

Mayr E (1992) Controversies in retrospect. Oxf Surv Evol Biol, 8:1-34

Lyons, S.K. (2003) A quantitative assessment of the range shifts of Pleistocene mammals. Journal of Mammalogy, 84(2):385-402.

McDonald, K.A. and Brown, J.H. (1992). Using montane mammals to model extinctions due to global change. Conserv. Biol., 6, 409-15.

Meng, J., Y.-M. Hu, And C.-K. Li. (2003). The osteology of Rhombomylus (Mammalia, Glires): Implications for phylogeny and evolution of Glires. Bulletin of the American Museum of Natural History, 275:1-247.

Meredith, R. W., Janecka, J. E., Gatesy, J., Ryder, O. A., Fisher, C. A., Teeling, E. C., ... \& Rabosky, D. L. (2011). Impacts of the Cretaceous Terrestrial Revolution and KPg extinction on mammal diversification. Science, 334(6055), 521-524. 
Merow, C., M. J. Smith, and J. A. Silander Jr. 2013. A practical guide to MaxEnt for modeling species' distributions: what it does, and why inputs and settings matter. Ecography, 36(10):1058-1069.

Murphy, W. J., Pringle, T. H., Crider, T. A., Springer, M. S., \& Miller, W. (2007). Using genomic data to unravel the root of the placental mammal phylogeny. Genome research, 17(4), 000-000.

Nalls A. V., Ammerman LK, Dowler RC (2012). Genetic and morphologic variation in the Davis Mountains cottontail (Sylvilagus robustus). Southwest Nat, 57:1-7

Nelson E.W. (1909) The Rabbits of North America. North American Fauna: Number 29: pp. $199-211$.

Newmark, William, D. (1995). Extinction of mammal populations in Western North American National Parks. Conservation Biology, 9. 3. 512-526.

Nix, H., McMahon, J. and Mackenzie, D. (1977). Potential areas of production and the future of pigeion pea and other grain legumes in Australia. In: The potential for pigeon pea in Australia. Proceedings of Pigeon Pea (Cajanus caja (L.) Millsp.) Field Day (E.S. Wallis, and P.C. Whiteman, eds). pp 5/1 - 5/12. Queensland: University of Queensland.

O’Leary, M.A., J.I.Bloch, J.J. Flynn, T.J. Gaudin, A. Giallombardo, N.P. Giannini, et al. (2013). The placental mammal ancestor and the post-K-Pg radiation of placentals. Science, 339: 662-667.

Parmesan, Camille. (2006). Ecological and evolutionary responses to recent climate change. Annual Review of Ecology, Evolution, and Systematics, 37: 637-669.

Pearson, R.G. and T.E. Dawson. (2003). Predicting the impacts of climate change on the distribution of species: are bioclimate envelope models useful? Global Ecology and Biogeography, 12: 361-372.

Pfenninger, M., \& Schwenk, K. (2007). Cryptic animal species are homogeneously distributed among taxa and biogeographical regions. BMC evolutionary biology, 7(1), 121.

Phillips S.J., Dudı'k M. (2008) Modeling of species distributions with Maxent: new extensions and a comprehensive evaluation. Ecography, 31: 161-175

Phillips, S., Anderson, R., \& Schapire, R. (2006). Maximum entropy modeling of species geographic distributions. Ecological Modelling, 190. 3-4. 231-259. 
Polly, P.D., and J.T. Eronen. (2010). Mammal associations in the Pleistocene of Britain: Implications of Eclogical Niche Modelling and a Method for Reconstructing Palaeoclimate. In The Ancient Human Occupation of Britain (N. Ashton, S. Lewis, and C. Stringer, eds) Elsevier.

Ramírez-Silva JP, González-Cózatl FX, Vázquez-Domínguez E, Cervantes FA (2010) Phylogenetic position of Mexican jackrabbits within the genus Lepus (Mammalia: Lagomorpha): A molecular perspective. Rev Mex Biodivers 81:

Rickart, E.A., (2001) Elevational diversity gradients, biogeography and the structure of montane mammal communitites in the intermountain region of North America. Global Ecology and Biogeography, 10:77-100.

Root, T.L., S.H. Schneider. (2006). Conservation and climate change: the challenges ahead. Conservation Biology, 20: 706-708.

Ronquist F, Teslenko M, van der Mark P, et al (2012) MrBayes 3.2: Efficient Bayesian phylogenetic inference and model choice across a large model space. Syst Biol, 61:539-542

Rose, K. D., DeLeon, V. B., Missiaen, P., Rana, R. S., Sahni, A., Singh, L., \& Smith, T. (2008). Early Eocene lagomorph (Mammalia) from Western India and the early diversification of Lagomorpha. Proceedings of the Royal Society of London B: Biological Sciences, 275(1639), 1203-12

Ruedas, L. A. (1998) Systematics of Sylvilagus Gray, 1867 (Lagomorpha : Leporidae) from southwestern North America. Journal of Mammalogy, 79(4):1355-1378.

Ruedas LA, Silva SM, French JH, et al. (2017). A prolegomenon to the systematics of the South American cottontail rabbits (Mammalia, Lagomorpha, Leporidae: Sylvilagus): designation of a neotype for S. brasiliensis (Linnaeus, 1758), and restoration of S. andinus (Thomas, 1897) and S. tapetillus Thomas, 1913. Miscellaneous Publication, Museum of Zoology, University of Michigan, 205:iiv $+1-67$ pp.

Silva SM, Ruedas LA, Hasnah Santos L, et al (2019) Illuminating the obscured phylogenetic radiation of South American Sylvilagus Gray, 1867 (Lagomorpha: Leporidae). J Mammal, 100:31-44 . doi: 10.1093/jmammal/gyy186

Simpson, G. G. (1943). Criteria for genera, species, and subspecies in zoology and paleontology. Annals of the New York Academy of Science, 44:145-178.

Simpson, G. G. (1961). Principles of Animal Taxonomy. Columbia University Press. 
Springer, M. S., Murphy, W. J., Eizirik, E., \& O'Brien, S. J. (2003). Placental mammal diversification and the Cretaceous-Tertiary boundary. Proceedings of the National Academy of Sciences, 100(3), 1056-1061.

Steenhof, Karen, and Michael N Kochert. (2013). Dietary responses of three raptor species to changing prey densities”. Journal of Animal Ecology, 57(1):37-48.

Stenseth, N.C., A. Mysterud, G. Otterson, J.W. Hurrel, K.S. Chan, M. Lima. (2002). Ecological Effects of climate fluctuations. Science. 297: 1292-1296.

Stamatakis, A. (2014). RAxML version 8: a tool for phylogenetic analysis and postanalysis of large phylogenies. Bioinformatics, 30(9), 1312-1313.

Storer, J. E. (1984). Mammals of the swift current creek local fauna (Eocene: Uintan), Saskatchewan. Natural History Contributions No. 7. Museum of natural History: Regina, Sakatchewan, Canada.

Stucky, R.K., and M.C. McKenna. (1993). Mammalia. Pp. 739 - 771. In: M.J. Benton (editor). The Fossil Record 2. Chapman and Hall: London.

Thomas, O. (1911). The mammals of the tenth edition of Linnæus, an attempt to fix the types of the genera and the exact bases and localities if the species. Proceedings of the Zoological Society of London, 1911:120-158.

Thompson JD, Higgins DG, Gibson TJ (1994) CLUSTAL W: Improving the sensitivity of progressive multiple sequence alignment through sequence weighting, position-specific gap penalties and weight matrix choice. Nucleic Acids Res, 22:4673-4680

Tursi RM, Hughes PT, Hoffman EA (2013) Taxonomy versus phylogeny: evolutionary history of marsh rabbits without hopping to conclusions. Divers Distrib, 19:120133

Wallace, R.L., and Dill, L.V., (1990) Feeding Ecology of the Rattlesmake, Crotalus viridis oreganus, in Northern Idaho. Journal of Herpetology, 24(3):246-253.

Waltari, E., and R. P. Guralnick. (2009). Ecological Niche Modelling of Montane Mammals in the Great Basin, North America: Examining Past and Present Connectivity of Species Across Basins and Ranges. Journal of Biogeography, 36. 1. $148-161$.

Wilson, R. R., and J. A. Shivik. (2011) Contender Pressure Versus Resource Dispersion as Predictors of Territory Size of Coyotes (Canis latrans). Can. J. Zool., 967:960967. 
Wood, A. E. (1940). The mammalian fauna of the White River Oligocene: Part III. Lagomorpha. Trans. Am. Phil. Soc., New Series, 28.3. 271-362.

Wood, A. (1957). What, If Anything, is a Rabbit? Evolution, 11(4), 417-425. doi: $10.2307 / 2406062$ 
APPENDIX A

Ecological niche modeling data

Occurrence data and input files used for ecological niche modeling in chapter 1.

\section{Known Occurrence data of the S. nuttallii species complex.}

\section{Table A1}

\begin{tabular}{|c|}
\hline es \\
\hline Sylvilagus nuttallii grangeri \\
\hline Sylvilagus nuttallii grangeri \\
\hline Sylvilagus nuttallii grangeri \\
\hline Sylvilagus nuttallii grangeri \\
\hline Sylvilagus nuttallii grangeri \\
\hline Sylvilagus nuttallii grangeri \\
\hline Sylvilagus nuttallii grangeri \\
\hline Sylvilagus nuttallii grangeri \\
\hline Sylvilagus nutta \\
\hline Sylvilagus nuttallii grangeri \\
\hline Sylvilagus nuttallii grangeri \\
\hline Sylvilagus \\
\hline Sylvilagus nuttallii grangeri \\
\hline Sylvilagus nuttallii grangeri \\
\hline Sylvilagus nuttallii grangeri \\
\hline Sylvilagus nuttallii grangeri \\
\hline Sylvilag \\
\hline Sylv \\
\hline Sylvilagus nut \\
\hline Sylvilagu \\
\hline Sylvilagus nuttallii grangeri \\
\hline Sylvilagus nuttallii grangeri \\
\hline Sylvilagus nuttallii grangeri \\
\hline Is nuttallin grai \\
\hline us $n$ \\
\hline lvilagus nu \\
\hline Sylvilagus nuttallii grangeri \\
\hline Sylv \\
\hline Sylvilagus nuttallii grangeri \\
\hline \\
\hline \\
\hline
\end{tabular}

\begin{tabular}{|c|c|}
\hline Longitude & Latitude \\
\hline-114.17691 & 39.27333 \\
\hline-118.8512 & 39.47361 \\
\hline-106.94583 & 41.77806 \\
\hline-103.5173 & 43.8934 \\
\hline-113.6774 & 43.5024 \\
\hline-113.5568 & 42.6681 \\
\hline-119.27939 & 38.46175 \\
\hline-103.6139 & 44.0831 \\
\hline-118.24639 & 40.5275 \\
\hline-107.23806 & 41.8056 \\
\hline-108.38722 & 42.04888 \\
\hline-115.78266 & 37.45884 \\
\hline-118.84251 & 39.42236 \\
\hline-103.533 & 43.9019 \\
\hline-108.58341 & 49.614 \\
\hline-113.6661 & 43.3704 \\
\hline-118.07989 & 37.43207 \\
\hline-108.38722 & 42.04888 \\
\hline-107.54583 & 41.02252 \\
\hline-113.5568 & 42.6681 \\
\hline-118.17378 & 37.49611 \\
\hline-115.40083 & 37.64417 \\
\hline-107.23806 & 41.83458 \\
\hline-107.60111 & 42.52 \\
\hline-117.46593 & 36.58766 \\
\hline-113.7825 & 42.6081 \\
\hline-113.6774 & 43.5024 \\
\hline-106.94583 & 41.77806 \\
\hline-113.6983 & 43.6367 \\
\hline-103.5173 & 43.8925 \\
\hline-118.18083 & 37.88056 \\
\hline
\end{tabular}




\begin{tabular}{|c|c|}
\hline-103.533 & 43.9019 \\
\hline-119.79492 & 38.77571 \\
\hline-117.53538 & 38.80111 \\
\hline-115.78266 & 37.45884 \\
\hline-118.17054 & 37.33884 \\
\hline-112.2278 & 43.4582 \\
\hline-117.06861 & 39.49333 \\
\hline-107.54583 & 41.02252 \\
\hline-115.40083 & 37.64417 \\
\hline-118.2352 & 37.40611 \\
\hline-106.2392 & 45.3016 \\
\hline-115.43111 & 41.91708 \\
\hline-107.0792 & 47.5829 \\
\hline-116.9328 & 43.6178 \\
\hline-116.79333 & 39.0675 \\
\hline-107.9096 & 40.03472 \\
\hline-115.24 & 41.49 \\
\hline-113.5568 & 42.6681 \\
\hline-114.1545 & 46.1814 \\
\hline-113.6983 & 43.6367 \\
\hline-103.533 & 43.9019 \\
\hline-115.50972 & 41.62736 \\
\hline-114.302 & 45.8896 \\
\hline-117.46593 & 36.58766 \\
\hline-117.1333 & 38.43694 \\
\hline-115.73389 & 37.45 \\
\hline-114.2158 & 46.7589 \\
\hline-117.79306 & 40.27833 \\
\hline-107.23806 & 41.79111 \\
\hline-108.2298 & 45.783 \\
\hline-114.7493 & 42.2181 \\
\hline-114.28 & 38.96917 \\
\hline-118.8512 & 39.47361 \\
\hline-113.277 & 44.9068 \\
\hline-119.50056 & 38.8972 \\
\hline-116.67069 & 43.21565 \\
\hline-117.06861 & 39.49333 \\
\hline-107.23806 & 41.79111 \\
\hline-103.533 & 43.9019 \\
\hline
\end{tabular}

Sylvilagus nuttallii grangeri

Sylvilagus nuttallii grangeri

Sylvilagus nuttallii grangeri

Sylvilagus nuttallii grangeri

Sylvilagus nuttallii grangeri

Sylvilagus nuttallii grangeri

Sylvilagus nuttallii grangeri

Sylvilagus nuttallii grangeri

Sylvilagus nuttallii grangeri

Sylvilagus nuttallii grangeri

Sylvilagus nuttallii grangeri

Sylvilagus nuttallii grangeri

Sylvilagus nuttallii grangeri

Sylvilagus nuttallii grangeri

Sylvilagus nuttallii grangeri

Sylvilagus nuttallii grangeri

Sylvilagus nuttallii grangeri

Sylvilagus nuttallii grangeri

Sylvilagus nuttallii grangeri

Sylvilagus nuttallii grangeri

Sylvilagus nuttallii grangeri

Sylvilagus nuttallii grangeri

Sylvilagus nuttallii grangeri

Sylvilagus nuttallii grangeri

Sylvilagus nuttallii grangeri

Sylvilagus nuttallii grangeri

Sylvilagus nuttallii grangeri

Sylvilagus nuttallii grangeri

Sylvilagus nuttallii grangeri

Sylvilagus nuttallii grangeri

Sylvilagus nuttallii grangeri

Sylvilagus nuttallii grangeri

Sylvilagus nuttallii grangeri

Sylvilagus nuttallii grangeri

Sylvilagus nuttallii grangeri

Sylvilagus nuttallii grangeri

Sylvilagus nuttallii grangeri

Sylvilagus nuttallii grangeri

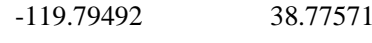

$-115.78266$

$\begin{array}{ll}-112.2278 & 43.4582\end{array}$

$\begin{array}{ll}-117.06861 & 39.49333\end{array}$

$\begin{array}{ll}-107.54583 & 41.02252\end{array}$

37.64417

$-118.2352$

$-115.43111 \quad 41.91708$

\begin{tabular}{l}
$-107.0792 \quad 47.5829$ \\
\hline
\end{tabular}

$\begin{array}{ll}-116.79333 & 39.0675\end{array}$

$\begin{array}{ll}-107.9096 & 40.03472\end{array}$

$\begin{array}{ll}-114.2158 & 46.7589\end{array}$

$\begin{array}{ll}-117.79306 & 40.27833\end{array}$

$-107.23806 \quad 41.79111$

$\begin{array}{ll}-114.7493 & 42.2181\end{array}$ 
Sylvilagus nuttallii grangeri

Sylvilagus nuttallii grangeri

$-109.23$

47.16

$-103.54$

44.19

Sylvilagus nuttallii grangeri 
Sylvilagus nuttallii grangeri

$\begin{array}{ll}-114.03 & 46.37\end{array}$

Sylvilagus nuttallii grangeri 
Sylvilagus nuttallii pinetis

$-105.15 \quad 36.55$

Sylvilagus nuttallii pinetis

$\begin{array}{ll}-106.18 & 36.27\end{array}$

Sylvilagus nuttallii pinetis

$-103.97 \quad 36.77$

Sylvilagus nuttallii pinetis

$-105.37 \quad 39.93$

Sylvilagus nuttallii pinetis

Sylvilagus nuttallii pinetis

$-103.97 \quad 36.77$

Sylvilagus nuttallii pinetis

Sylvilagus nuttallii pinetis

Sylvilagus nuttallii pinetis

Sylvilagus nuttallii pinetis

Sylvilagus nuttallii pinetis

$\begin{array}{ll}-111.96 & 35.98\end{array}$

$\begin{array}{ll}-106.18 & 36.45\end{array}$

$\begin{array}{ll}-106.76 & 36.49\end{array}$

$\begin{array}{ll}-103.97 & 36.77\end{array}$

$\begin{array}{ll}-111.96 & 35.98\end{array}$

$\begin{array}{ll}-106.18 & 36.27\end{array}$

Sylvilagus nuttallii pinetis

$-105.35665 \quad 40.02385$

Sylvilagus nuttallii pinetis

$-107.34873 \quad 40.48906$

Sylvilagus nuttallii pinetis

$\begin{array}{ll}-108.2858 & 37.34229\end{array}$

Sylvilagus nuttallii pinetis

$-104.91712 \quad 39.0576$

Sylvilagus nuttallii pinetis

$\begin{array}{ll}-104.9795 & 37.4063\end{array}$

Sylvilagus nuttallii pinetis

$-106.97417$

36.08778

Sylvilagus nuttallii pinetis

$-105.22056$

39.75556 
Sylvilagus nuttallii pinetis

$-108.92431$

38.37131

Sylvilagus nuttallii pinetis

$-104.98947$

38.81273

Sylvilagus nuttallii pinetis

$-108.9132$

37.80129

Sylvilagus nuttallii pinetis

$-105.88028$

38.71582

Sylvilagus nuttallii pinetis

$-109.30592$

33.65339

Sylvilagus nuttallii pinetis

$-104.3745$

36.93159 
List of bioclimate variables used for Ecological Niche Models.

Table A2

\begin{tabular}{|c|c|c|c|c|c|c|}
\hline $\begin{array}{l}\text { Variable } \\
\text { Number }\end{array}$ & Variable & $\begin{array}{l}\text { Minimum } \\
\text { temp }\left({ }^{\circ} \mathrm{C}\right)\end{array}$ & $\begin{array}{l}\text { Maximum } \\
\text { temp }\left({ }^{\circ} \mathrm{C}\right)\end{array}$ & $\begin{array}{c}\text { Rainfall } \\
(\mathrm{mm} \text { month } \\
1 \text { ) }\end{array}$ & $\begin{array}{l}\text { Radiation (W } \\
\left.\mathrm{m}^{-2} \mathrm{~d}^{-1}\right)\end{array}$ & $\begin{array}{c}\text { Pan evaporation } \\
\left(\mathrm{mm} \mathrm{d}^{-1}\right)\end{array}$ \\
\hline Bio01 & $\begin{array}{c}\text { Annual mean } \\
\text { temperature }\left({ }^{\circ} \mathrm{C}\right)\end{array}$ & $\times$ & $\times$ & & & \\
\hline Bio02 & $\begin{array}{c}\text { Mean diurnal } \\
\text { temperature range } \\
(\text { mean }(\text { period max- } \\
\min ))\left({ }^{\circ} \mathrm{C}\right) \\
\end{array}$ & $x$ & $\times$ & & & \\
\hline Bio03 & $\begin{array}{c}\text { Isothermality } \\
(\text { Bio02 } \div \text { Bio07) }\end{array}$ & $\times$ & $\times$ & & & \\
\hline Bio04 & $\begin{array}{c}\text { Temperature } \\
\text { seasonality }(\mathrm{C} \text { of } \mathrm{V}) \\
\end{array}$ & $x$ & $x$ & & & \\
\hline Bio05 & $\begin{array}{l}\text { Max temperature of } \\
\text { warmest week }\left({ }^{\circ} \mathrm{C}\right)\end{array}$ & & $\times$ & & & \\
\hline Bio06 & $\begin{array}{l}\text { Min temperature of } \\
\text { coldest week }\left({ }^{\circ} \mathrm{C}\right)\end{array}$ & $\times$ & & & & \\
\hline Bio07 & $\begin{array}{c}\text { Temperature annual } \\
\text { range }(\mathrm{Bio} 05- \\
\text { Bio06) }\left({ }^{\circ} \mathrm{C}\right) \\
\end{array}$ & $x$ & $x$ & & & \\
\hline Bio08 & $\begin{array}{c}\text { Mean temperature } \\
\text { of wettest quarter } \\
\left({ }^{\circ} \mathrm{C}\right)\end{array}$ & $x$ & $\times$ & $x$ & & \\
\hline Bio09 & $\begin{array}{c}\text { Mean temperature } \\
\text { of driest quarter } \\
\left({ }^{\circ} \mathrm{C}\right)\end{array}$ & $x$ & $\times$ & $\times$ & & \\
\hline Bio10 & $\begin{array}{l}\text { Mean temperature } \\
\text { of warmest quarter } \\
\left({ }^{\circ} \mathrm{C}\right)\end{array}$ & $\times$ & $\times$ & & & \\
\hline Bio11 & $\begin{array}{c}\text { Mean temperature } \\
\text { of coldest quarter } \\
\left({ }^{\circ} \mathrm{C}\right)\end{array}$ & $\times$ & $x$ & & & \\
\hline Bio12 & $\begin{array}{c}\text { Annual } \\
\text { precipitation }(\mathrm{mm}) \\
\end{array}$ & & & $x$ & & \\
\hline Bio13 & $\begin{array}{c}\text { Precipitation of } \\
\text { wettest week }(\mathrm{mm})\end{array}$ & & & $x$ & & \\
\hline Bio14 & $\begin{array}{c}\text { Precipitation of } \\
\text { driest week }(\mathrm{mm})\end{array}$ & & & $x$ & & \\
\hline Bio15 & $\begin{array}{c}\text { Precipitation } \\
\text { seasonality }(\mathrm{C} \text { of } \mathrm{V})\end{array}$ & & & $x$ & & \\
\hline Bio16 & $\begin{array}{l}\text { Precipitation of } \\
\text { wettest quarter } \\
(\mathrm{mm})\end{array}$ & & & $\times$ & & \\
\hline Bio17 & $\begin{array}{c}\text { Precipitation of } \\
\text { driest quarter }(\mathrm{mm})\end{array}$ & & & $x$ & & \\
\hline Bio18 & $\begin{array}{c}\text { Precipitation of } \\
\text { warmest quarter } \\
(\mathrm{mm})\end{array}$ & $\times$ & $\times$ & $\times$ & & \\
\hline Bio19 & $\begin{array}{l}\text { Precipitation of } \\
\text { coldest quarter } \\
(\mathrm{mm})\end{array}$ & $x$ & $x$ & $x$ & & \\
\hline Bio20 & $\begin{array}{c}\text { Annual mean } \\
\text { radiation }\left(\mathrm{W} \mathrm{m}^{-2}\right)\end{array}$ & & & & $x$ & \\
\hline Bio21 & $\begin{array}{l}\text { Highest weekly } \\
\text { radiation }\left(\mathrm{W} \mathrm{m}^{-2}\right)\end{array}$ & & & & $x$ & \\
\hline Bio22 & $\begin{array}{l}\text { Lowest weekly } \\
\text { radiation }\left(\mathrm{W} \mathrm{m}^{-2}\right.\end{array}$ & & & & $x$ & \\
\hline Bio23 & $\begin{array}{c}\text { Radiation } \\
\text { seasonality }(\mathrm{C} \text { of } \mathrm{V}) \\
\end{array}$ & & & & $\times$ & \\
\hline Bio24 & $\begin{array}{c}\text { Radiation of wettest } \\
\text { quarter }\left(\mathrm{W} \mathrm{m}^{-2}\right)\end{array}$ & & & $x$ & $\times$ & \\
\hline
\end{tabular}




\begin{tabular}{|c|c|c|c|c|c|c|}
\hline Bio25 & $\begin{array}{c}\text { Radiation of driest } \\
\text { quarter }\left(\mathrm{W} \mathrm{m}^{-2}\right)\end{array}$ & & & $x$ & $\times$ & \\
\hline Bio26 & $\begin{array}{c}\text { Radiation of } \\
\text { warmest quarter (W } \\
\mathrm{m}^{-2} \text { ) }\end{array}$ & $x$ & $\times$ & & $x$ & \\
\hline Bio27 & $\begin{array}{l}\text { Radiation of coldest } \\
\text { quarter }\left(\mathrm{W} \mathrm{m}^{-2}\right)\end{array}$ & $x$ & $x$ & & $\times$ & \\
\hline Bio28 & $\begin{array}{l}\text { Annual mean } \\
\text { moisture index }\end{array}$ & & & $x$ & & $x$ \\
\hline Bio29 & $\begin{array}{l}\text { Highest weekly } \\
\text { moisture index }\end{array}$ & & & $\times$ & & $x$ \\
\hline Bio30 & $\begin{array}{l}\text { Lowest weekly } \\
\text { moisture index }\end{array}$ & & & $x$ & & $x$ \\
\hline Bio31 & $\begin{array}{c}\text { Moisture index } \\
\text { seasonality }(\mathrm{C} \text { of } \mathrm{V})\end{array}$ & & & $x$ & & $x$ \\
\hline Bio32 & $\begin{array}{c}\text { Mean moisture } \\
\text { index of wettest } \\
\text { quarter }\end{array}$ & & & $x$ & & $x$ \\
\hline Bio33 & $\begin{array}{c}\text { Mean moisture } \\
\text { index of driest } \\
\text { quarter } \\
\end{array}$ & & & $x$ & & $x$ \\
\hline Bio34 & $\begin{array}{c}\text { Mean moisture } \\
\text { index of warmest } \\
\text { quarter }\end{array}$ & $x$ & $x$ & $x$ & & $x$ \\
\hline Bio35 & $\begin{array}{c}\text { Mean moisture } \\
\text { index of coldest } \\
\text { quarter }\end{array}$ & $x$ & $x$ & $x$ & & $x$ \\
\hline
\end{tabular}


Correlation of variables used in Ecological Niche Models. Highly correlated variables were removed to prevent skewed model outputs.

Table A3

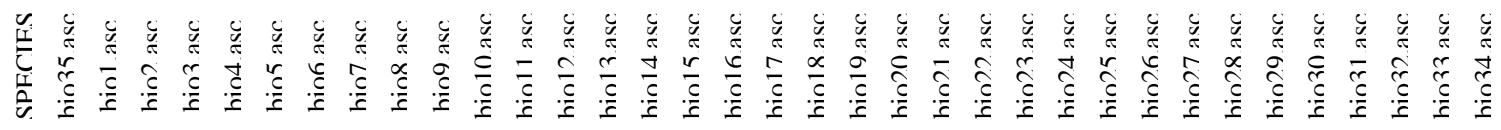

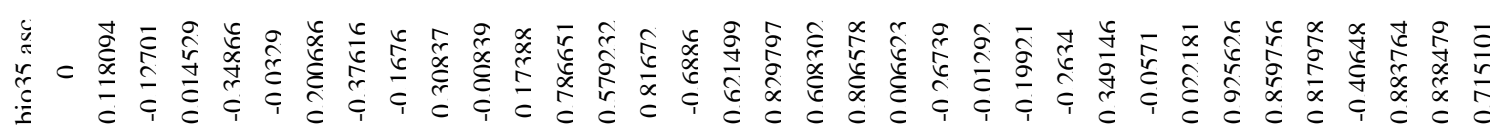

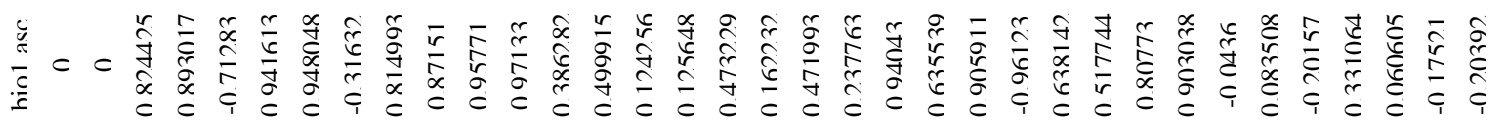

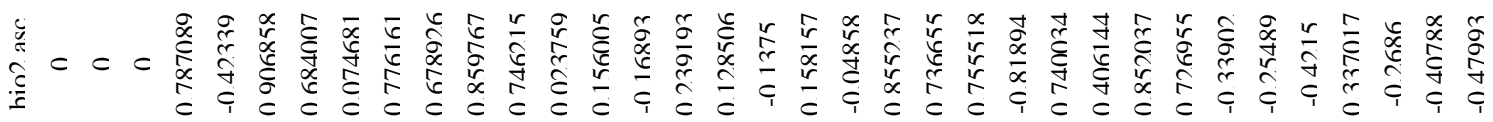

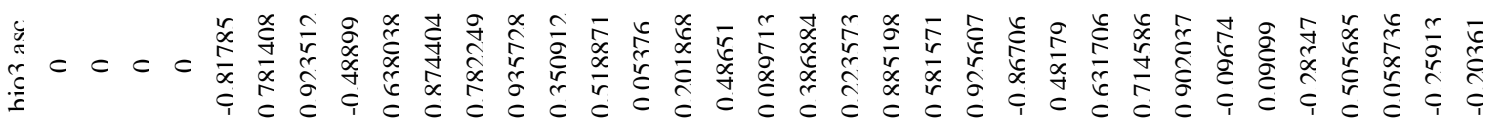

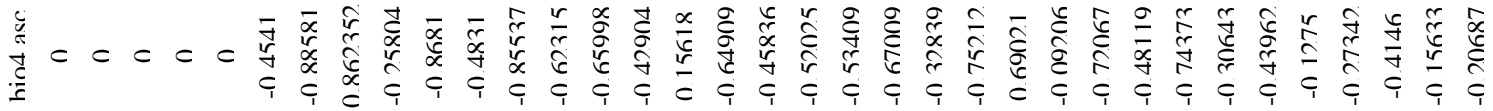

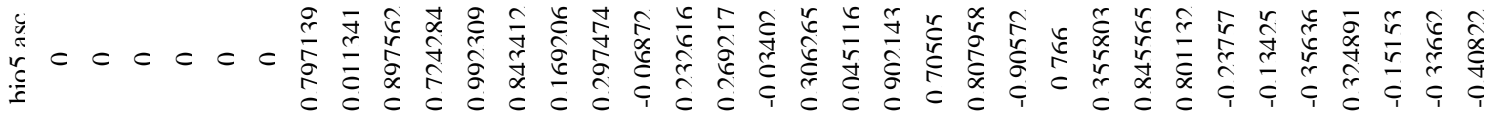

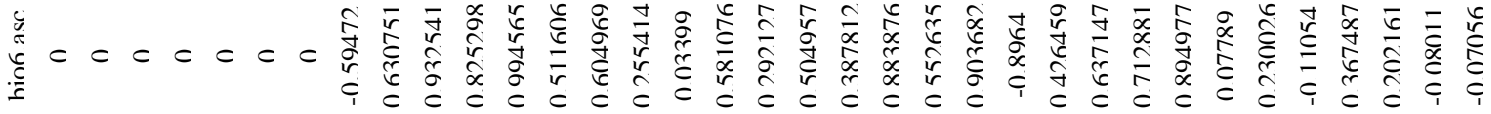

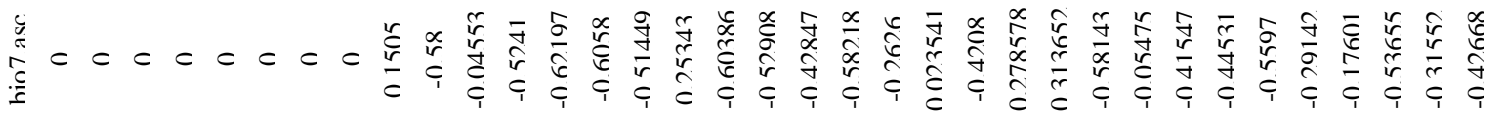




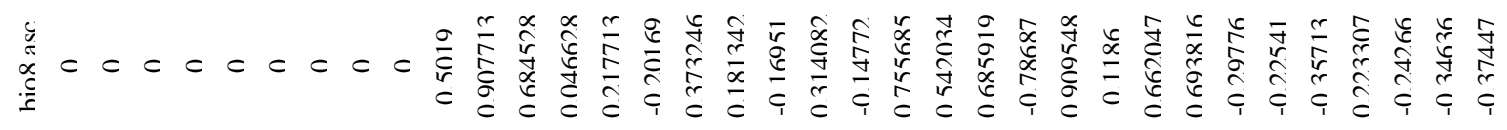

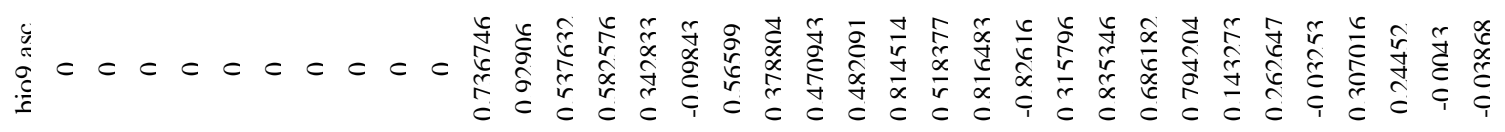

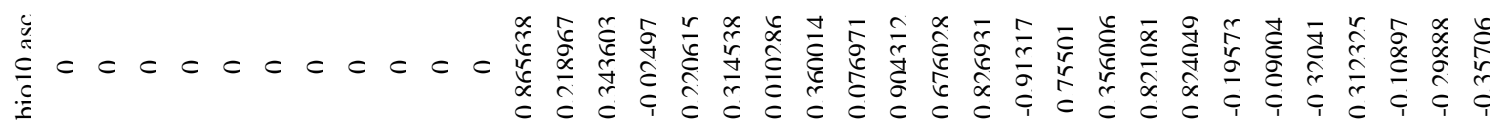

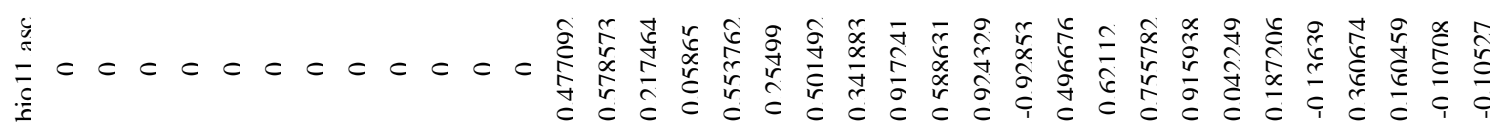

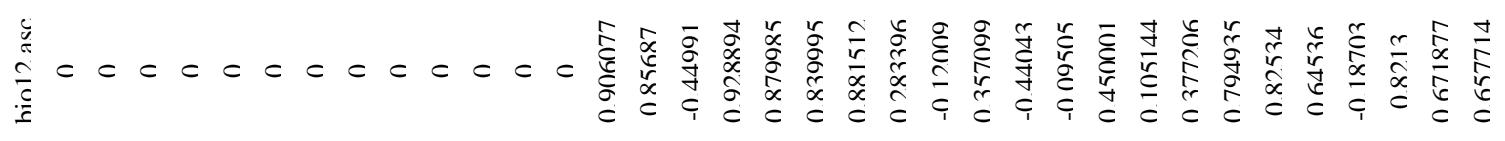

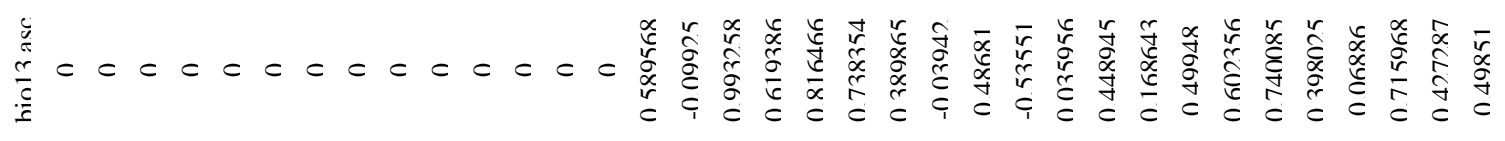

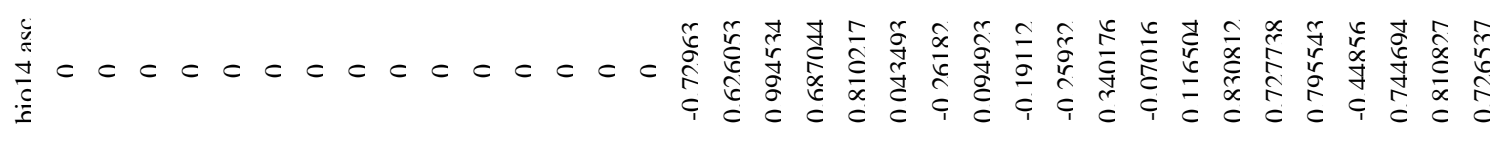

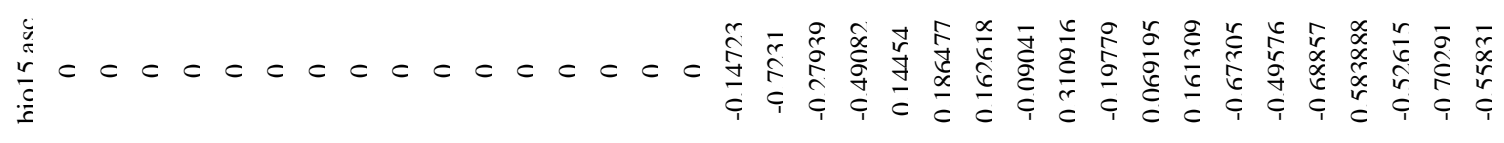

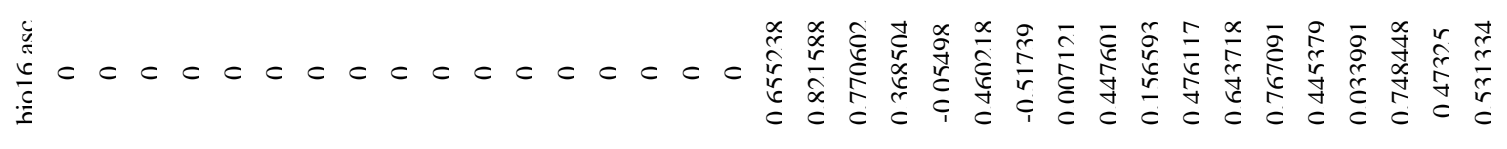

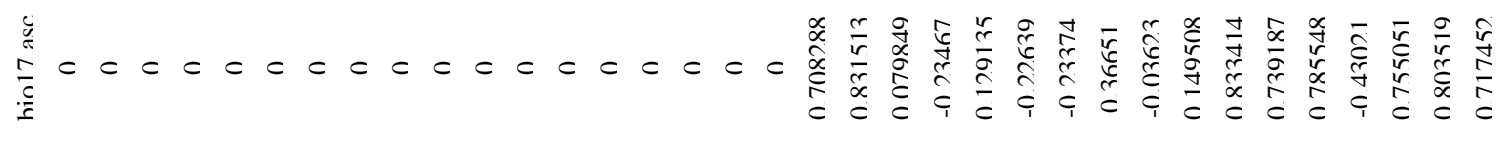




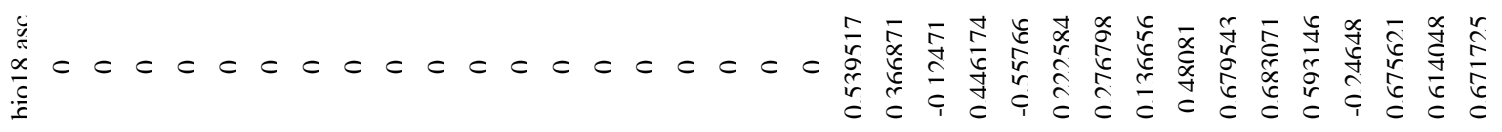

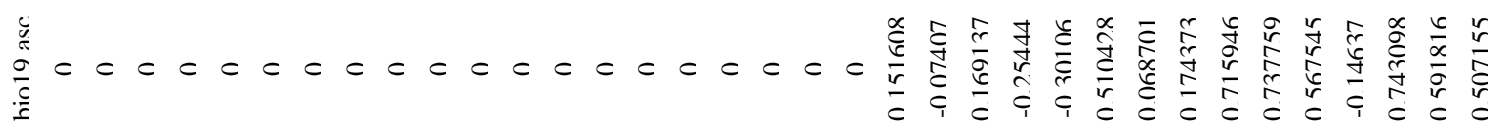

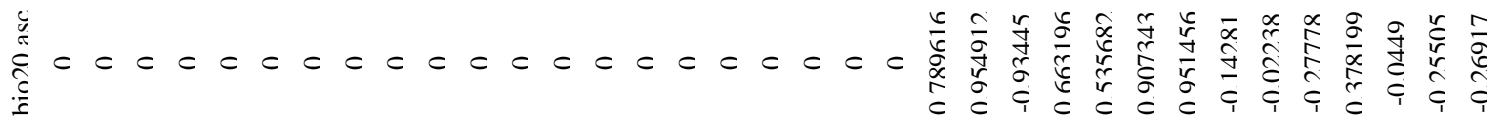

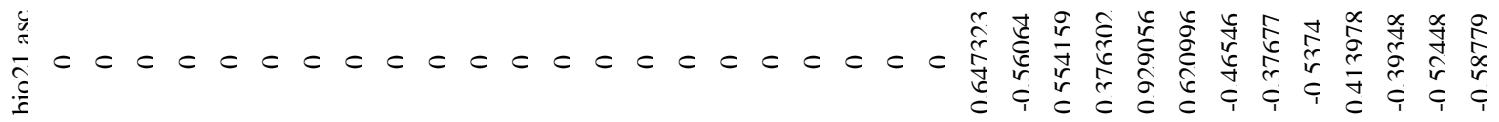

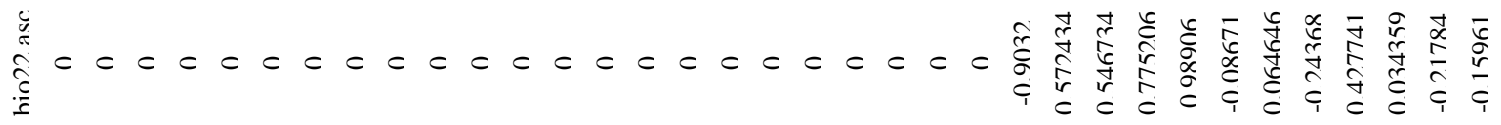

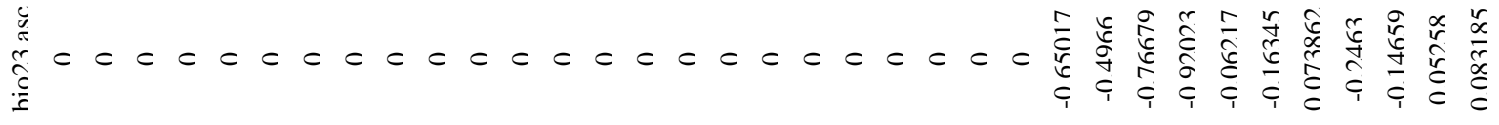

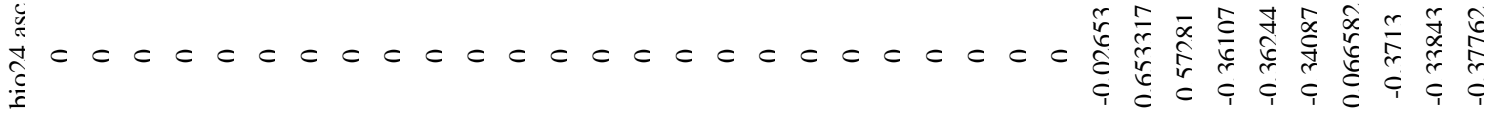

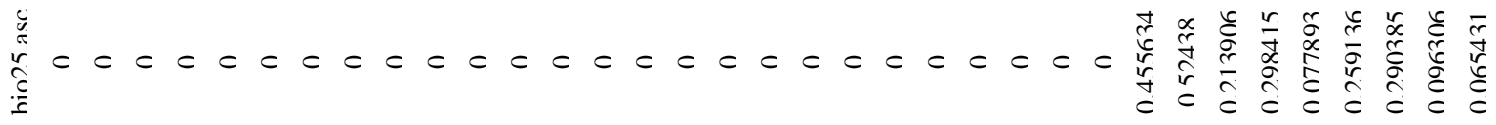

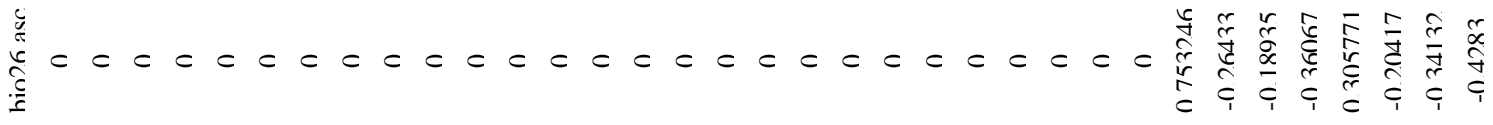

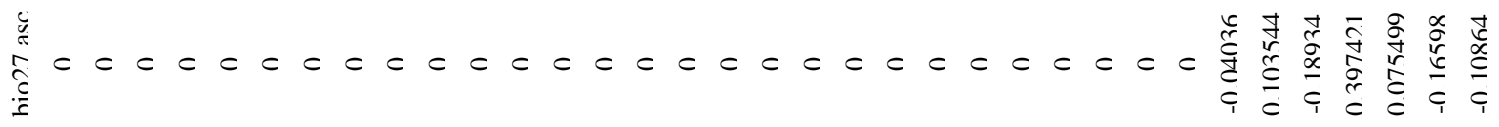




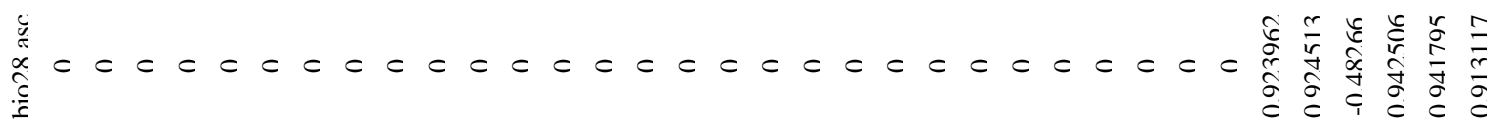

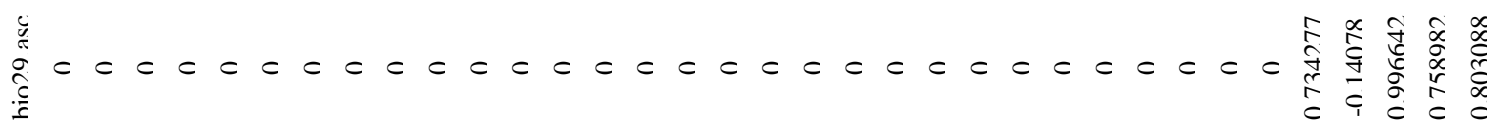

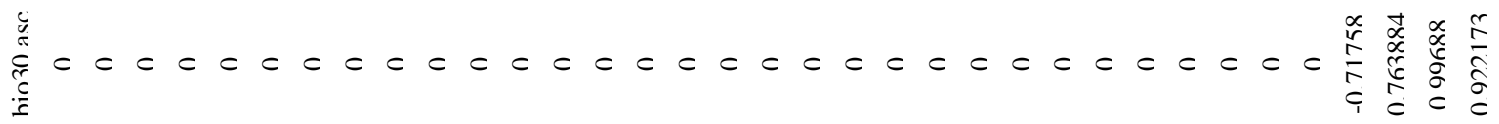

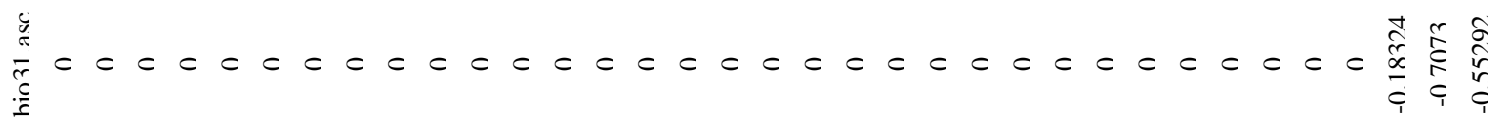

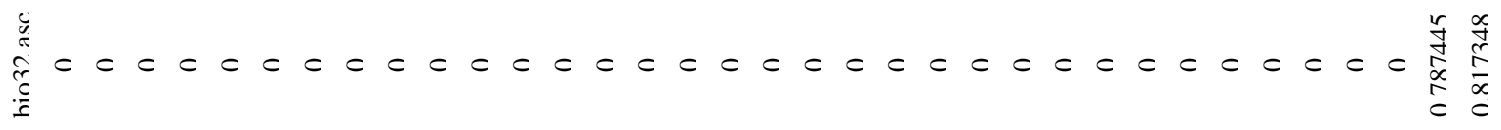

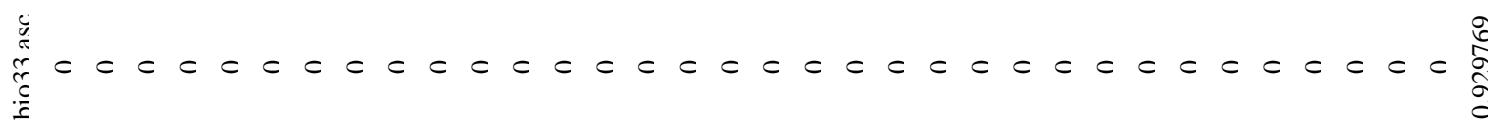

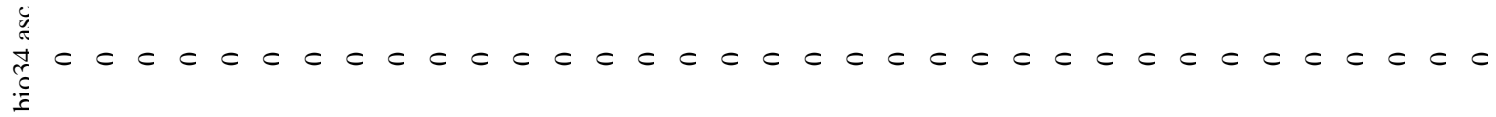




\section{APPENDIX B}

Representative Concentration Pathway 2.6 model results

Model output results and figures for Representative Concentration Pathway 2.6 (RCP 2.6) from the IPCC 5th Assessment Report (AR5). RCP 2.6 projects a $1^{\circ} \mathrm{C}$ mean increase in temperature by 2100 (0.3 - 1.7 likely range).

\section{Analysis of omission/commission}

The following picture shows the test omission rate and predicted area as a function of the cumulative threshold, averaged over the replicate runs. The omission rate should be close to the predicted omission, because of the definition of the cumulative threshold.

Figure B1

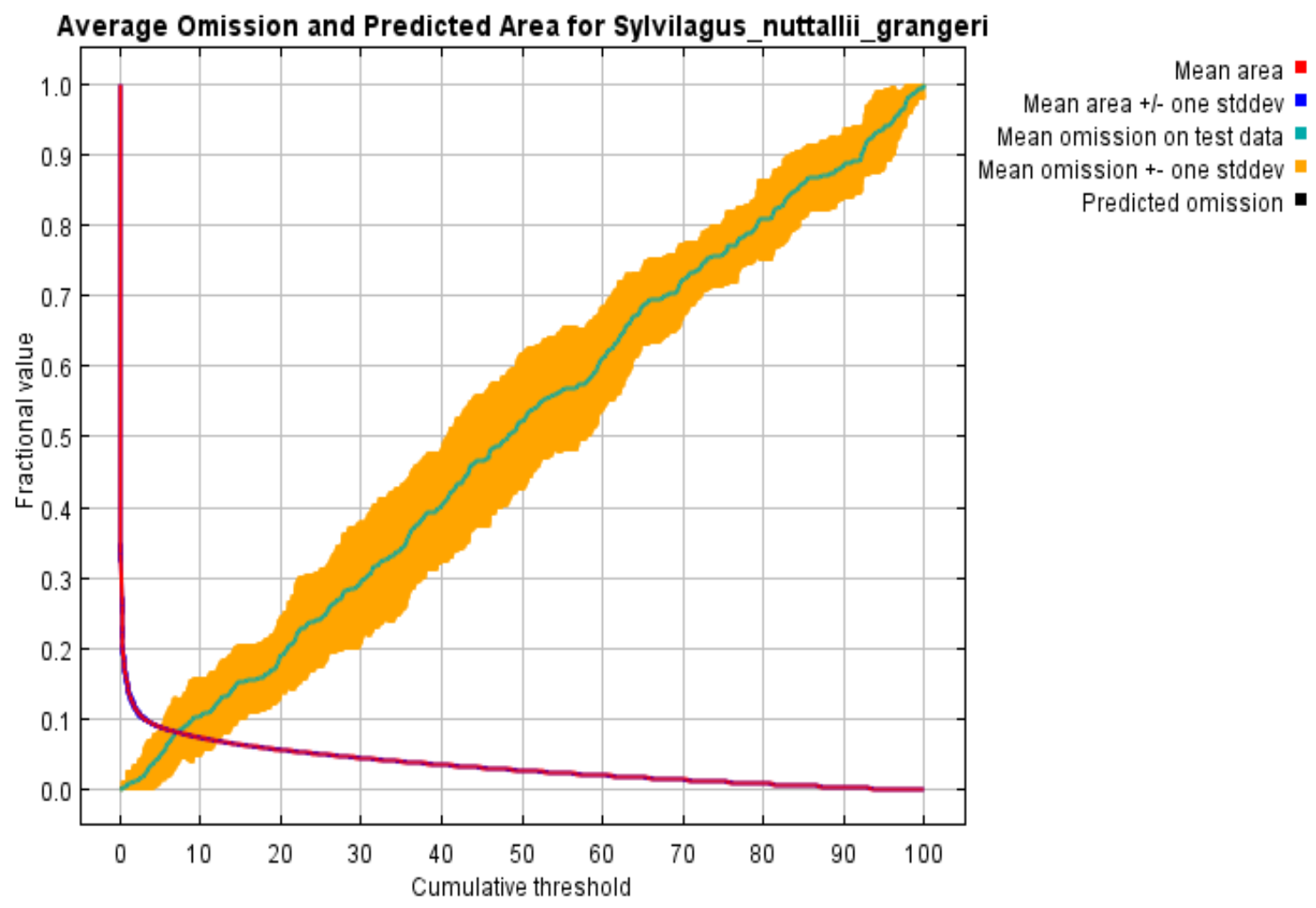


Figure B2

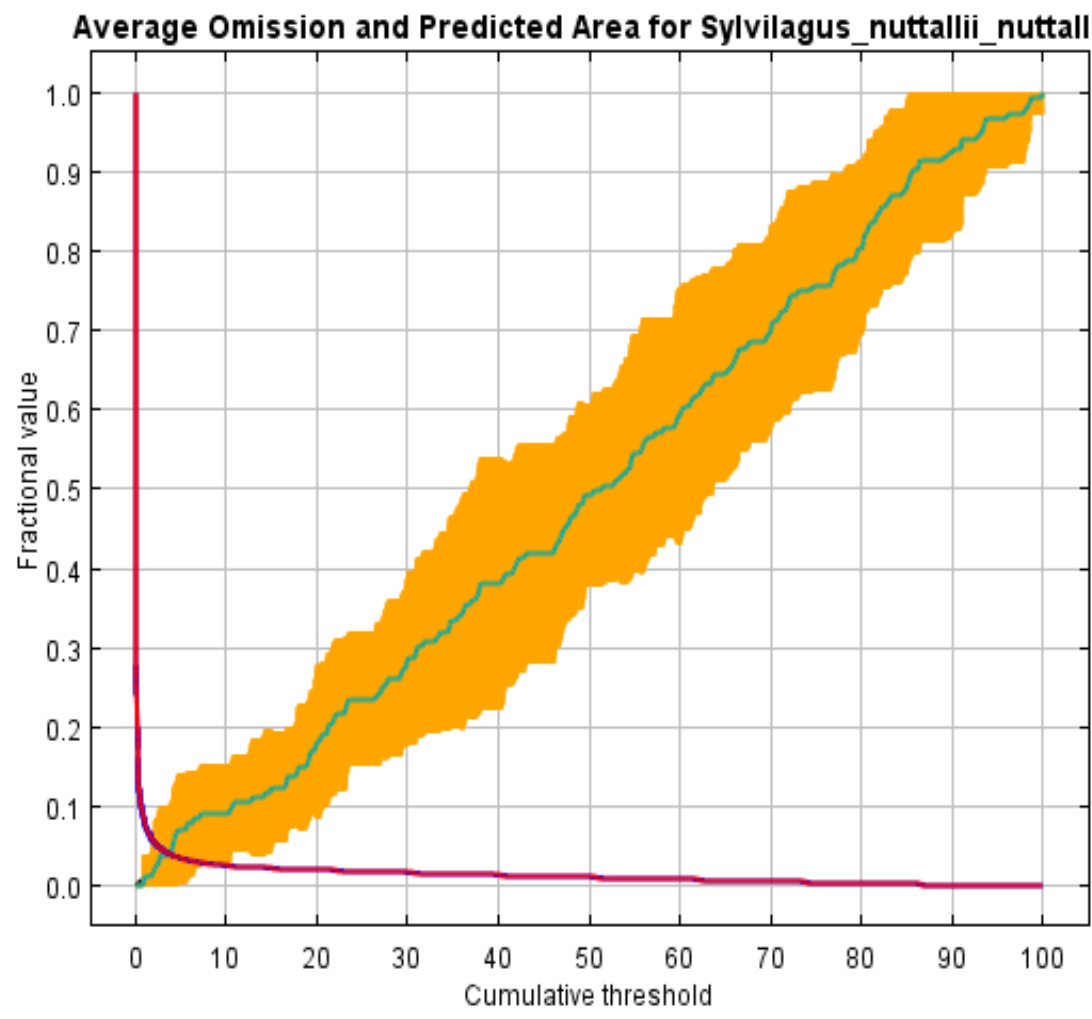

Mean area

Mean area $+/$ - one stddev Mean omission on test data Mean omission +- one stddev Predicted omission - 
Figure B3

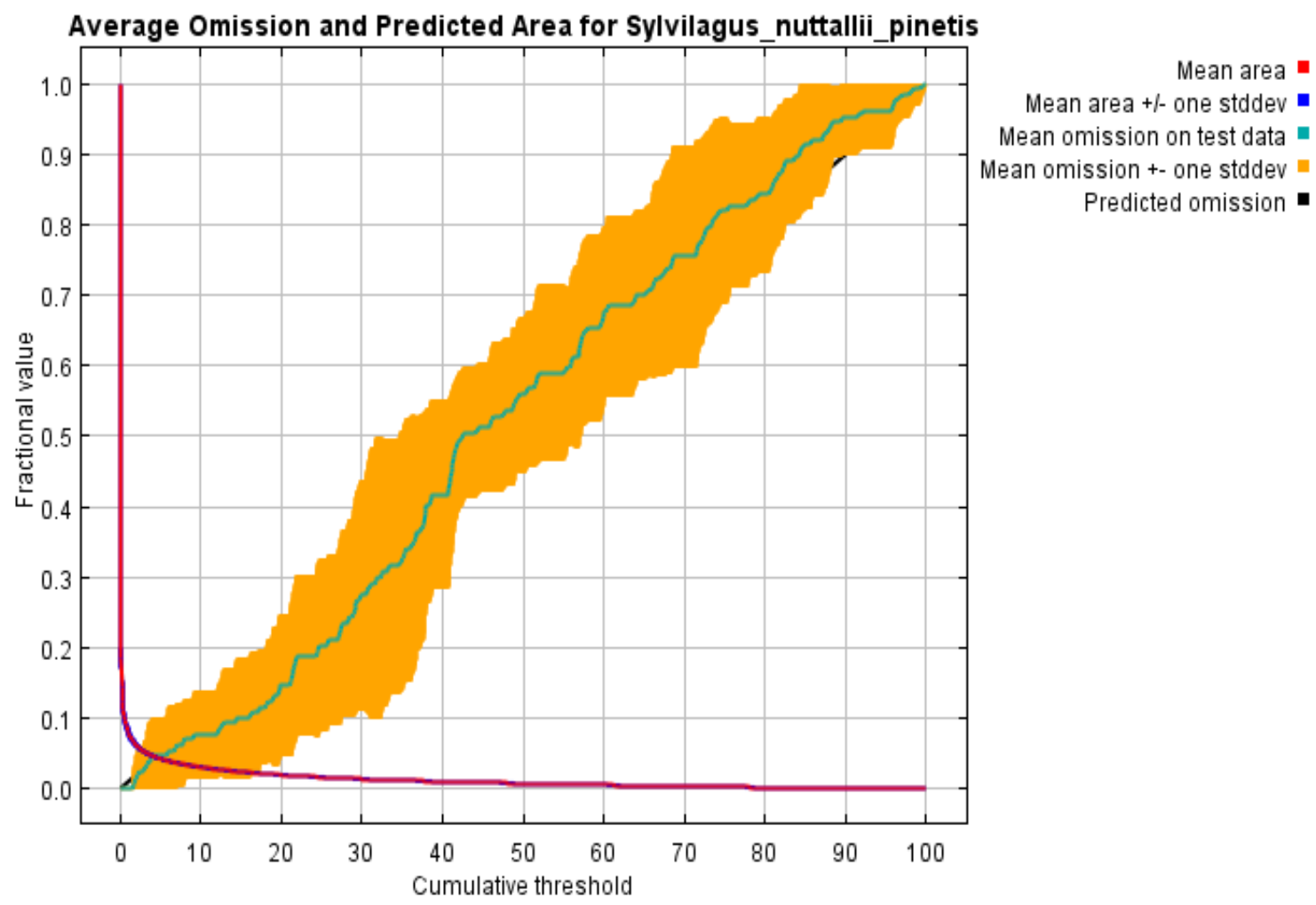

The next picture is the receiver operating characteristic (ROC) curve for the same data, again averaged over the replicate runs. Note that the specificity is defined using predicted area, rather than true commission (see the paper by Phillips, Anderson and Schapire cited for discussion of what this means). The average test AUC for the replicate runs is 0.965 , 0.986 , and 0.988 respectively and the standard deviation is 0.005 . 
Figure B4

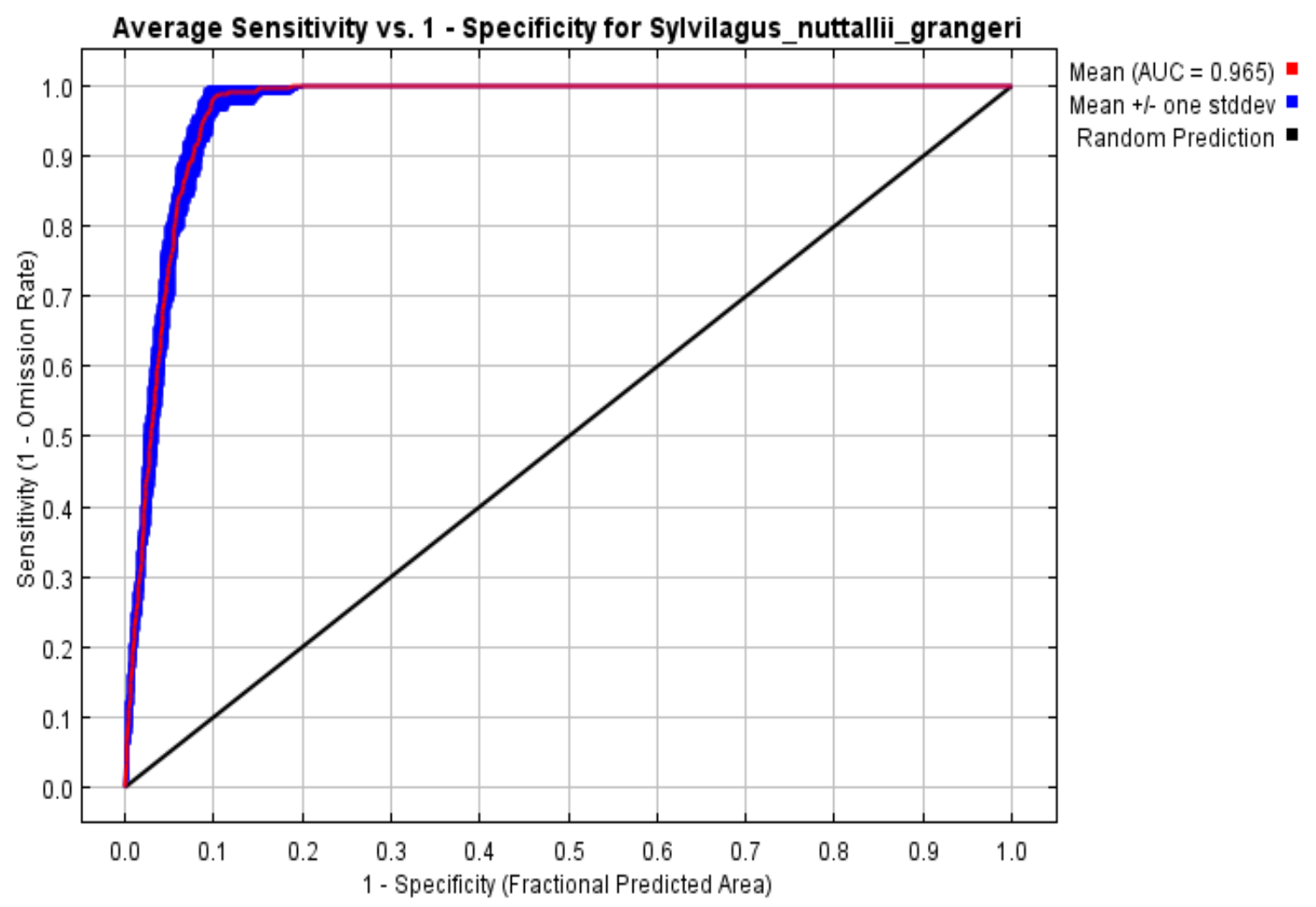


Figure B5

Average Sensitivity vs. 1 - Specificity for Sylvilagus_nuttallii_nuttallii

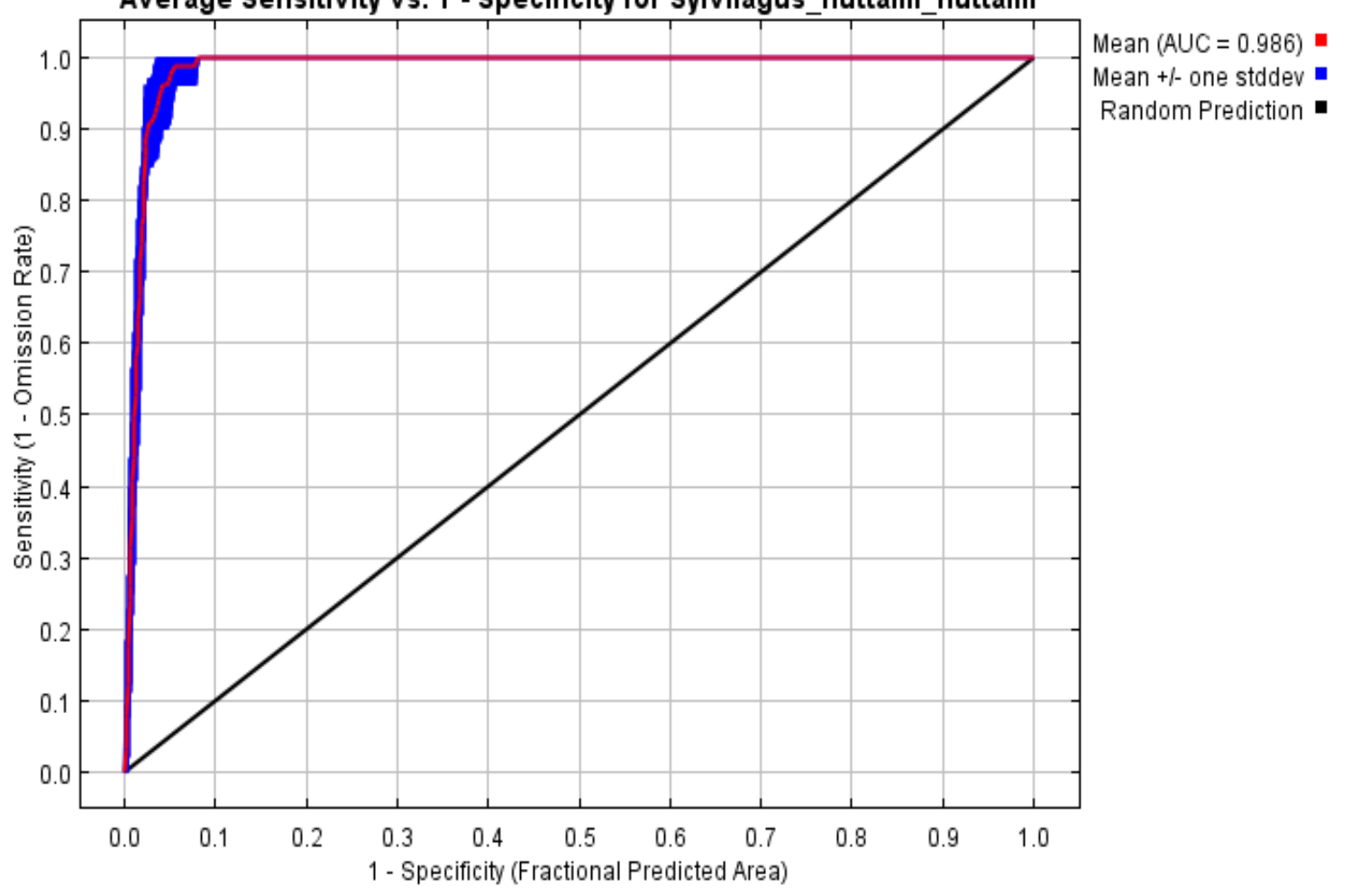


Figure B6

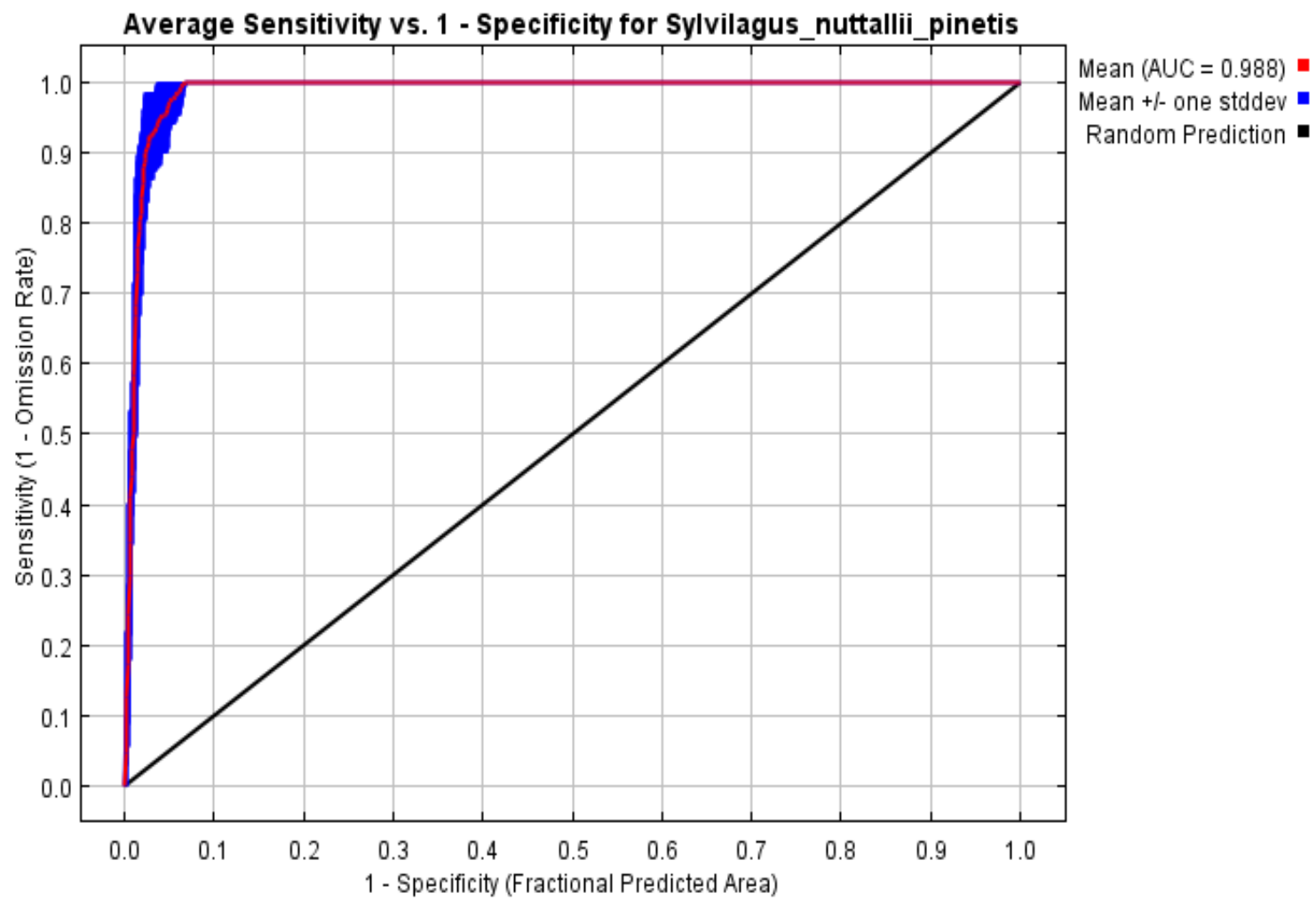

Pictures of the model

The following pictures show the point-wise mean and standard deviation of the 10 output grids. Other available summary grids are $\underline{\min }, \underline{\max }$ and $\underline{\text { median. }}$.

Sylvilagus nuttallii grangeri:

Figure B7

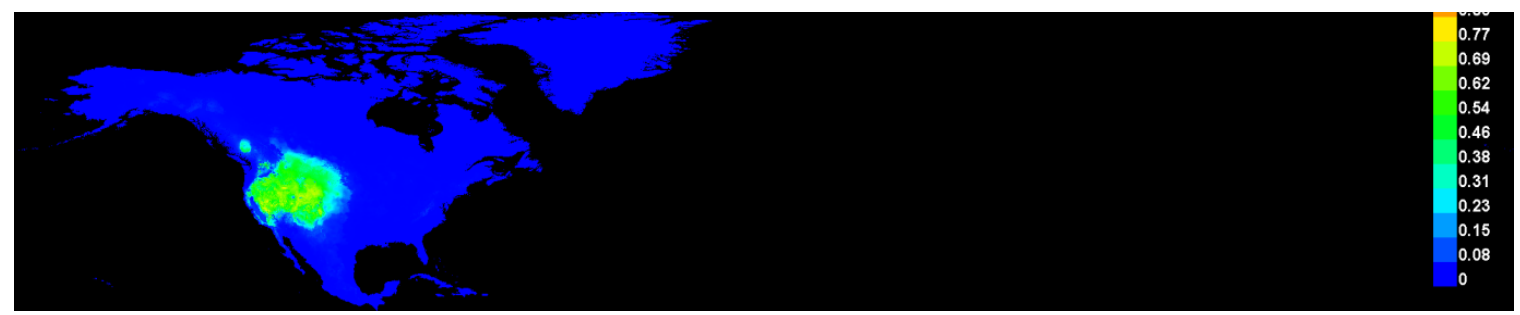

Figure B8

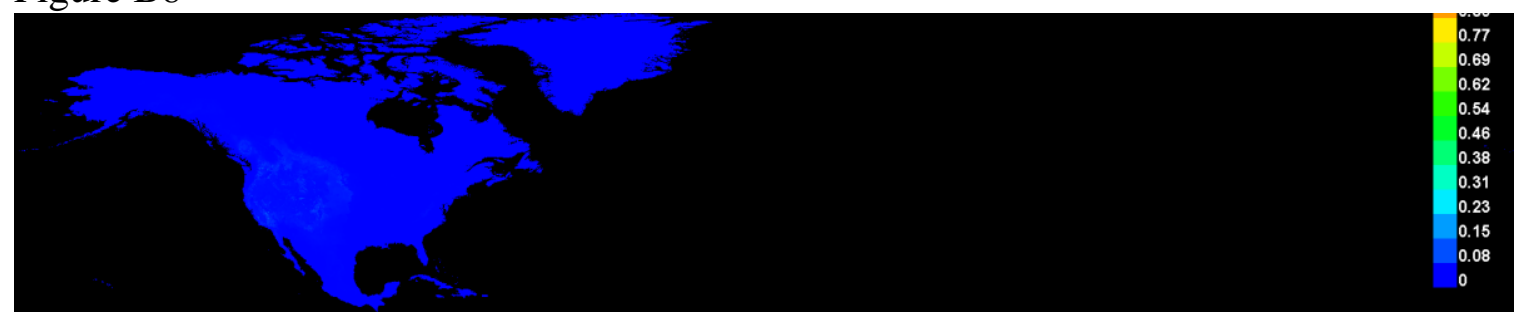


Sylvilagus nuttallii nuttallii:

Figure B9

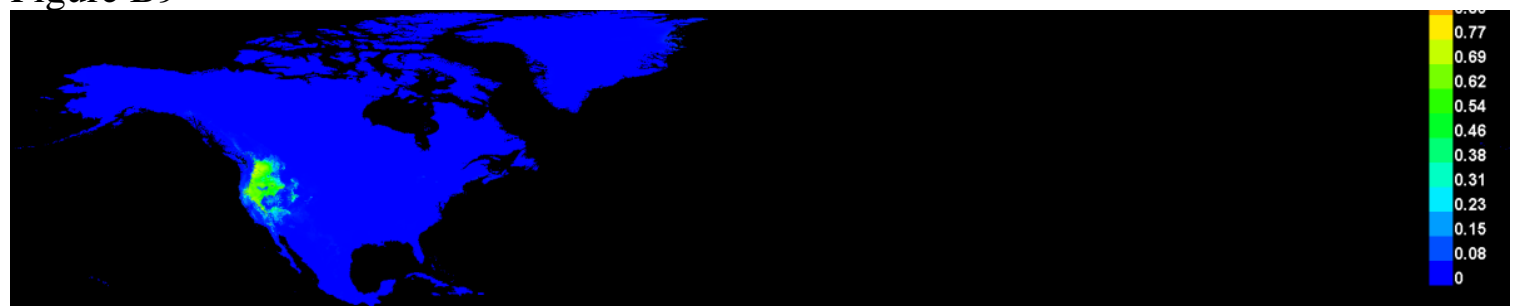

Figure B10

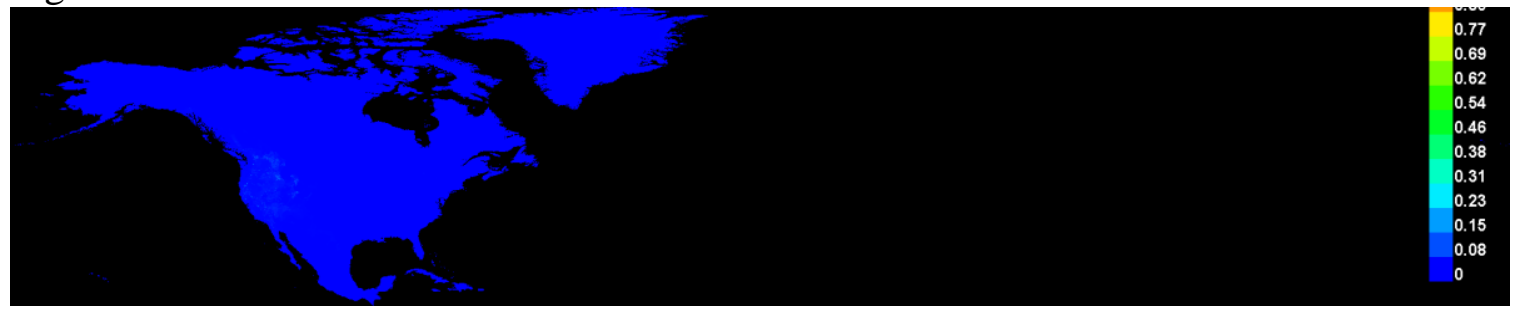

Sylvilagus nuttallii pinetis:

Figure B11

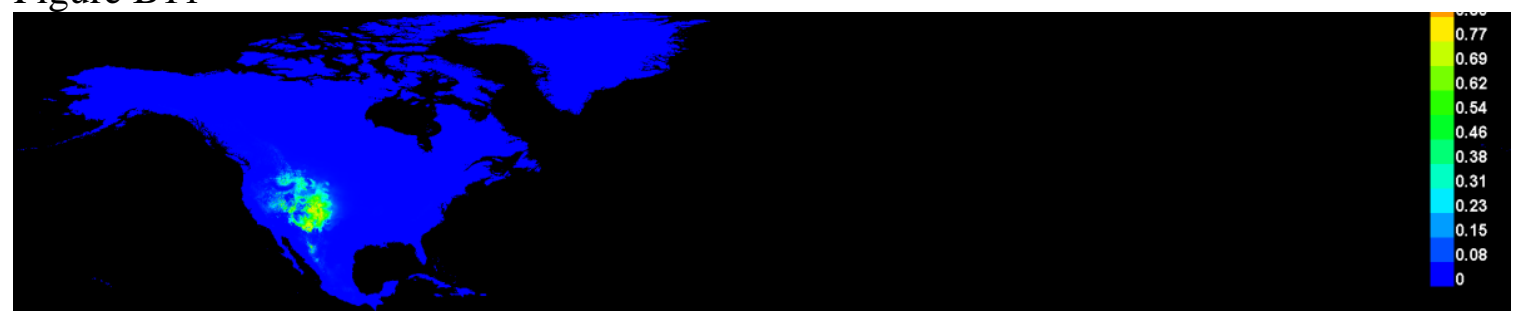

Figure B12

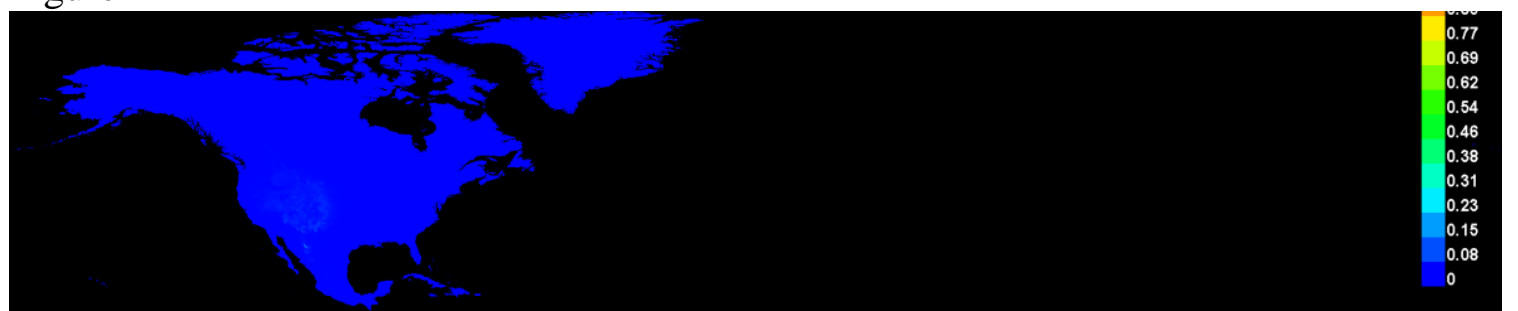

The following pictures show the point-wise mean and standard deviation of the 10 models applied to the environmental layers in ASCII. Other available summary grids are $\underline{\min }, \underline{\max }$ and median. 
Sylvilagus nuttallii grangeri

Figure B13

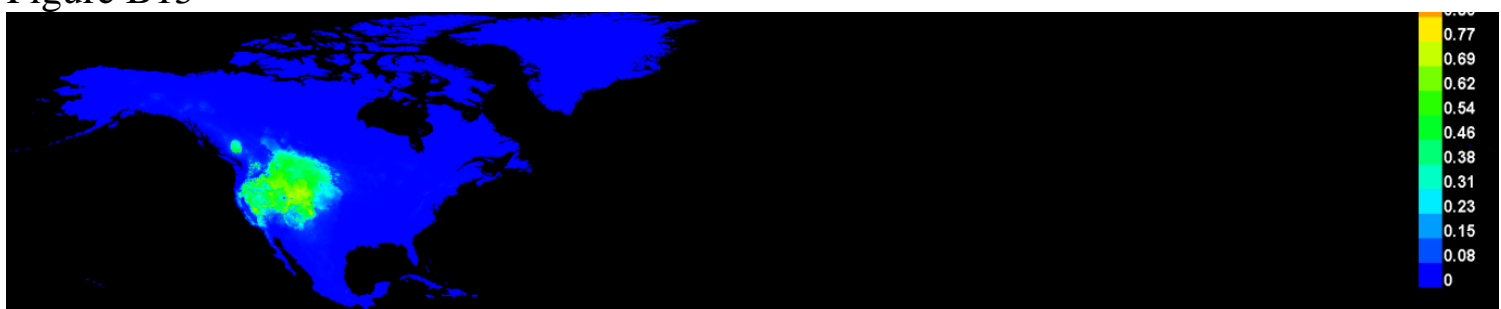

Figure B14

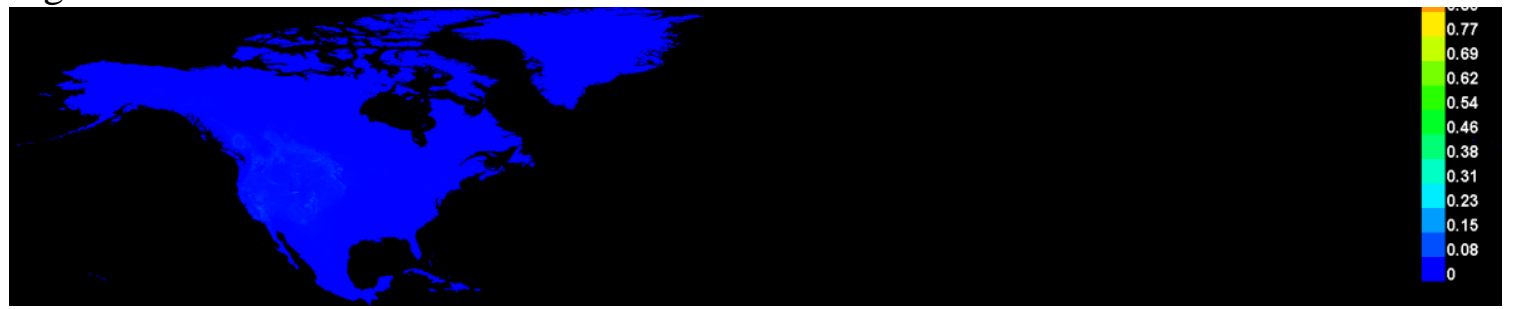

Sylvilagus nuttallii nuttallii:

Figure B15

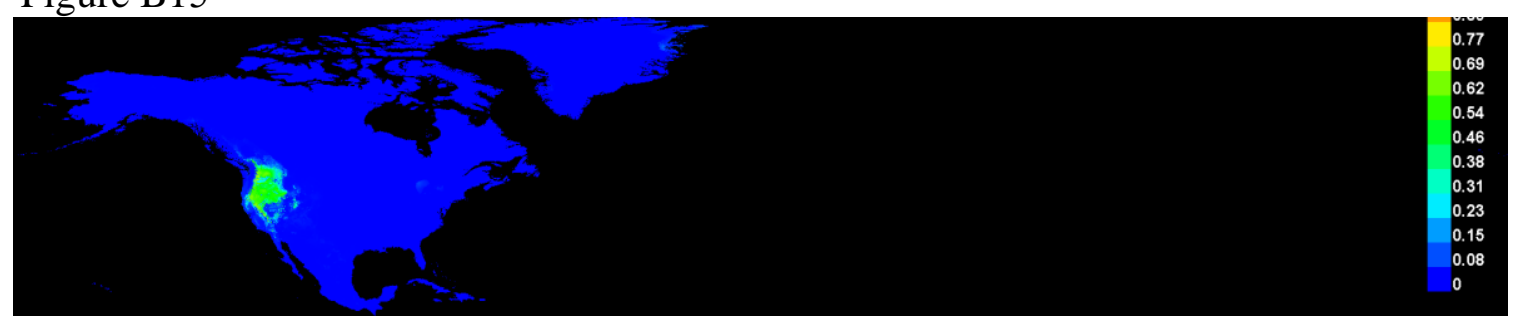


Figure B16

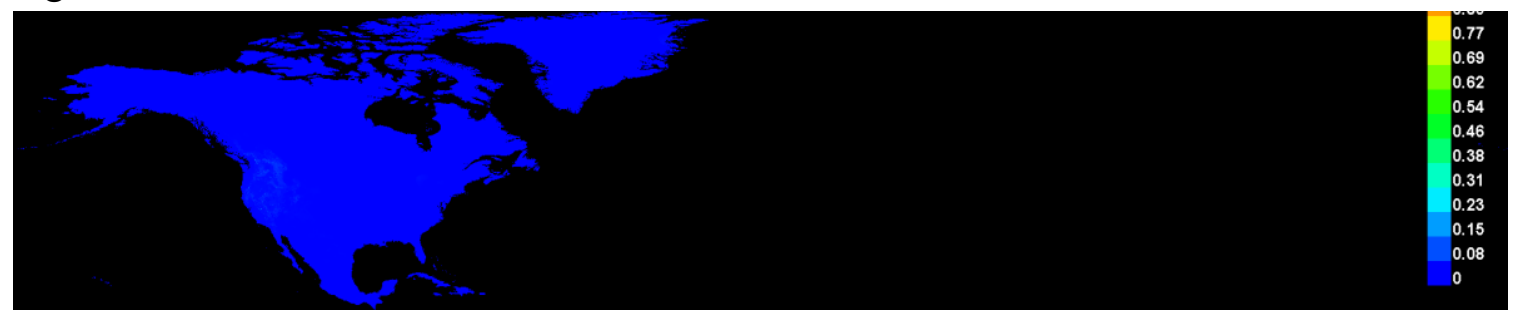

Sylvilagus nuttallii pinetis:

Figure B17

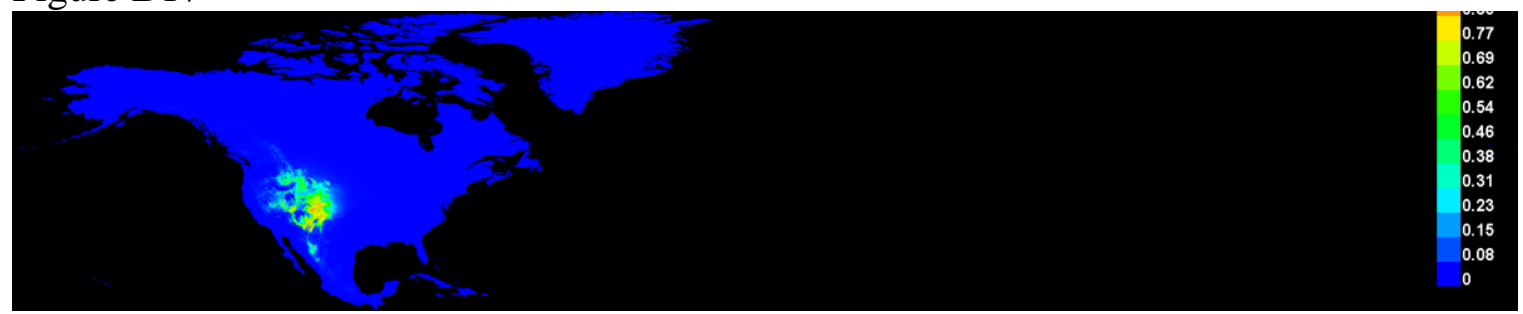

Figure B18

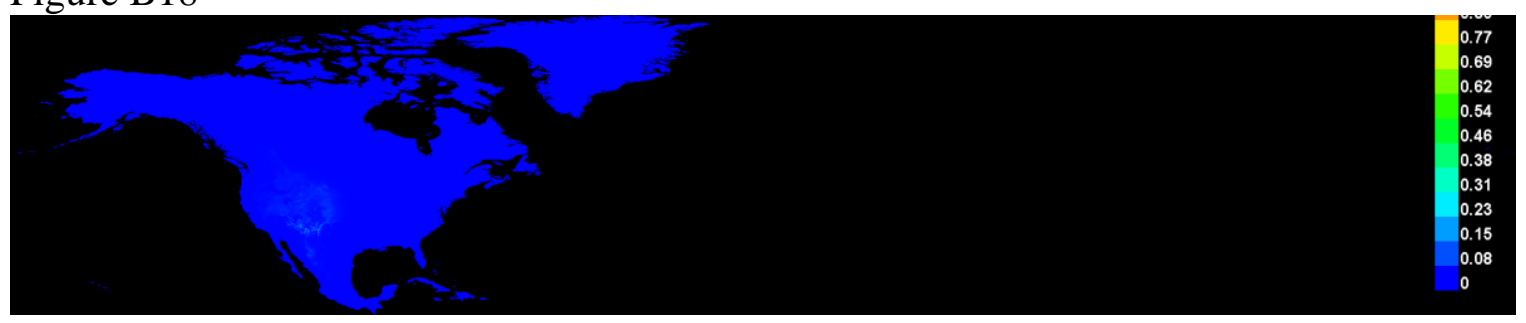




\section{Response curves}

These curves show how each environmental variable affects the Maxent prediction. The curves show how the logistic prediction changes as each environmental variable is varied, keeping all other environmental variables at their average sample value. Click on a response curve to see a larger version. Note that the curves can be hard to interpret if you have strongly correlated variables, as the model may depend on the correlations in ways that are not evident in the curves. In other words, the curves show the marginal effect of changing exactly one variable, whereas the model may take advantage of sets of variables changing together. The curves show the mean response of the 10 replicate Maxent runs (red) and and the mean +/- one standard deviation (blue, two shades for categorical variables).

Sylvilagus nuttallii grangeri

Figure B19
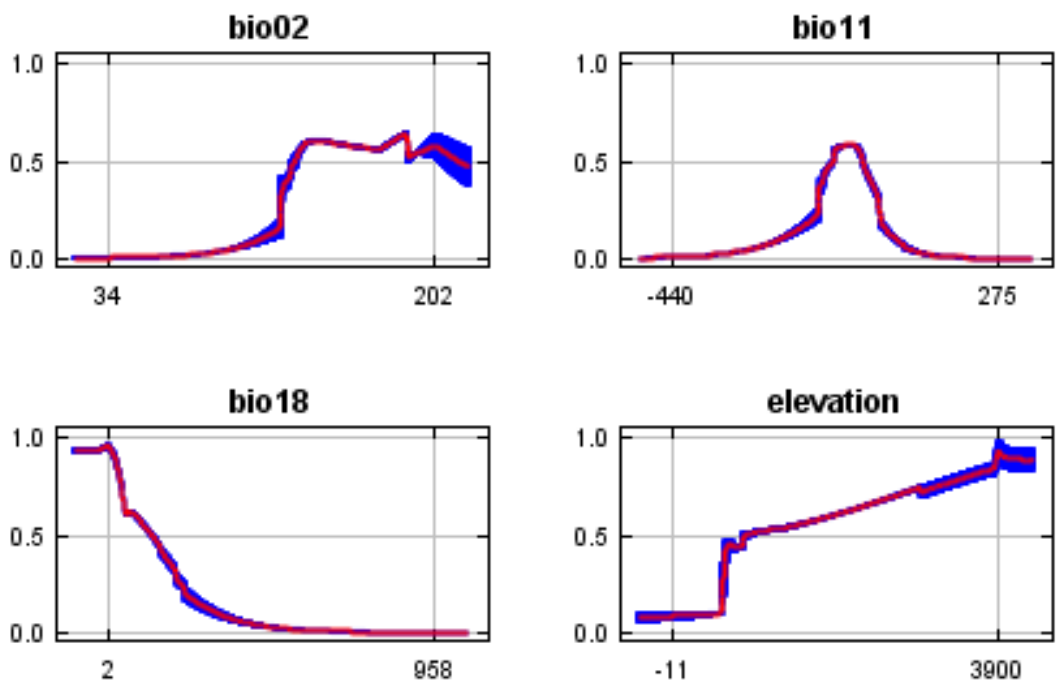

Sylvilagus nuttallii nuttallii

Figure B20
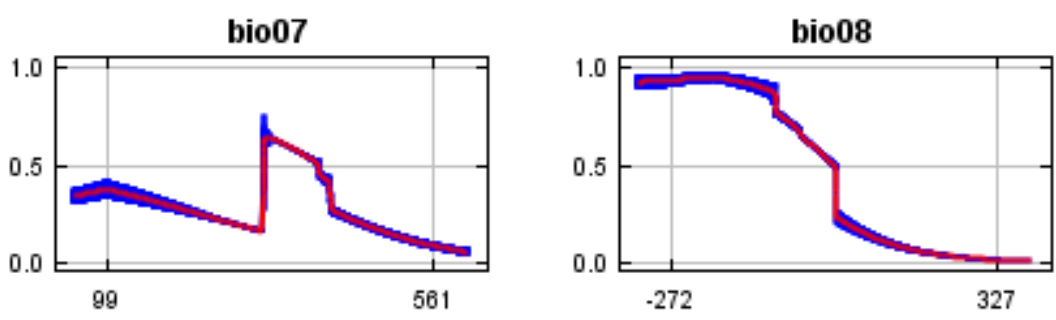

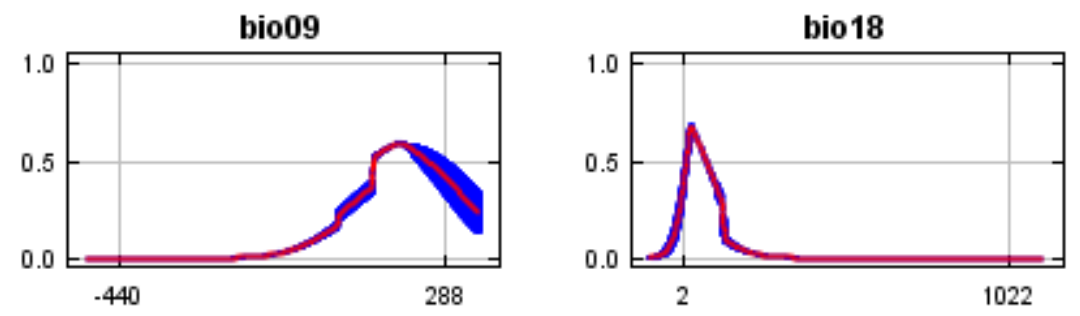

Sylvilagus nuttallii pinetis

Figure B21
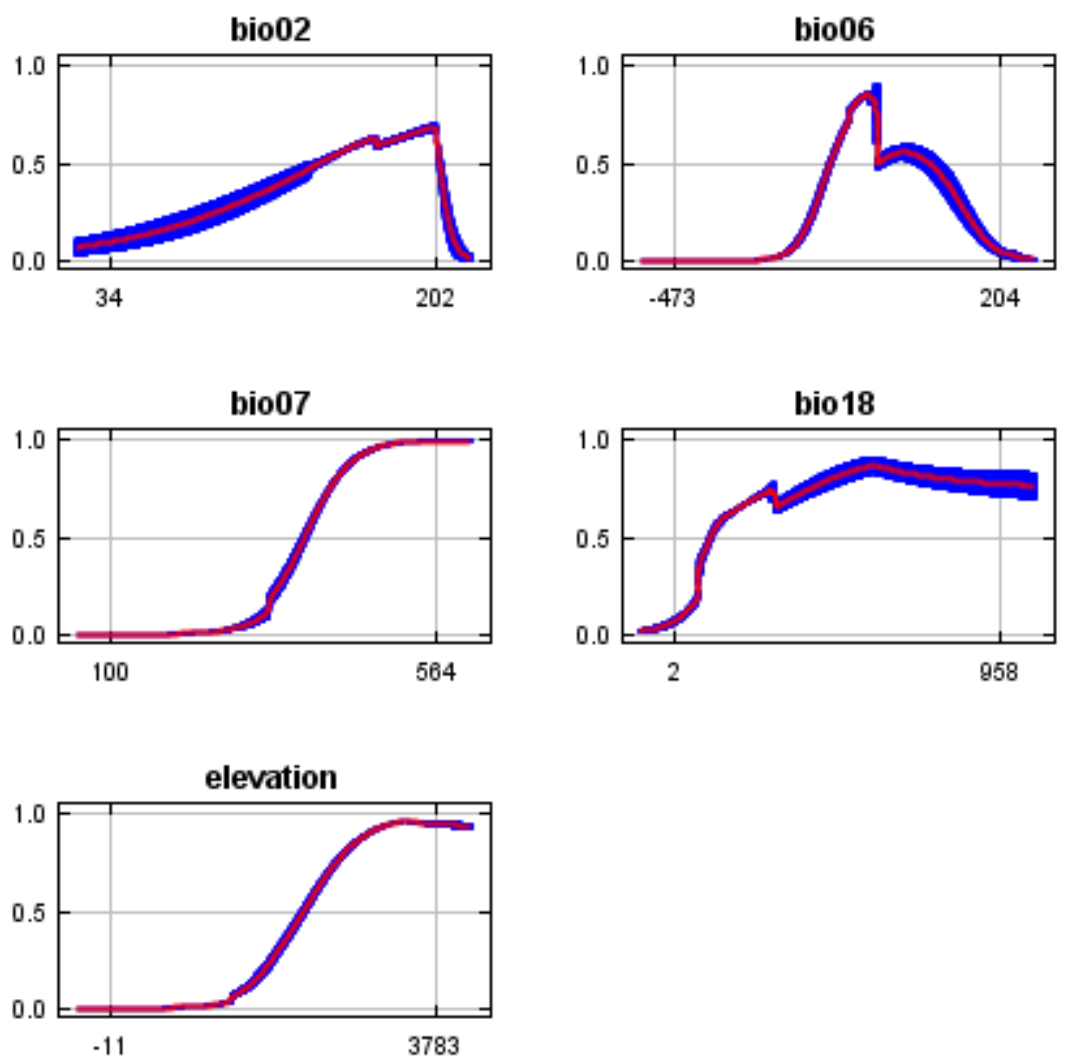
In contrast to the above marginal response curves, each of the following curves represents a different model, namely, a Maxent model created using only the corresponding variable. These plots reflect the dependence of predicted suitability both on the selected variable and on dependencies induced by correlations between the selected variable and other variables. They may be easier to interpret if there are strong correlations between variables.

Sylvilagus nuttallii grangeri

Figure B22
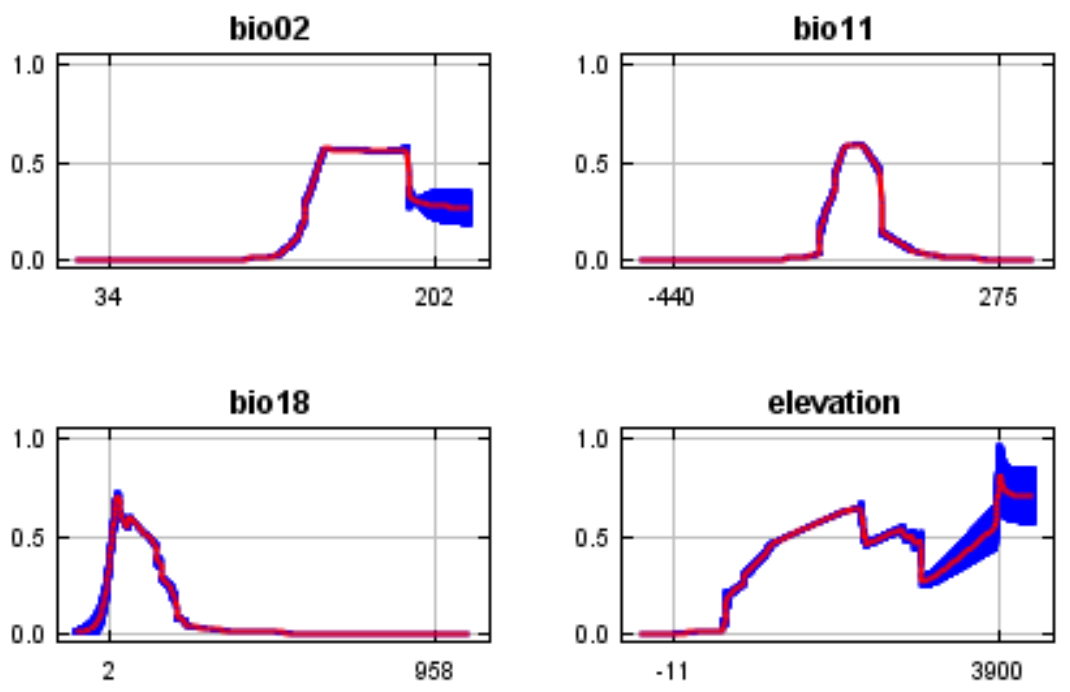
Sylvilagus nuttallii nuttallii

Figure B23
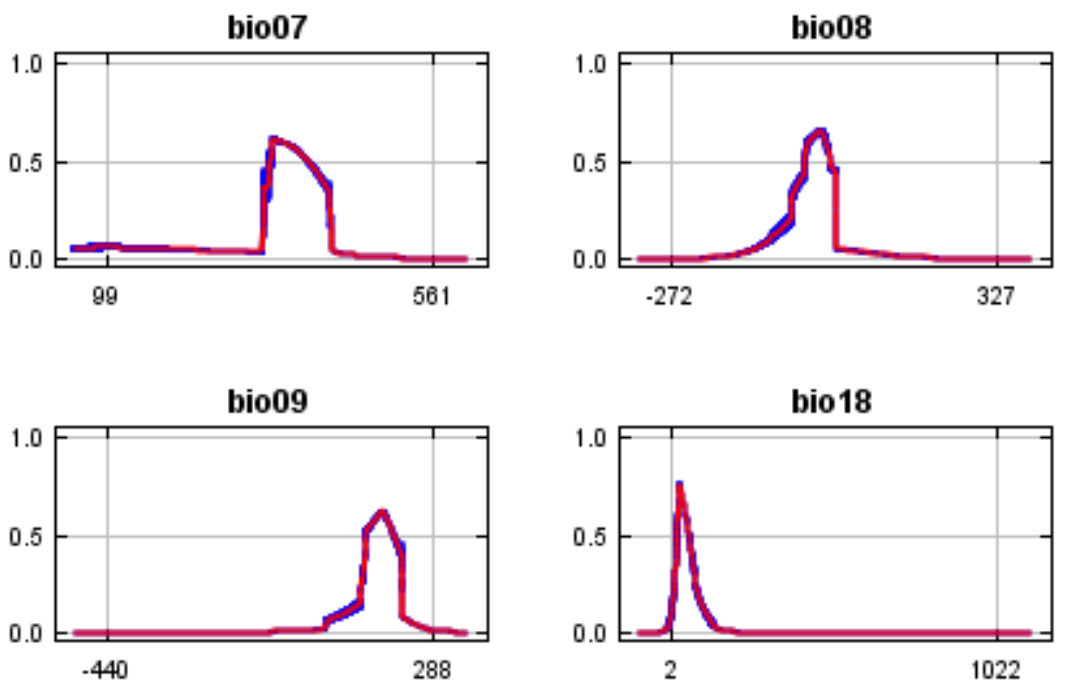

Sylvilagus nuttallii pinetis

Figure B24
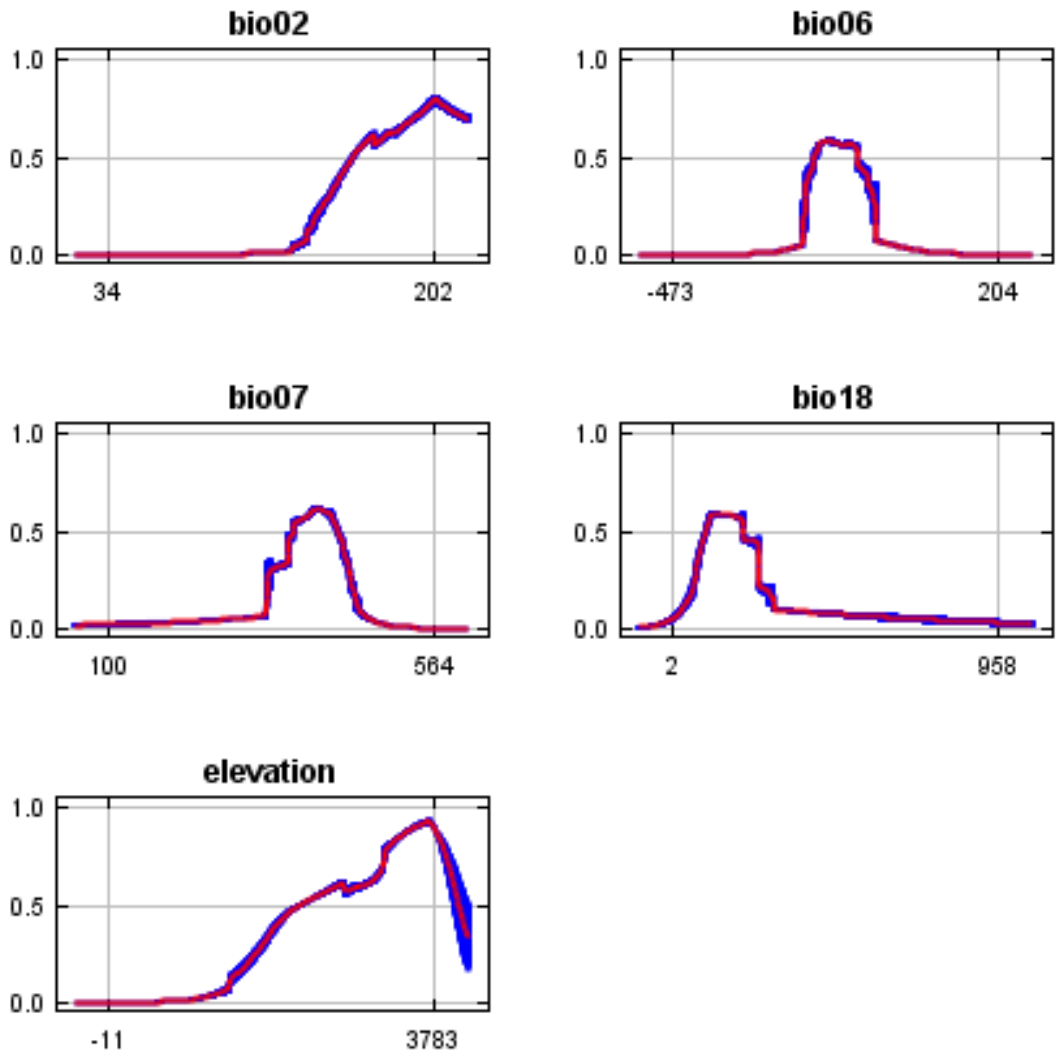


\section{Analysis of variable contributions}

The following table gives estimates of relative contributions of the environmental variables to the Maxent model. To determine the first estimate, in each iteration of the training algorithm, the increase in regularized gain is added to the contribution of the corresponding variable, or subtracted from it if the change to the absolute value of lambda is negative. For the second estimate, for each environmental variable in turn, the values of that variable on training presence and background data are randomly permuted. The model is reevaluated on the permuted data, and the resulting drop in training AUC is shown in the table, normalized to percentages. As with the variable jackknife, variable contributions should be interpreted with caution when the predictor variables are correlated. Values shown are averages over replicate runs.

Sylvilagus nuttallii grangeri

Table B1

$\begin{array}{ccc}\text { Variable } & \text { Percent contribution } & \text { Permutation importance } \\ \text { bio02 } & 53.7 & 43 \\ \text { bio11 } & 20.5 & 30.8 \\ \text { elevation } & 15.1 & 13.6 \\ \text { bio18 } & 10.8 & 12.6\end{array}$

Sylvilagus nuttallii nuttallii

Table B2

Variable Percent contribution Permutation importance

$\begin{array}{ccc}\text { bio09 } & 53.2 & 71 \\ \text { bio08 } & 25 & 9.2 \\ \text { bio18 } & 18.5 & 18.2 \\ \text { bio07 } & 3.3 & 1.7\end{array}$

Sylvilagus nuttallii pinetis

Table B3

Variable Percent contribution Permutation importance

$\begin{array}{ccc}\text { bio02 } & 45.9 & 1 \\ \text { elevation } & 40.1 & 48.8 \\ \text { bio06 } & 7.8 & 40.4 \\ \text { bio07 } & 3.4 & 7.4 \\ \text { bio18 } & 2.8 & 2.5\end{array}$


The following picture shows the results of the jackknife test of variable importance. The environmental variable with highest gain when used in isolation is bio02, which therefore appears to have the most useful information by itself. The environmental variable that decreases the gain the most when it is omitted is bio11, which therefore appears to have the most information that isn't present in the other variables. Values shown are averages over replicate runs.

Figure B25

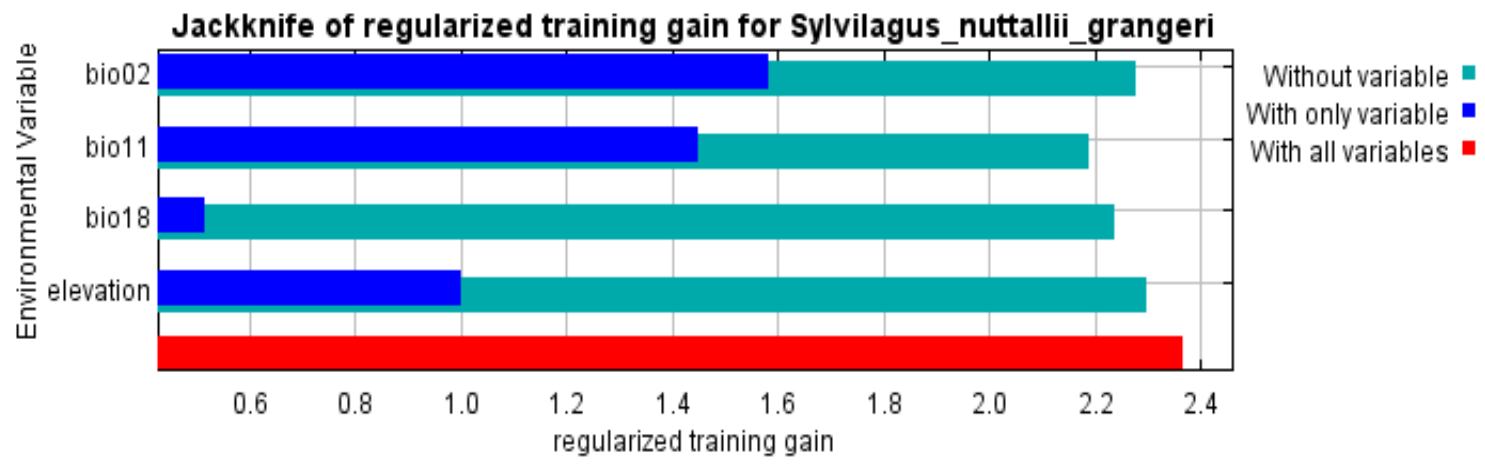

Figure B26

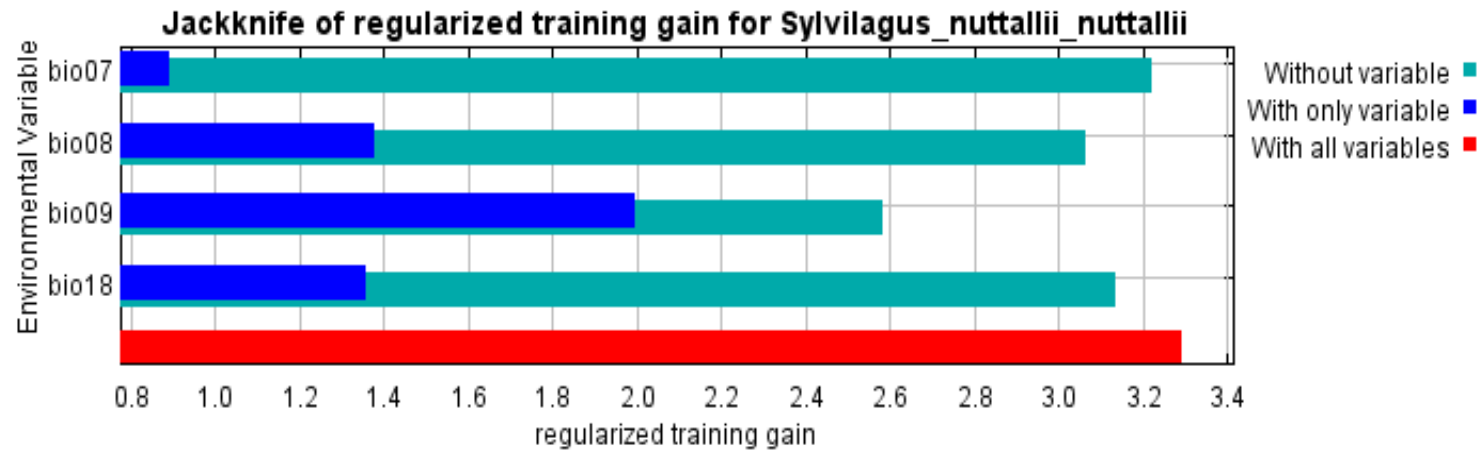

Figure B27

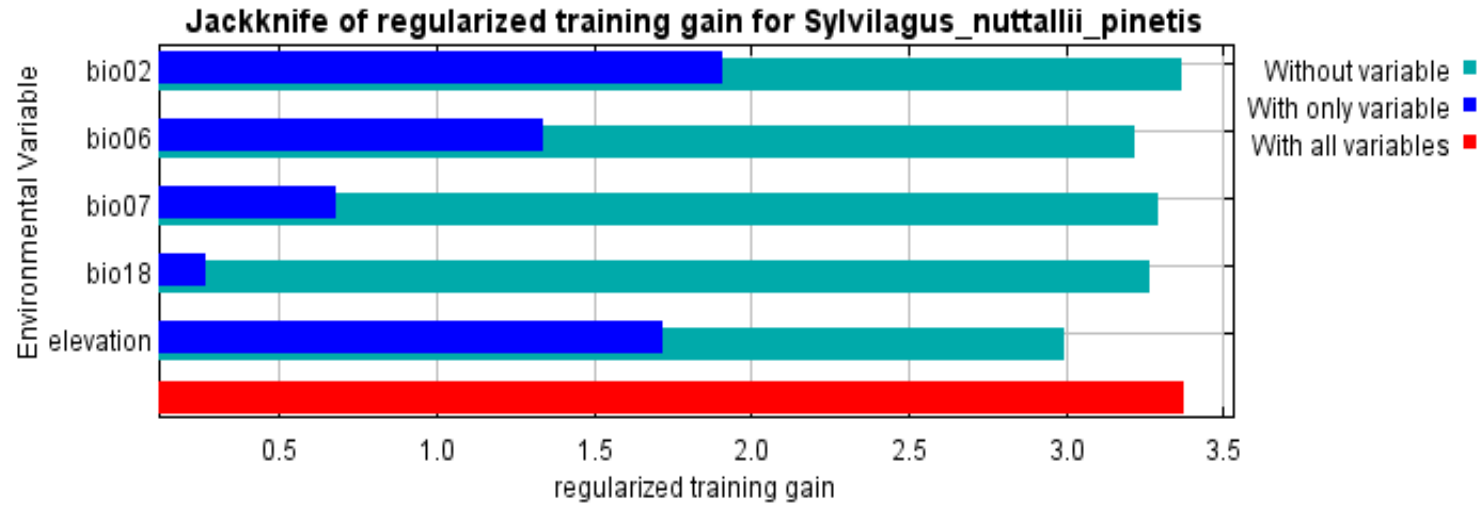

The next picture shows the same jackknife test, using test gain instead of training gain. 
Note that conclusions about which variables are most important can change, now that we're looking at test data.

Figure B28

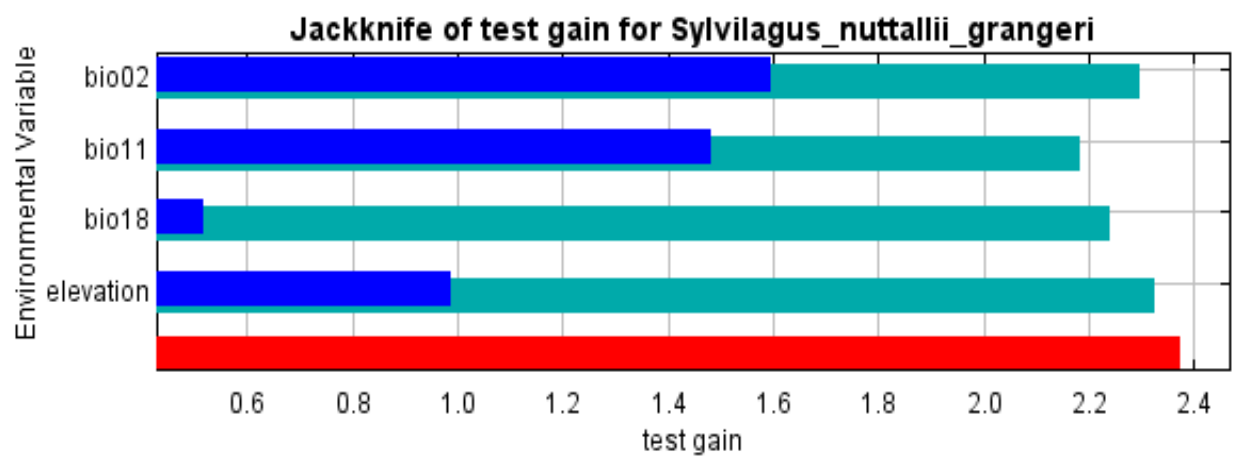

Without variable With only variable With all variables.

Figure B29

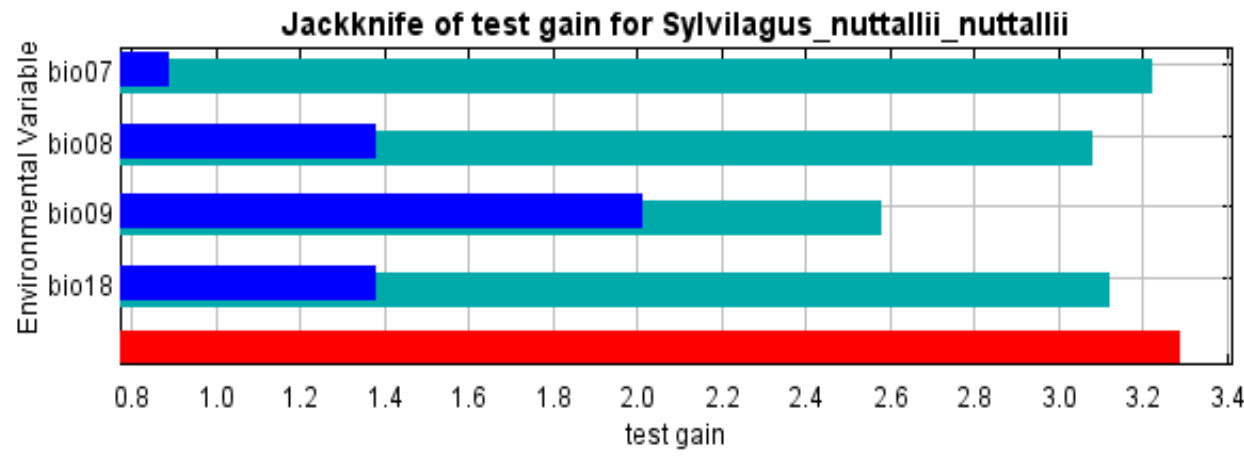

Without variable With only variable With all variables

Figure B30

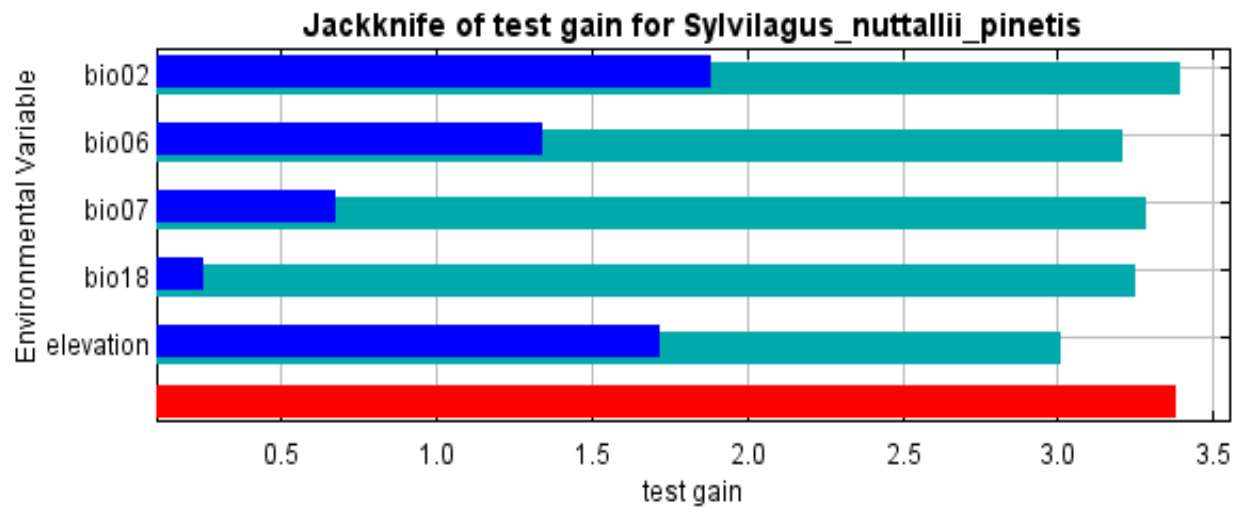

Without variable With only variable With all variables -

Lastly, we have the same jackknife test, using AUC on test data.

Figure B29 
Figure B31

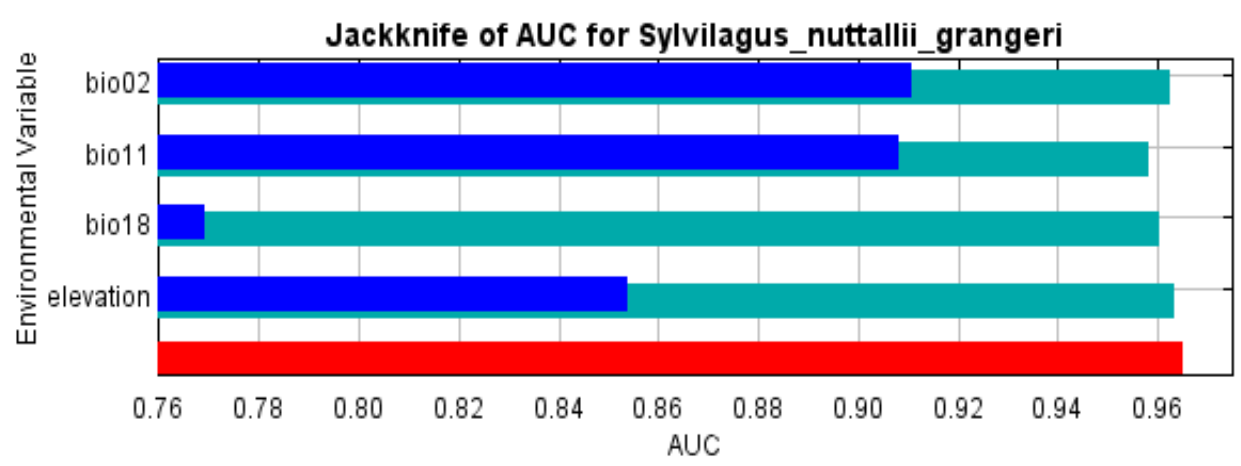

Without variable With only variable With all variables -

Figure B32

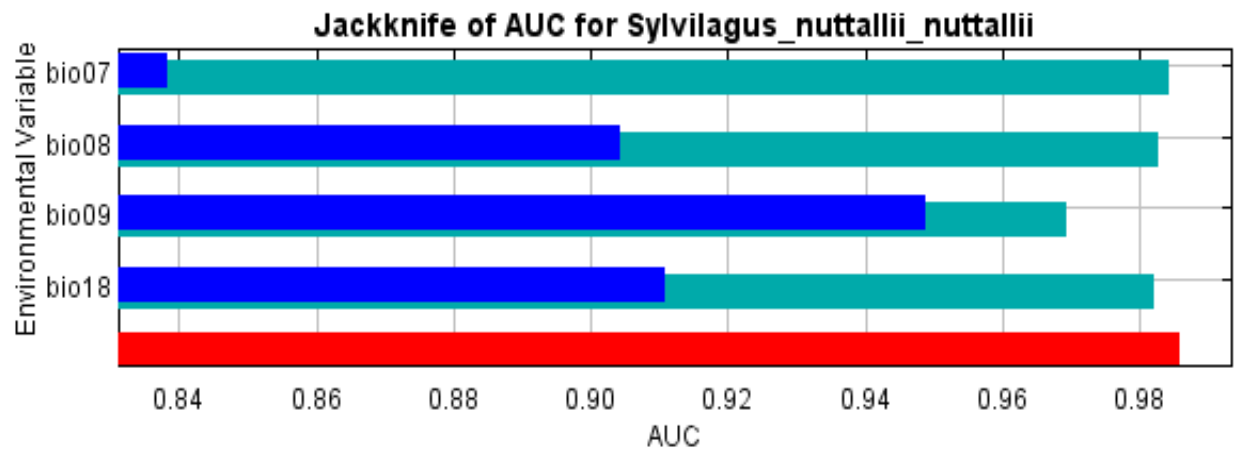

Without variable With only variable With all variables

Figure B33

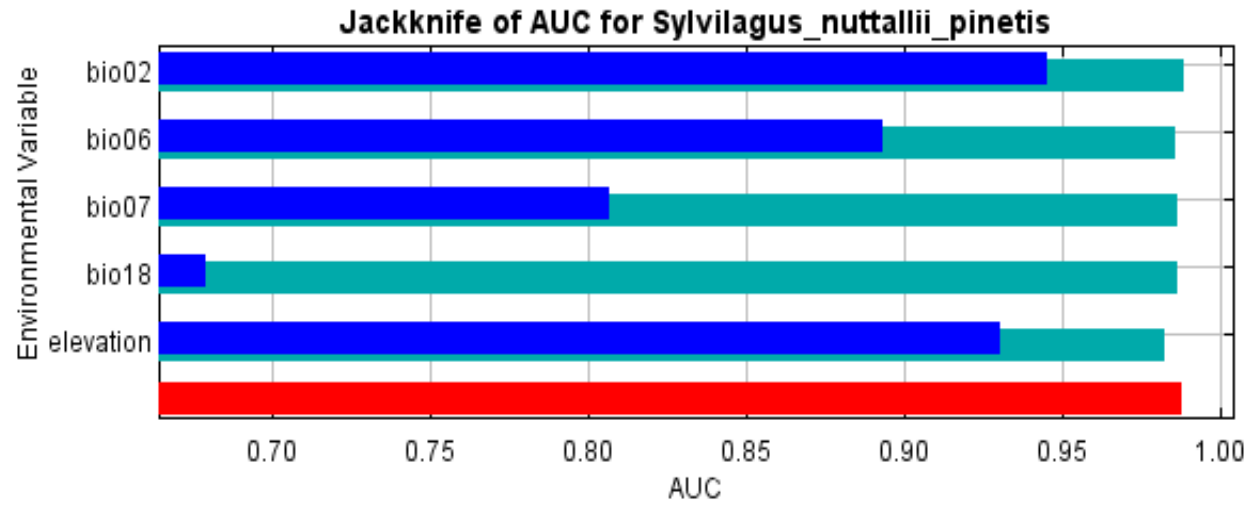




\section{APPENDIX C}

Representative Concentration Pathway 4.5 model results

Model output results and figures for Representative Concentration Pathway 4.5 (RCP 4.5) from the IPCC 5th Assessment Report (AR5). RCP 4.5 projects a $1.8^{\circ} \mathrm{C}$ mean increase in temperature by 2100 ( $1.1-2.6$ likely range).

\section{Analysis of omission/commission}

The following picture shows the test omission rate and predicted area as a function of the cumulative threshold, averaged over the replicate runs. The omission rate should be close to the predicted omission, because of the definition of the cumulative threshold.

Figure $\mathrm{C} 1$

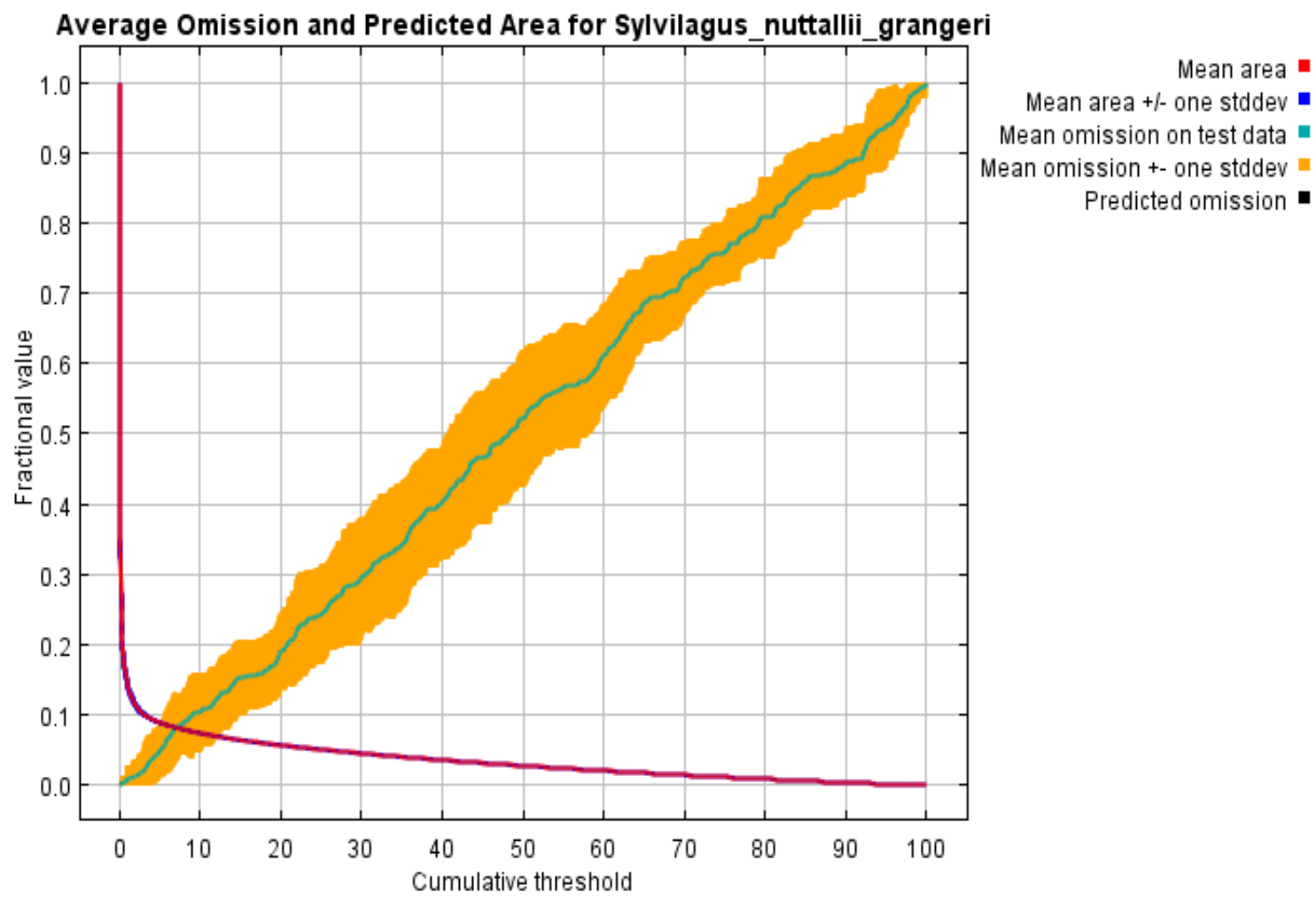


Figure C2

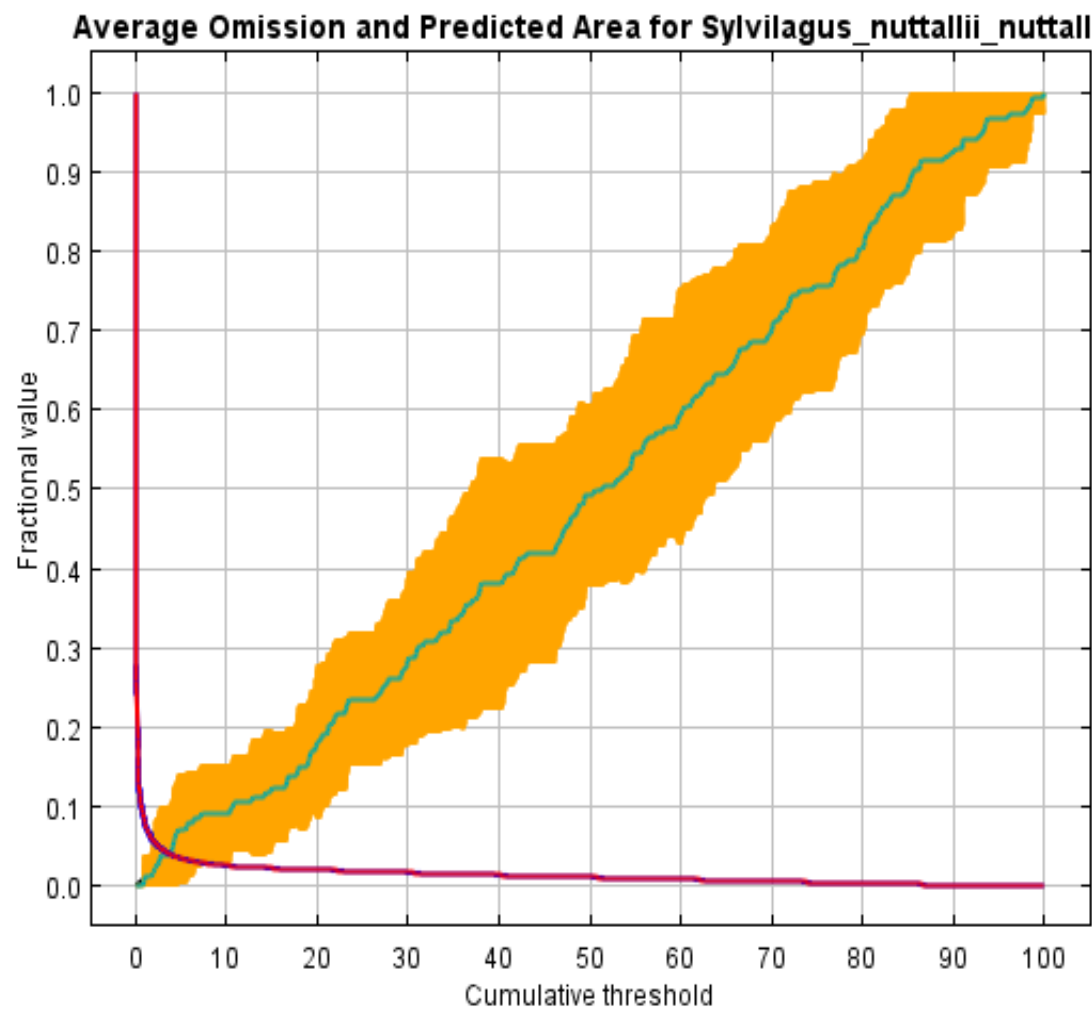

Mean area

Mean area $+/$ - one stddev Mean omission on test data Mean omission +- one stddev Predicted omission - 
Figure C3

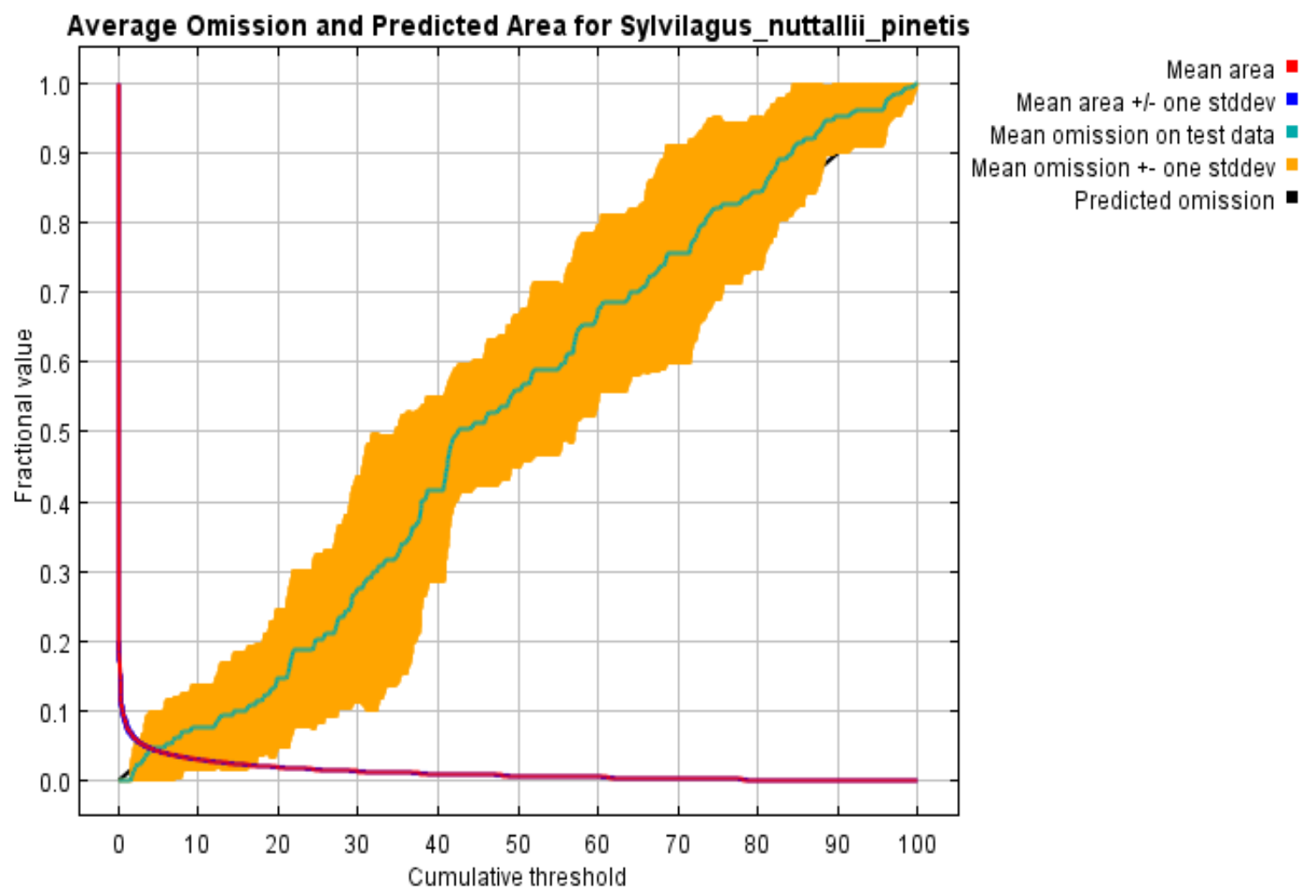

The next picture is the receiver operating characteristic (ROC) curve for the same data, again averaged over the replicate runs. Note that the specificity is defined using predicted area, rather than true commission (see the paper by Phillips, Anderson and Schapire cited for discussion of what this means). The average test AUC for the replicate runs is 0.965 , 0.986 , and 0.988 respectively and the standard deviation is 0.005 . 
Figure C4

Average Sensitivity vs. 1 - Specificity for Sylvilagus nuttallii grangeri

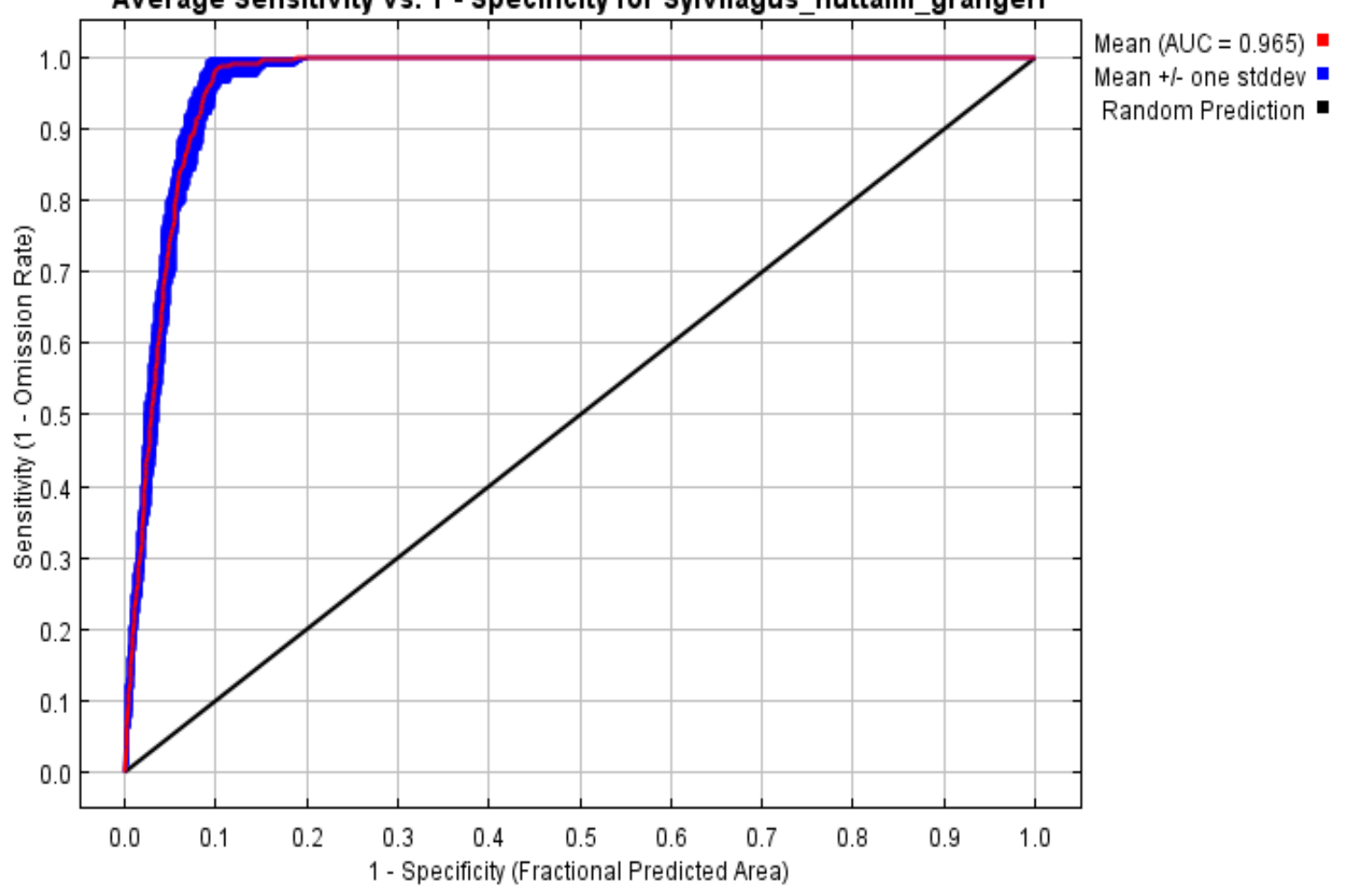


Figure C5

Average Sensitivity vs. 1 - Specificity for Sylvilagus nuttallii nuttallii

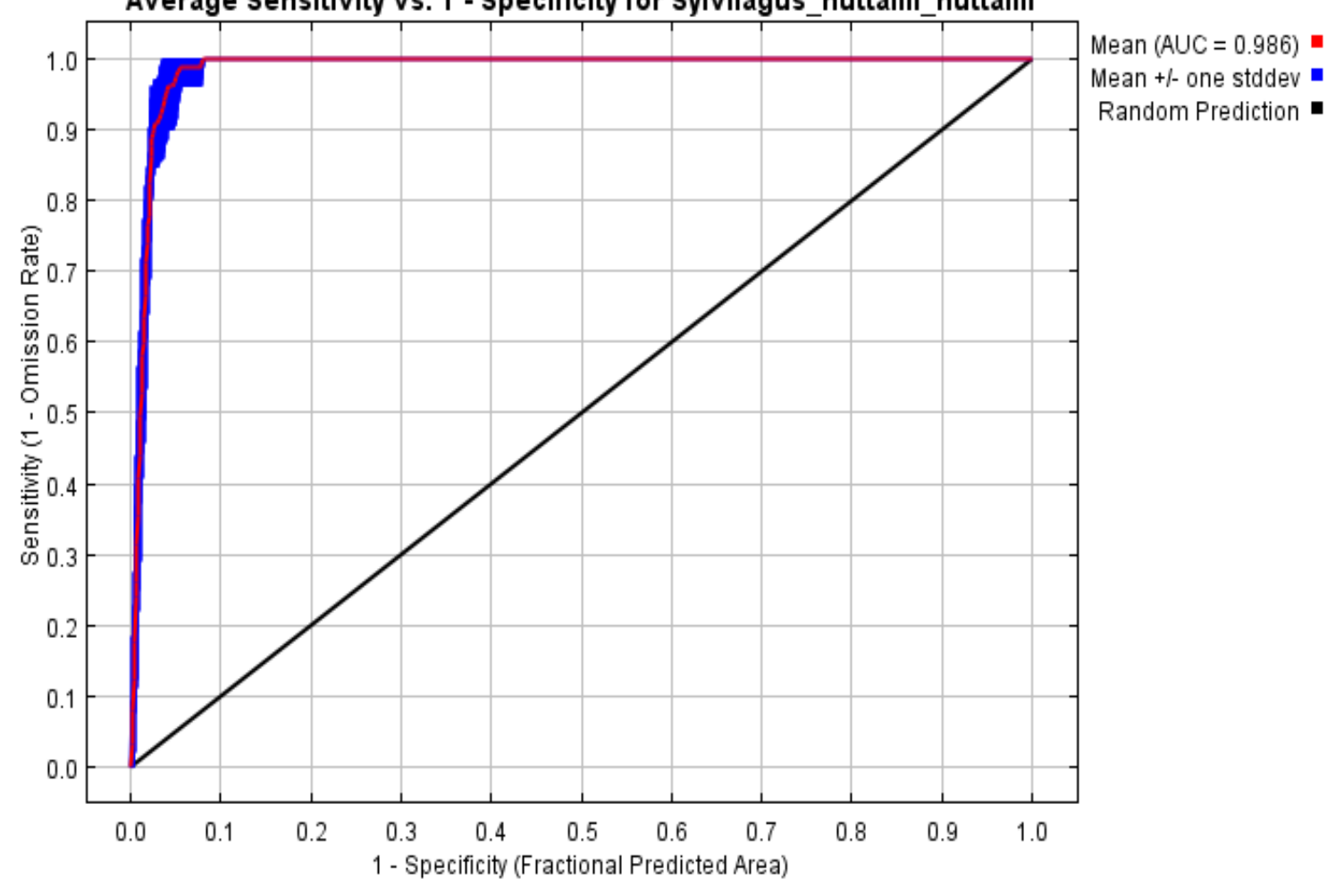


Figure C6

Average Sensitivity vs. 1 - Specificity for Sylvilagus_nuttallii_pinetis

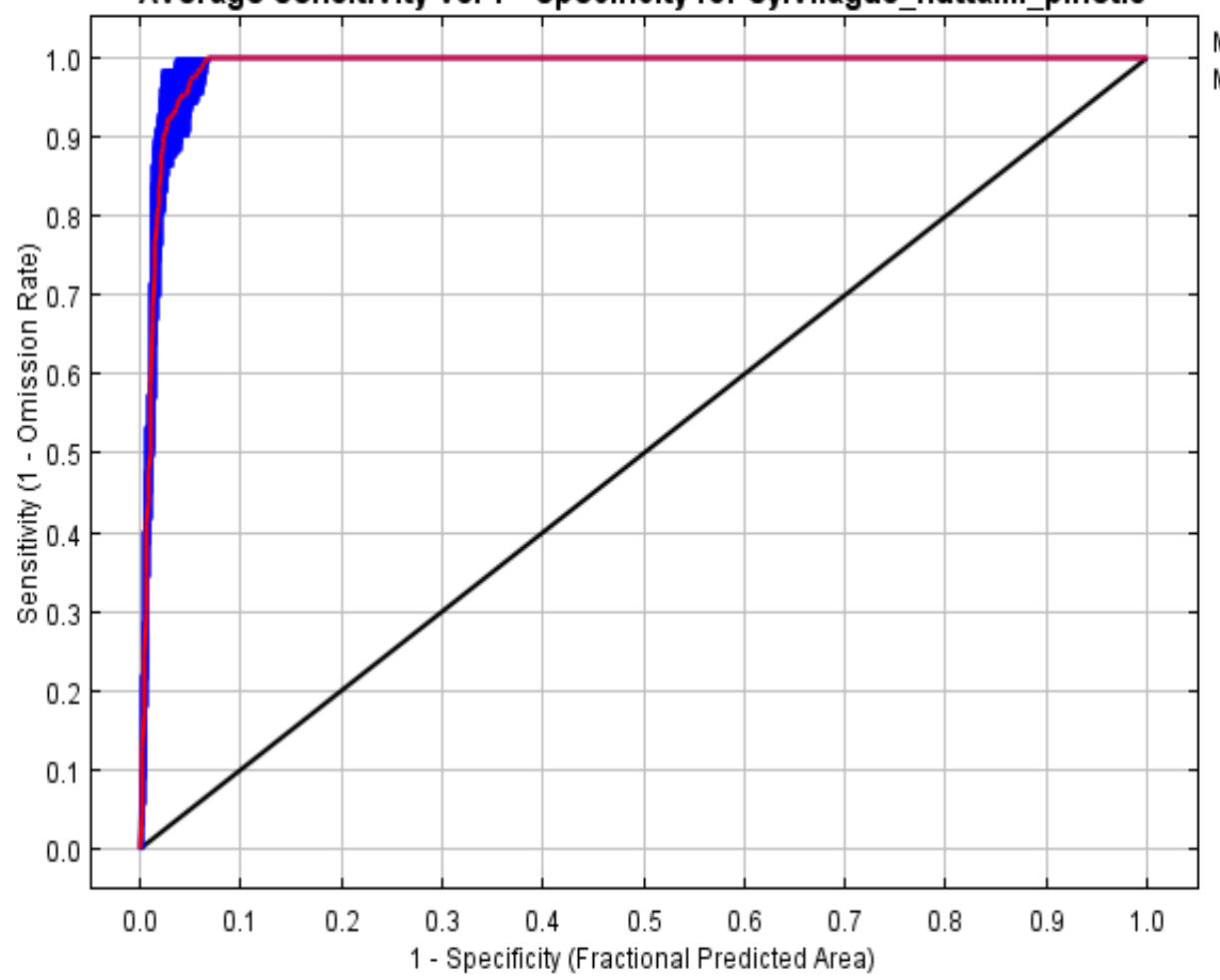

Mean $(\mathrm{AUC}=0.988)$ -

Mean + - one stddev $=$

Random Prediction -

Pictures of the model

The following pictures show the point-wise mean and standard deviation of the 10 output grids. Other available summary grids are $\underline{\min } \underline{\max }$ and median.

Sylvilagus nuttallii grangeri:

Figure C7

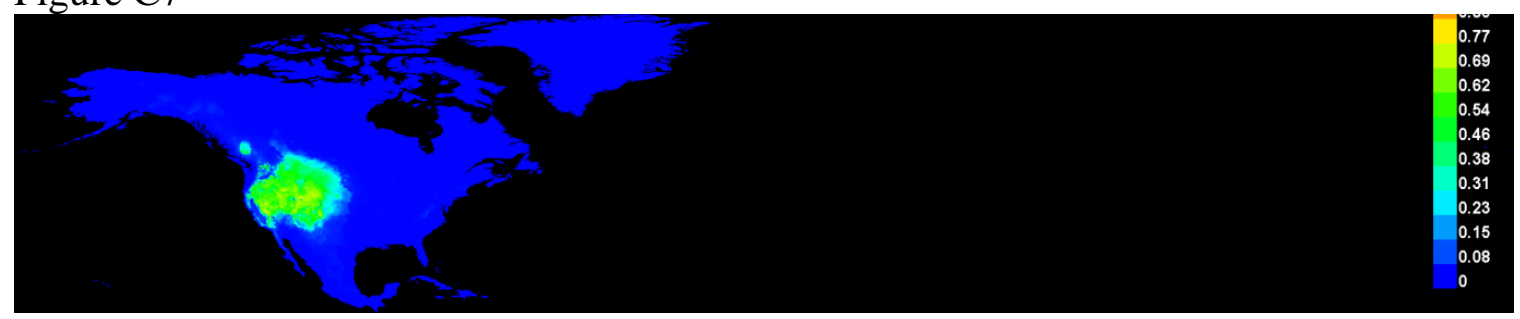

Figure C8

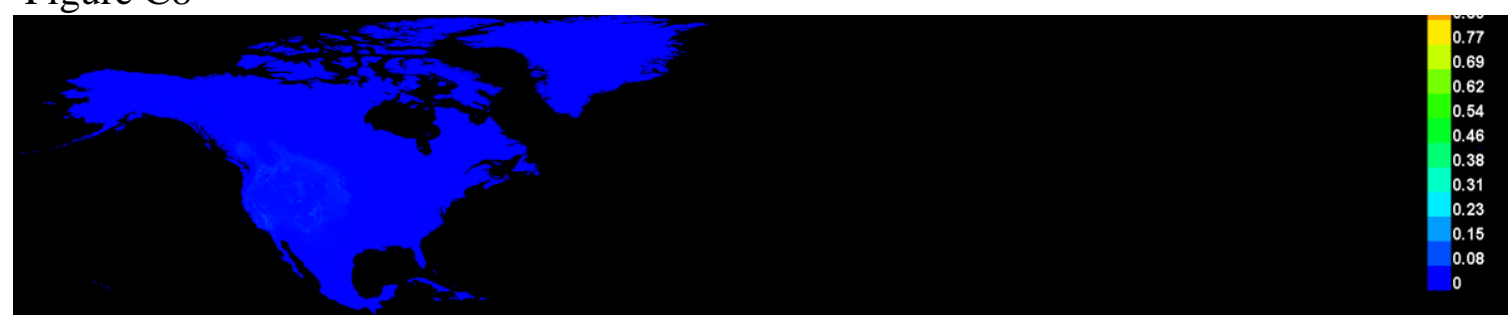


Sylvilagus nuttallii nuttallii:

Figure C9

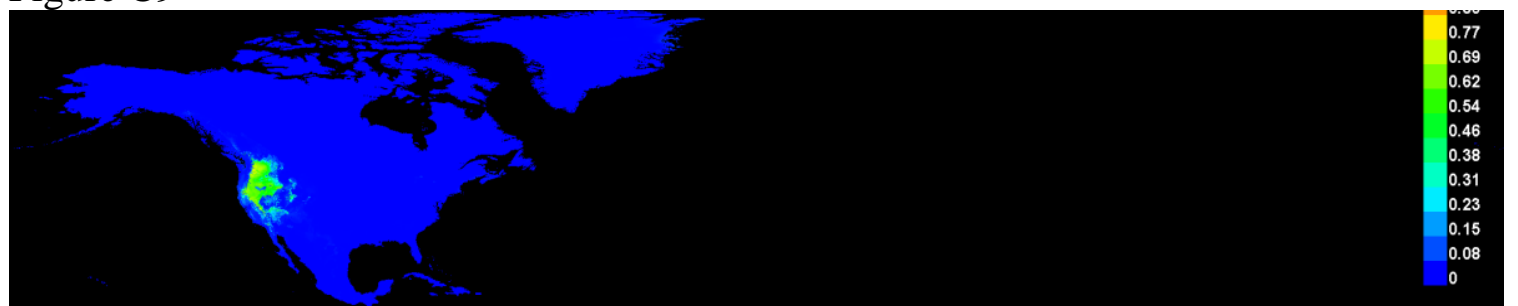

Figure C10

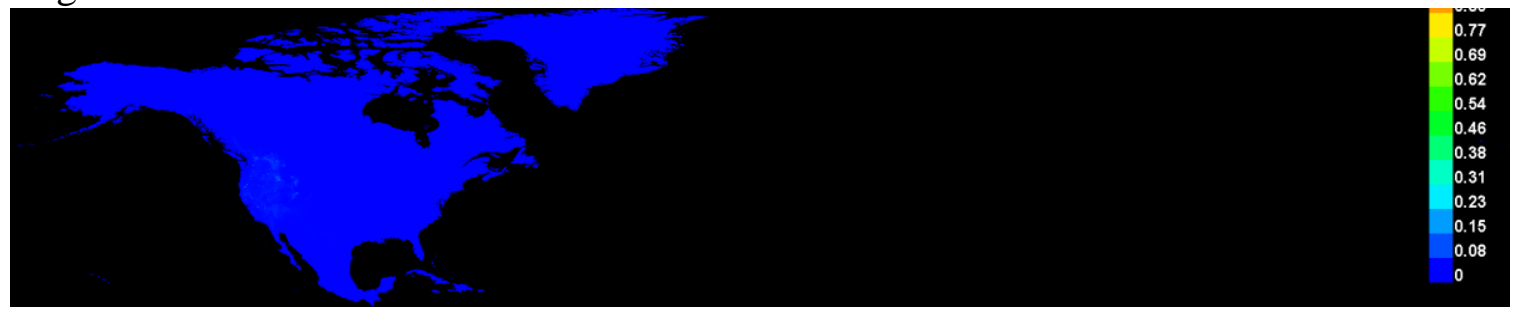

Sylvilagus nuttallii pinetis:

Figure C11

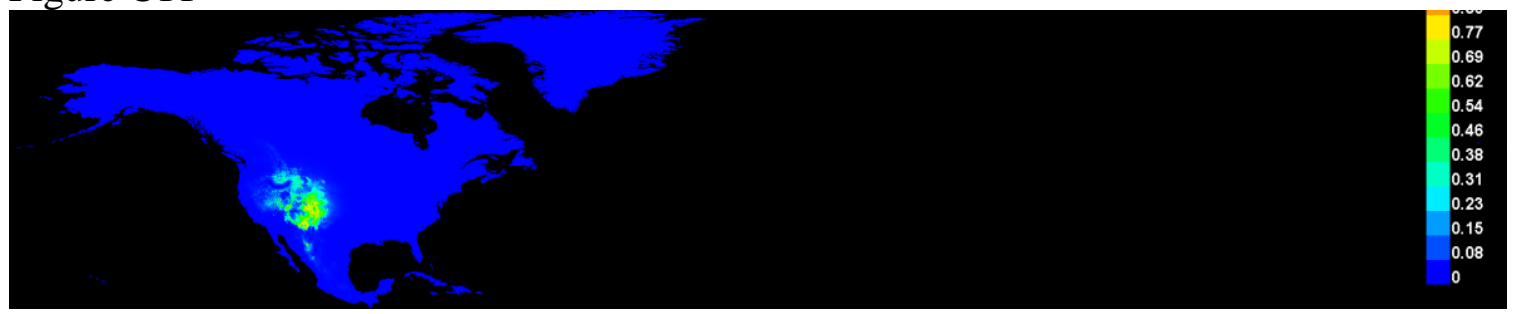

Figure C12

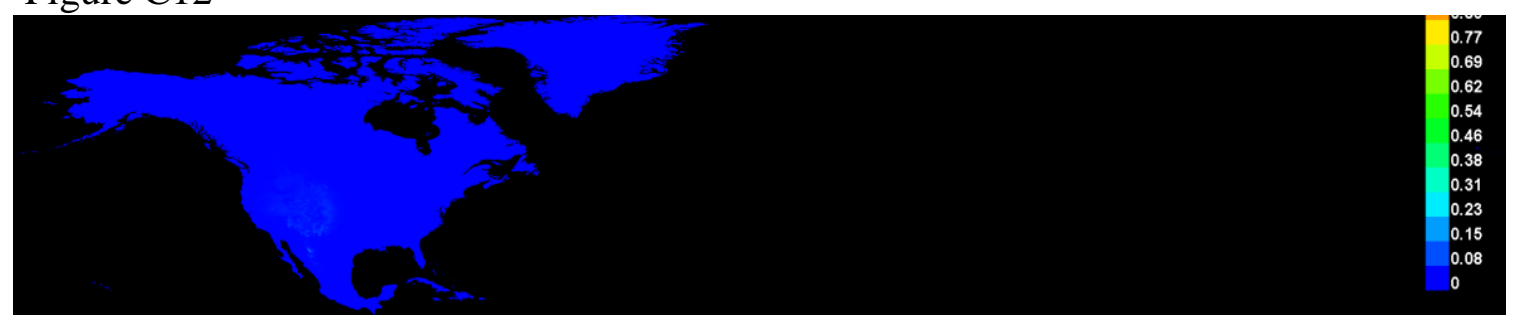

The following pictures show the point-wise mean and standard deviation of the 10 models applied to the environmental layers in ASCII. Other available summary grids are $\underline{\min }, \underline{\max }$ and median. 
Sylvilagus nuttallii grangeri

Figure C13

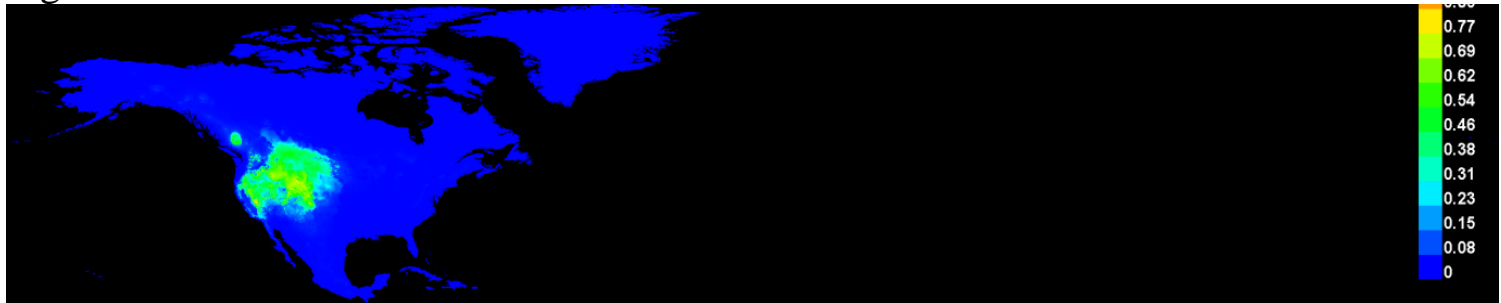

Figure C14

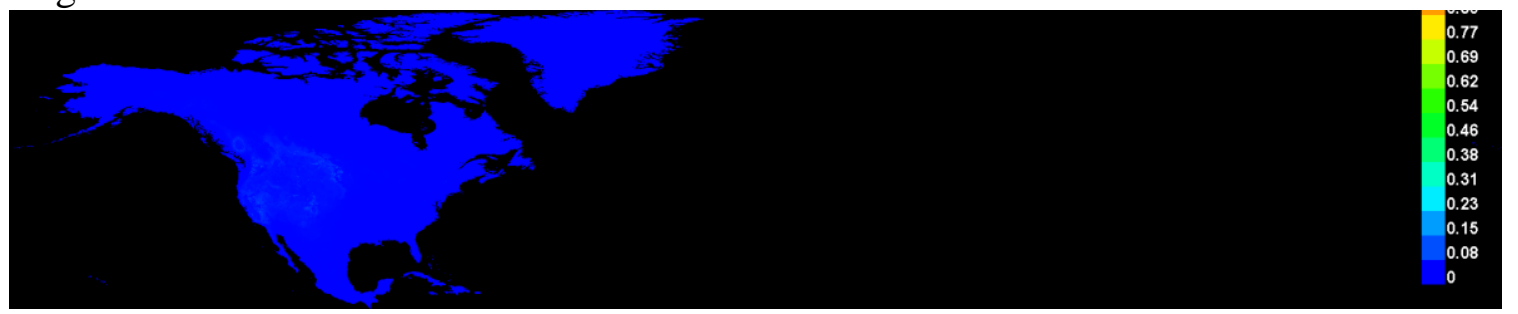

Sylvilagus nuttallii nuttallii:

Figure C15

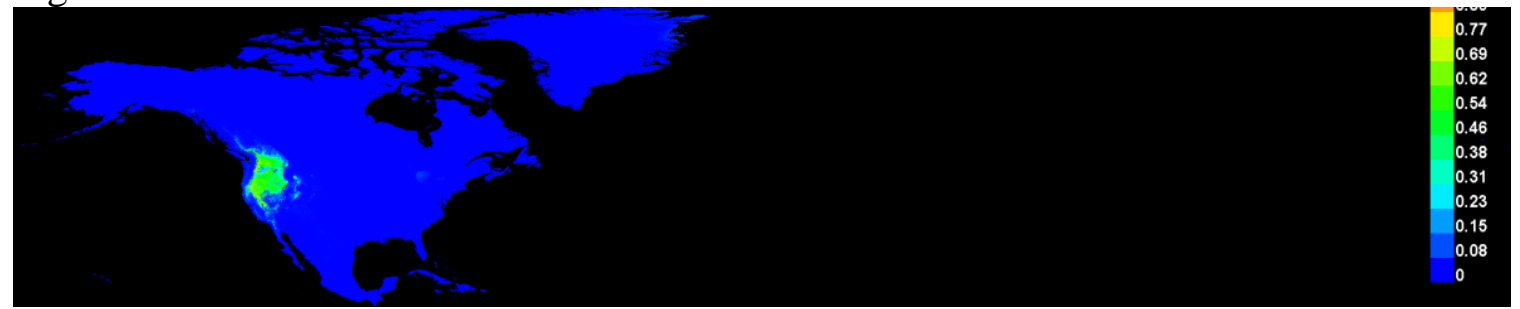

Figure C16

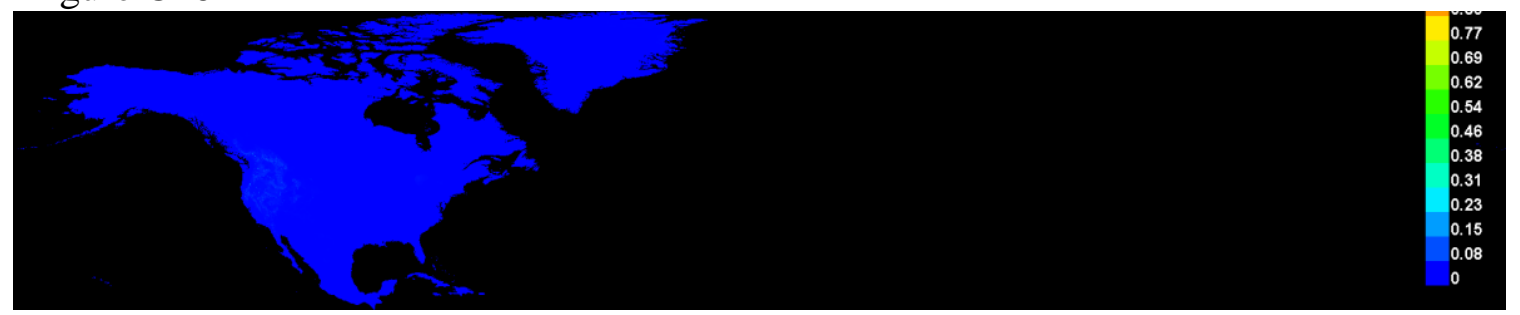


Sylvilagus nuttallii pinetis

Figure C17

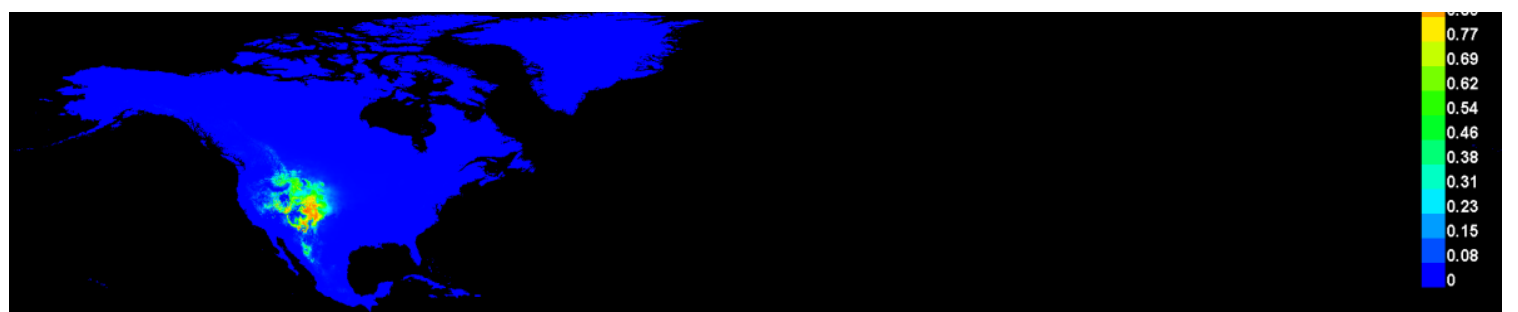

Figure C18

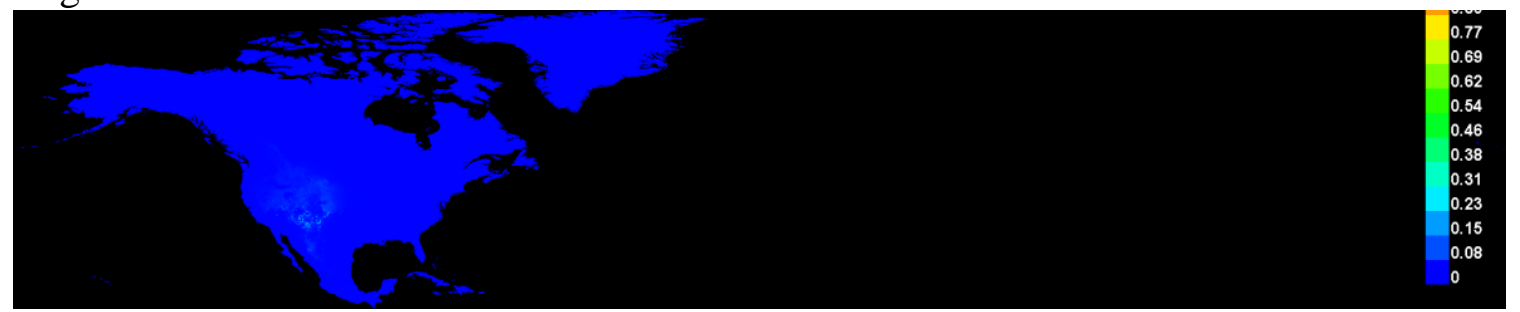




\section{Response curves}

These curves show how each environmental variable affects the Maxent prediction. The curves show how the logistic prediction changes as each environmental variable is varied, keeping all other environmental variables at their average sample value. Click on a response curve to see a larger version. Note that the curves can be hard to interpret if you have strongly correlated variables, as the model may depend on the correlations in ways that are not evident in the curves. In other words, the curves show the marginal effect of changing exactly one variable, whereas the model may take advantage of sets of variables changing together. The curves show the mean response of the 10 replicate Maxent runs (red) and and the mean $+/$ - one standard deviation (blue, two shades for categorical variables).

Sylvilagus nuttallii grangeri

Figure C19
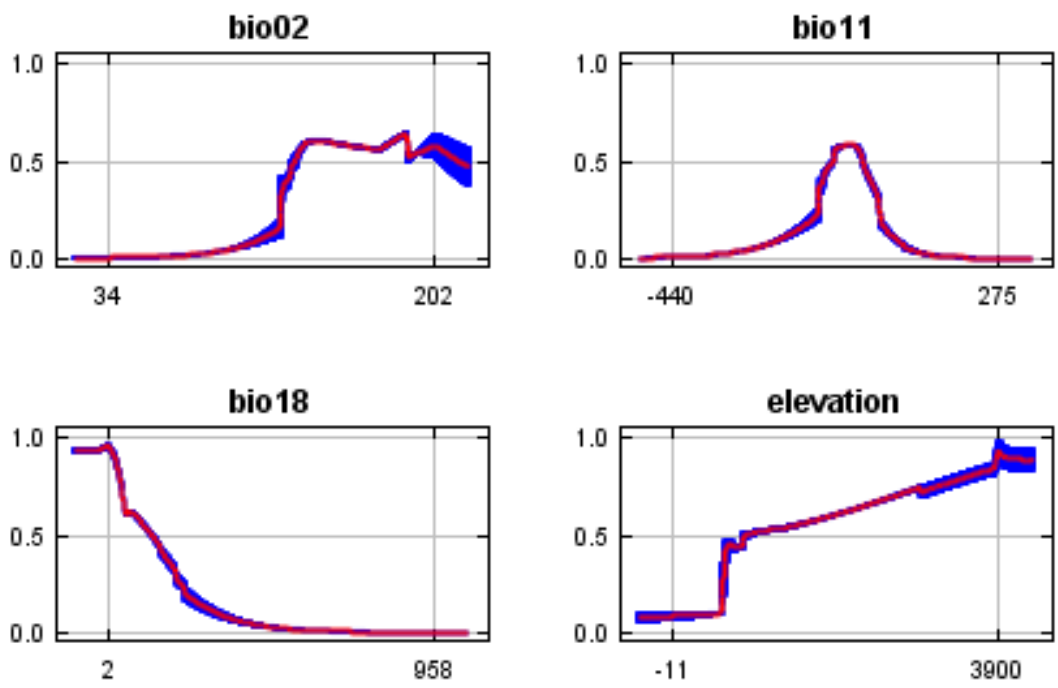
Sylvilagus nuttallii nuttallii

Figure C20
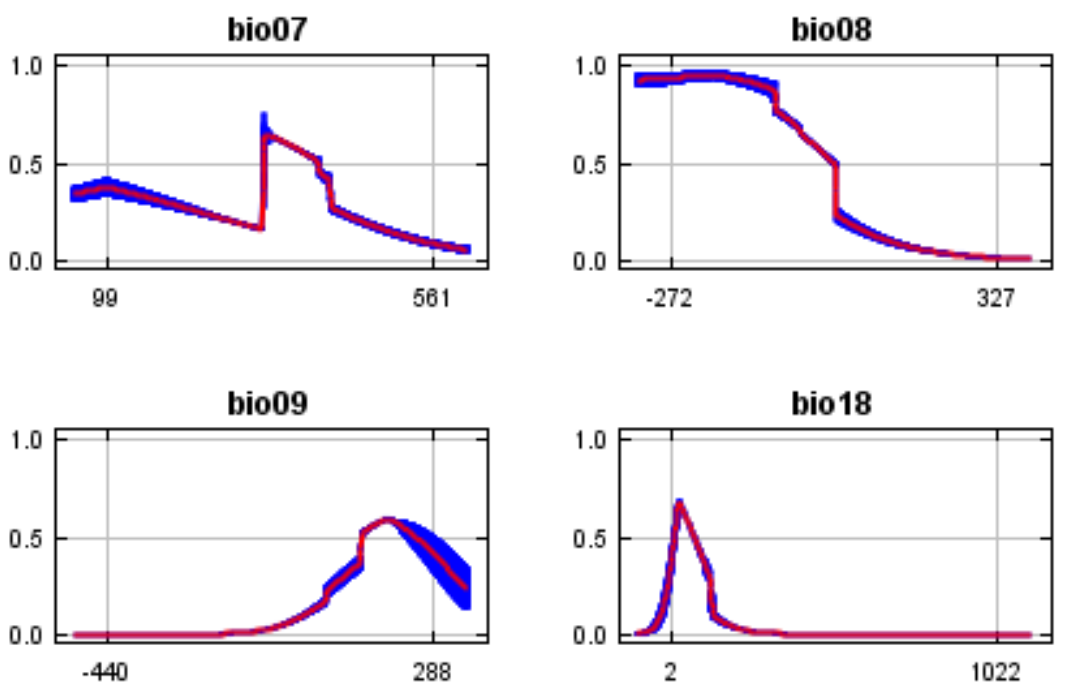

Sylvilagus nuttallii pinetis

Figure C21
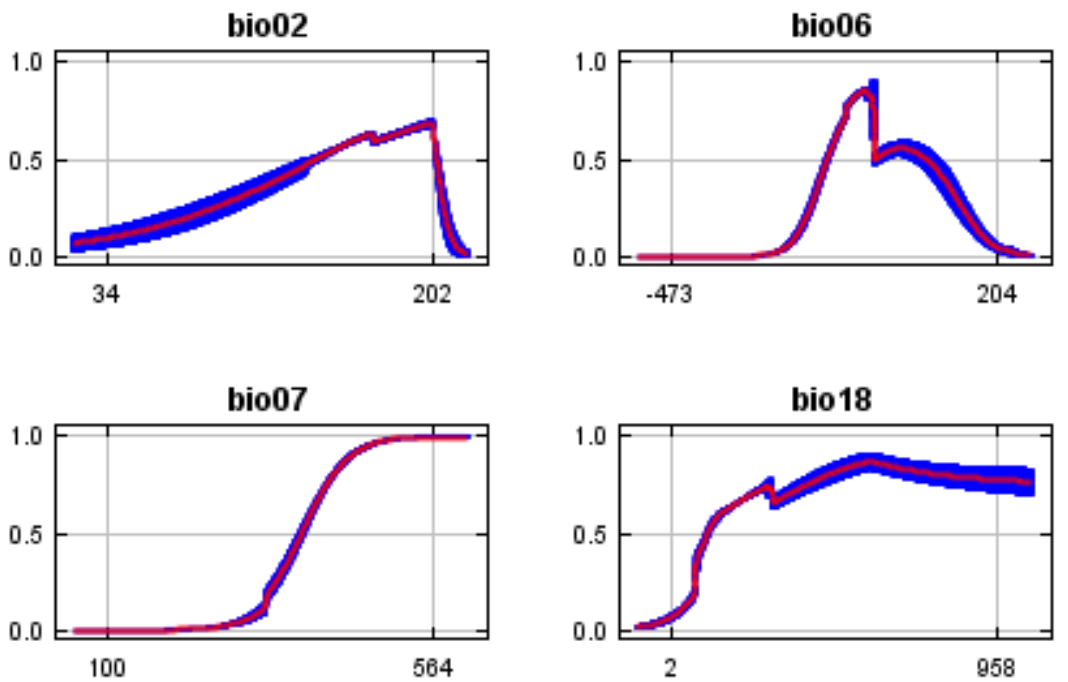


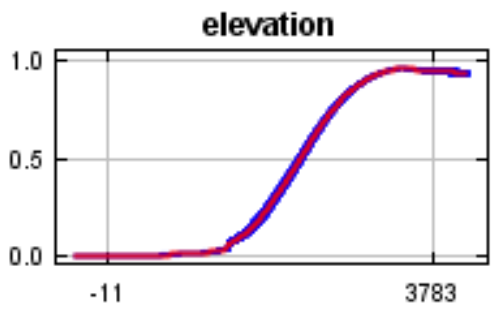

In contrast to the above marginal response curves, each of the following curves represents a different model, namely, a Maxent model created using only the corresponding variable. These plots reflect the dependence of predicted suitability both on the selected variable and on dependencies induced by correlations between the selected variable and other variables. They may be easier to interpret if there are strong correlations between variables.

Sylvilagus nuttallii grangeri

Figure C22
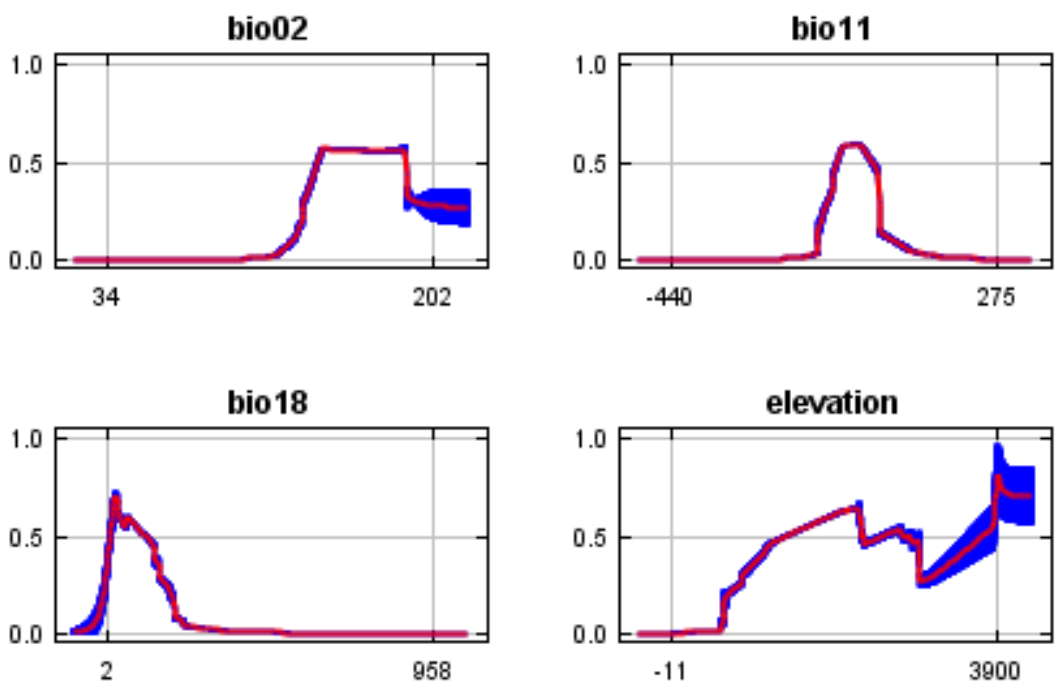
Sylvilagus nuttallii nuttallii

Figure C23
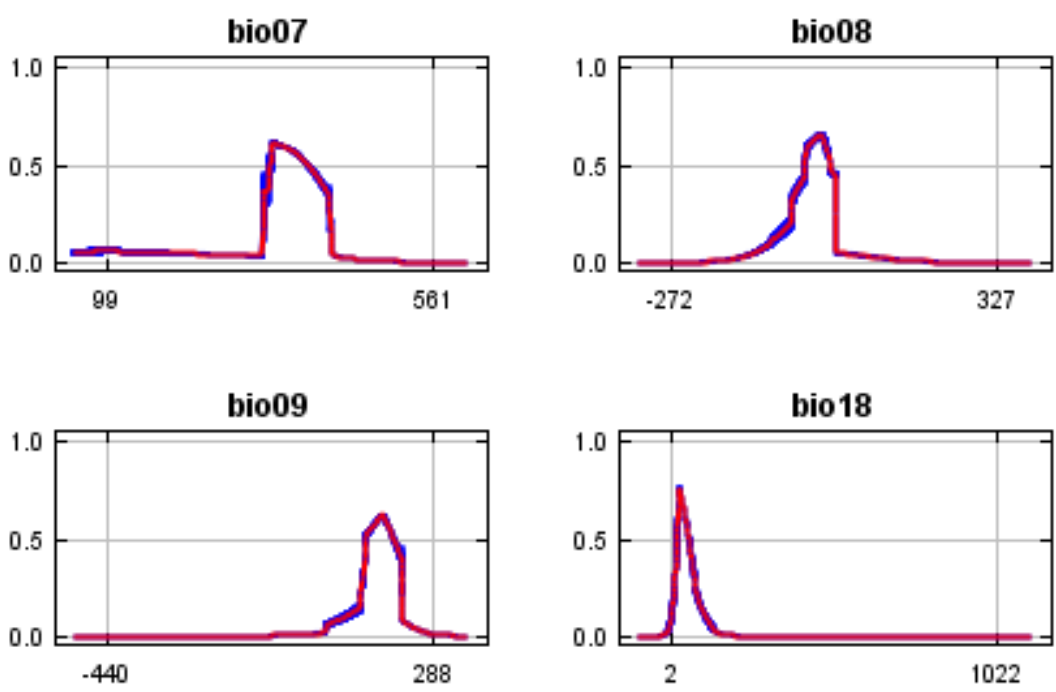

Sylvilagus nuttallii pinetis

Figure C24
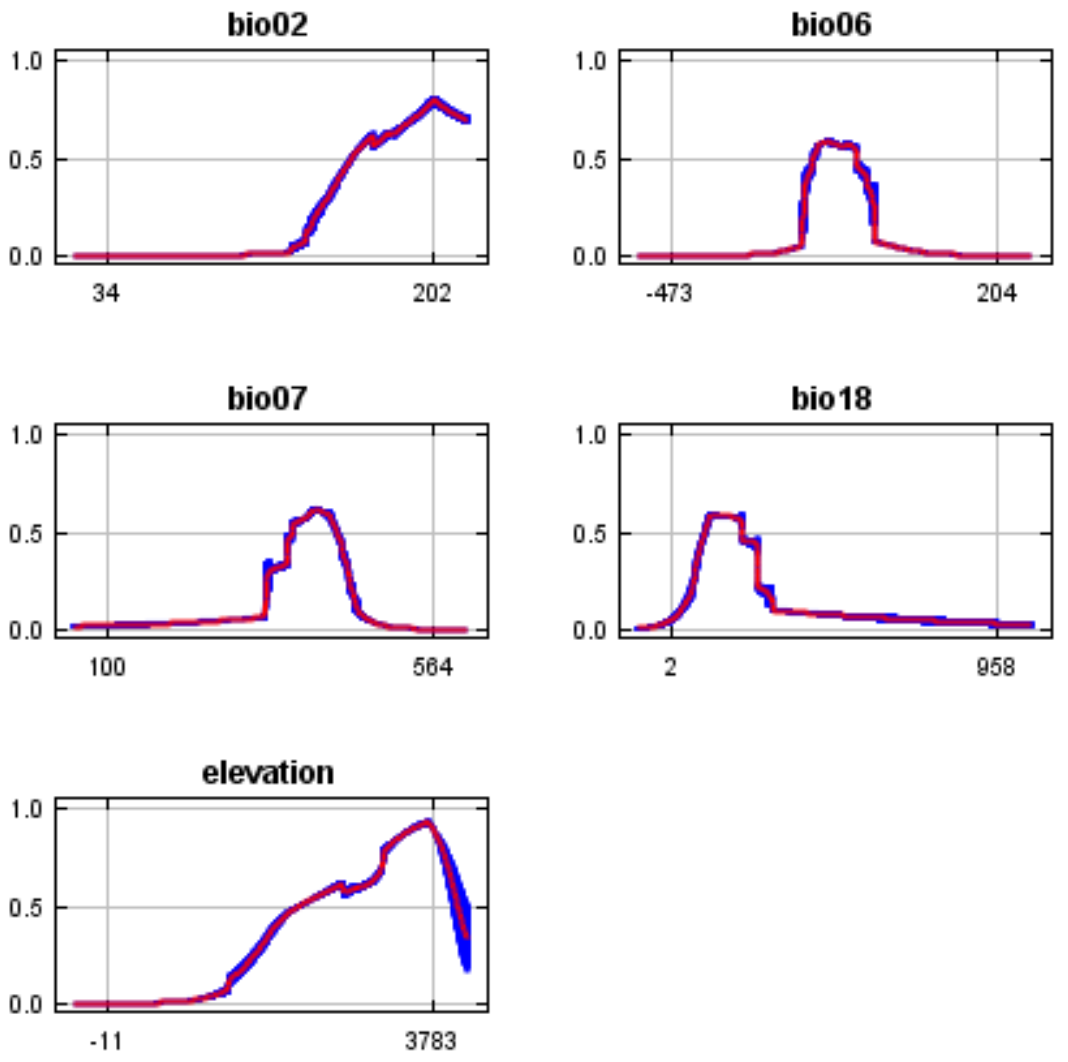
Analysis of variable contributions

The following table gives estimates of relative contributions of the environmental variables to the Maxent model. To determine the first estimate, in each iteration of the training algorithm, the increase in regularized gain is added to the contribution of the corresponding variable, or subtracted from it if the change to the absolute value of lambda is negative. For the second estimate, for each environmental variable in turn, the values of that variable on training presence and background data are randomly permuted. The model is reevaluated on the permuted data, and the resulting drop in training AUC is shown in the table, normalized to percentages. As with the variable jackknife, variable contributions should be interpreted with caution when the predictor variables are correlated. Values shown are averages over replicate runs.

Sylvilagus nuttallii grangeri

Table C1

Variable Percent contribution Permutation importance

$\begin{array}{ccc}\text { bio02 } & 53.7 & 43 \\ \text { bio11 } & 20.5 & 30.8 \\ \text { elevation } & 15.1 & 13.6 \\ \text { bio18 } & 10.8 & 12.6\end{array}$

Sylvilagus nuttallii nuttallii

Table C2

Variable Percent contribution Permutation importance

$\begin{array}{lcc}\text { bio09 } & 53.2 & 71 \\ \text { bio08 } & 25 & 9.2 \\ \text { bio18 } & 18.5 & 18.2 \\ \text { bio07 } & 3.3 & 1.7\end{array}$

Sylvilagus nuttallii pinetis

Table C3

Variable Percent contribution Permutation importance

$\begin{array}{ccc}\text { bio02 } & 45.9 & 1 \\ \text { elevation } & 40.1 & 48.8 \\ \text { bio06 } & 7.8 & 40.4 \\ \text { bio07 } & 3.4 & 7.4 \\ \text { bio18 } & 2.8 & 2.5\end{array}$


The following picture shows the results of the jackknife test of variable importance. The environmental variable with highest gain when used in isolation is bio02, which therefore appears to have the most useful information by itself. The environmental variable that decreases the gain the most when it is omitted is bio11, which therefore appears to have the most information that isn't present in the other variables. Values shown are averages over replicate runs.

Figure $\mathrm{C} 25$

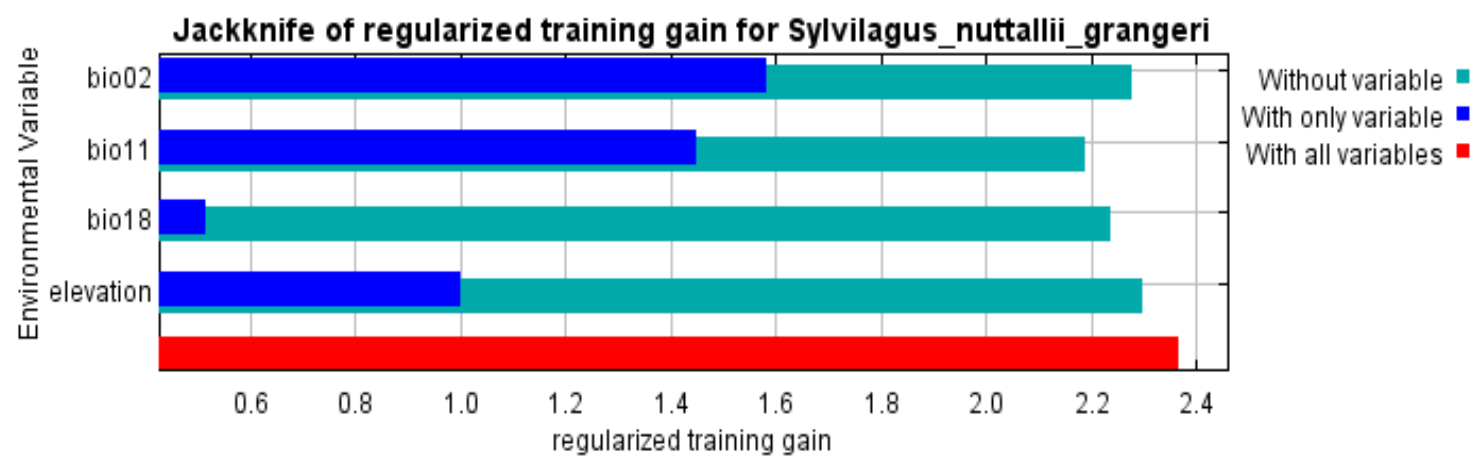

Figure $\mathrm{C} 26$

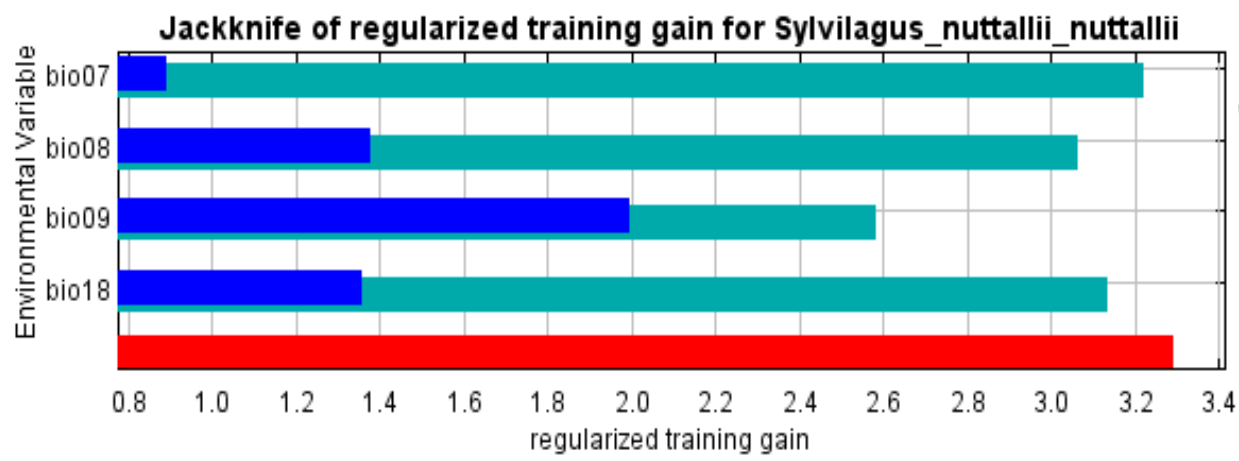

Without variable With only variable $\mathbf{~}$ With all variables -

Figure $\mathrm{C} 27$

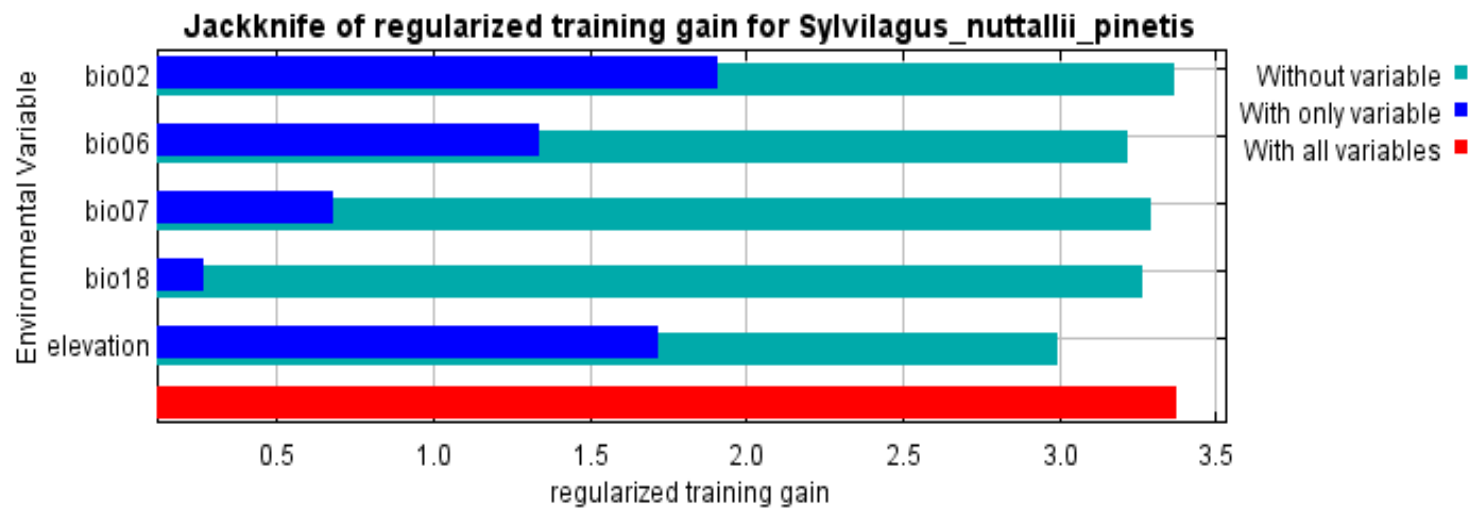

The next picture shows the same jackknife test, using test gain instead of training gain. 
Note that conclusions about which variables are most important can change, now that we're looking at test data.

Figure C28

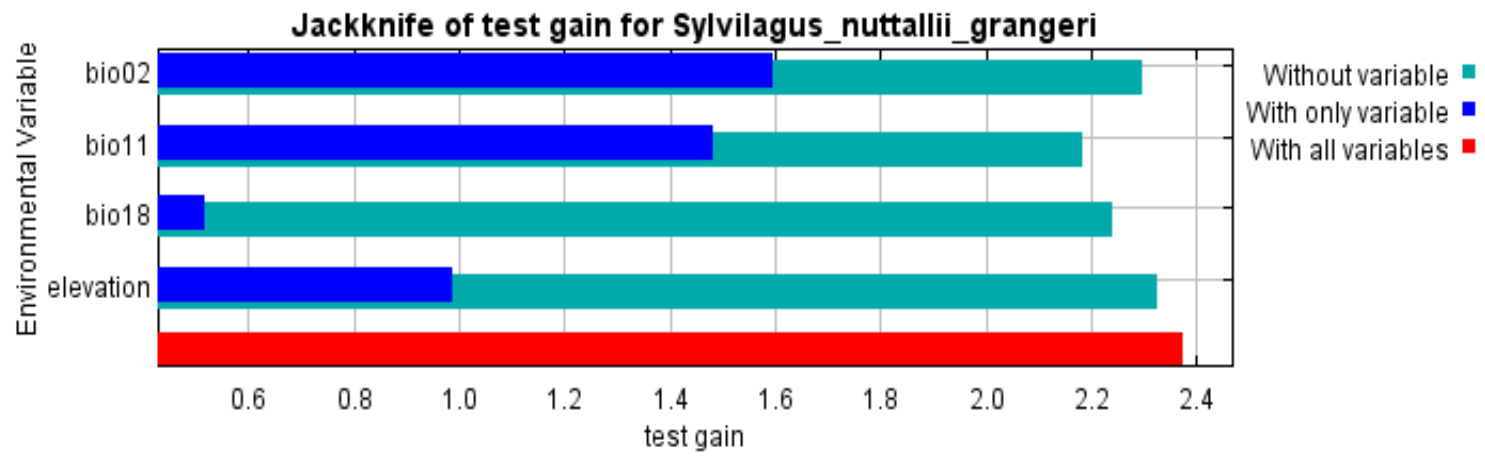

Figure C29

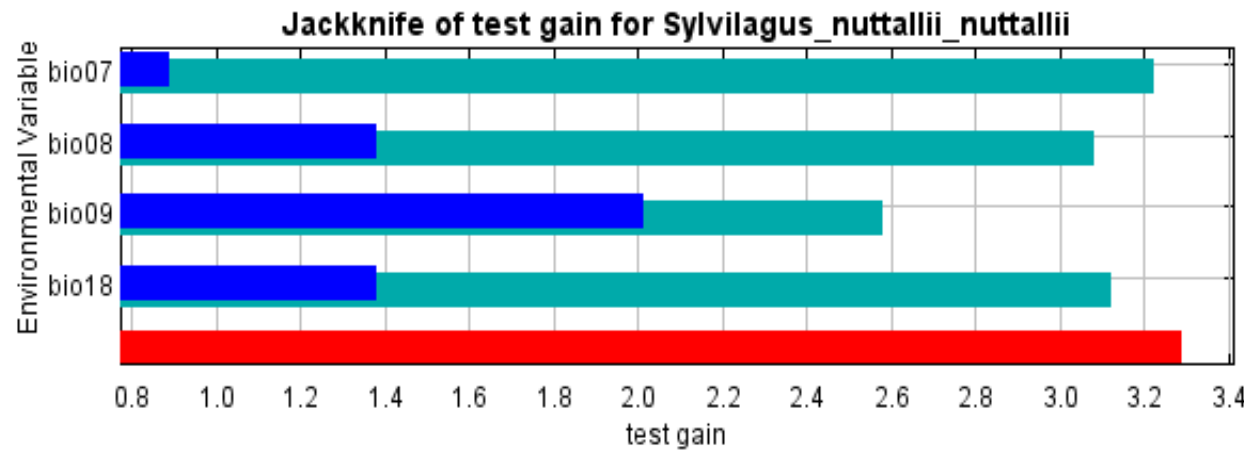

Without variable With only variable With all variables -

Figure $\mathrm{C} 30$

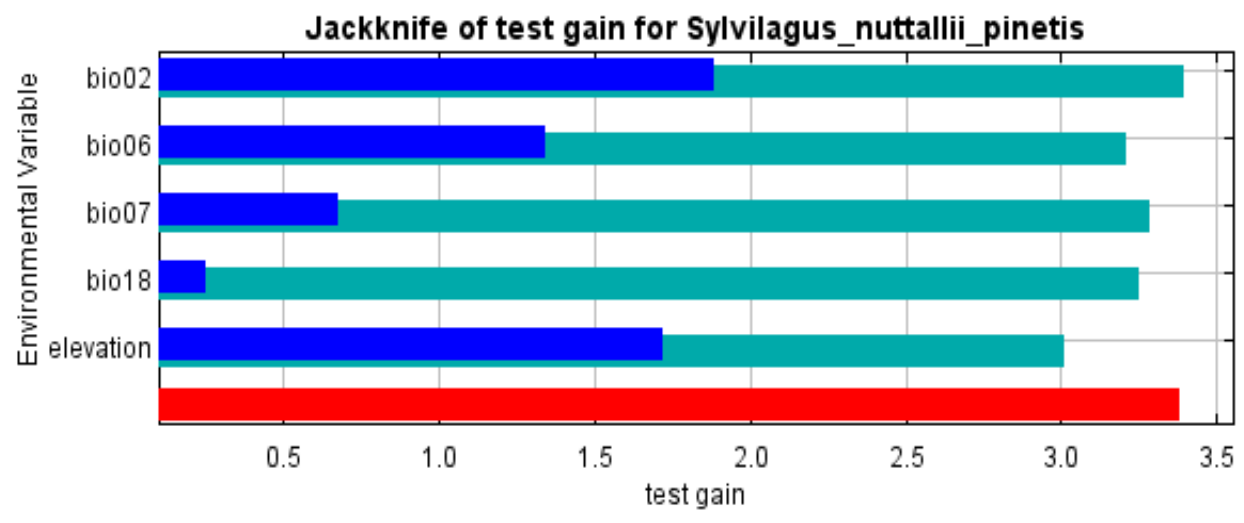

Without variable With only variable With all variables 
Lastly, we have the same jackknife test, using AUC on test data. Figure C31

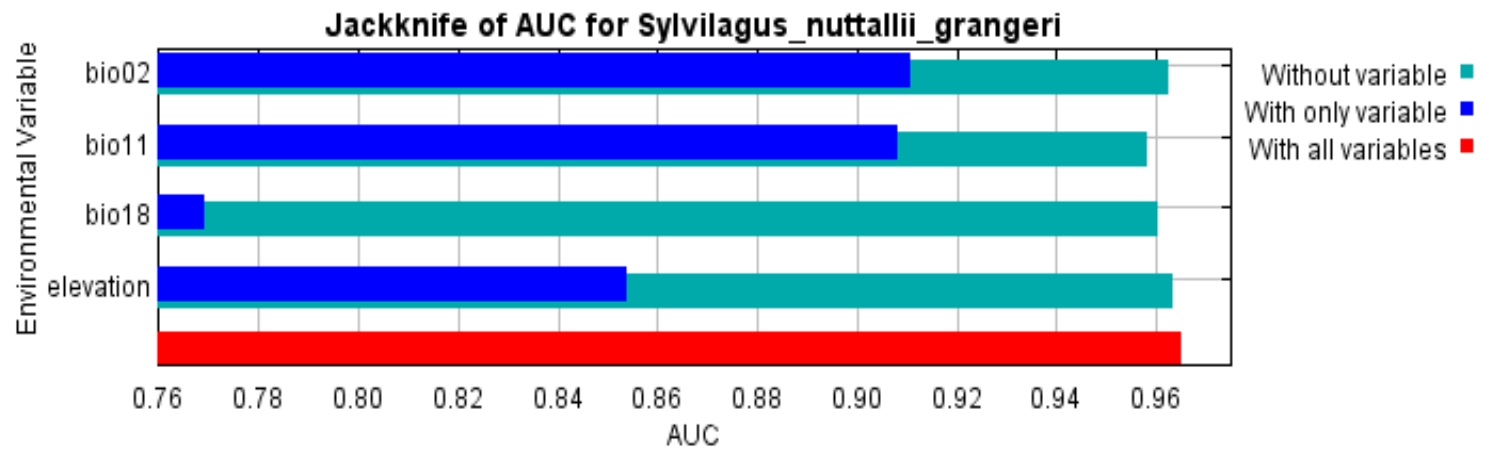

Figure C32

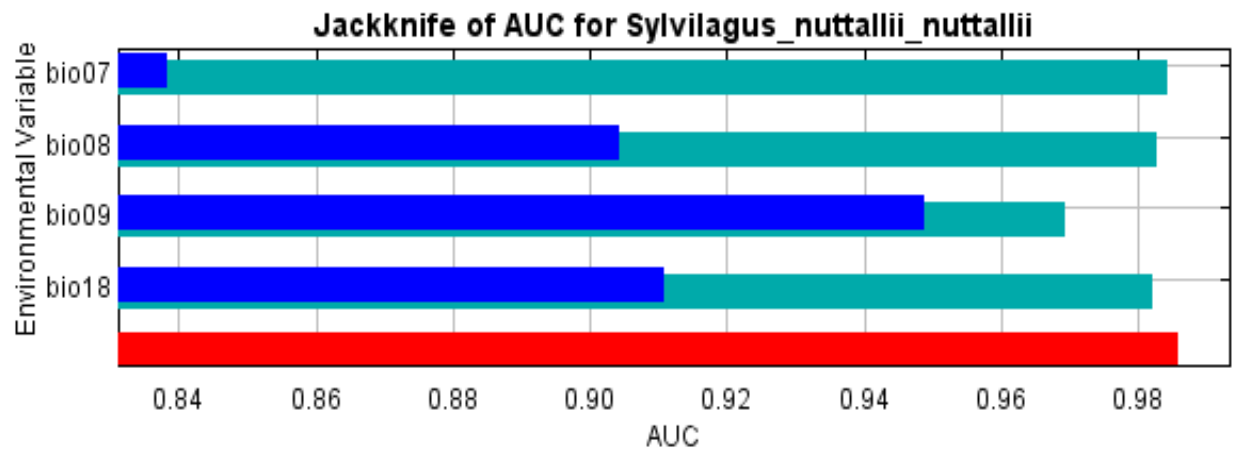

Without variable With only variable With all variables

Figure C33

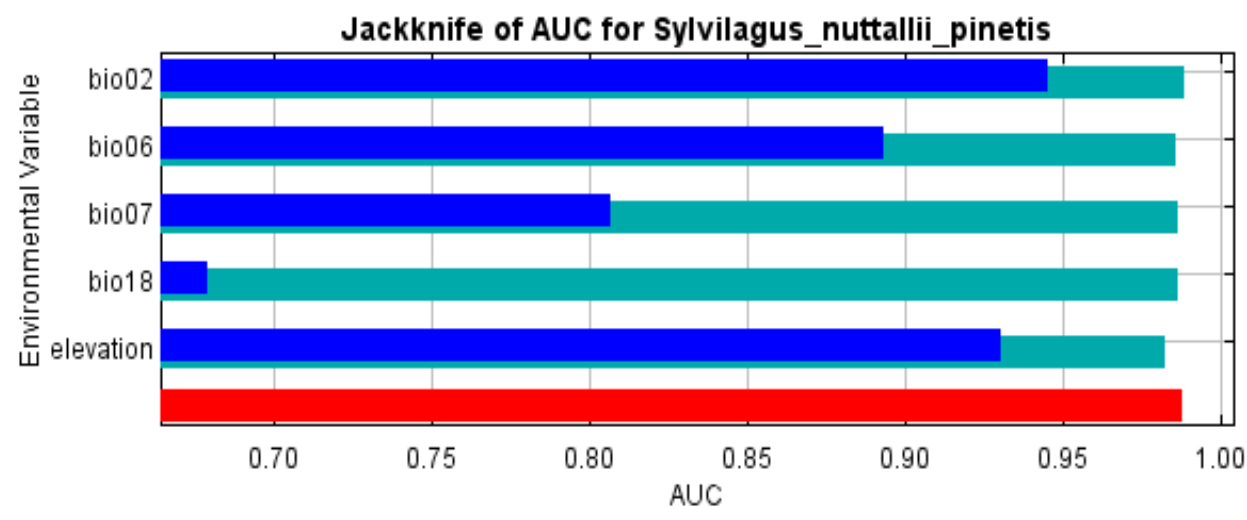

Without variable With only variable With all variables 


\section{APPENDIX D}

Representative Concentration Pathway 6.0 model results

Model output results and figures for Representative Concentration Pathway 6.0 (RCP 6.0) from the IPCC 5th Assessment Report (AR5). RCP 6.0 projects a $2.2^{\circ} \mathrm{C}$ mean increase in temperature by 2100 (1.4 - 3.1 likely range).

\section{Analysis of omission/commission}

The following picture shows the test omission rate and predicted area as a function of the cumulative threshold, averaged over the replicate runs. The omission rate should be close to the predicted omission, because of the definition of the cumulative threshold.

Figure D1

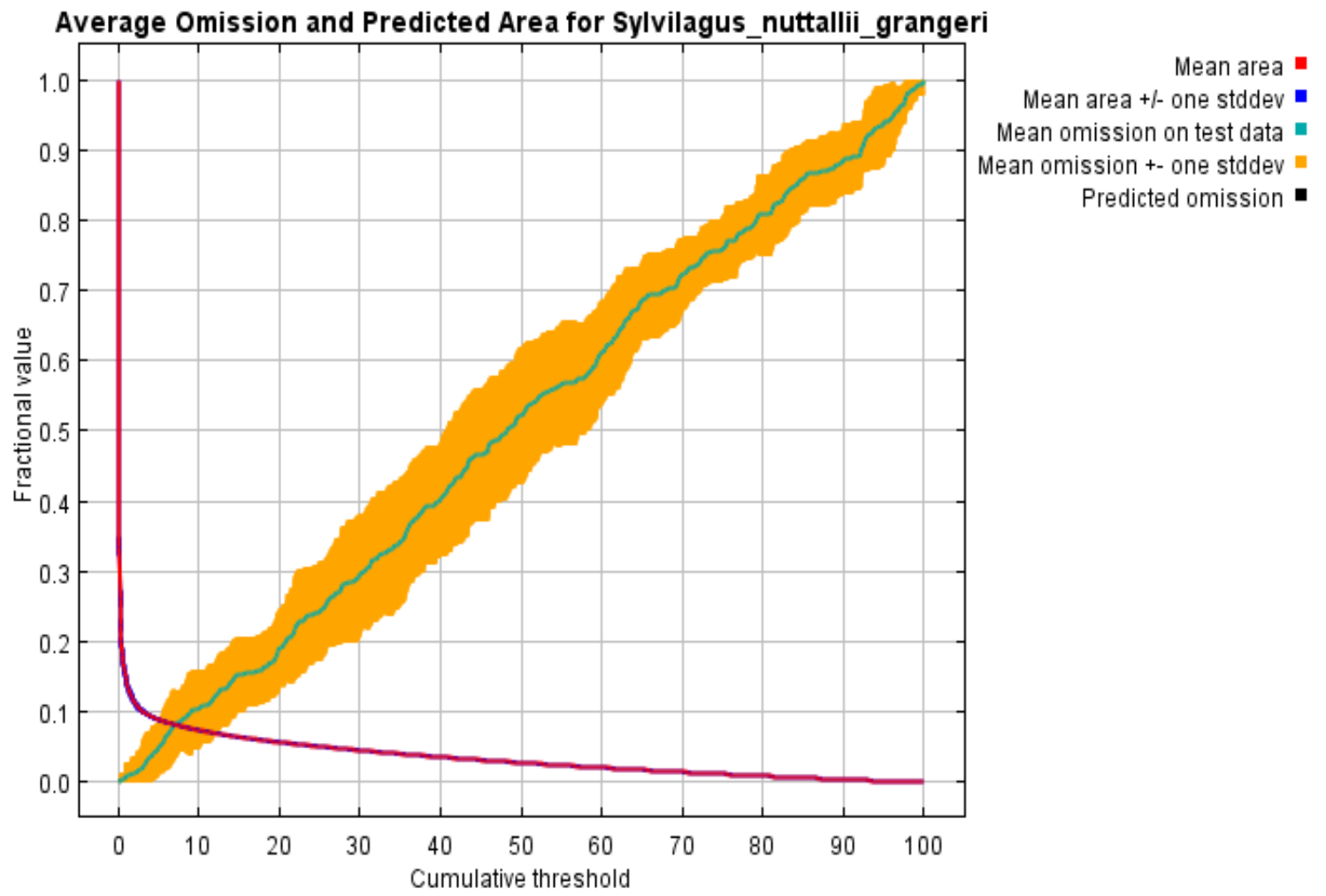


Figure D2

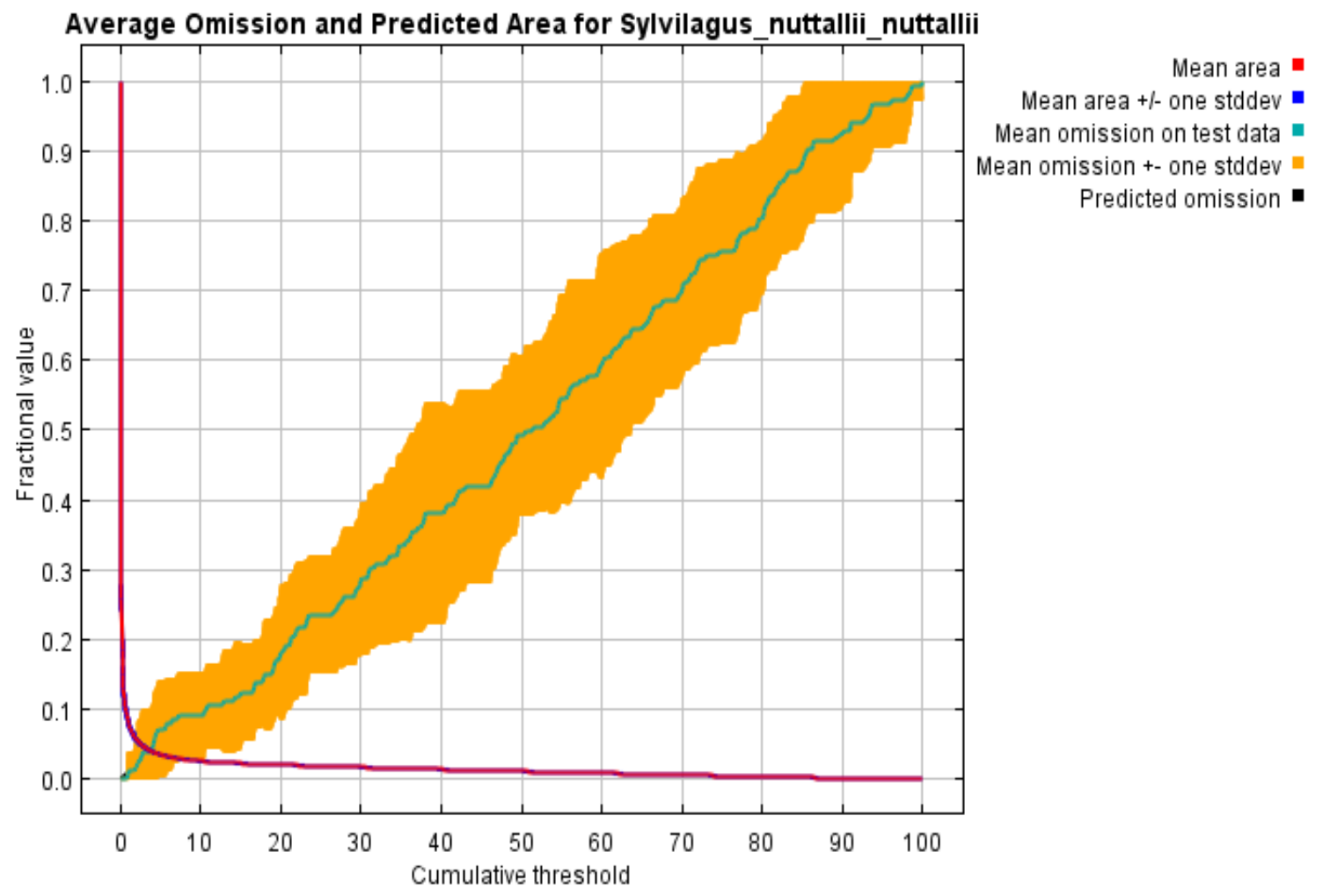


Figure D3

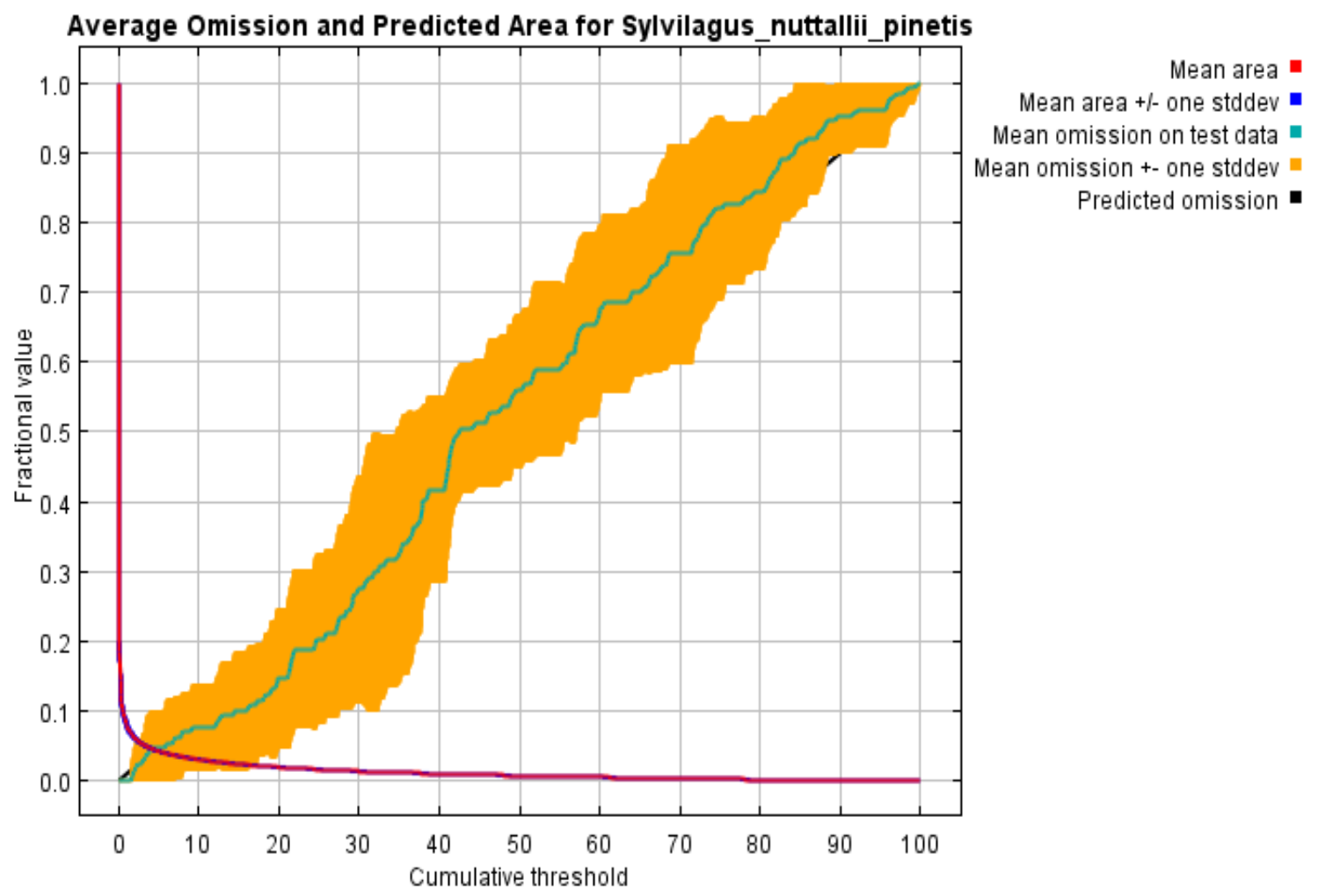

The next picture is the receiver operating characteristic (ROC) curve for the same data, again averaged over the replicate runs. Note that the specificity is defined using predicted area, rather than true commission (see the paper by Phillips, Anderson and Schapire cited for discussion of what this means). The average test AUC for the replicate runs is 0.965 , 0.986 , and 0.988 respectively and the standard deviation is 0.005 . 
Figure D4

Average Sensitivity vs. 1 - Specificity for Sylvilagus_nuttallii_grangeri

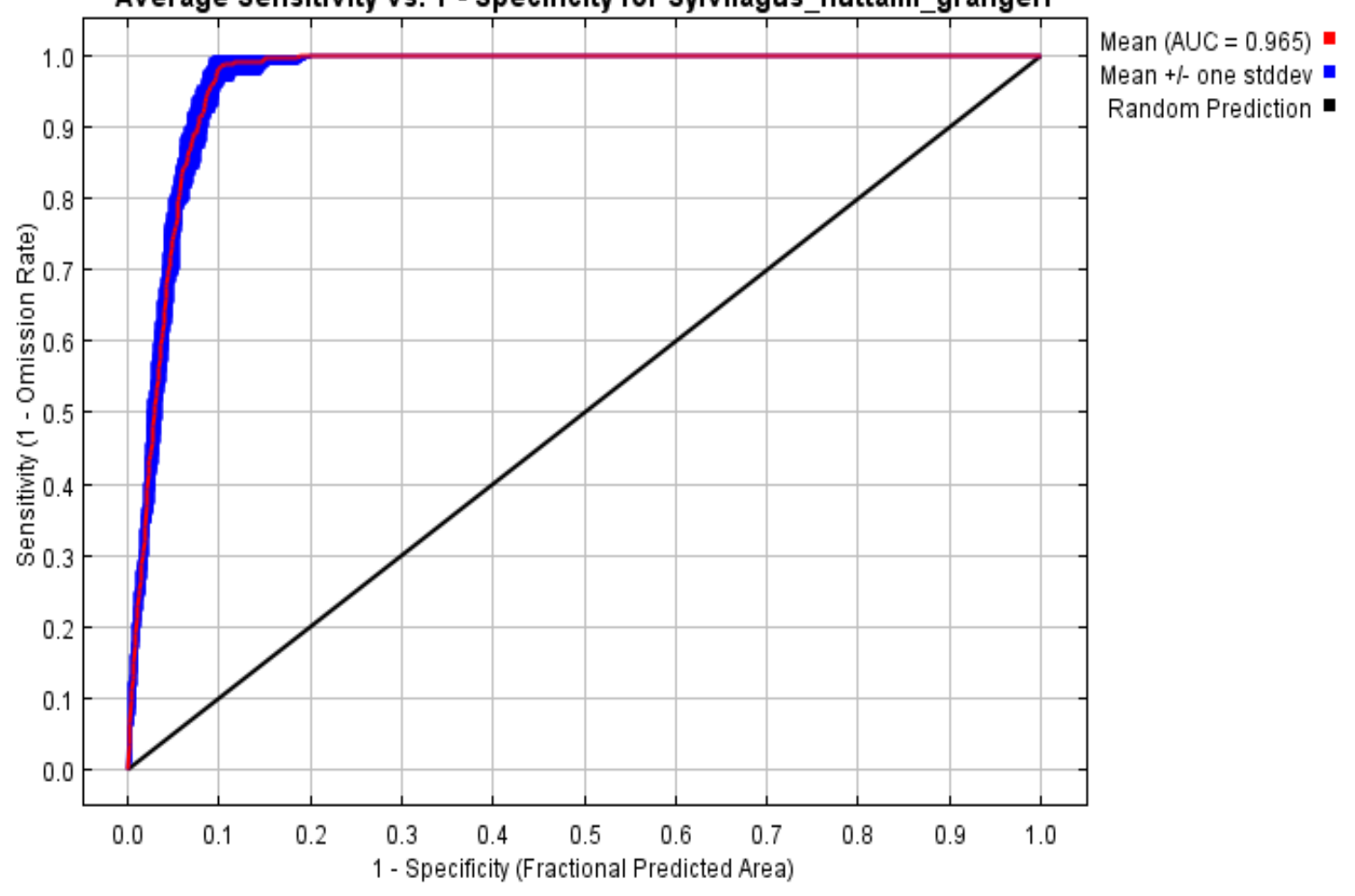


Figure D5

Average Sensitivity vs. 1 - Specificity for Sylvilagus_nuttallii_nuttallii

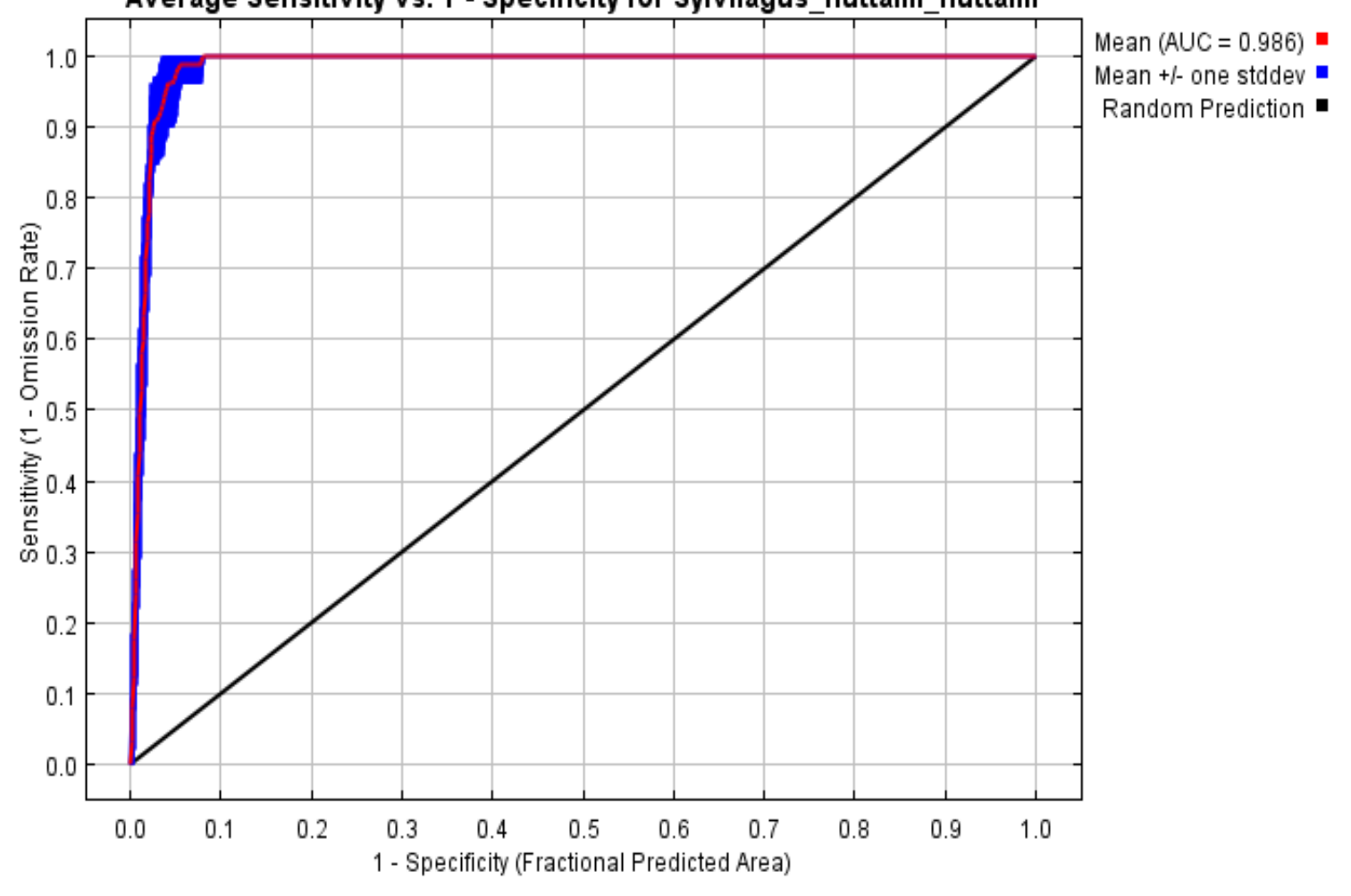


Figure D6

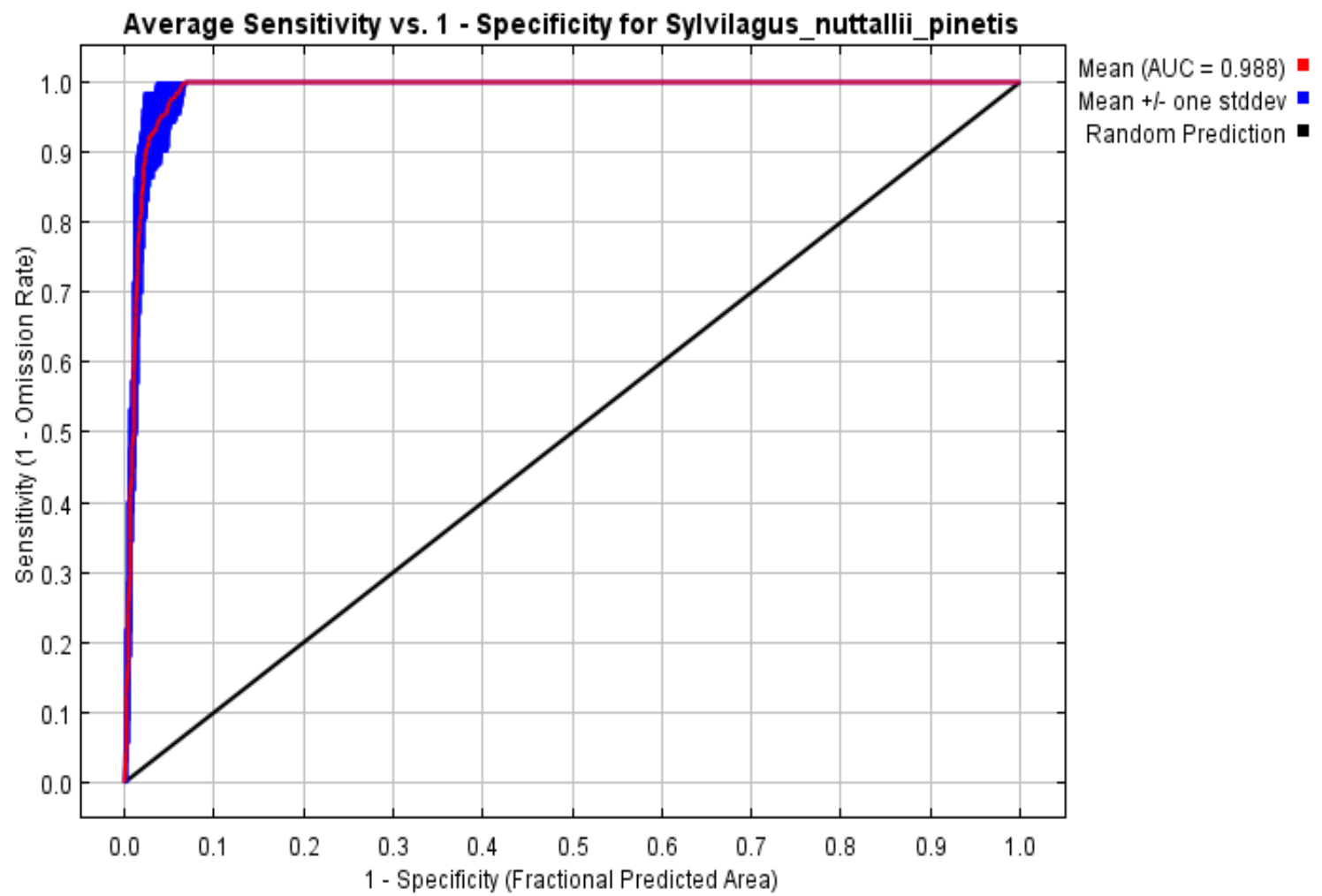

Pictures of the model

The following pictures show the point-wise mean and standard deviation of the 10 output grids. Other available summary grids are $\underline{\min }, \underline{\max }$ and $\underline{\text { median. }}$.

Sylvilagus nuttallii grangeri:

Figure D7

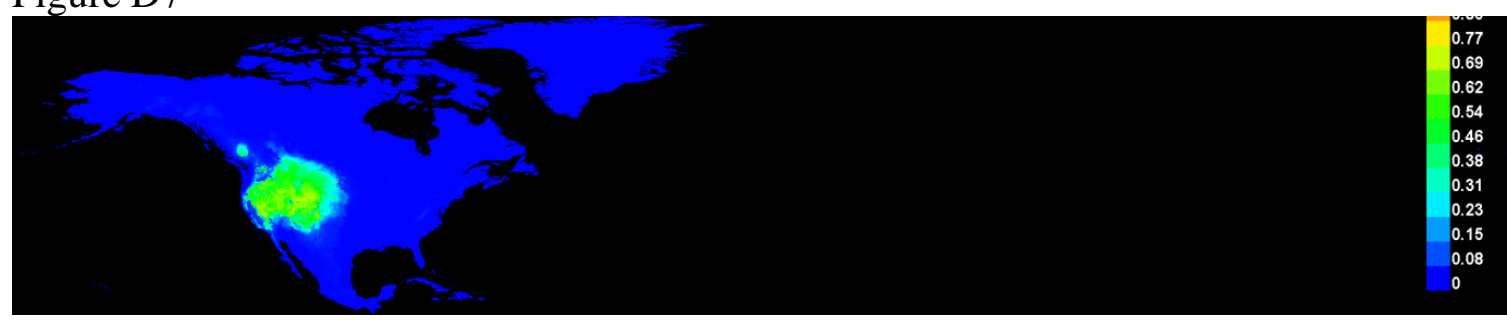

Figure D8

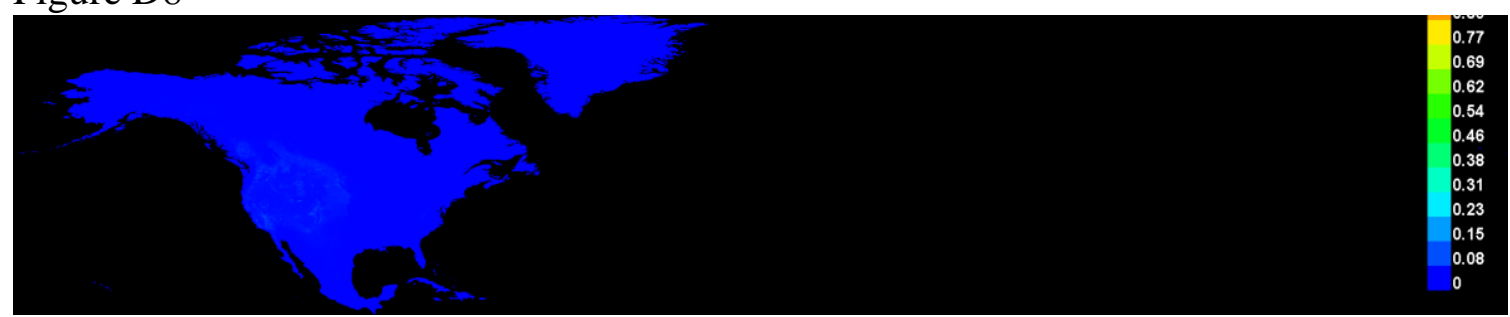


Sylvilagus nuttallii nuttallii:

Figure D9

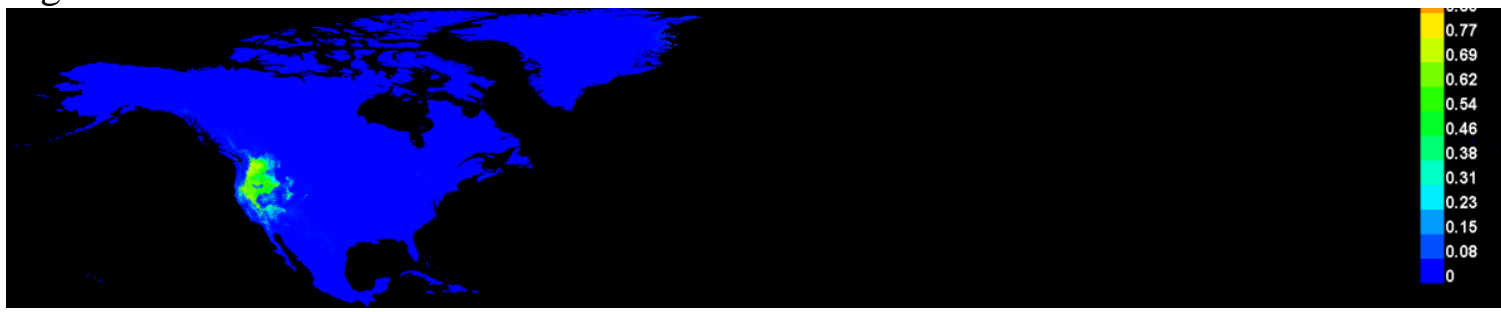

Figure D10

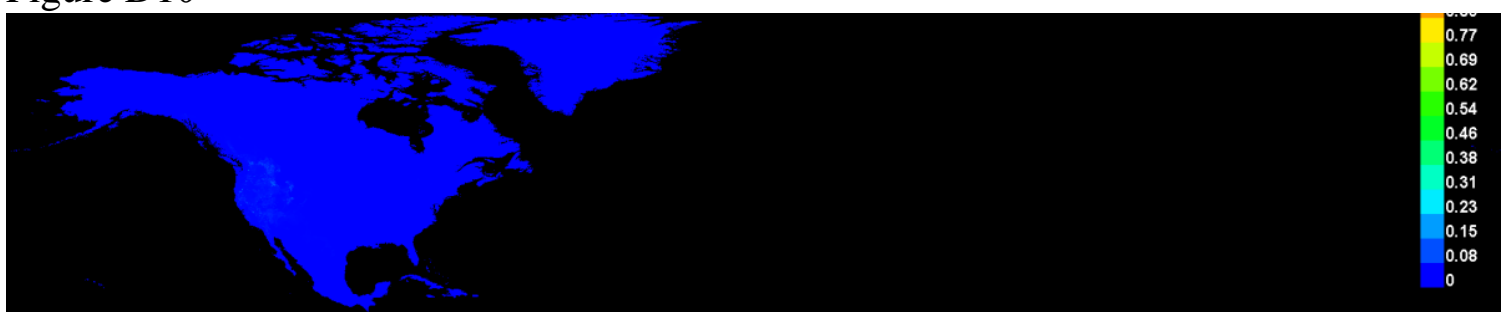

Sylvilagus nuttallii pinetis:

Figure D11

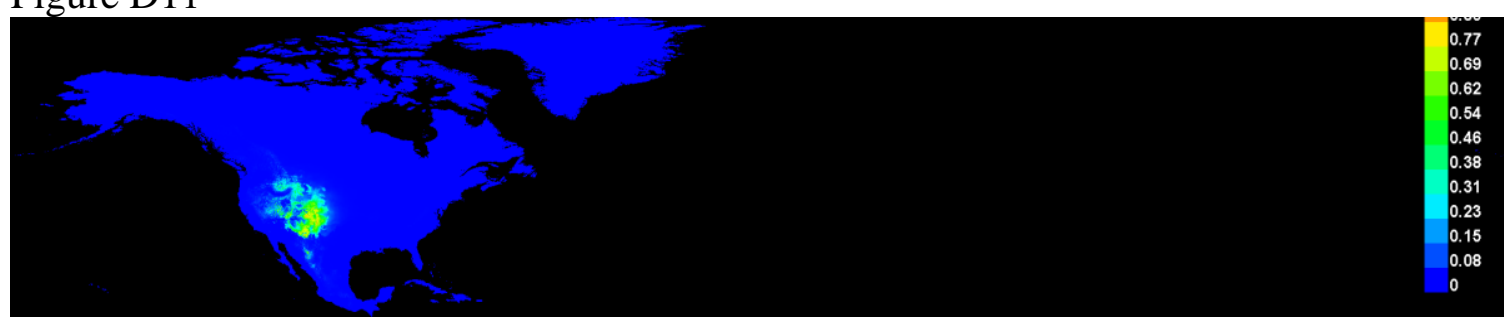

Figure D12

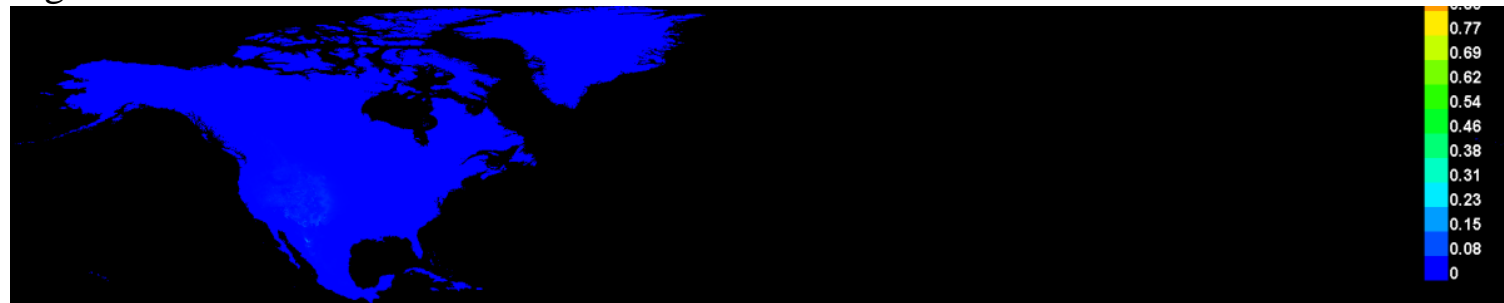

The following pictures show the point-wise mean and standard deviation of the 10 
models applied to the environmental layers in ASCII. Other available summary grids are $\underline{\min }, \underline{\max }$ and median.

Sylvilagus nuttallii grangeri

Figure D13

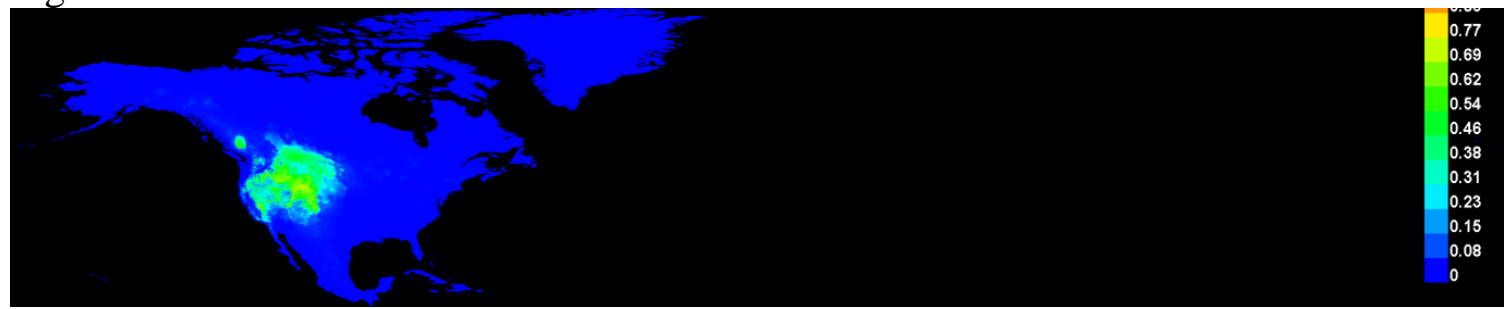

Figure D14

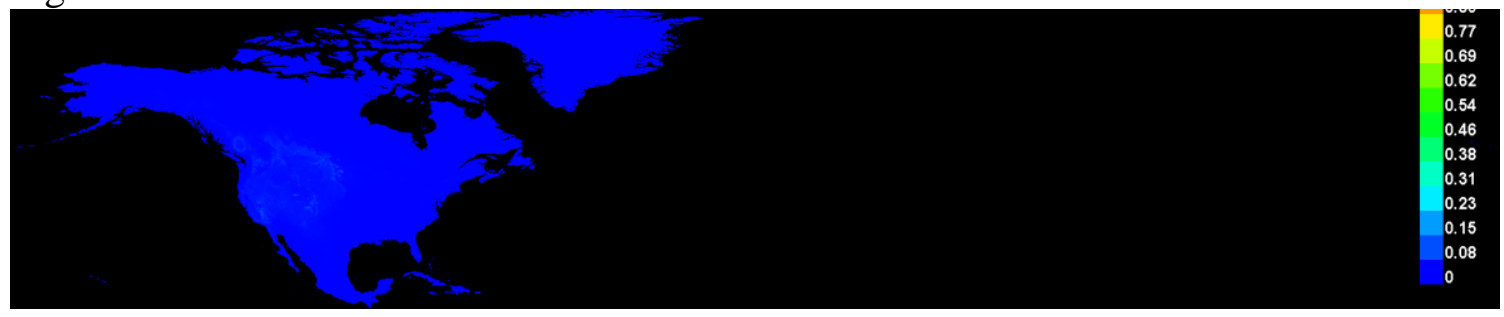

Sylvilagus nuttallii nuttallii:

Figure D15

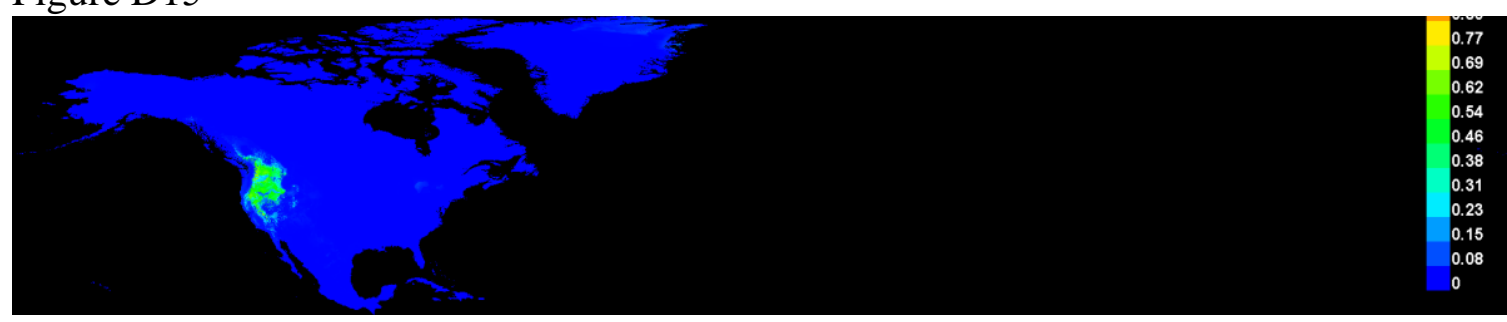

Figure D16

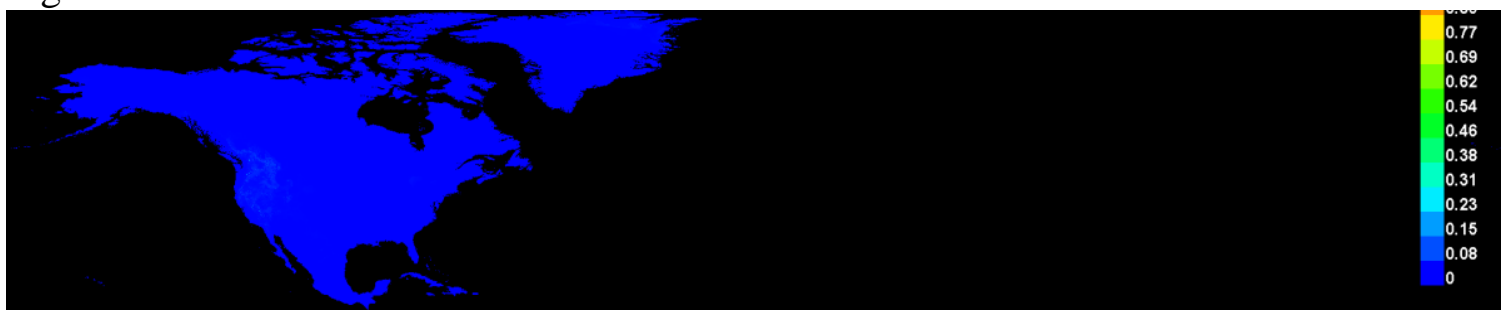


Sylvilagus nuttallii pinetis

Figure D17

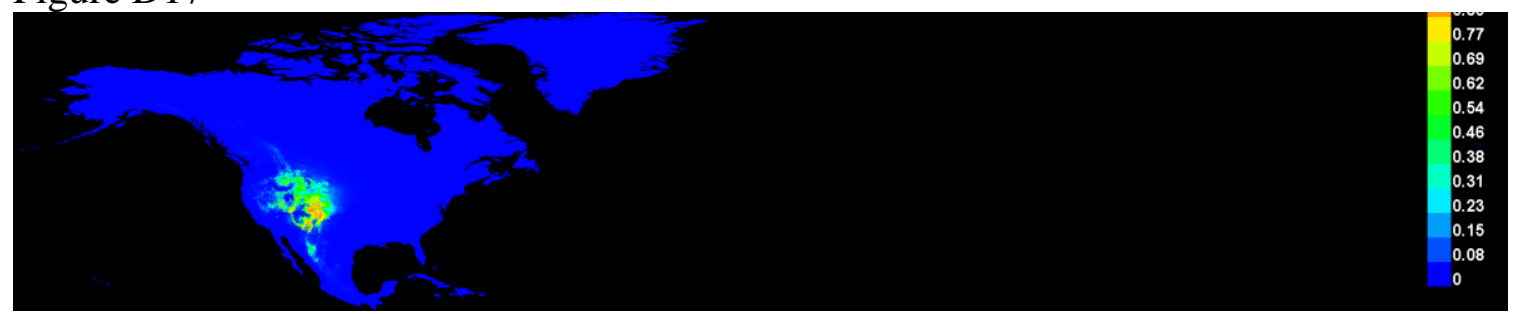

Figure D18

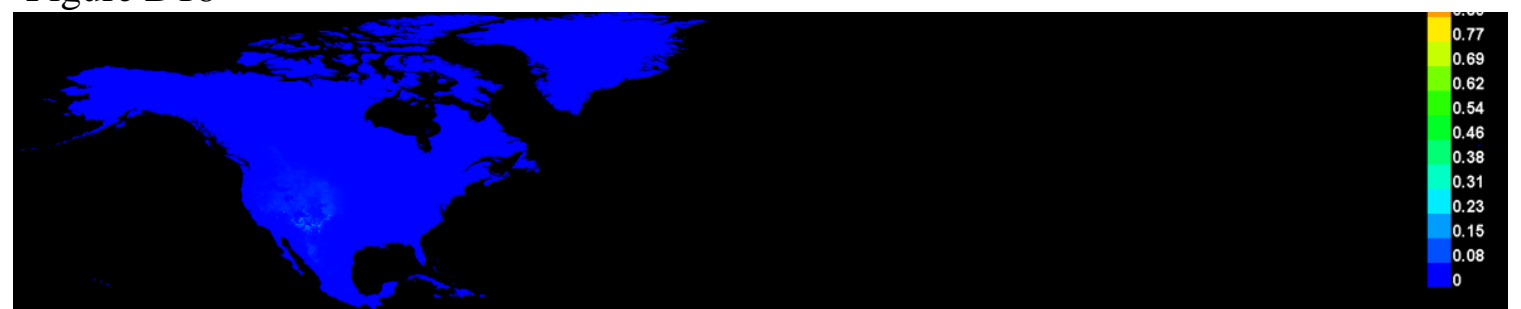




\section{Response curves}

These curves show how each environmental variable affects the Maxent prediction. The curves show how the logistic prediction changes as each environmental variable is varied, keeping all other environmental variables at their average sample value. Click on a response curve to see a larger version. Note that the curves can be hard to interpret if you have strongly correlated variables, as the model may depend on the correlations in ways that are not evident in the curves. In other words, the curves show the marginal effect of changing exactly one variable, whereas the model may take advantage of sets of variables changing together. The curves show the mean response of the 10 replicate Maxent runs (red) and and the mean $+/$ - one standard deviation (blue, two shades for categorical variables).

Sylvilagus nuttallii grangeri

Figure D19
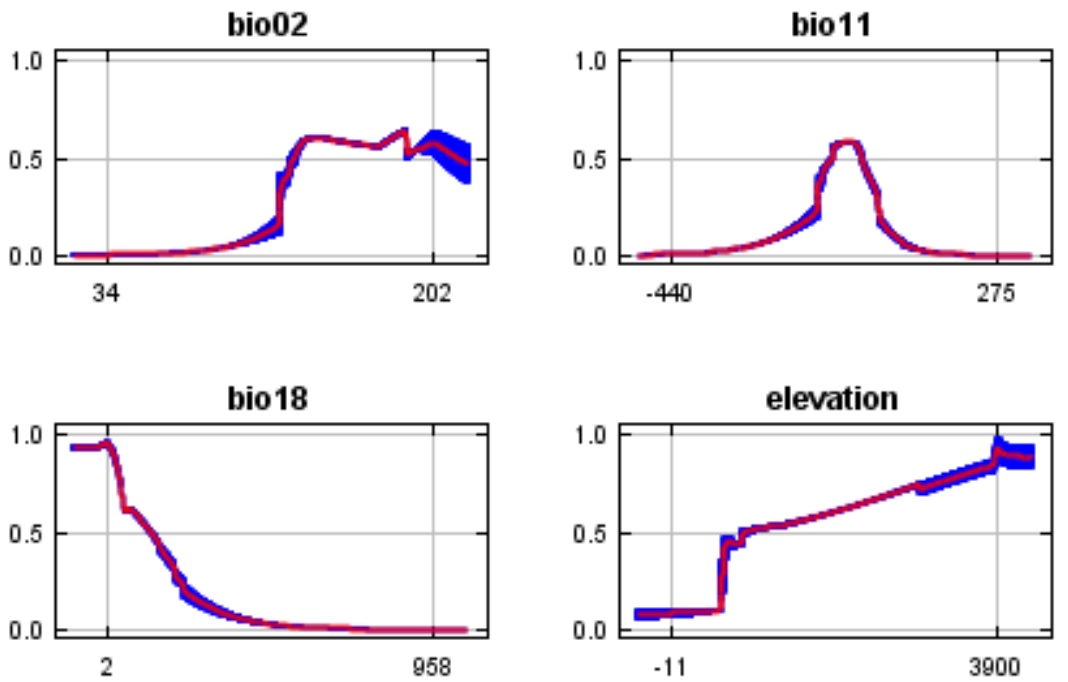
Sylvilagus nuttallii nuttallii

Figure D20
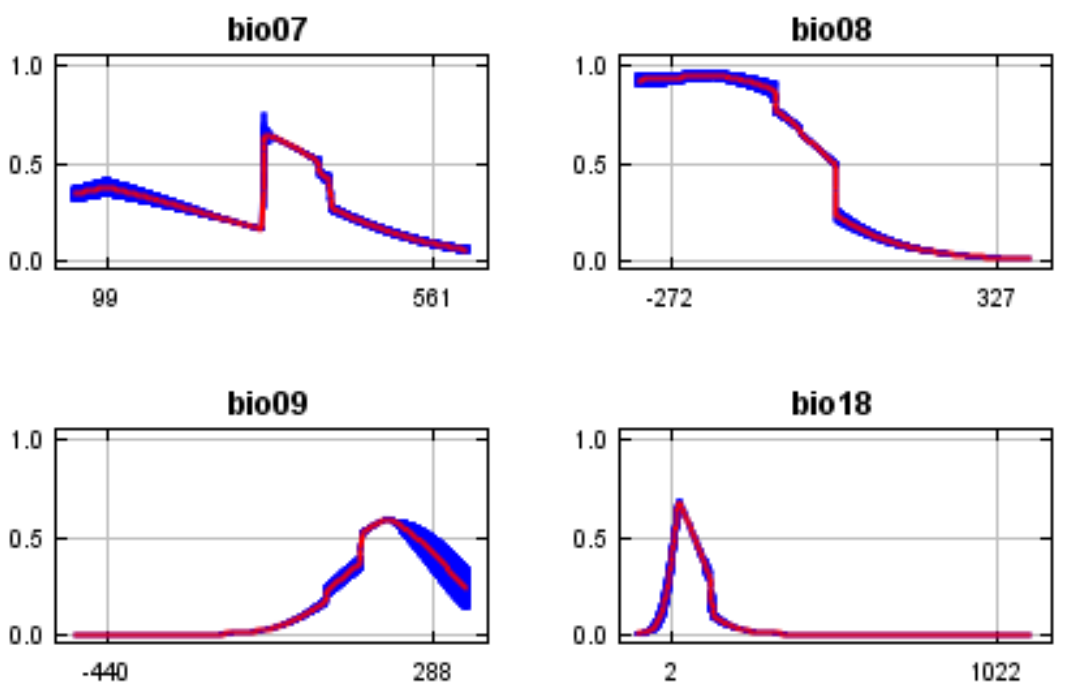

Sylvilagus nuttallii pinetis

Figure D21
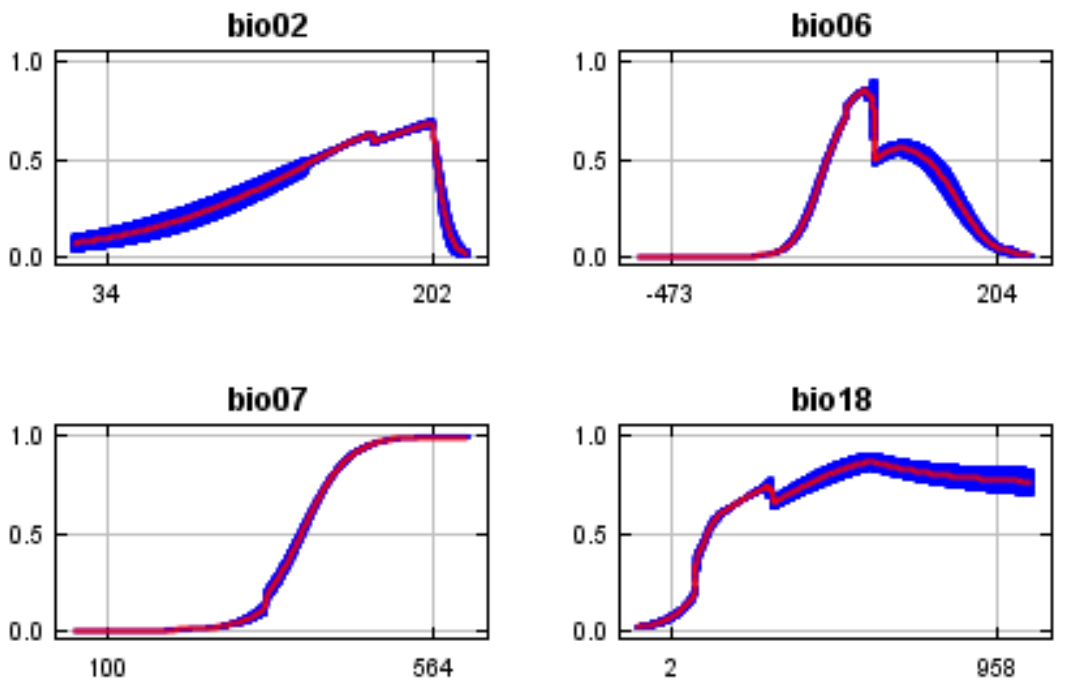


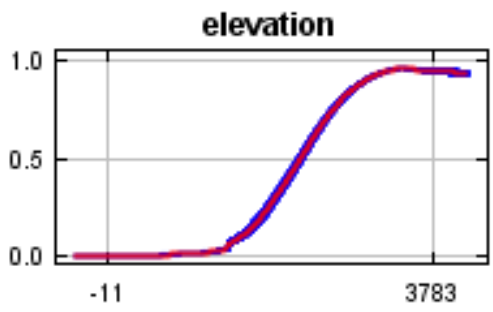

In contrast to the above marginal response curves, each of the following curves represents a different model, namely, a Maxent model created using only the corresponding variable. These plots reflect the dependence of predicted suitability both on the selected variable and on dependencies induced by correlations between the selected variable and other variables. They may be easier to interpret if there are strong correlations between variables.

Figure D22

Sylvilagus nuttallii grangeri
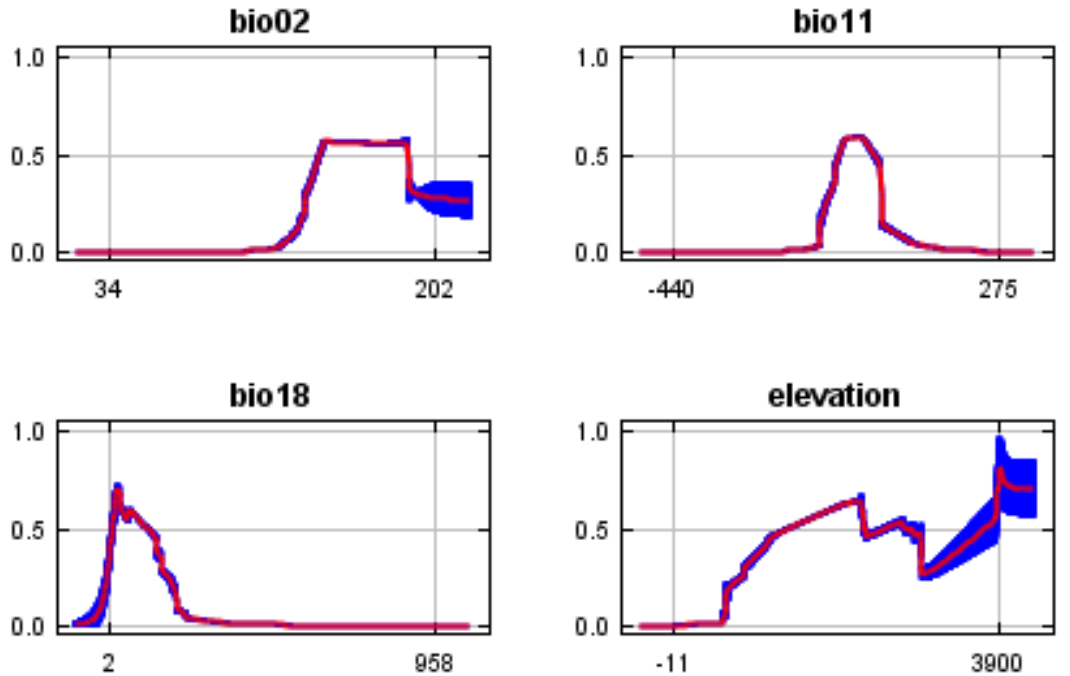
Sylvilagus nuttallii nuttallii

Figure D23
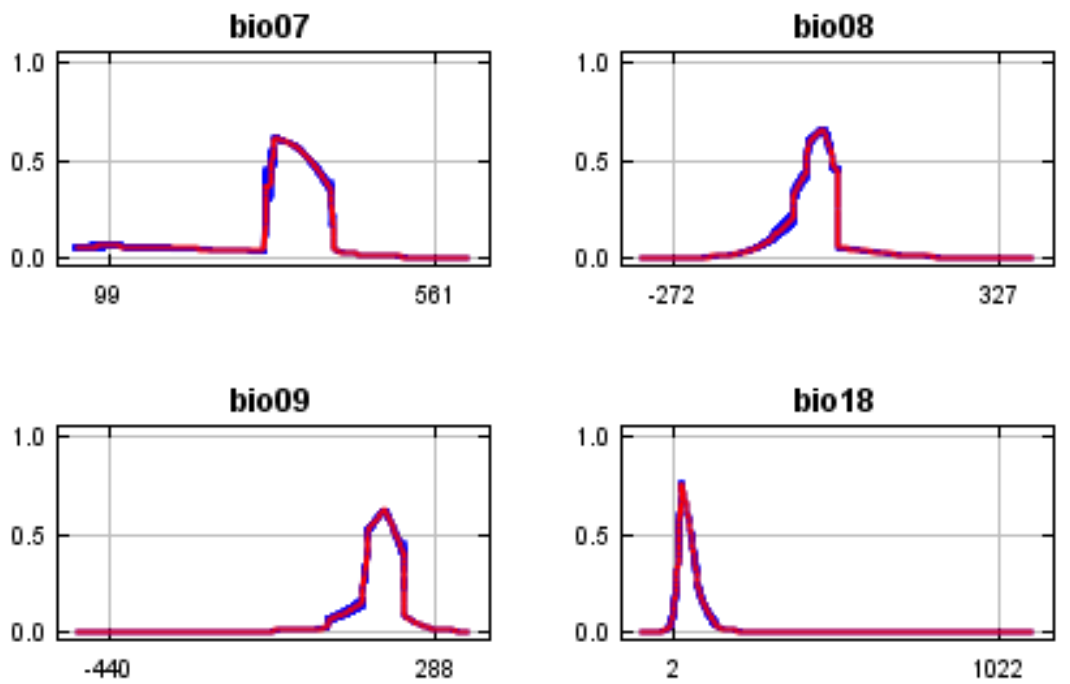

Sylvilagus nuttallii pinetis

Figure D24
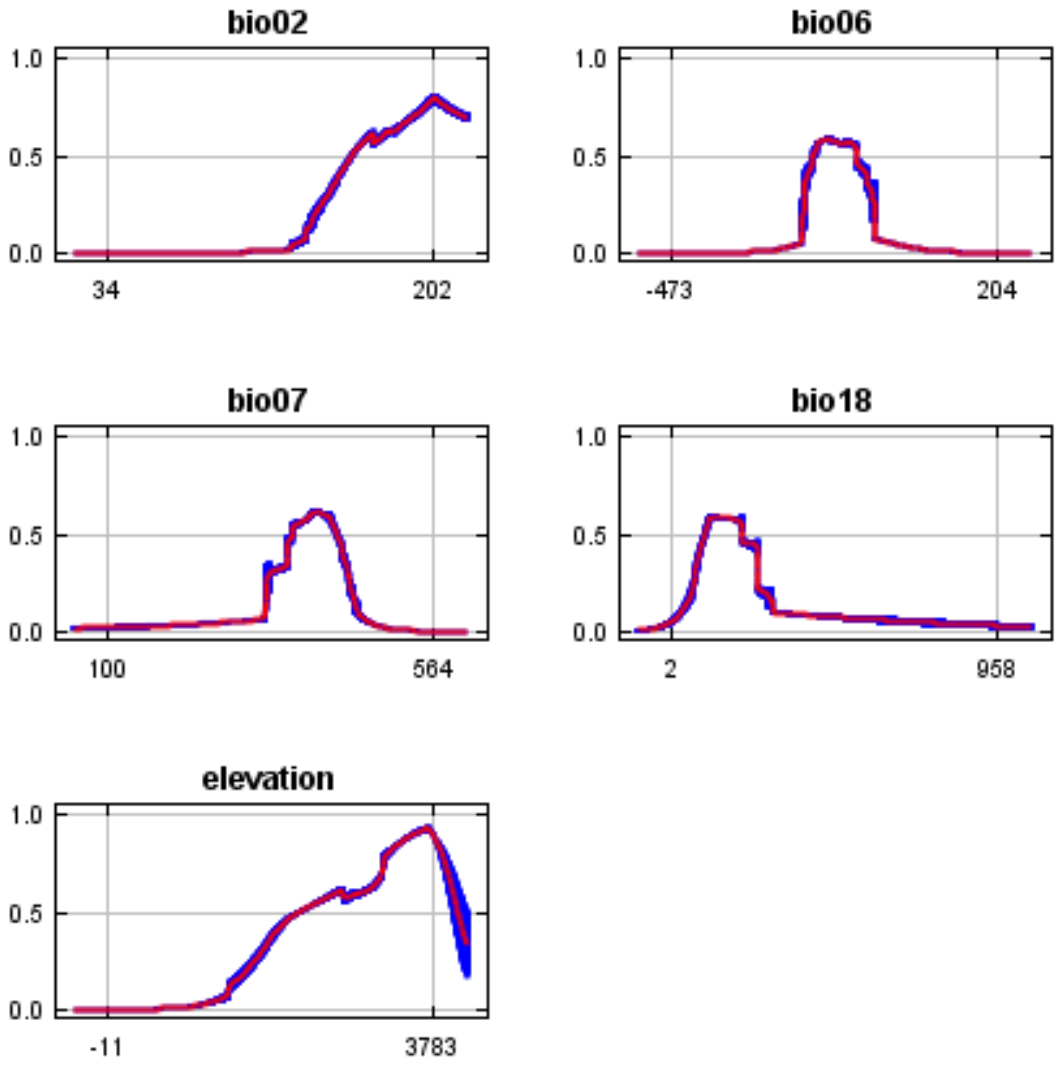
Analysis of variable contributions

The following table gives estimates of relative contributions of the environmental variables to the Maxent model. To determine the first estimate, in each iteration of the training algorithm, the increase in regularized gain is added to the contribution of the corresponding variable, or subtracted from it if the change to the absolute value of lambda is negative. For the second estimate, for each environmental variable in turn, the values of that variable on training presence and background data are randomly permuted. The model is reevaluated on the permuted data, and the resulting drop in training AUC is shown in the table, normalized to percentages. As with the variable jackknife, variable contributions should be interpreted with caution when the predictor variables are correlated. Values shown are averages over replicate runs.

Sylvilagus nuttallii grangeri

Table D1

Variable Percent contribution Permutation importance

$\begin{array}{ccc}\text { bio02 } & 53.7 & 43 \\ \text { bio11 } & 20.5 & 30.8 \\ \text { elevation } & 15.1 & 13.6 \\ \text { bio18 } & 10.8 & 12.6\end{array}$

Sylvilagus nuttallii nuttallii

Table D2

Variable Percent contribution Permutation importance

$\begin{array}{ccc}\text { bio09 } & 53.2 & 71 \\ \text { bio08 } & 25 & 9.2 \\ \text { bio18 } & 18.5 & 18.2 \\ \text { bio07 } & 3.3 & 1.7\end{array}$

Sylvilagus nuttallii pinetis

Table D3

Variable Percent contribution Permutation importance

$\begin{array}{lll}\text { bio02 } & 45.9 & 1\end{array}$

$\begin{array}{lll}\text { elevation } & 40.1 & 48.8\end{array}$

$\begin{array}{lll}\text { bio06 } & 7.8 & 40.4\end{array}$

$\begin{array}{lll}\text { bio07 } & 3.4 & 7.4\end{array}$

$\begin{array}{lll}\text { bio18 } 2.8 & 2.5\end{array}$ 
The following picture shows the results of the jackknife test of variable importance. The environmental variable with highest gain when used in isolation is bio02, which therefore appears to have the most useful information by itself. The environmental variable that decreases the gain the most when it is omitted is bio11, which therefore appears to have the most information that isn't present in the other variables. Values shown are averages over replicate runs.

Figure D25

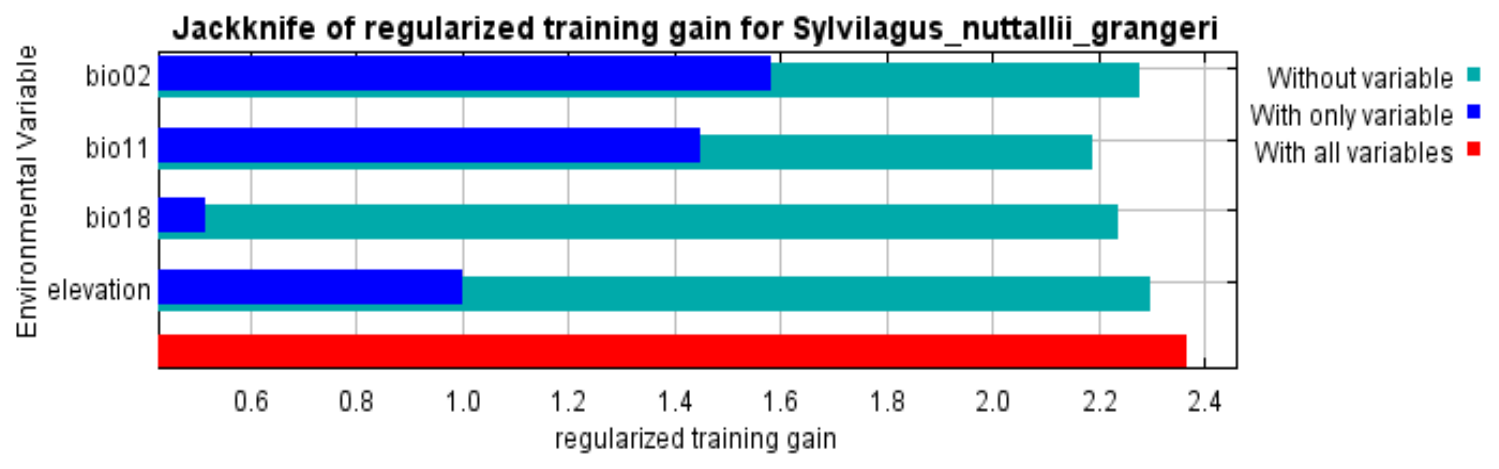

Figure D26

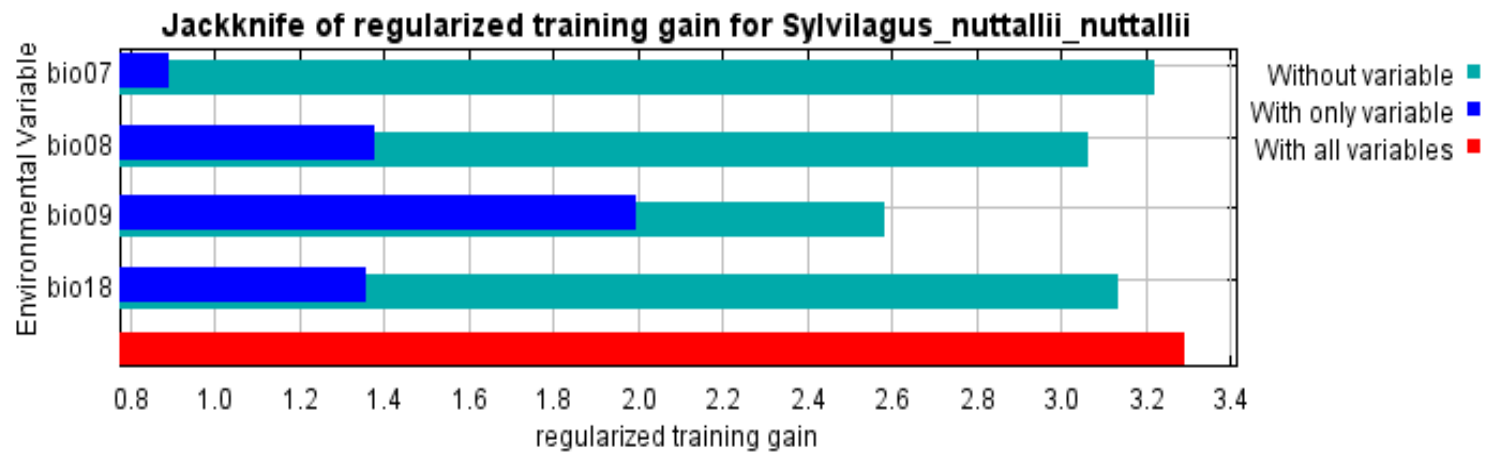


Figure D27

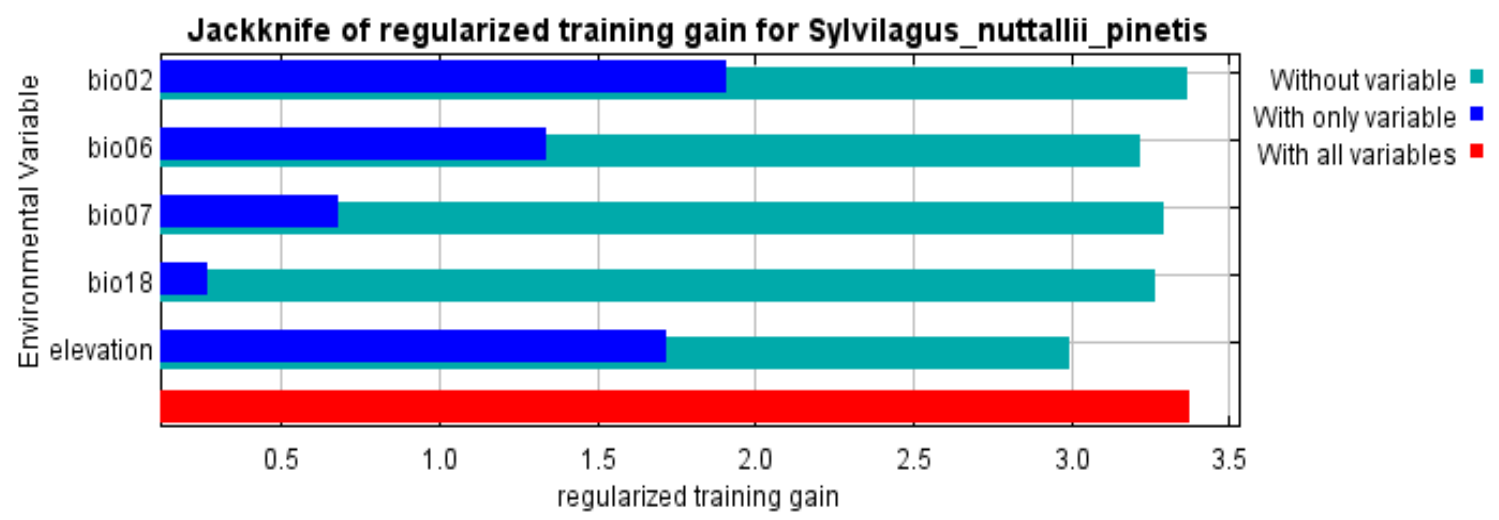

The next picture shows the same jackknife test, using test gain instead of training gain. Note that conclusions about which variables are most important can change, now that we're looking at test data.

Figure D28

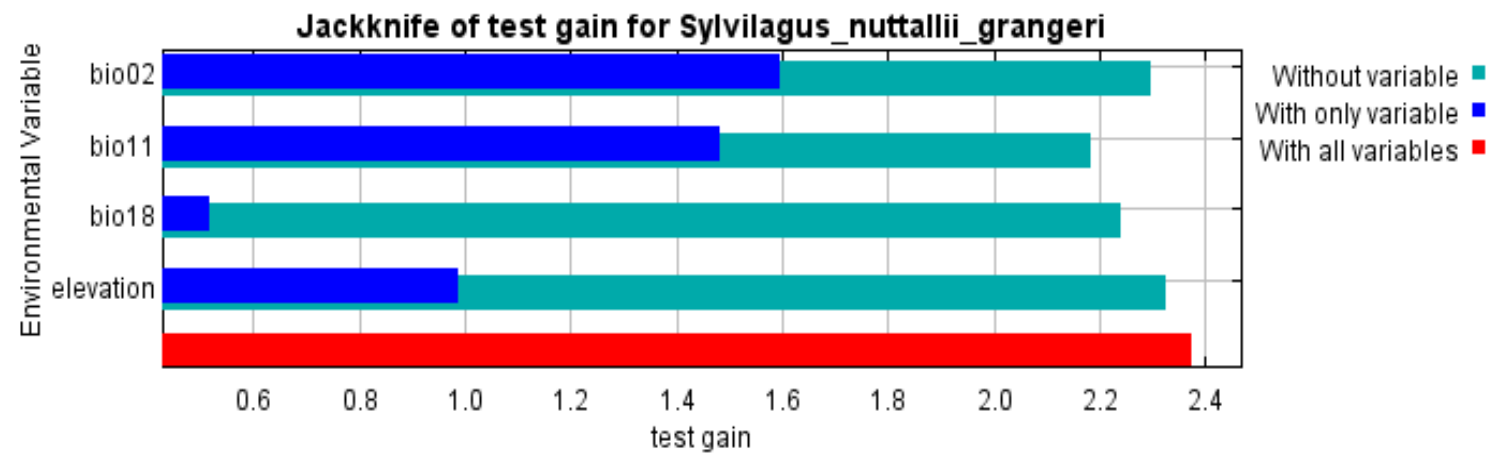

Figure D29

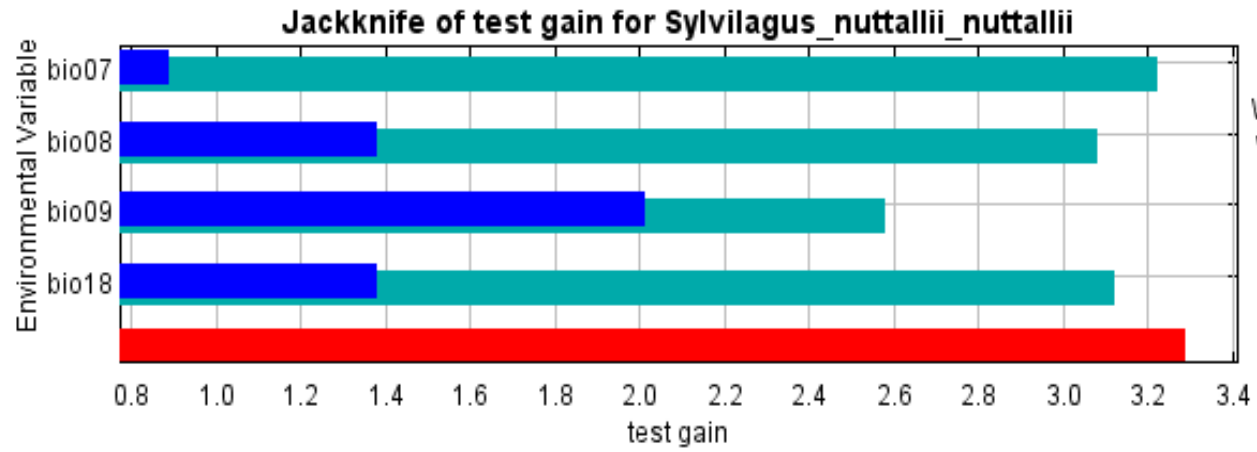

Without variable With only variable With all variables $\mathbf{~}$ 
Figure D30

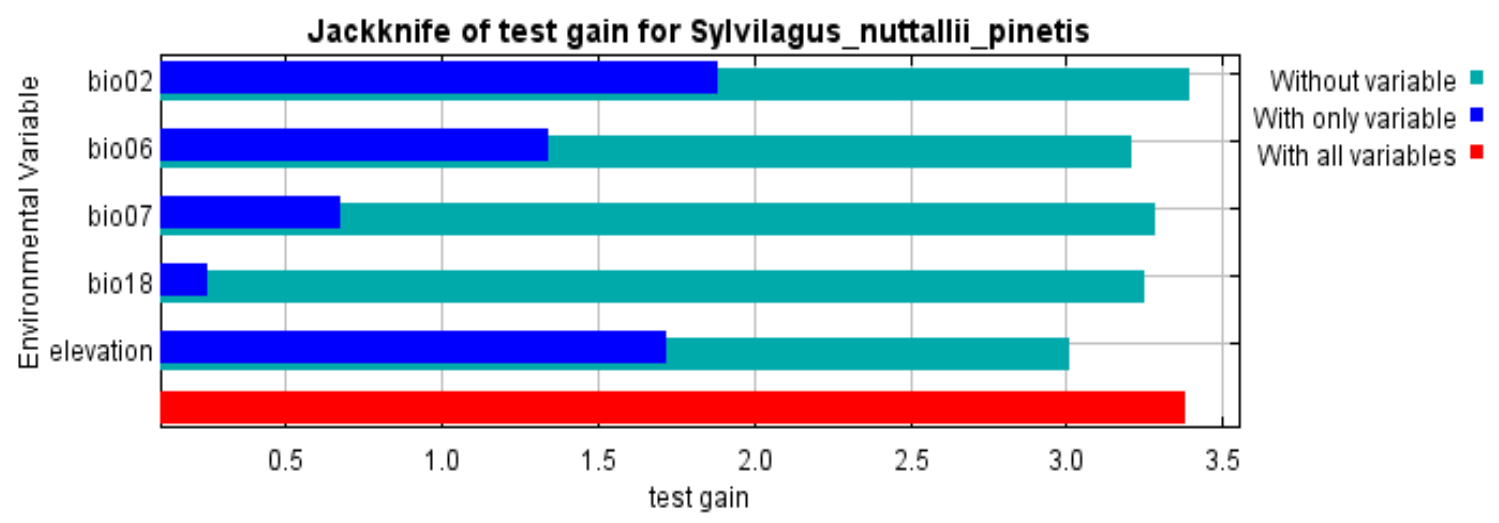

Lastly, we have the same jackknife test, using AUC on test data. Figure D31

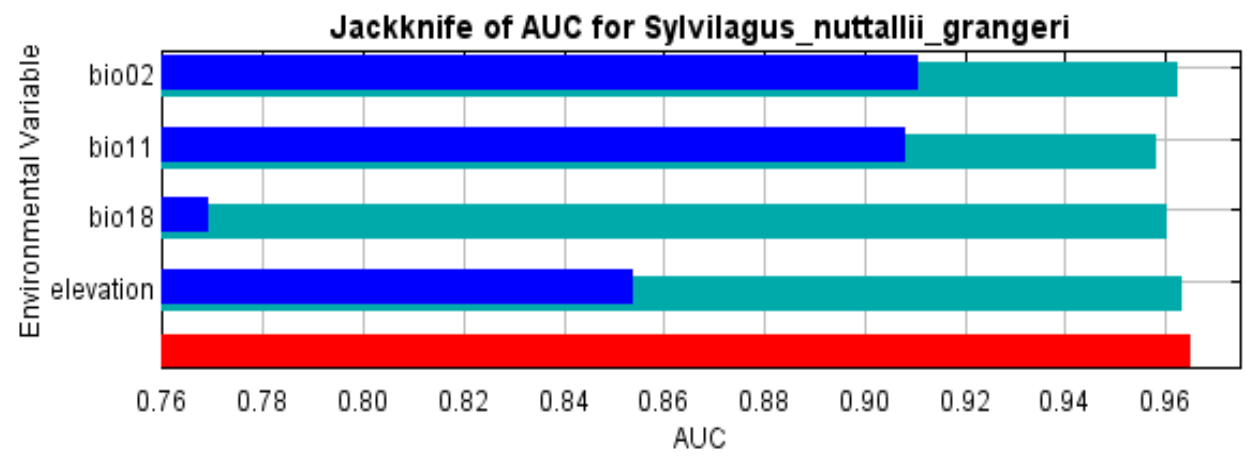

Without variable With only variable $\mathbf{~}$ With all variables 
Figure D32

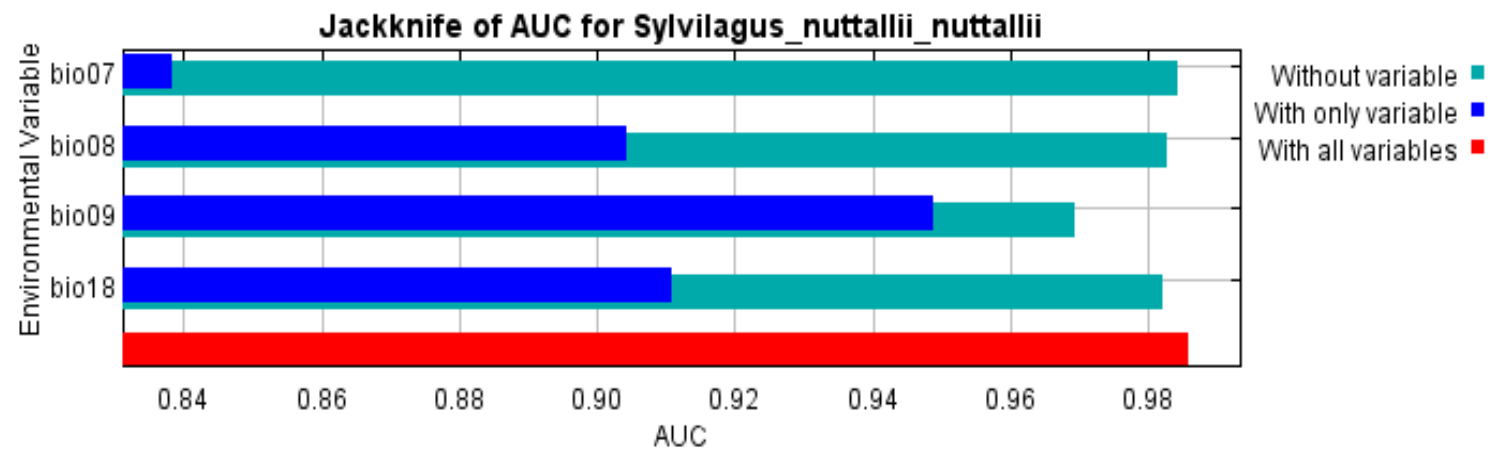

Figure D33

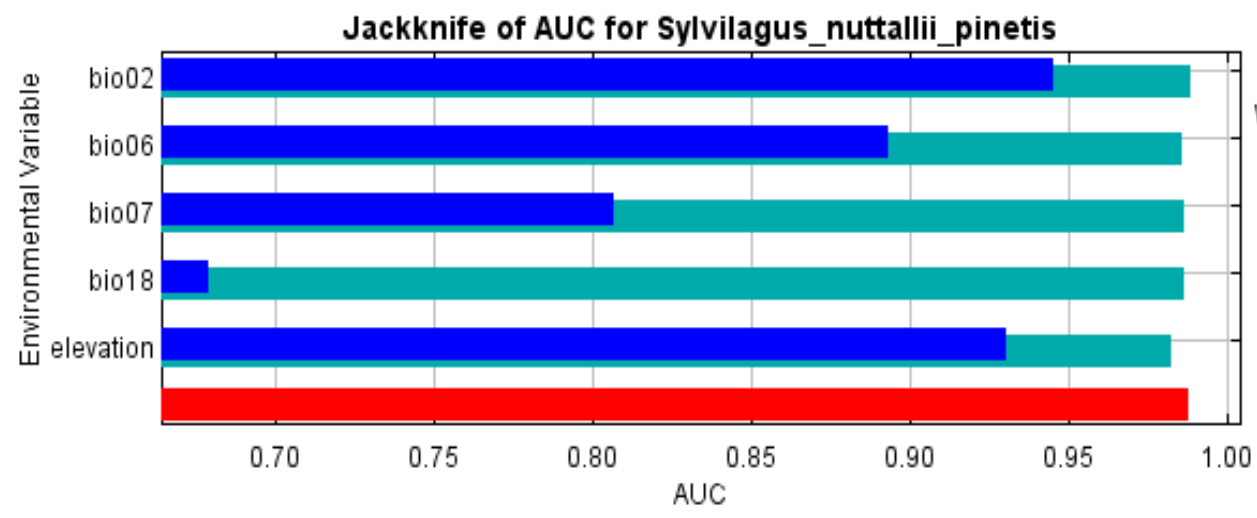

Without variable With only variable With all variables - 


\section{APPENDIX E}

Representative Concentration Pathway 8.5 model results

Model output results and figures for Representative Concentration Pathway 8.5 (RCP 8.5) from the IPCC 5th Assessment Report (AR5). RCP 8.5 projects a $3.7^{\circ} \mathrm{C}$ mean increase in temperature by 2100 (2.6 - 4.8 likely range).

\section{Analysis of omission/commission}

The following picture shows the test omission rate and predicted area as a function of the cumulative threshold, averaged over the replicate runs. The omission rate should be close to the predicted omission, because of the definition of the cumulative threshold.

Figure E1

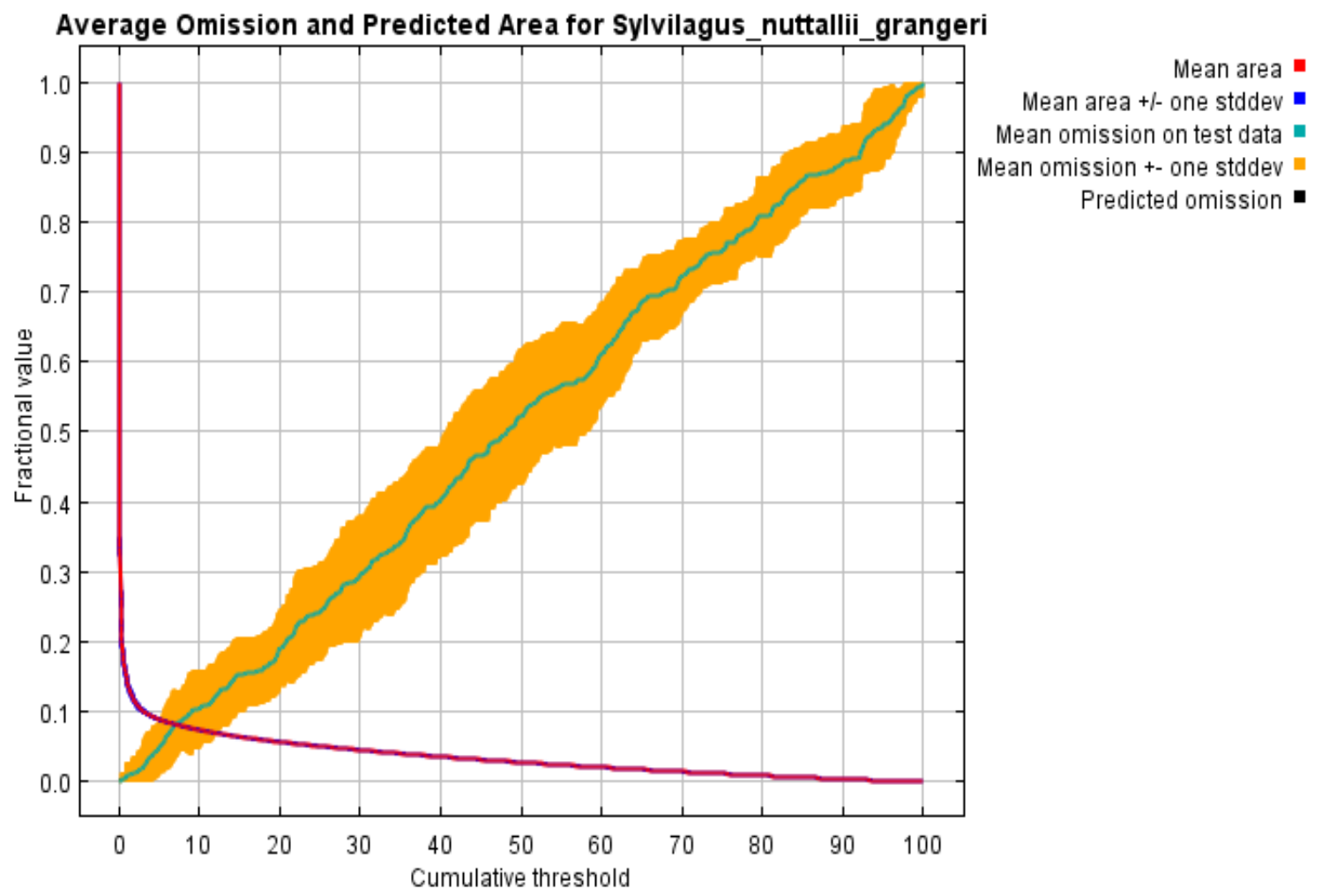


Figure E2

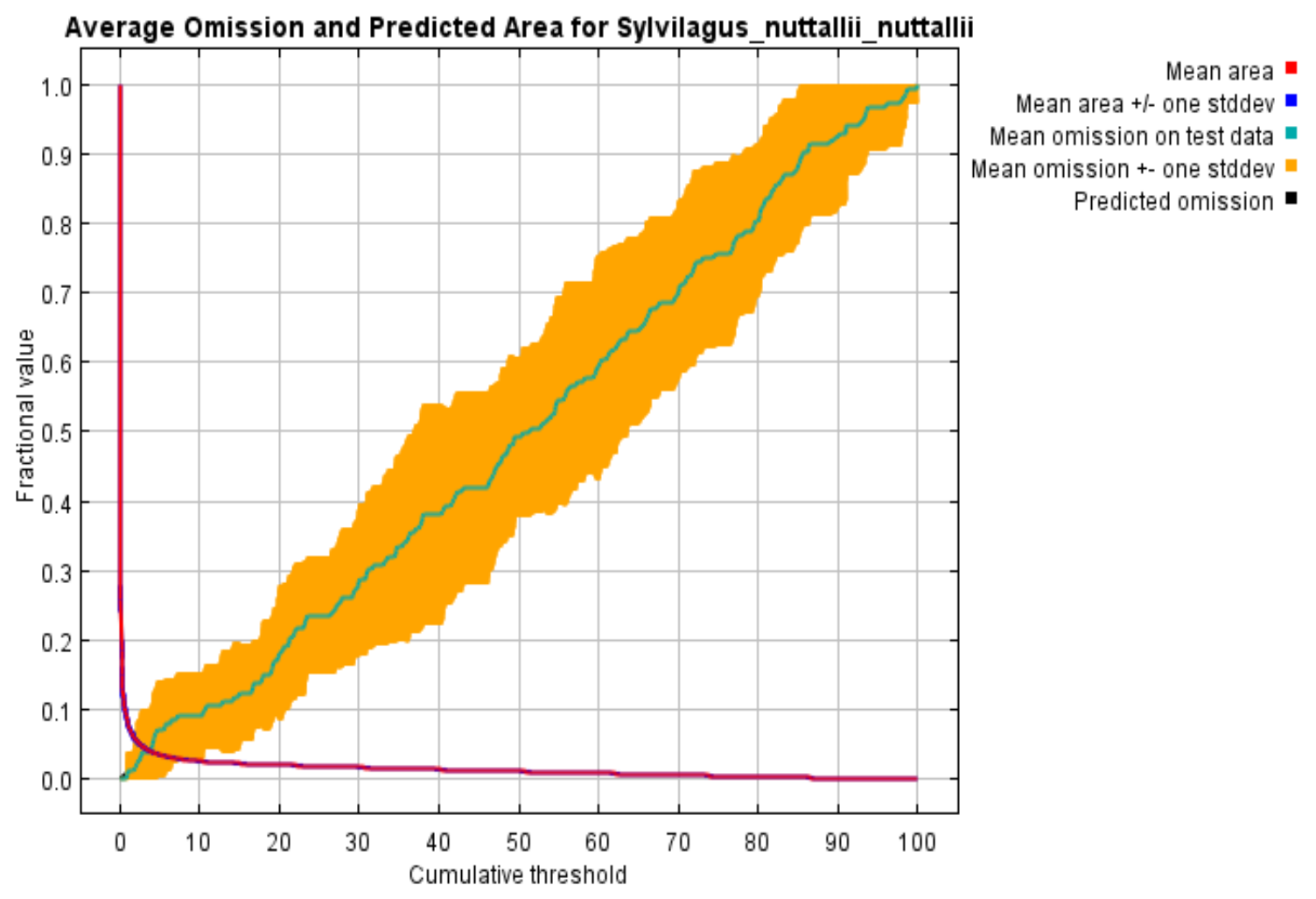


Figure E3

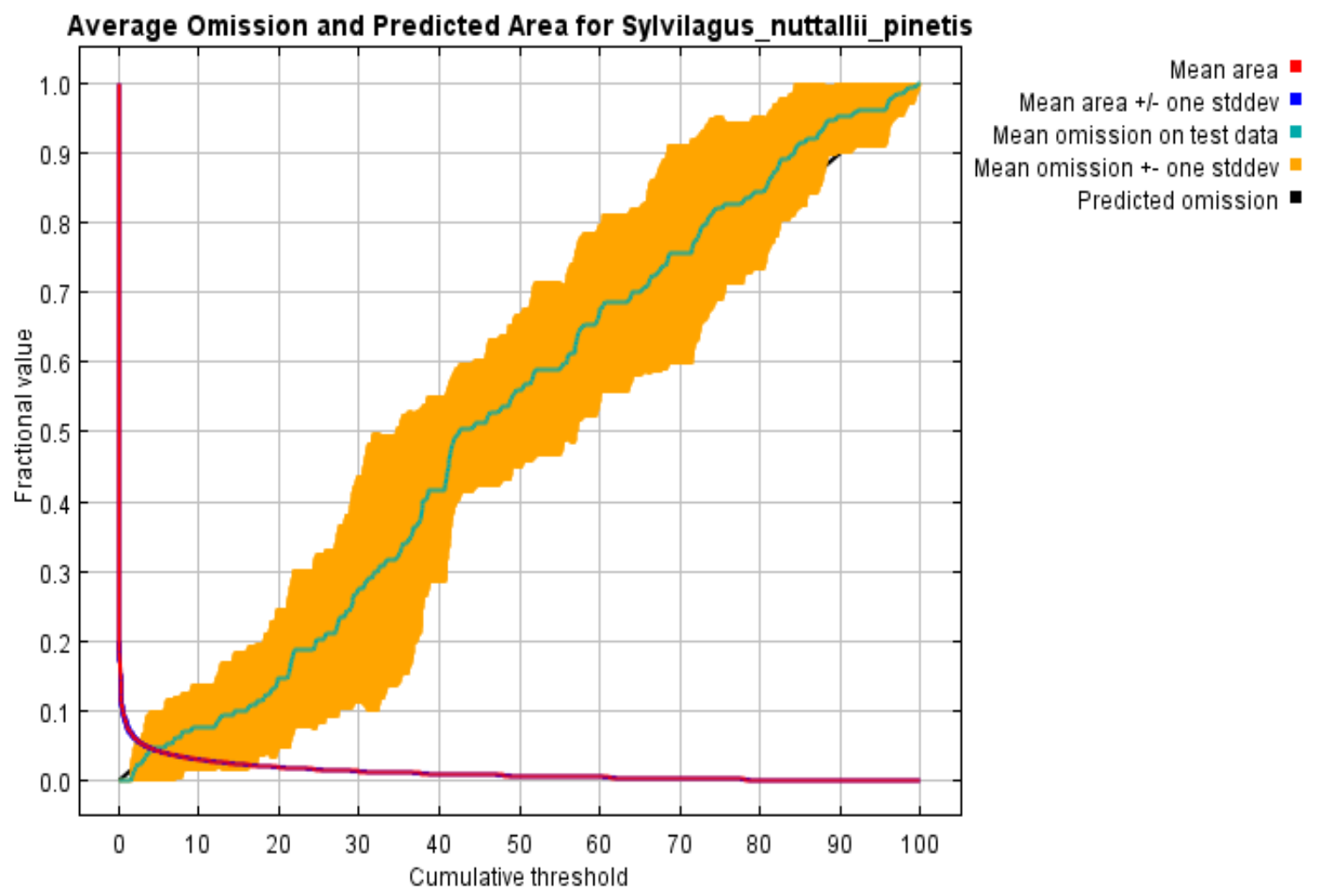

The next picture is the receiver operating characteristic (ROC) curve for the same data, again averaged over the replicate runs. Note that the specificity is defined using predicted area, rather than true commission (see the paper by Phillips, Anderson and Schapire cited for discussion of what this means). The average test AUC for the replicate runs is 0.965 , 0.986 , and 0.988 respectively and the standard deviation is 0.005 . 
Figure E4

Average Sensitivity vs. 1 - Specificity for Sylvilagus_nuttallii_grangeri

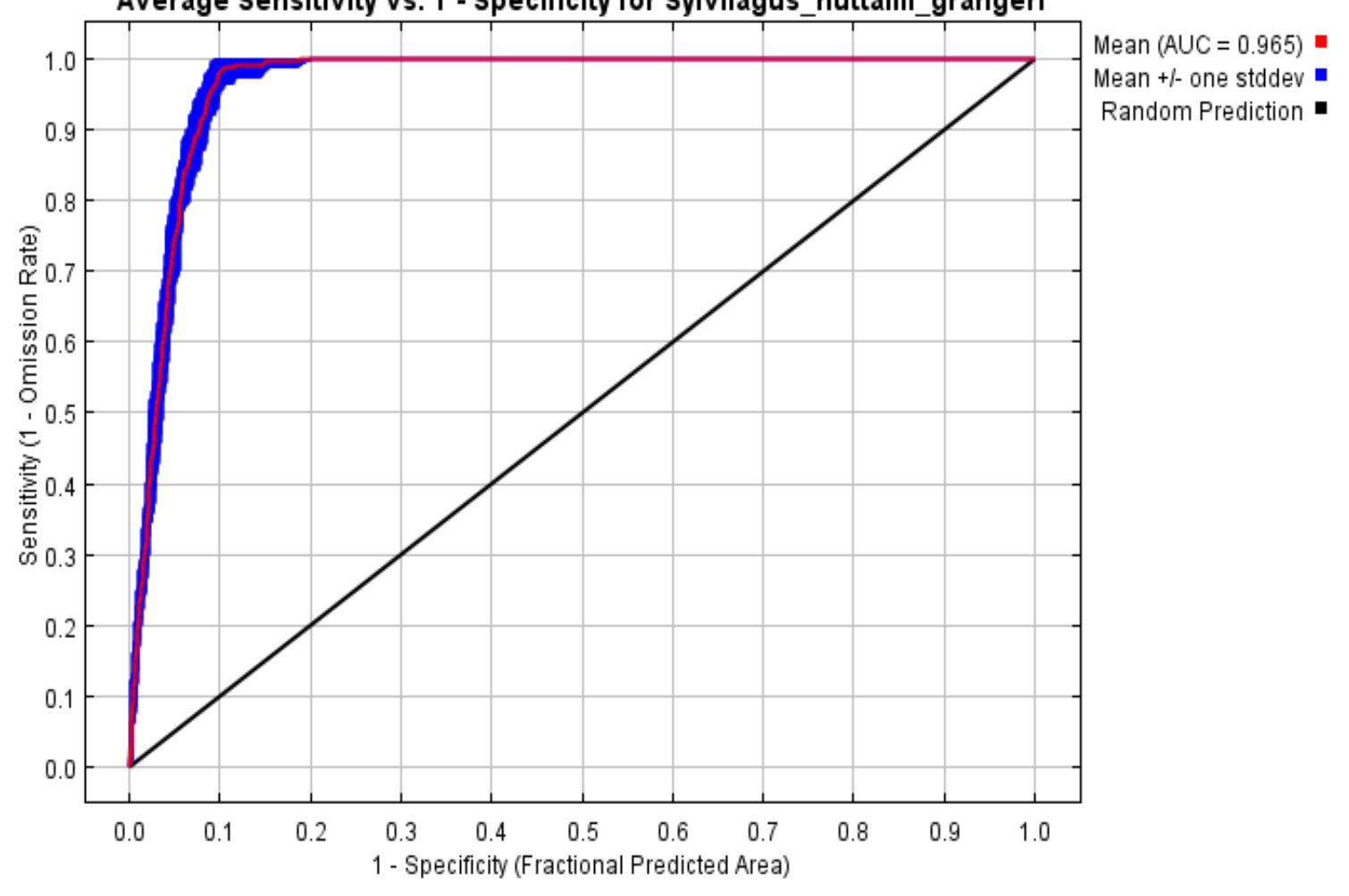


Figure E5

Average Sensitivity vs. 1 - Specificity for Sylvilagus nuttallii nuttallii

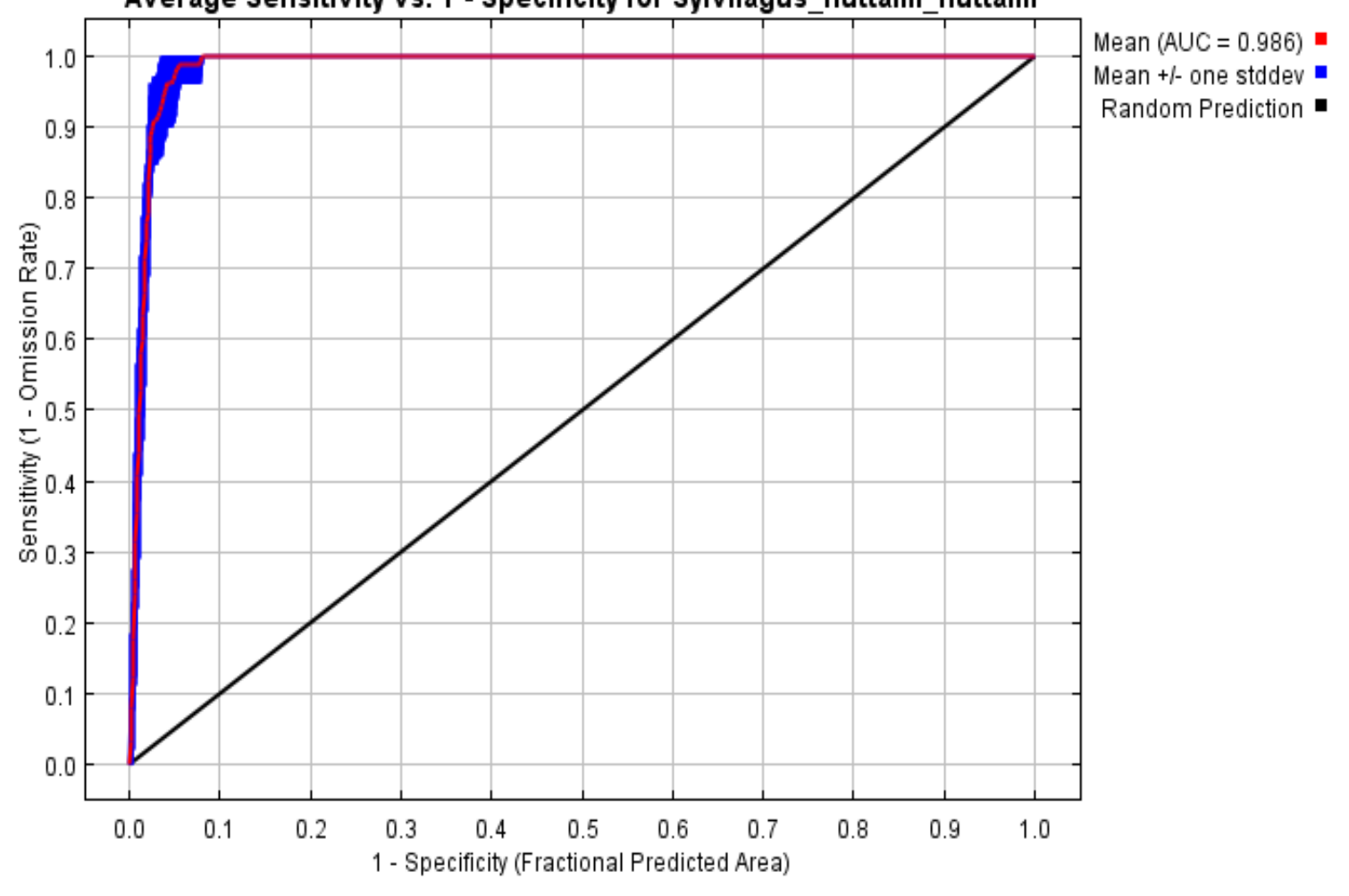


Figure E6

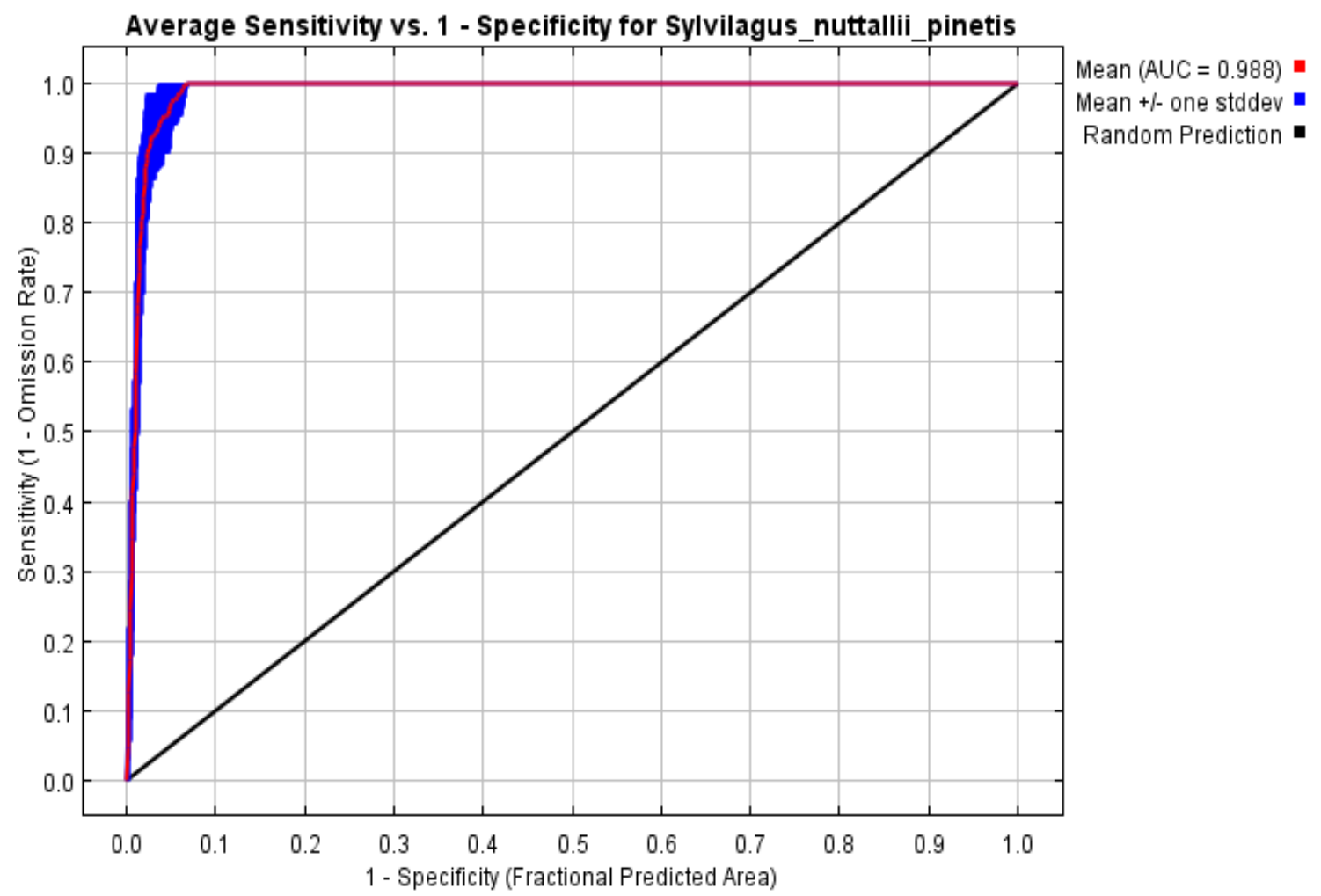

Pictures of the model

The following pictures show the point-wise mean and standard deviation of the 10 output grids. Other available summary grids are $\underline{\min }, \underline{\max }$ and median.

Sylvilagus nuttallii grangeri:

Figure E7

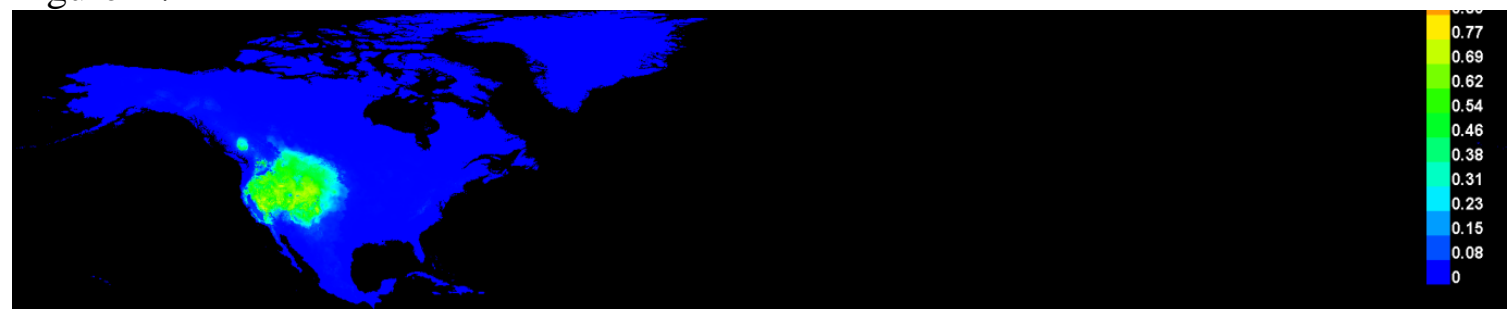

Figure E8

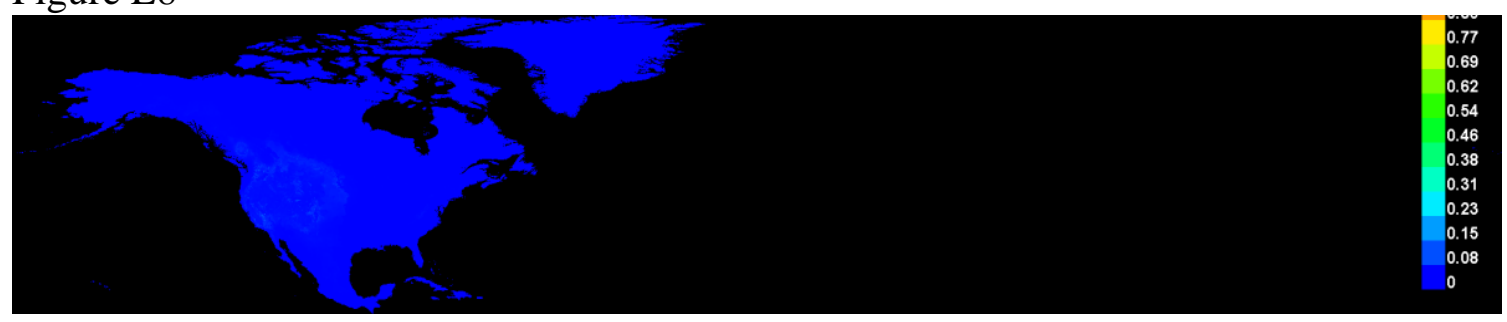


Sylvilagus nuttallii nuttallii:

Figure E9

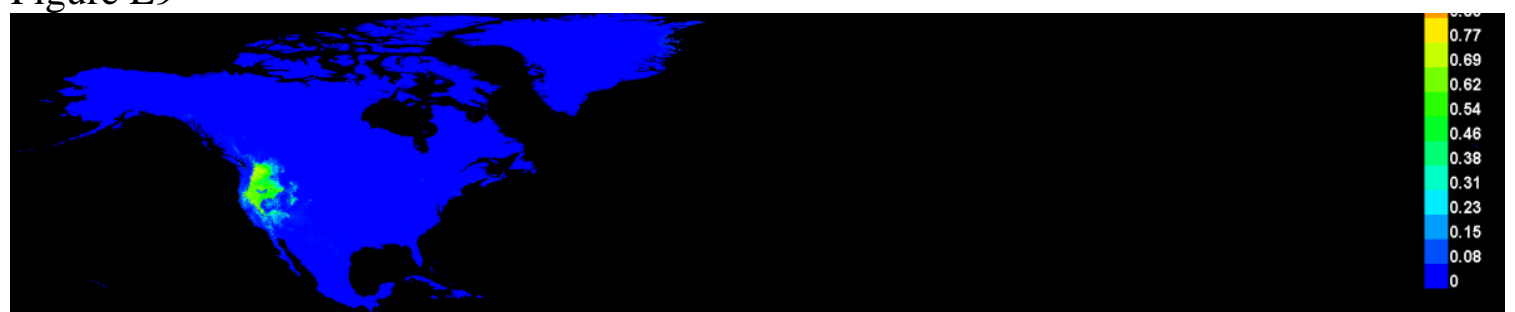

Figure E10

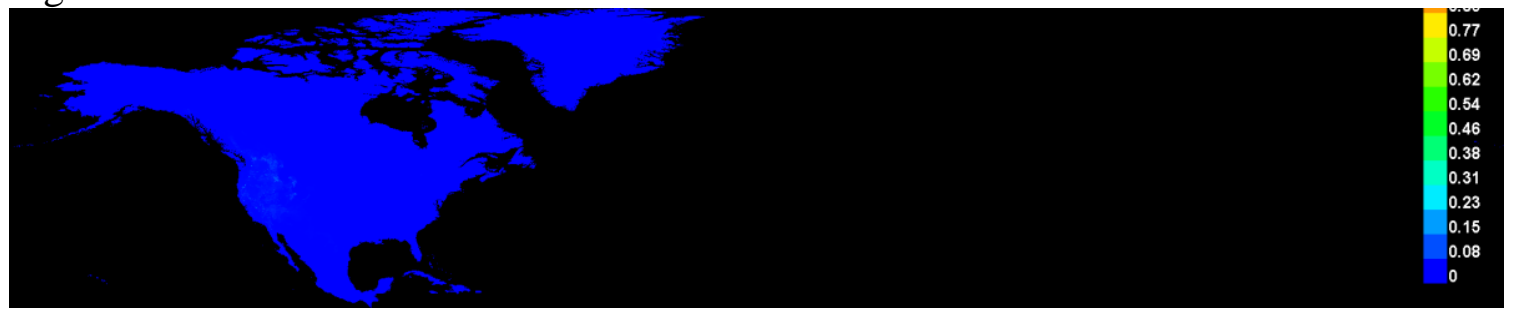

Sylvilagus nuttallii pinetis:

Figure E11

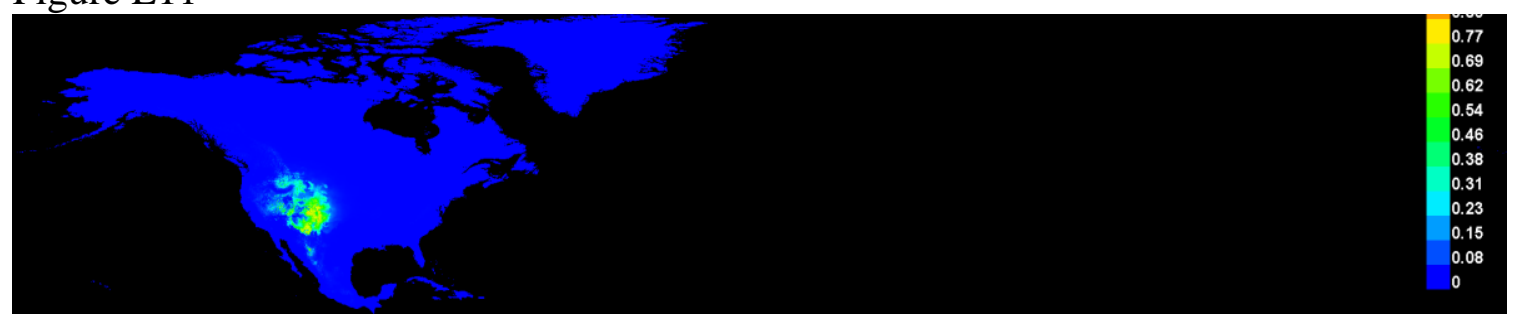

Figure E12

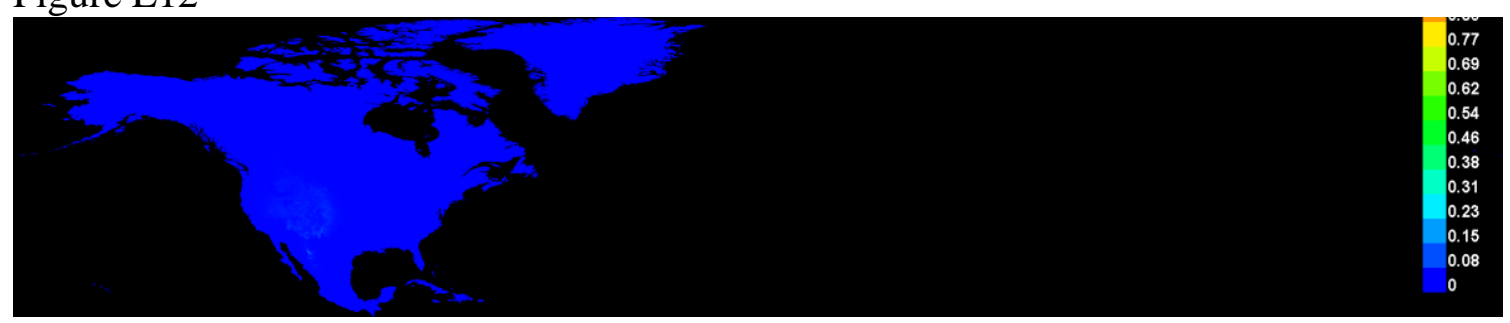


The following pictures show the point-wise mean and standard deviation of the 10 models applied to the environmental layers in ASCII. Other available summary grids are min, $\underline{\max }$ and median.

Sylvilagus nuttallii grangeri

Figure E13

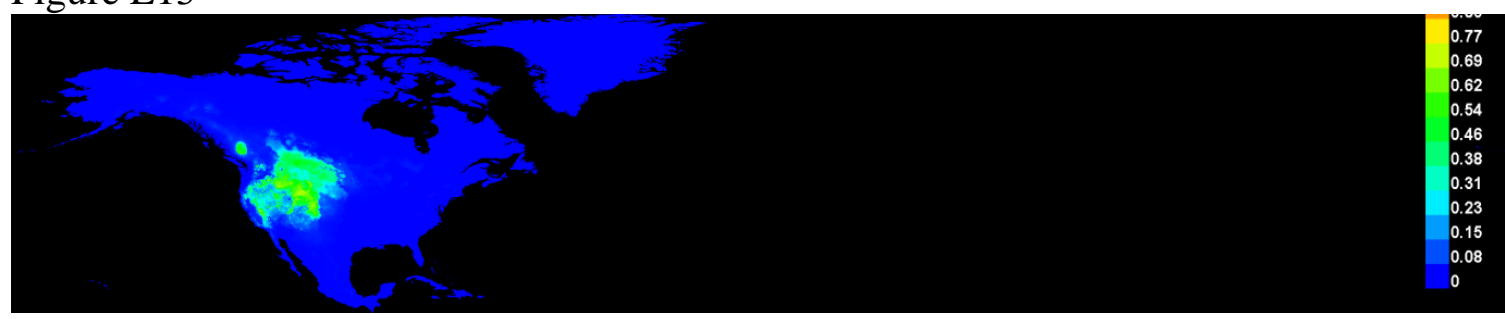

Figure E14

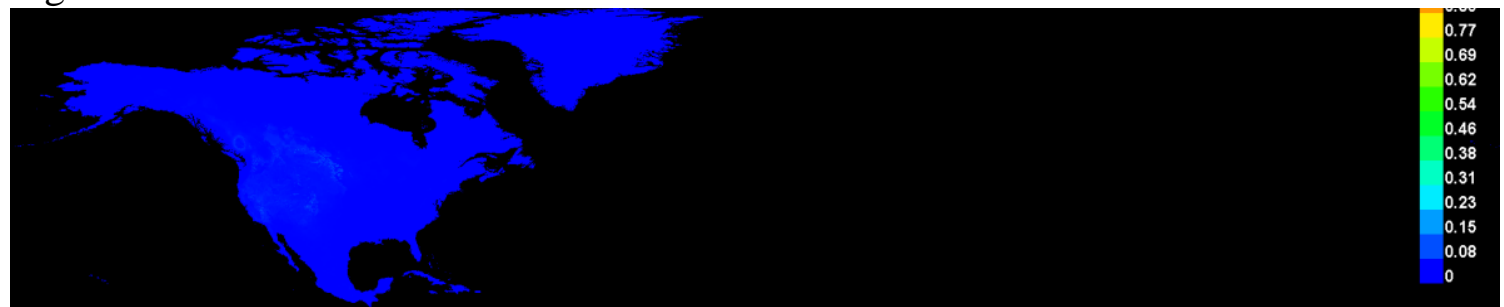

Sylvilagus nuttallii nuttallii:

Figure E15

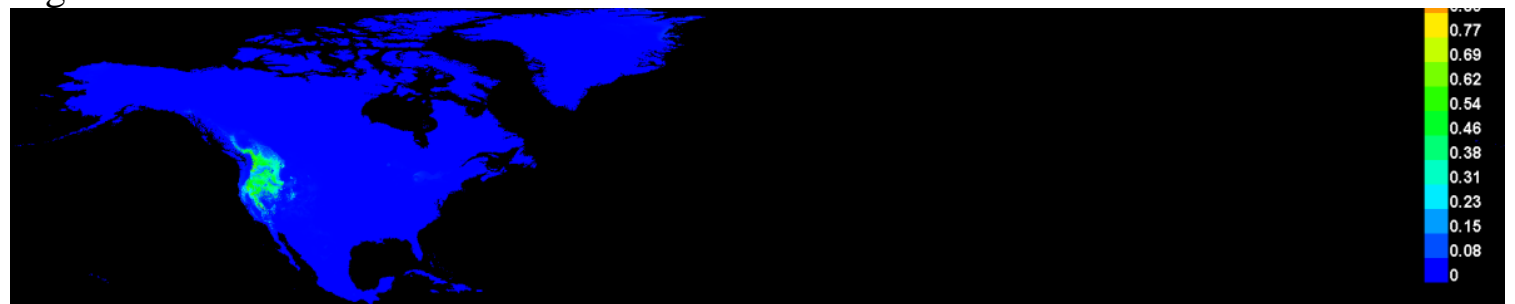

Figure E16

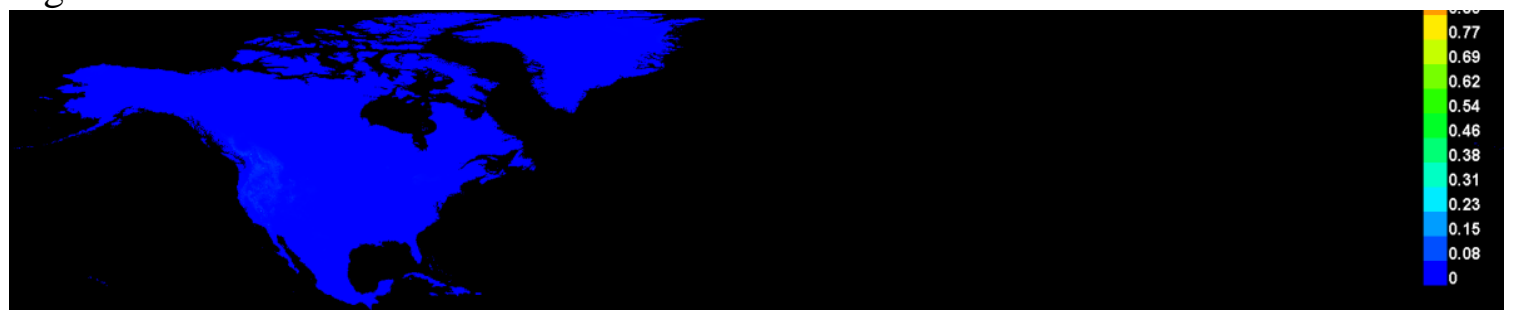


Sylvilagus nuttallii pinetis:

Figure E17

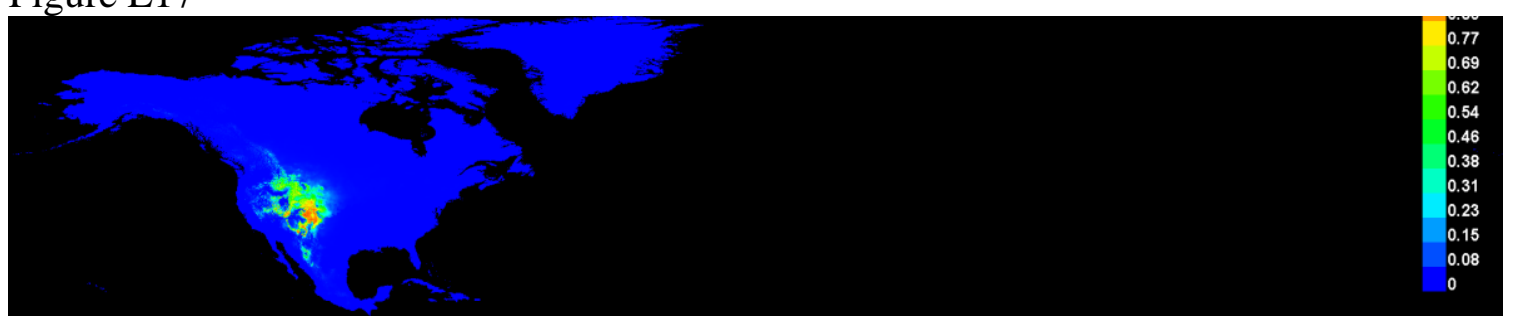

Figure E18

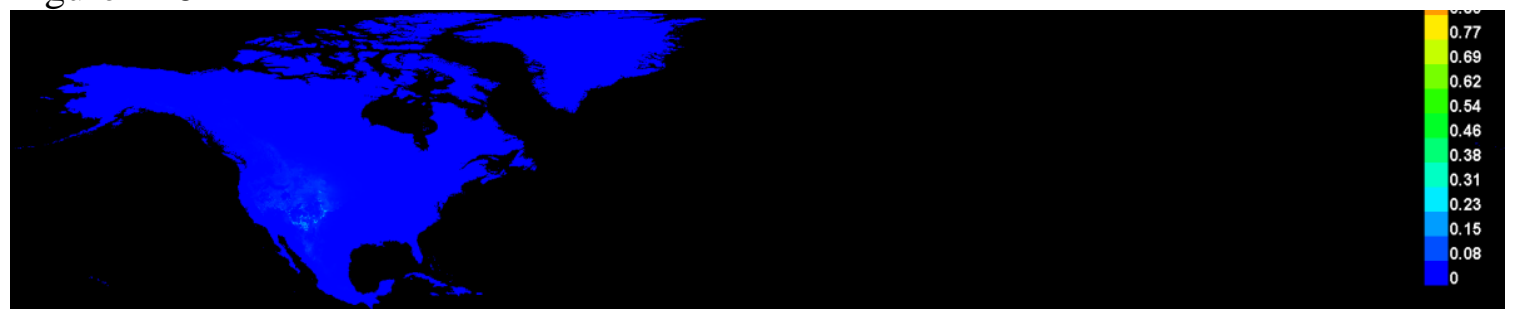




\section{Response curves}

These curves show how each environmental variable affects the Maxent prediction. The curves show how the logistic prediction changes as each environmental variable is varied, keeping all other environmental variables at their average sample value. Click on a response curve to see a larger version. Note that the curves can be hard to interpret if you have strongly correlated variables, as the model may depend on the correlations in ways that are not evident in the curves. In other words, the curves show the marginal effect of changing exactly one variable, whereas the model may take advantage of sets of variables changing together. The curves show the mean response of the 10 replicate Maxent runs (red) and and the mean +/- one standard deviation (blue, two shades for categorical variables).

Sylvilagus nuttallii grangeri

Figure E19
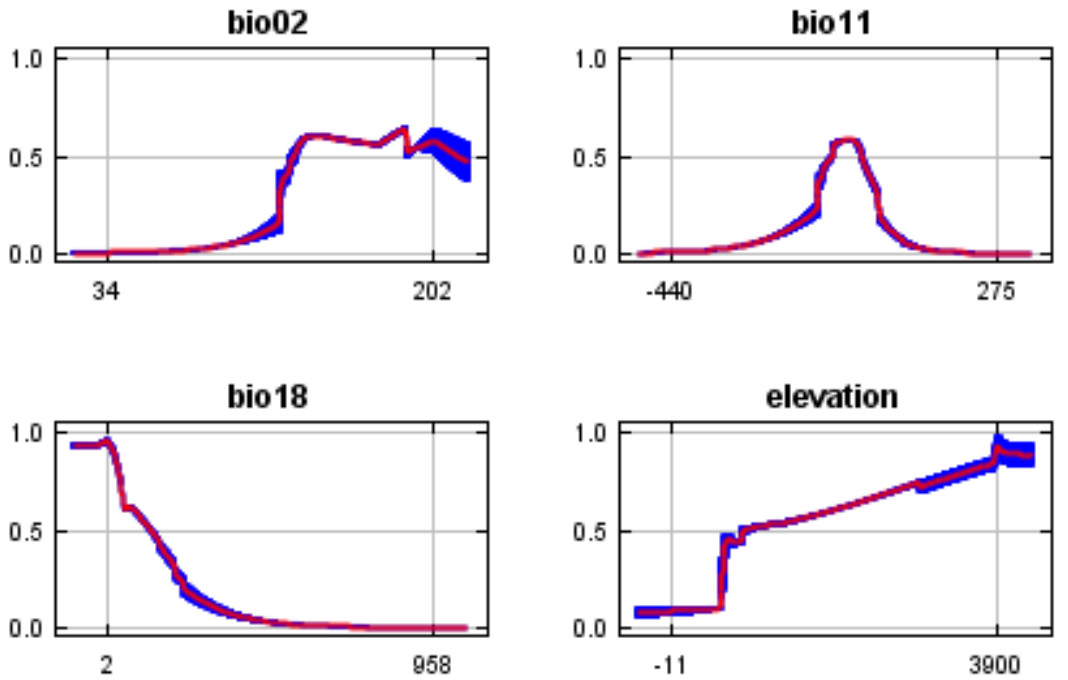
Sylvilagus nuttallii nuttallii

Figure E20
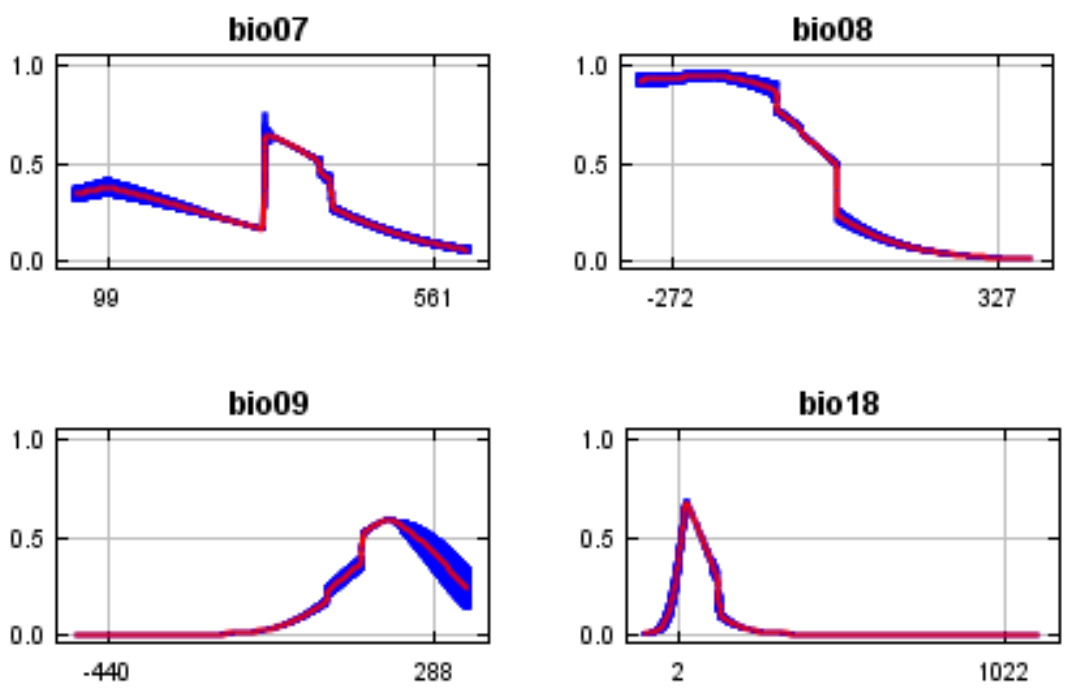

Sylvilagus nuttallii pinetis

Figure E21
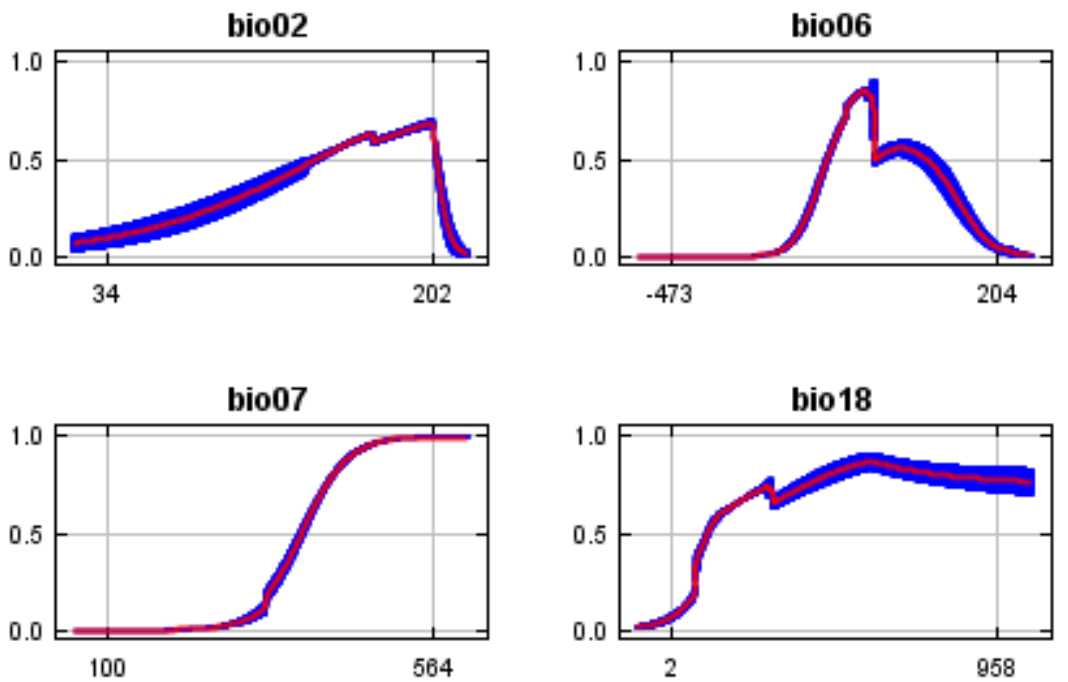


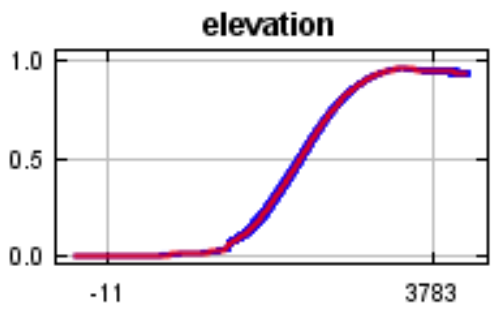

In contrast to the above marginal response curves, each of the following curves represents a different model, namely, a Maxent model created using only the corresponding variable. These plots reflect the dependence of predicted suitability both on the selected variable and on dependencies induced by correlations between the selected variable and other variables. They may be easier to interpret if there are strong correlations between variables.

Sylvilagus nuttallii grangeri

Figure E22
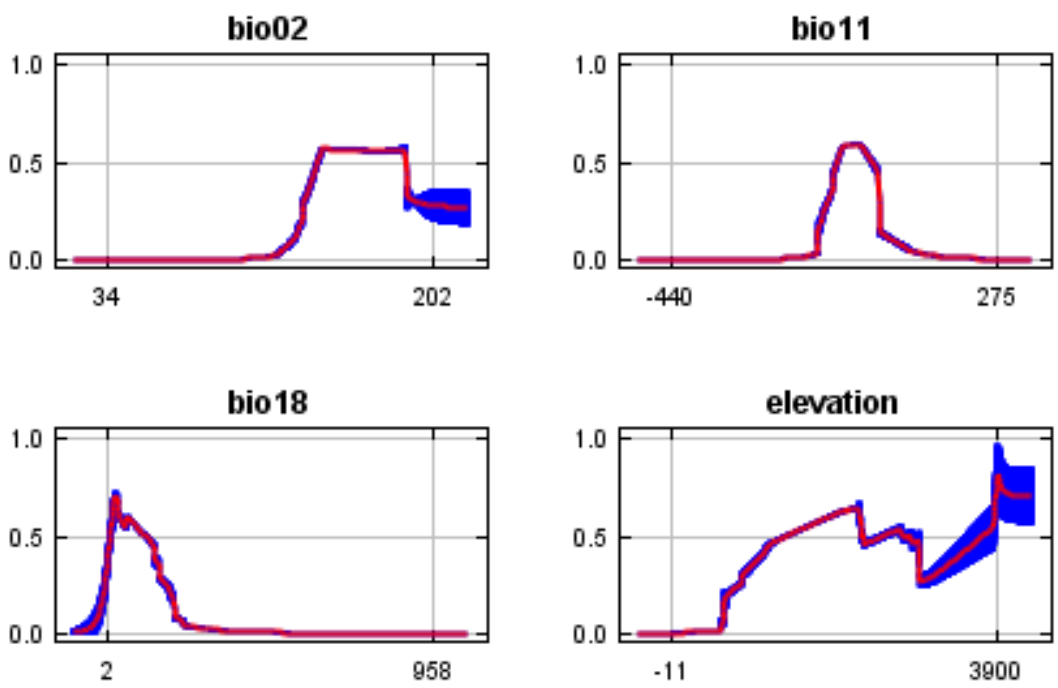
Sylvilagus nuttallii nuttallii

Figure E23
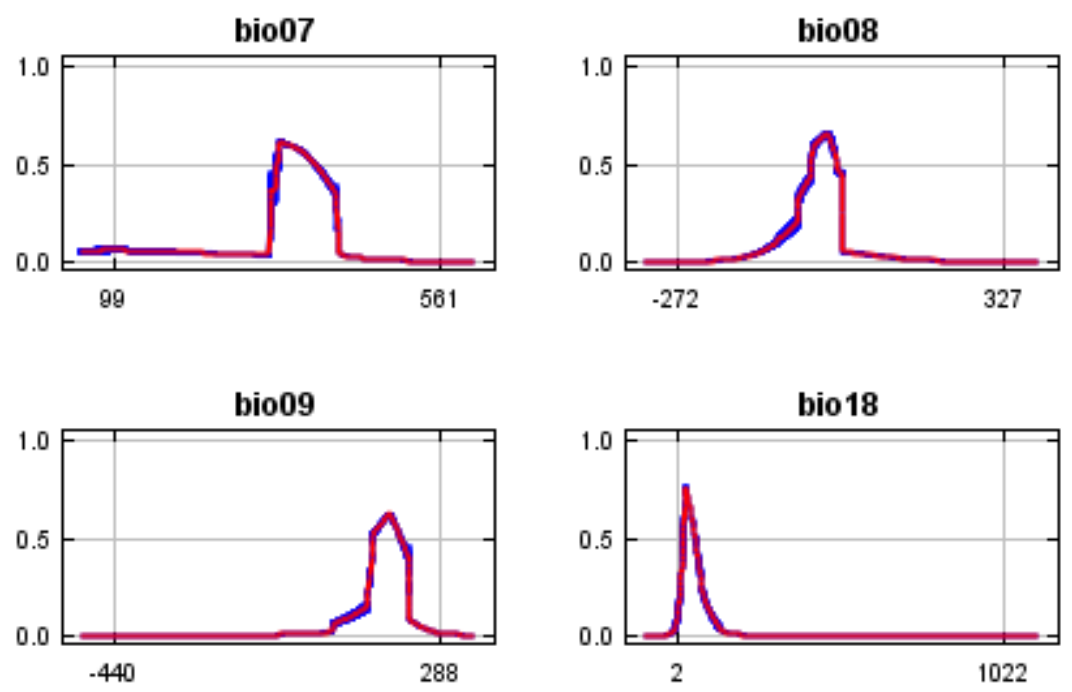

Sylvilagus nuttallii pinetis

Figure E24
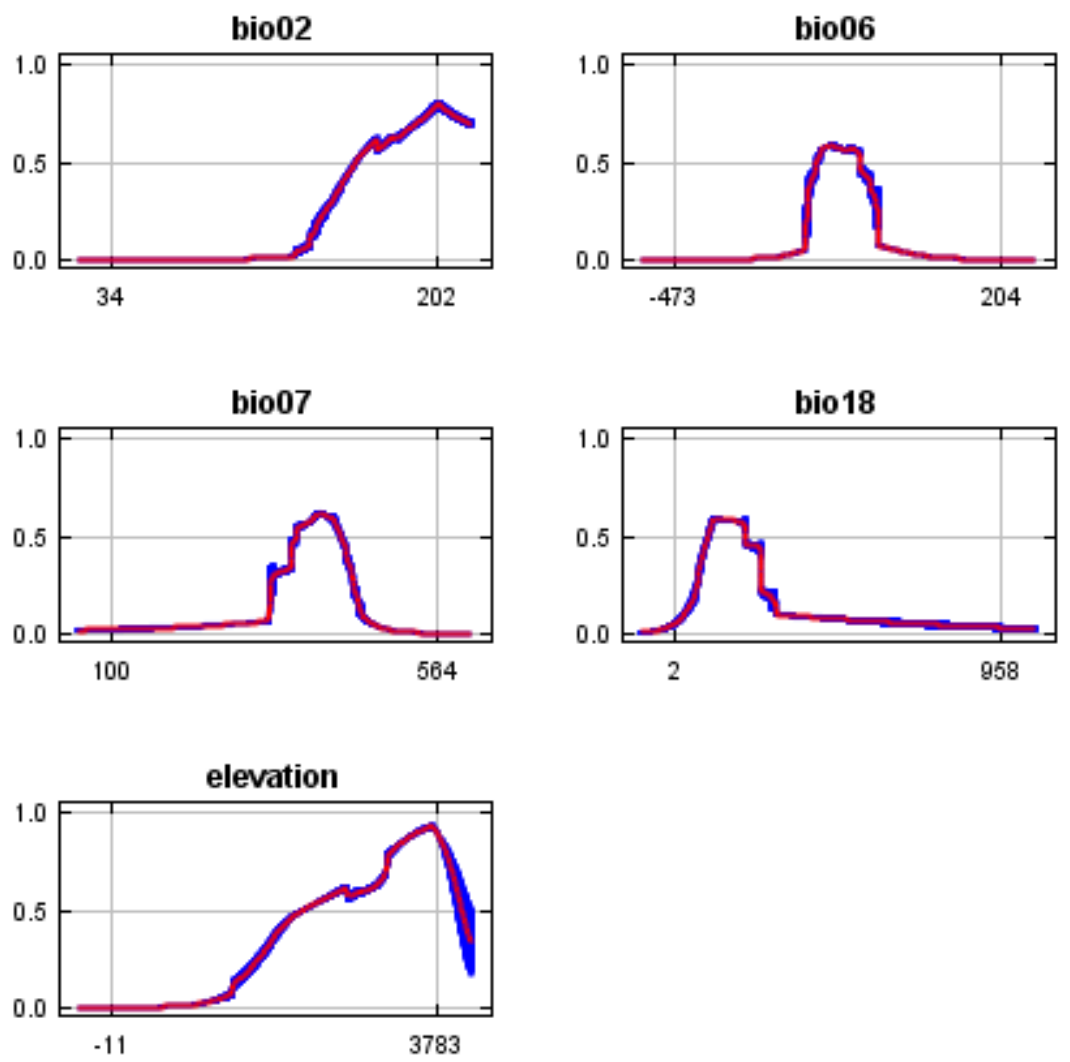
Analysis of variable contributions

The following table gives estimates of relative contributions of the environmental variables to the Maxent model. To determine the first estimate, in each iteration of the training algorithm, the increase in regularized gain is added to the contribution of the corresponding variable, or subtracted from it if the change to the absolute value of lambda is negative. For the second estimate, for each environmental variable in turn, the values of that variable on training presence and background data are randomly permuted. The model is reevaluated on the permuted data, and the resulting drop in training AUC is shown in the table, normalized to percentages. As with the variable jackknife, variable contributions should be interpreted with caution when the predictor variables are correlated. Values shown are averages over replicate runs.

Sylvilagus nuttallii grangeri

Table E1

Variable Percent contribution Permutation importance

$\begin{array}{ccc}\text { bio02 } & 53.7 & 43 \\ \text { bio11 } & 20.5 & 30.8 \\ \text { elevation } & 15.1 & 13.6 \\ \text { bio18 } & 10.8 & 12.6\end{array}$

Sylvilagus nuttallii nuttallii

Table E2

Variable Percent contribution Permutation importance

$\begin{array}{rrr}\text { bio09 } & 53.2 & 71 \\ \text { bio08 } & 25 & 9.2 \\ \text { bio18 } & 18.5 & 18.2 \\ \text { bio07 } & 3.3 & 1.7\end{array}$

Sylvilagus nuttallii pinetis

Table E3

Variable Percent contribution Permutation importance

$\begin{array}{ccc}\text { bio02 } & 45.9 & 1 \\ \text { elevation } & 40.1 & 48.8 \\ \text { bio06 } & 7.8 & 40.4 \\ \text { bio07 } & 3.4 & 7.4 \\ \text { bio18 } & 2.8 & 2.5\end{array}$


The following picture shows the results of the jackknife test of variable importance. The environmental variable with highest gain when used in isolation is bio02, which therefore appears to have the most useful information by itself. The environmental variable that decreases the gain the most when it is omitted is bio11, which therefore appears to have the most information that isn't present in the other variables. Values shown are averages over replicate runs.

Figure E25

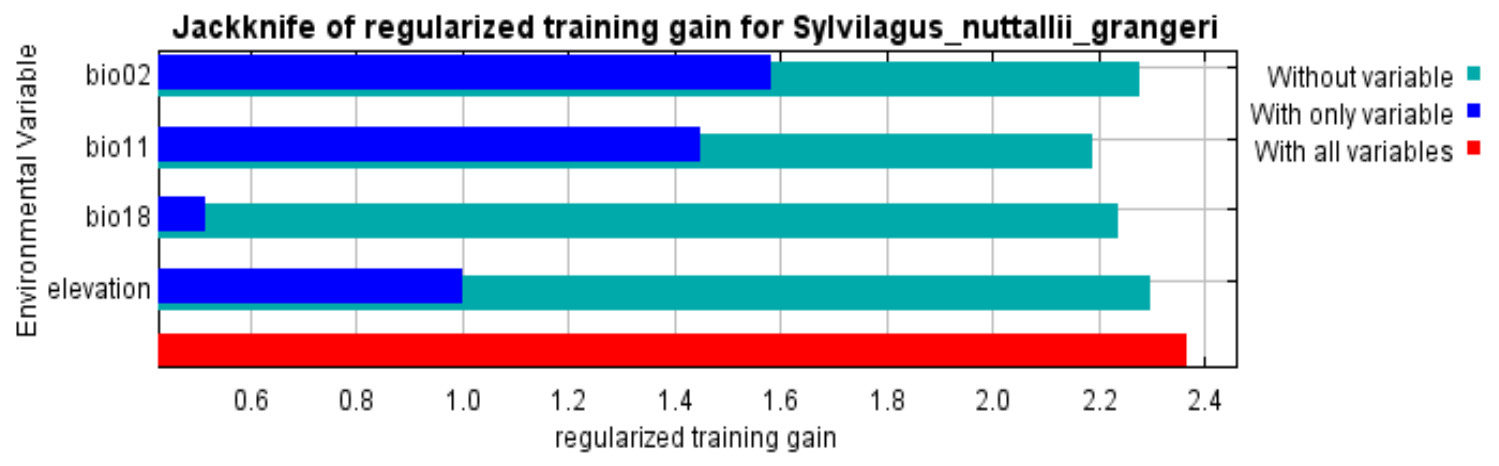

Figure E26

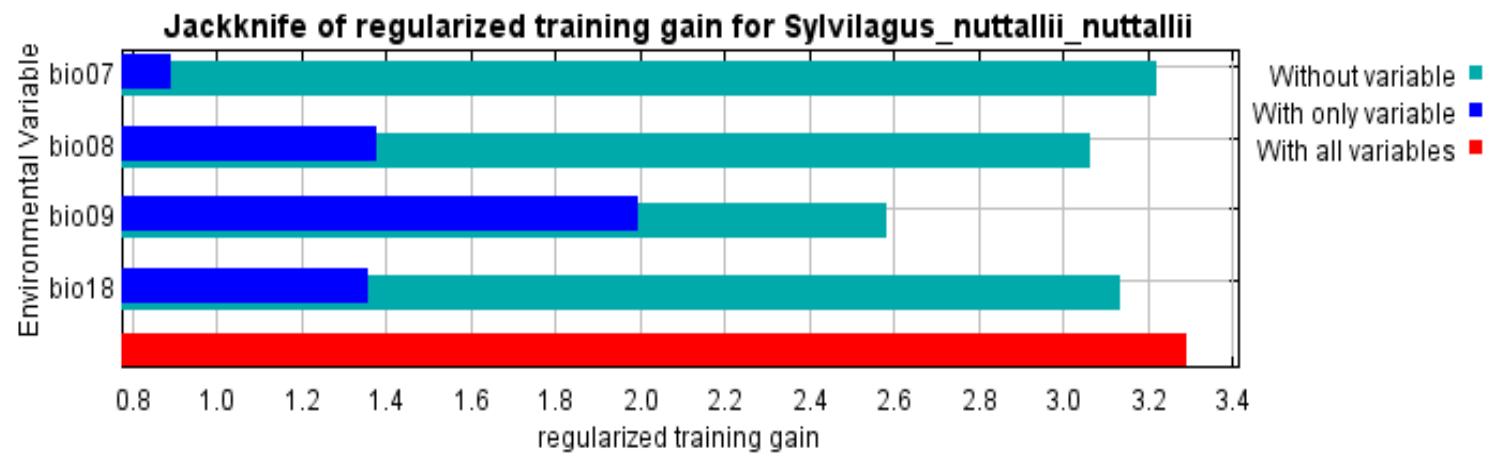

Figure E27

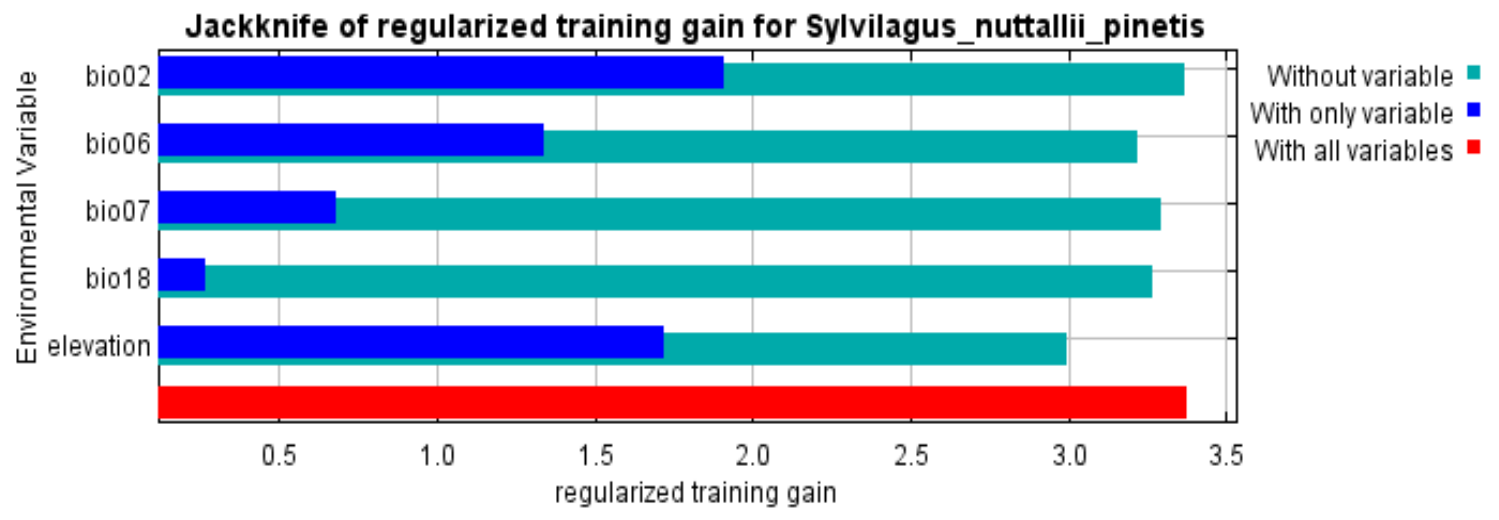

The next picture shows the same jackknife test, using test gain instead of training gain. 
Note that conclusions about which variables are most important can change, now that we're looking at test data.

Figure E28

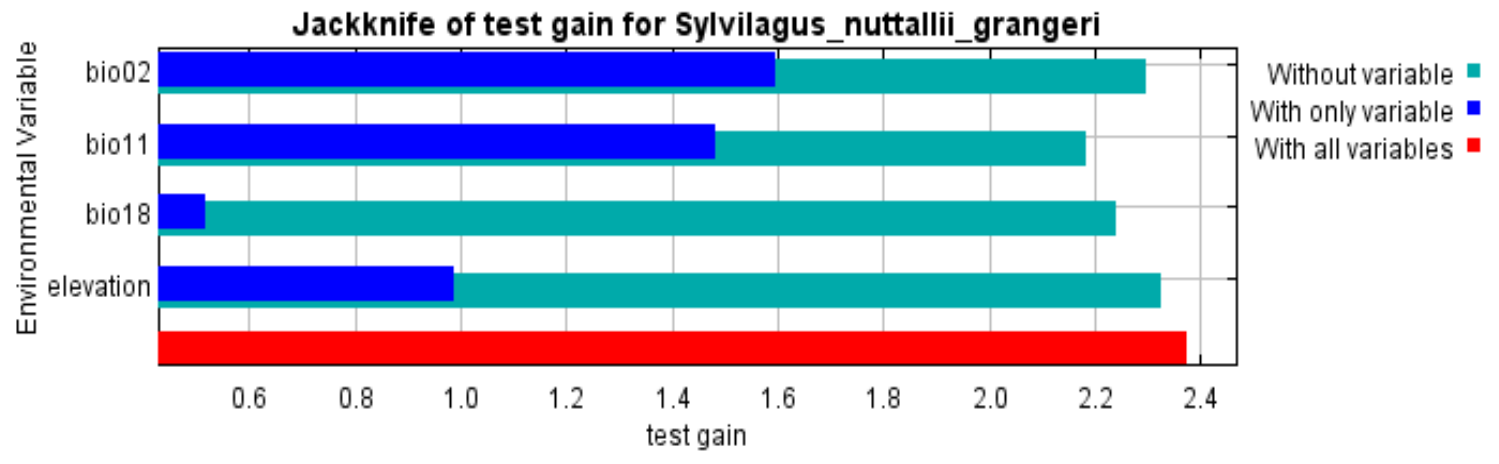

Figure E29

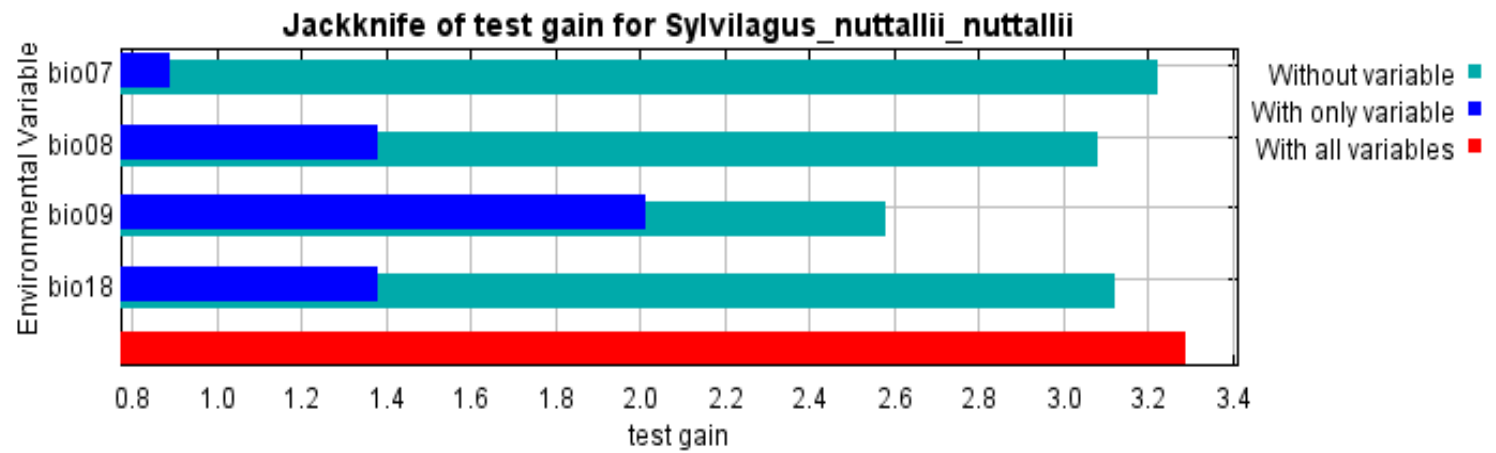

Figure E30

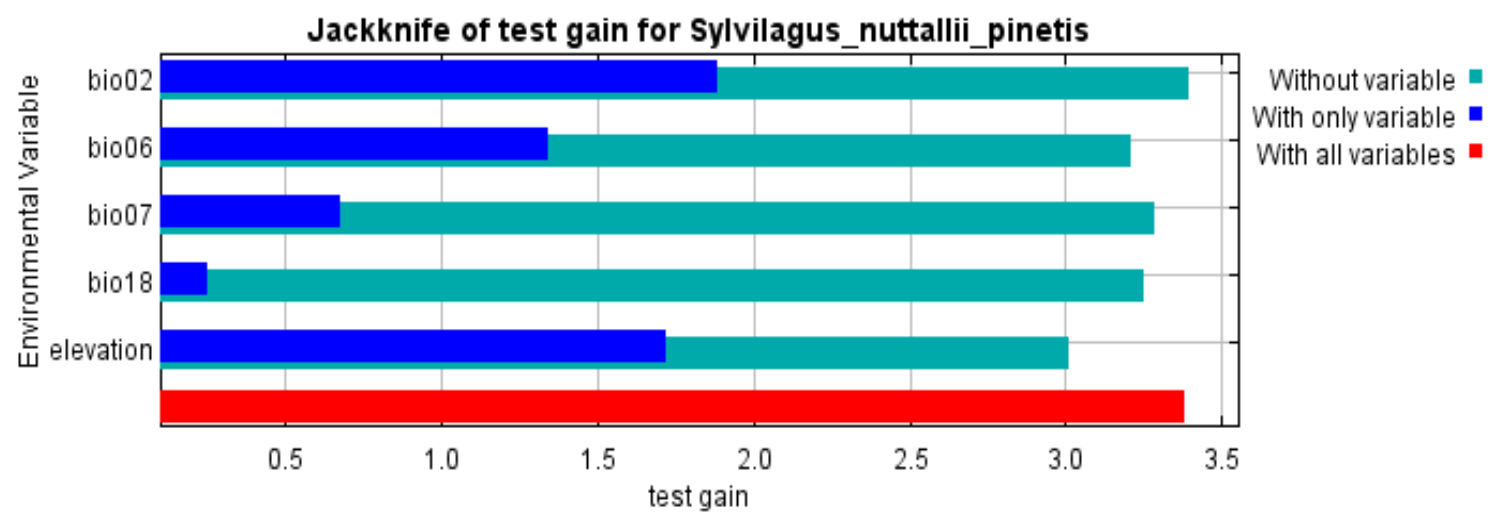

Lastly, we have the same jackknife test, using AUC on test data. 
Figure E31

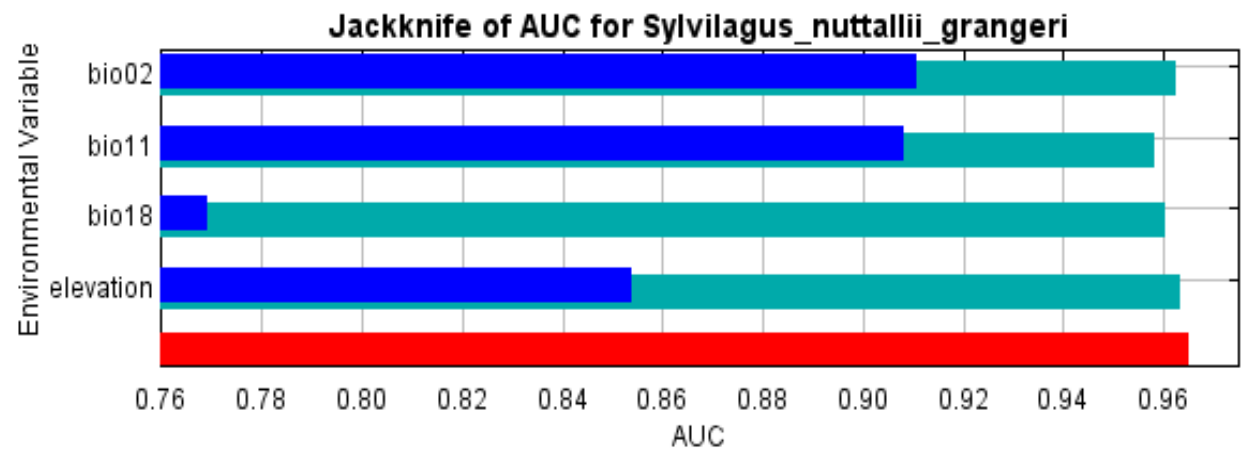

Without variable With only variable With all variables

Figure E32

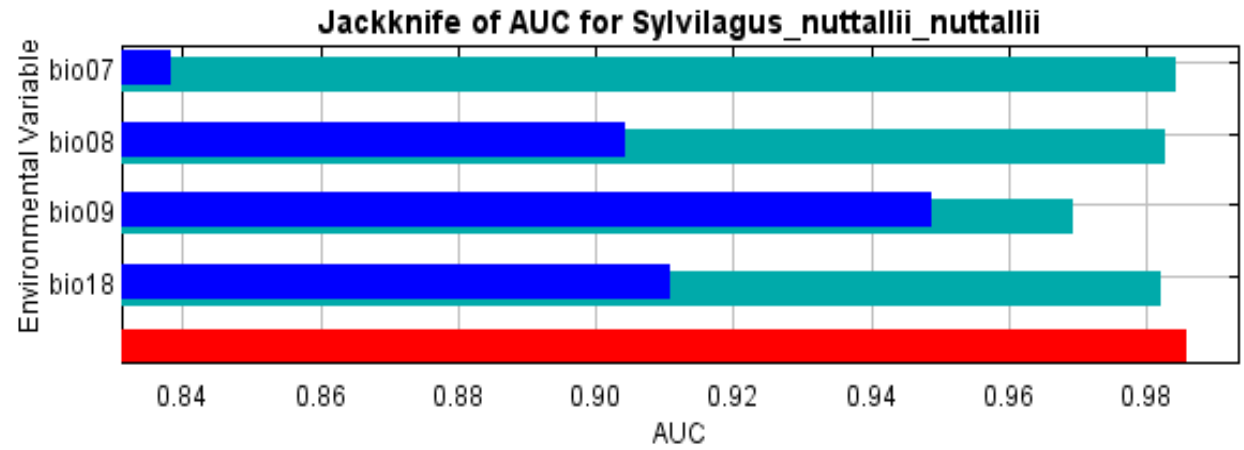

Without variable With only variable With all variables

Figure E33

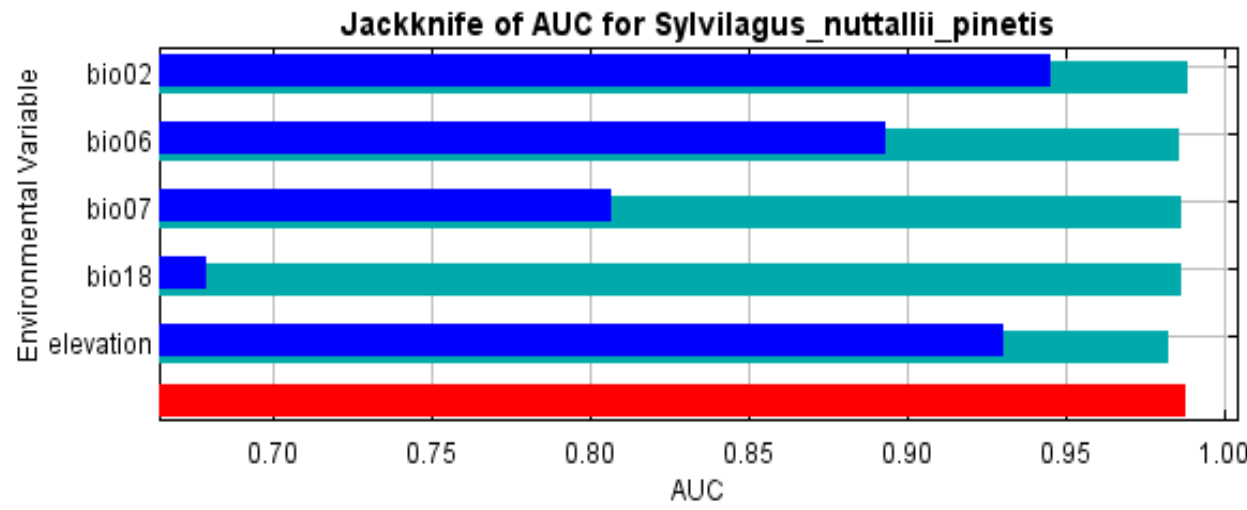

Without variable With only variable With all variables 


\section{APPENDIX F}

Model output results and figures for the Last Interglacial Period ( 120KYBP $\sim 140 \mathrm{KYBP}$ ).

\section{Analysis of omission/commission}

The following picture shows the test omission rate and predicted area as a function of the cumulative threshold, averaged over the replicate runs. The omission rate should be close to the predicted omission, because of the definition of the cumulative threshold.

Figure F1

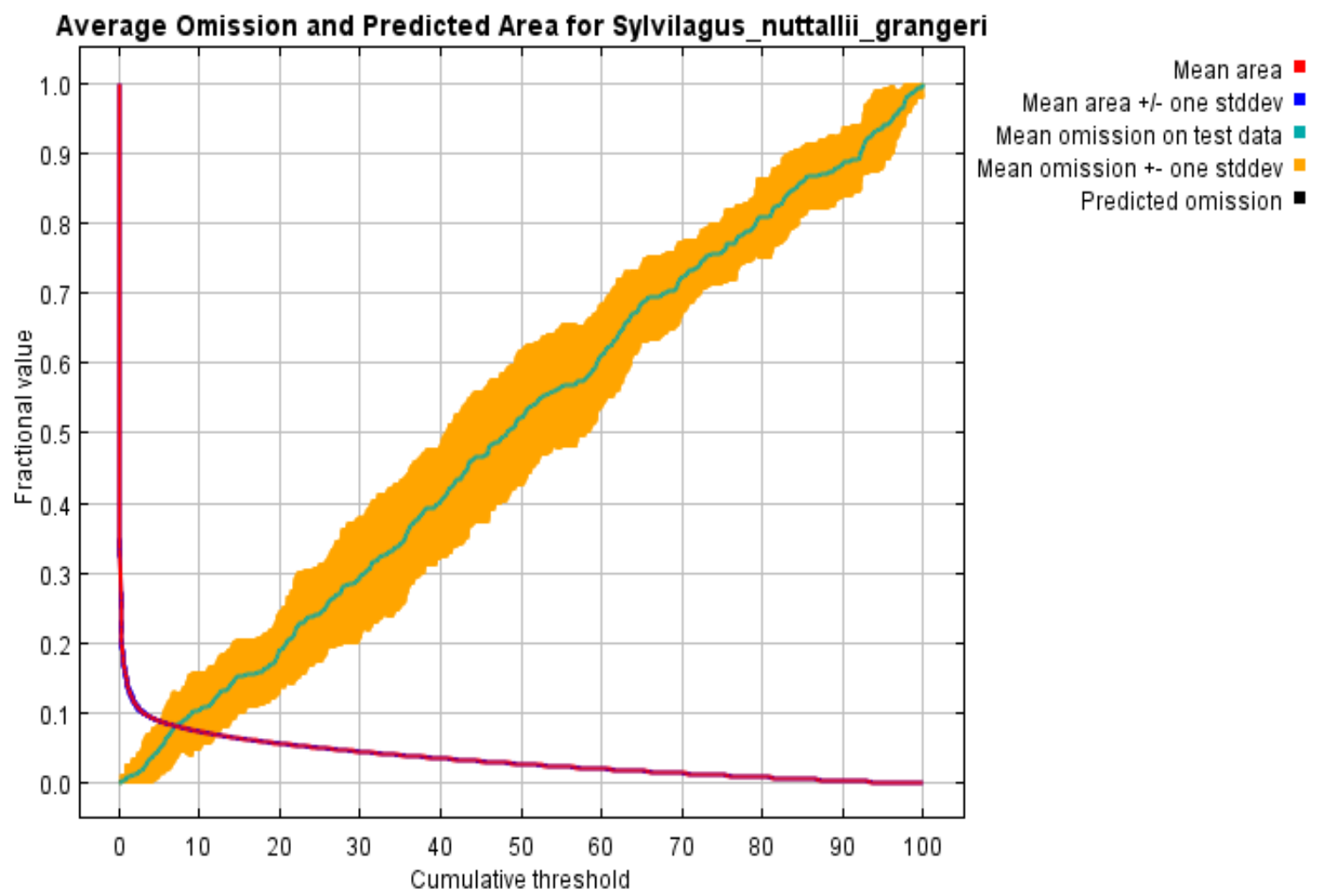


Figure F2

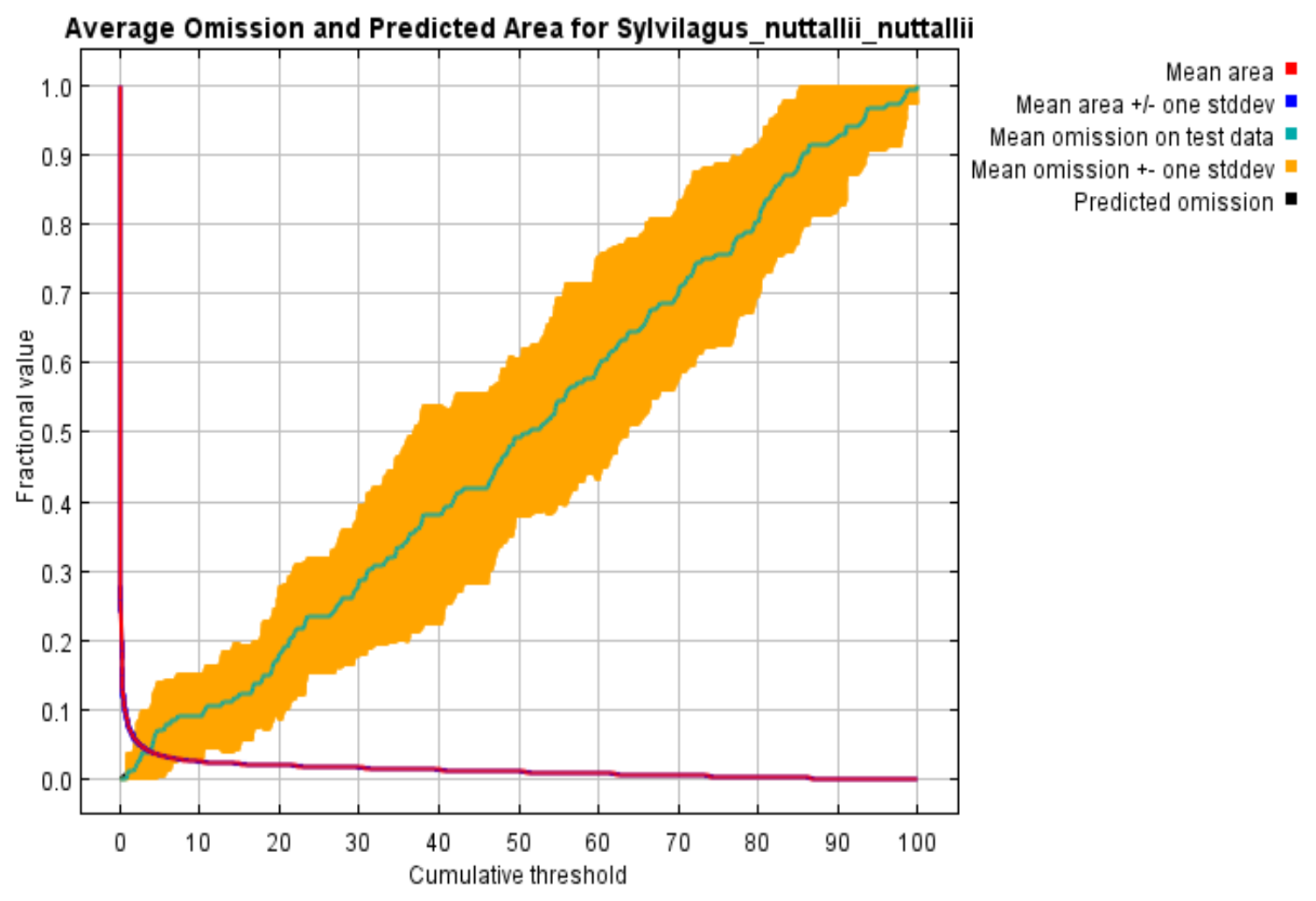


Figure F3

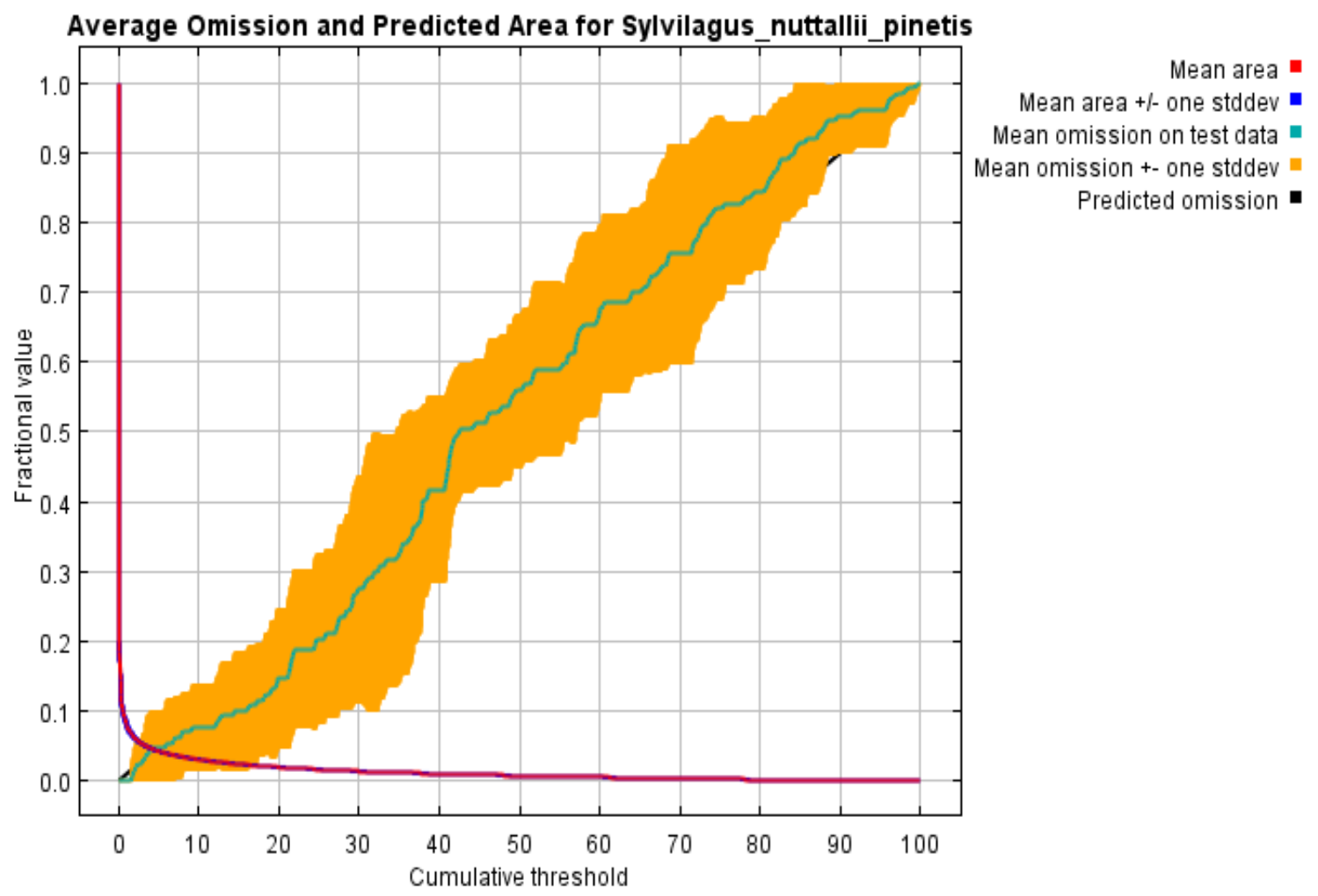

The next picture is the receiver operating characteristic (ROC) curve for the same data, again averaged over the replicate runs. Note that the specificity is defined using predicted area, rather than true commission (see the paper by Phillips, Anderson and Schapire cited for discussion of what this means). The average test AUC for the replicate runs is 0.965 , 0.986 , and 0.988 respectively and the standard deviation is 0.005 . 
Figure F4

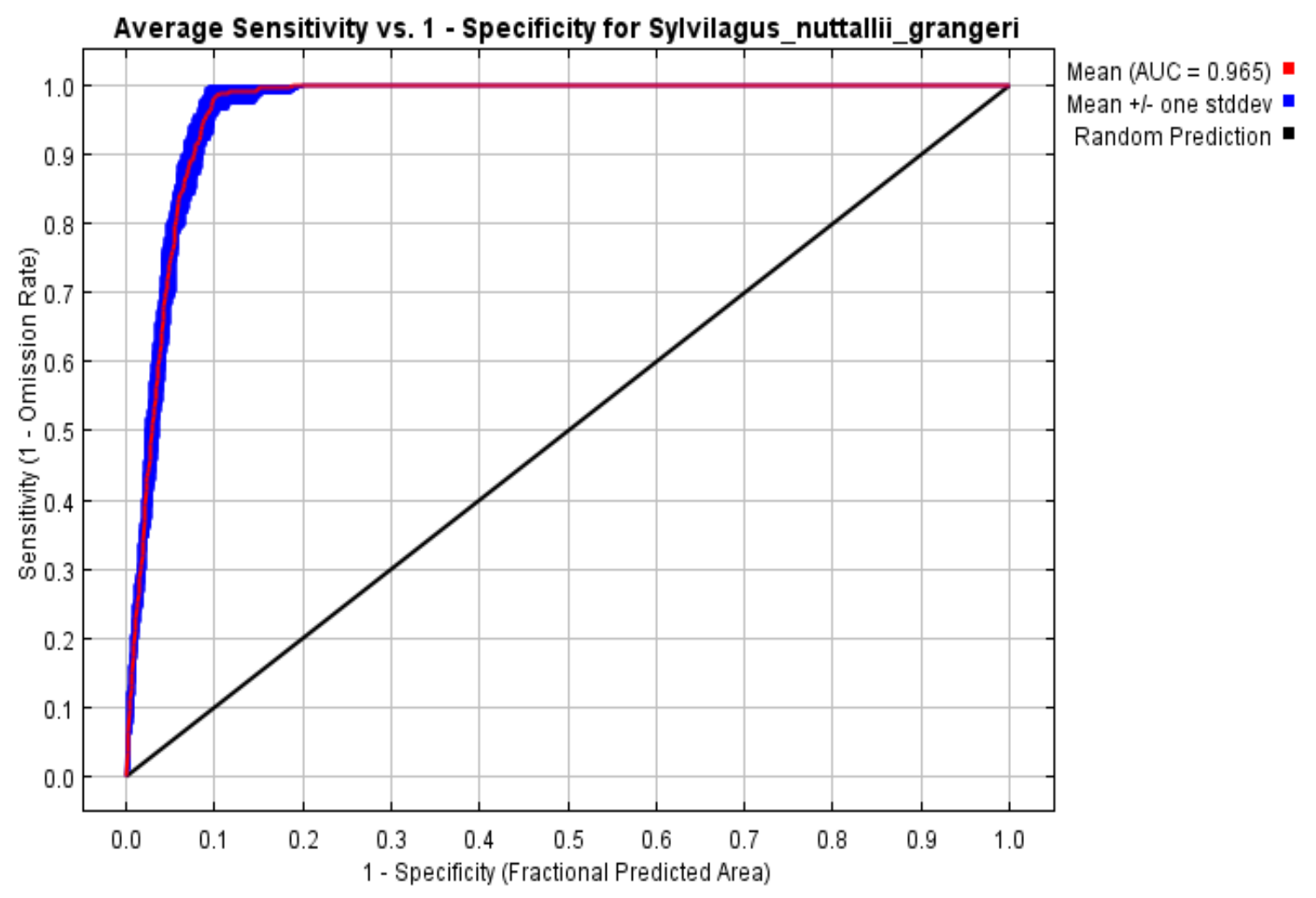


Figure F5

Average Sensitivity vs. 1 - Specificity for Sylvilagus nuttallii nuttallii

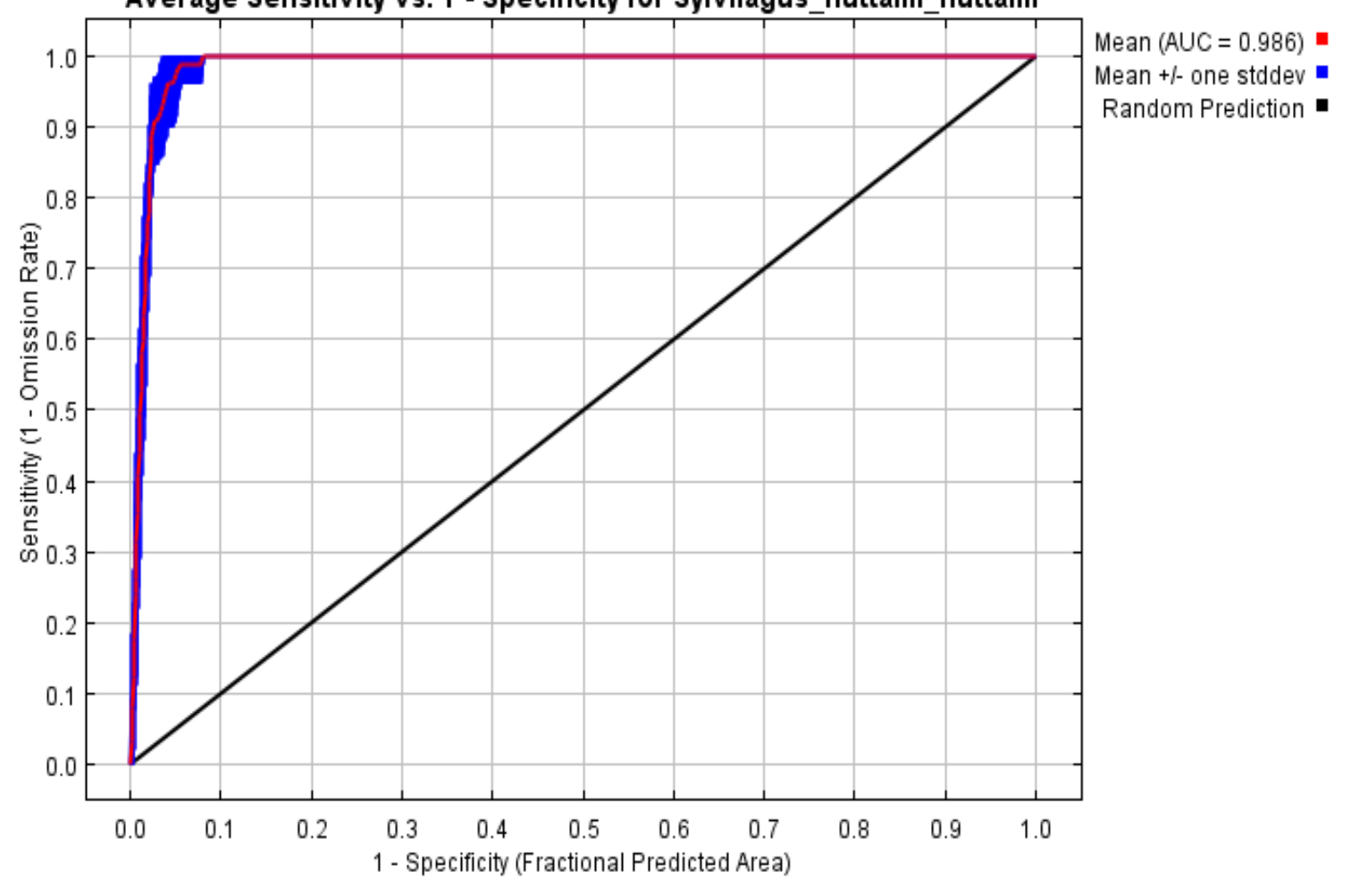


Figure F6

Average Sensitivity vs. 1 - Specificity for Sylvilagus_nuttallii_pinetis

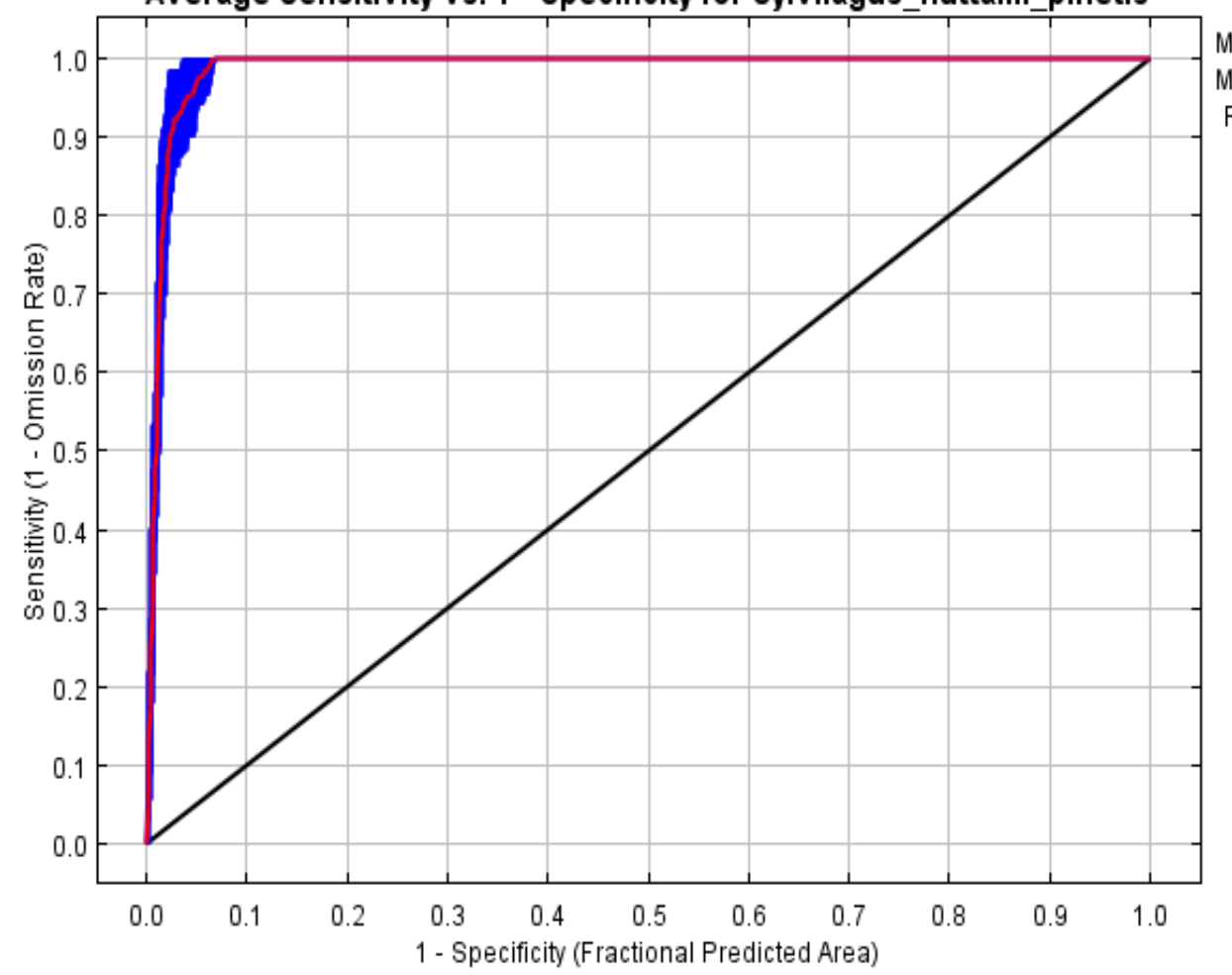

Mean $(\mathrm{AUC}=0.988)$ Mean + - one stddev -

Random Prediction -

Pictures of the model

The following pictures show the point-wise mean and standard deviation of the 10 output grids. Other available summary grids are $\underline{\min }, \underline{\max }$ and median.

Sylvilagus nuttallii grangeri:

Figure F7

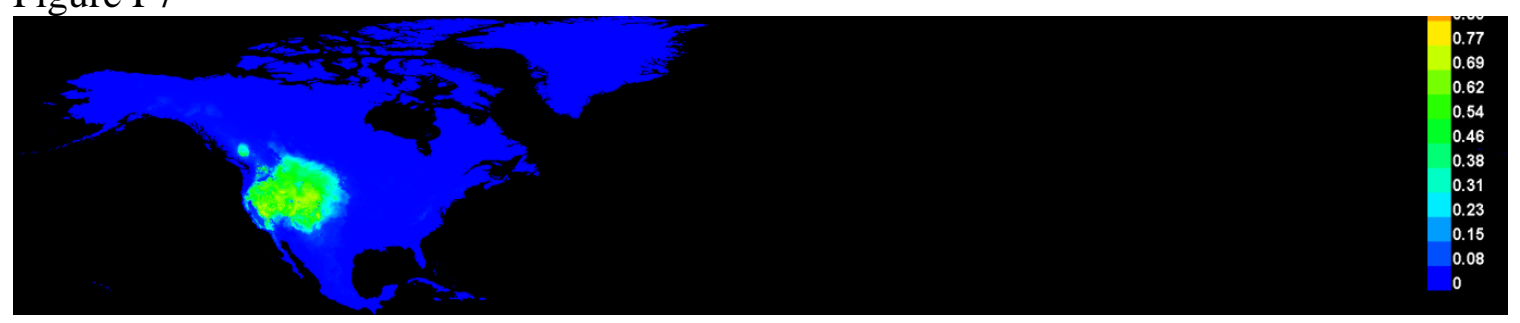

Figure F8

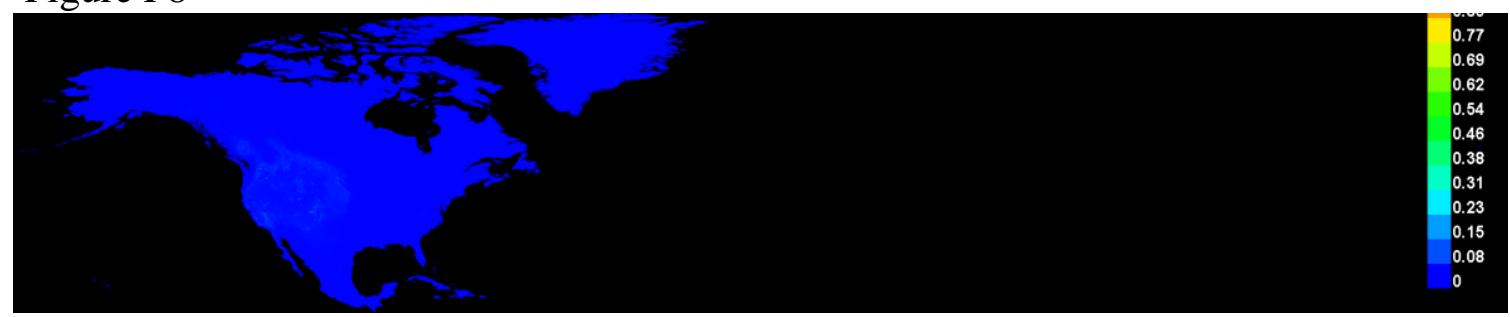


Sylvilagus nuttallii nuttallii:

Figure F9

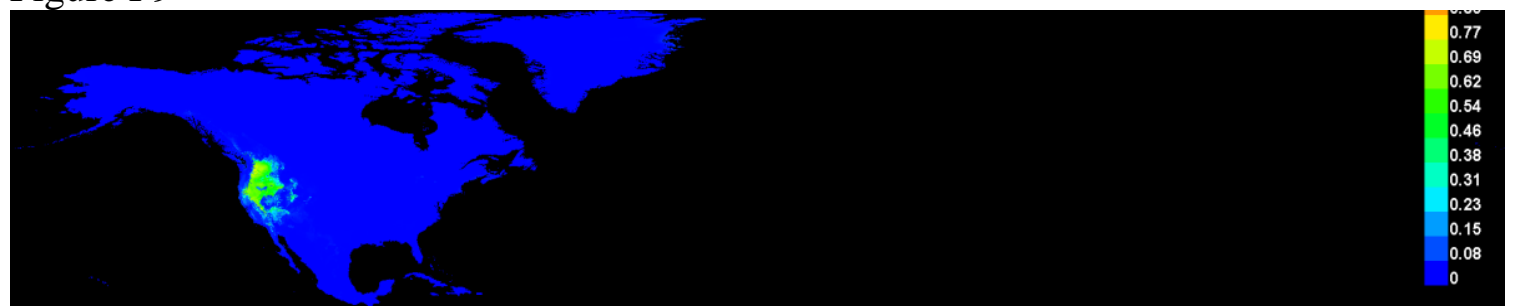

Figure F10

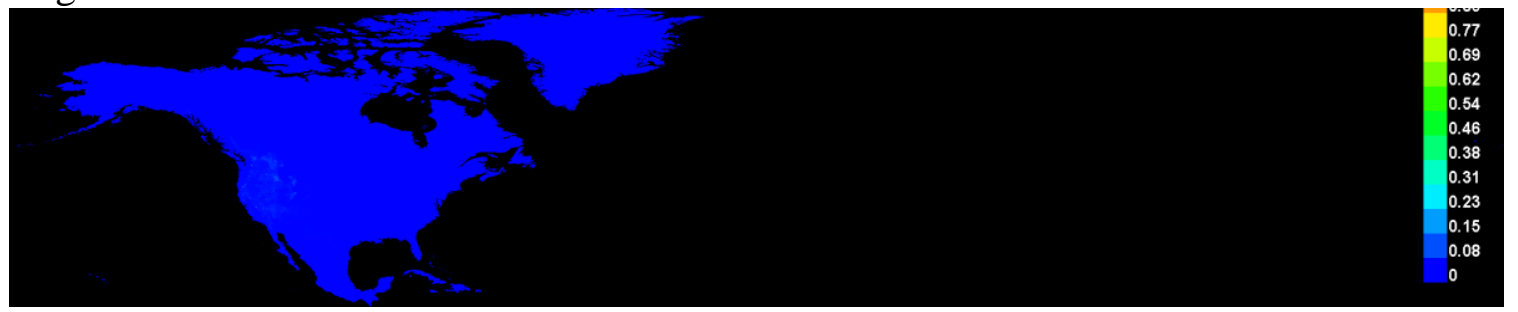

Sylvilagus nuttallii pinetis:

Figure F11

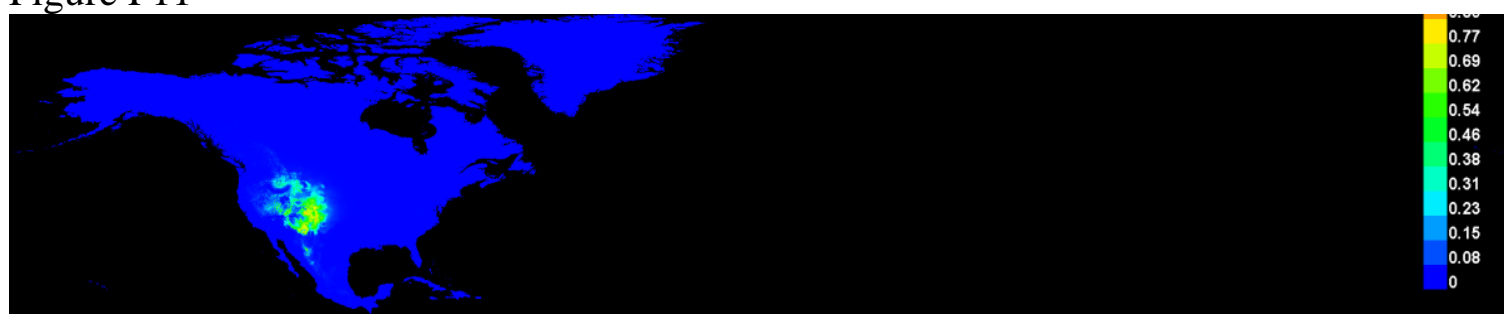

Figure F12

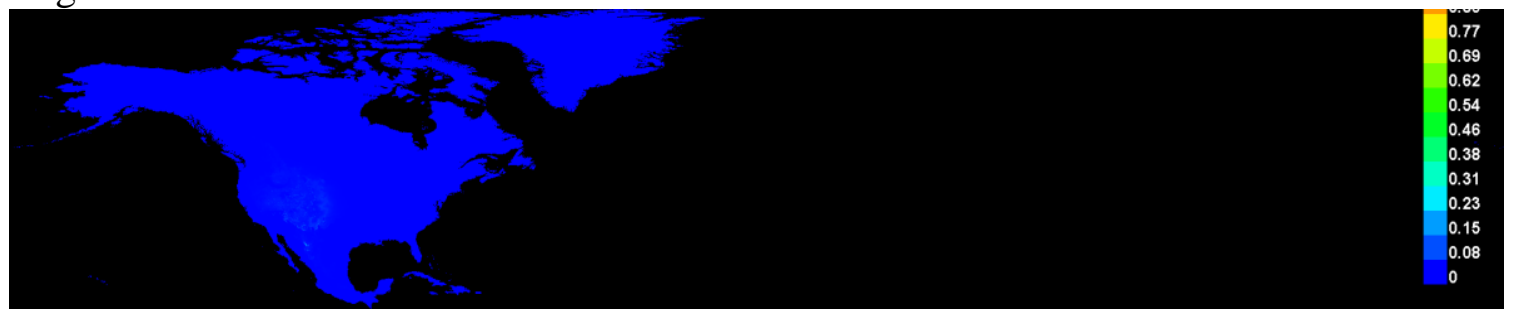

The following pictures show the point-wise mean and standard deviation of the 10 
models applied to the environmental layers in ASCII. Other available summary grids are $\underline{\min }, \underline{\max }$ and median.

Sylvilagus nuttallii grangeri

Figure F13

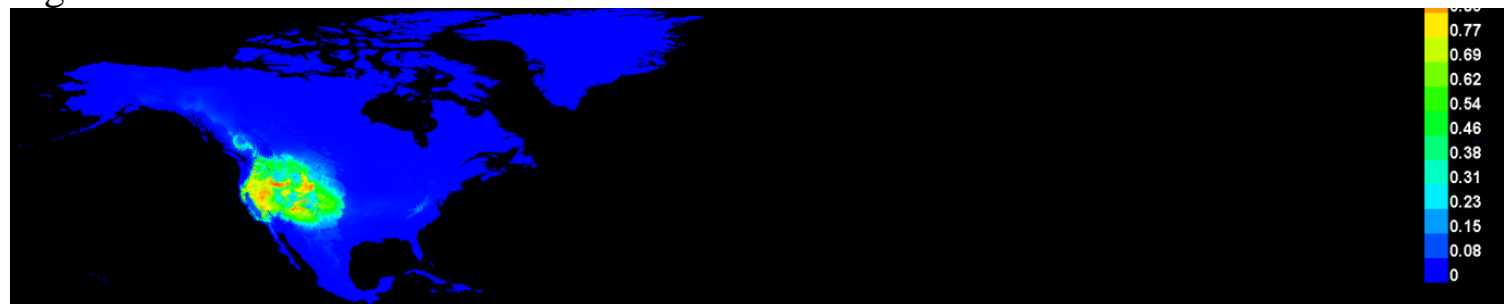

Figure F14

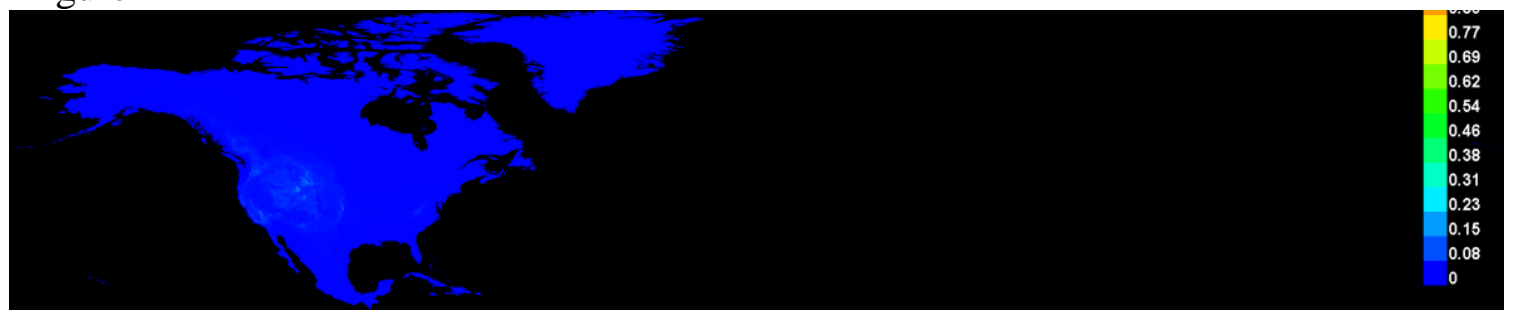

Sylvilagus nuttallii nuttallii:

Figure F15

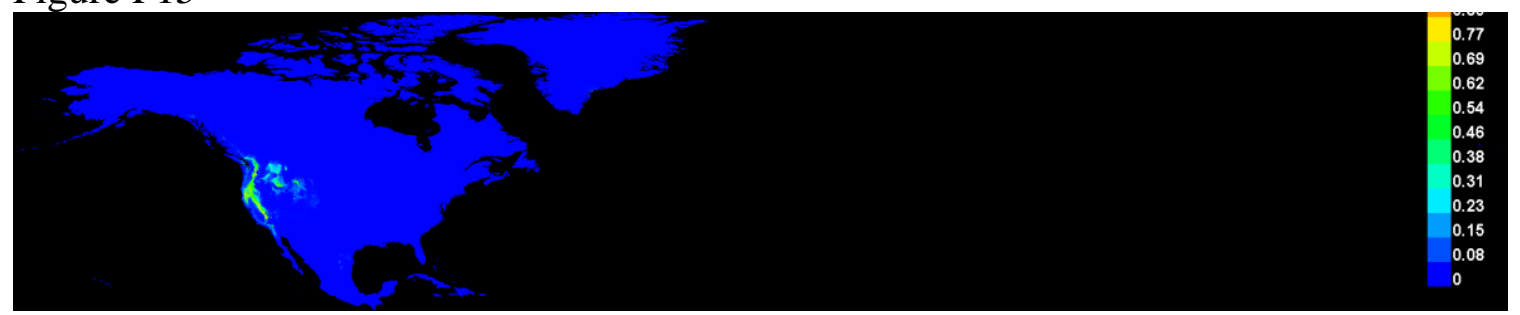

Figure F16

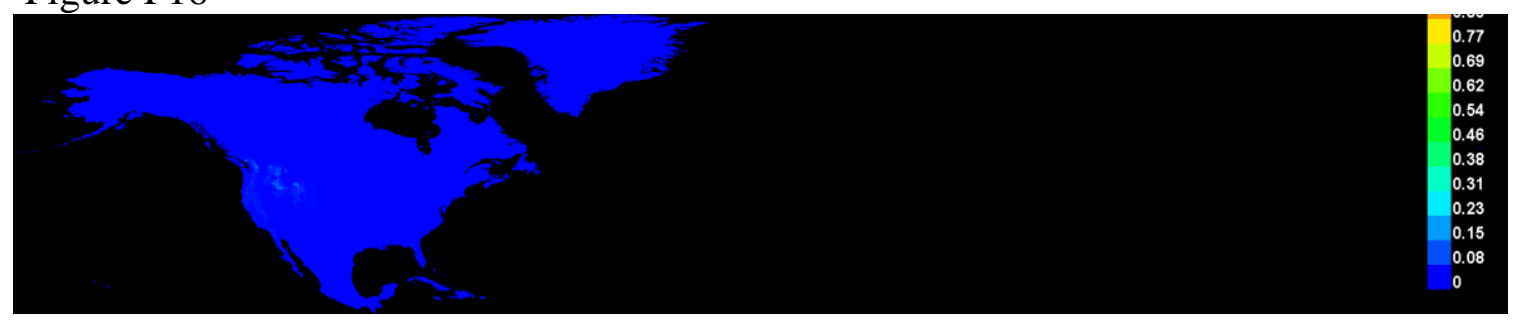


Sylvilagus nuttallii pinetis

Figure F17

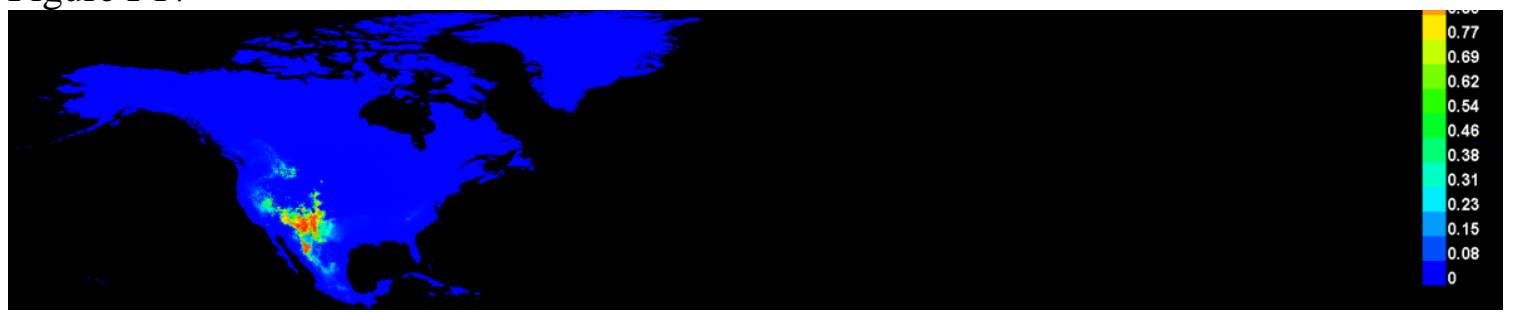

Figure F18

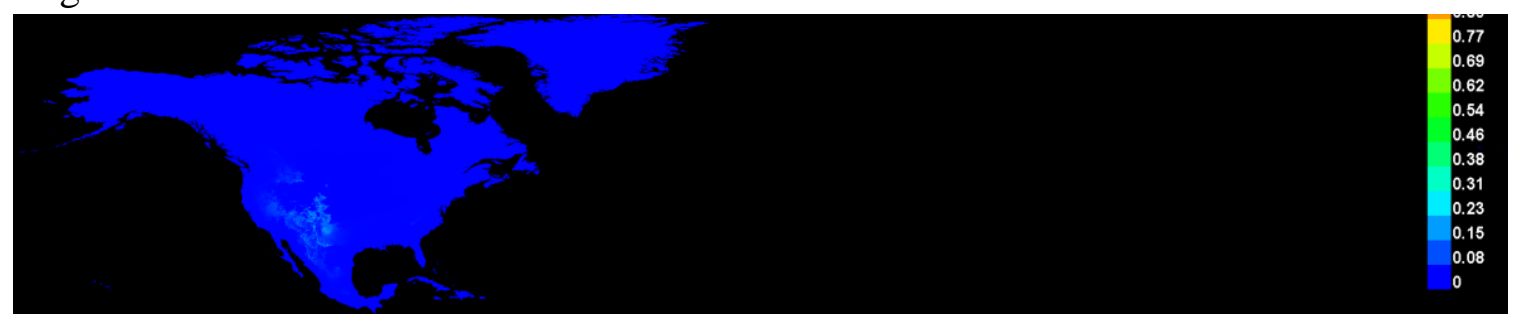




\section{Response curves}

These curves show how each environmental variable affects the Maxent prediction. The curves show how the logistic prediction changes as each environmental variable is varied, keeping all other environmental variables at their average sample value. Click on a response curve to see a larger version. Note that the curves can be hard to interpret if you have strongly correlated variables, as the model may depend on the correlations in ways that are not evident in the curves. In other words, the curves show the marginal effect of changing exactly one variable, whereas the model may take advantage of sets of variables changing together. The curves show the mean response of the 10 replicate Maxent runs (red) and and the mean $+/$ - one standard deviation (blue, two shades for categorical variables).

Sylvilagus nuttallii grangeri

Figure F19
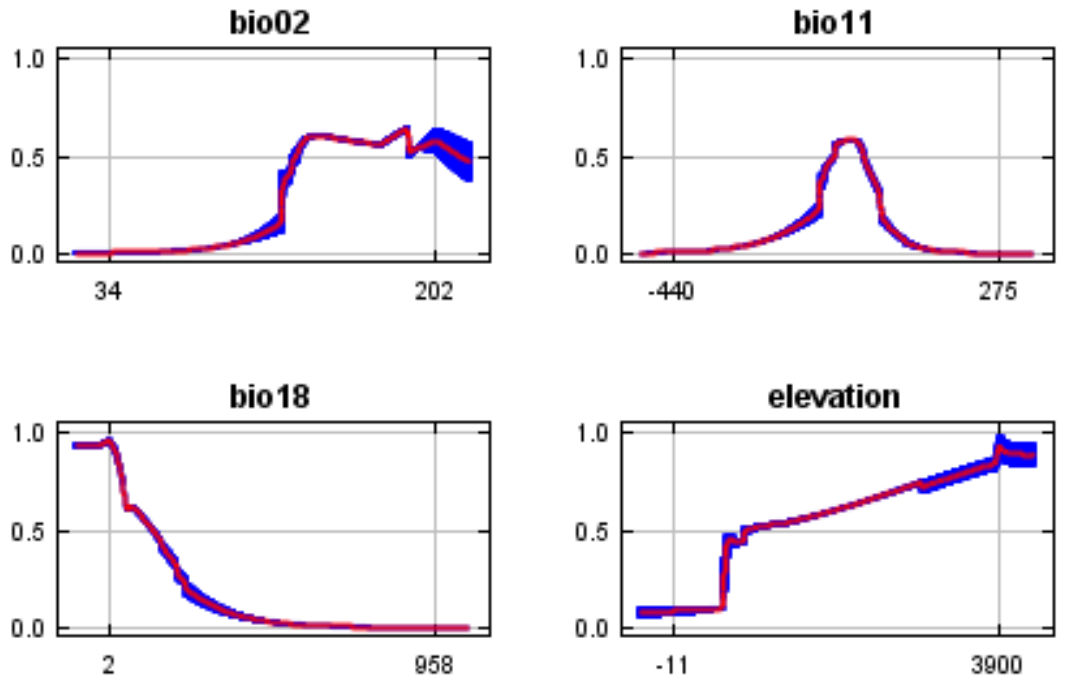
Sylvilagus nuttallii nuttallii

Figure F20
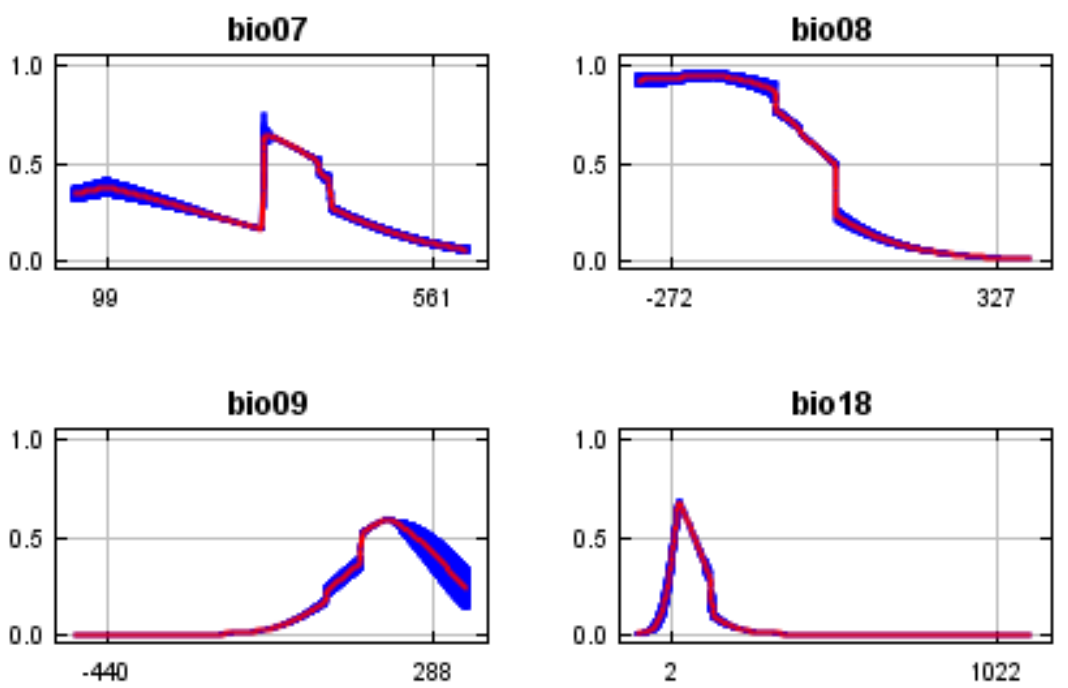

Sylvilagus nuttallii pinetis

Figure F21
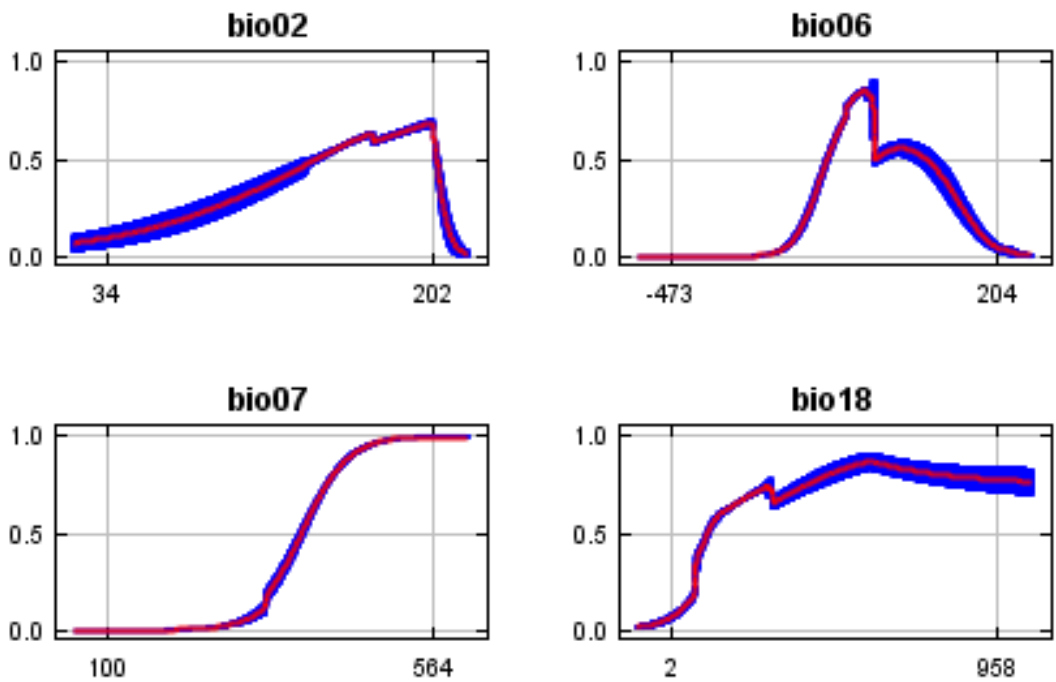


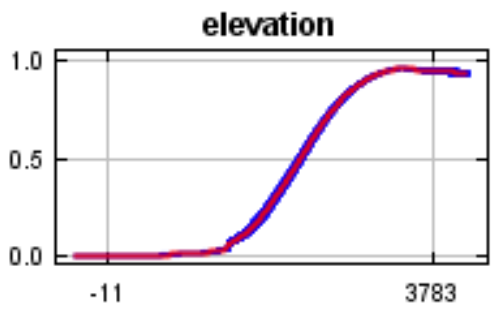

In contrast to the above marginal response curves, each of the following curves represents a different model, namely, a Maxent model created using only the corresponding variable. These plots reflect the dependence of predicted suitability both on the selected variable and on dependencies induced by correlations between the selected variable and other variables. They may be easier to interpret if there are strong correlations between variables.

Sylvilagus nuttallii grangeri

Figure F22
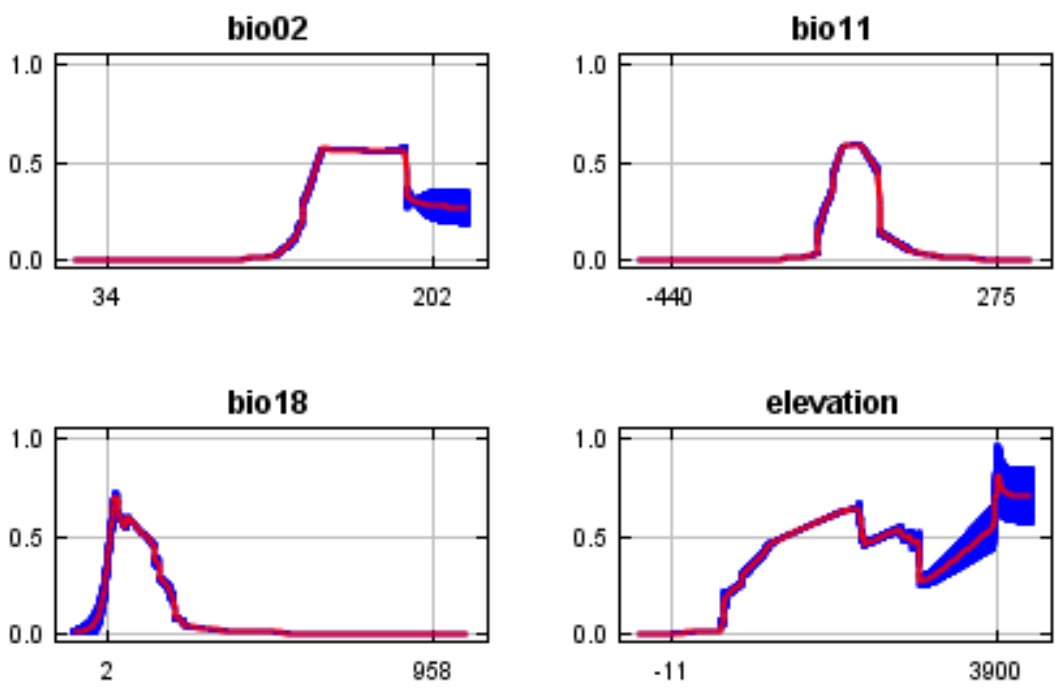
Sylvilagus nuttallii nuttallii

Figure F23
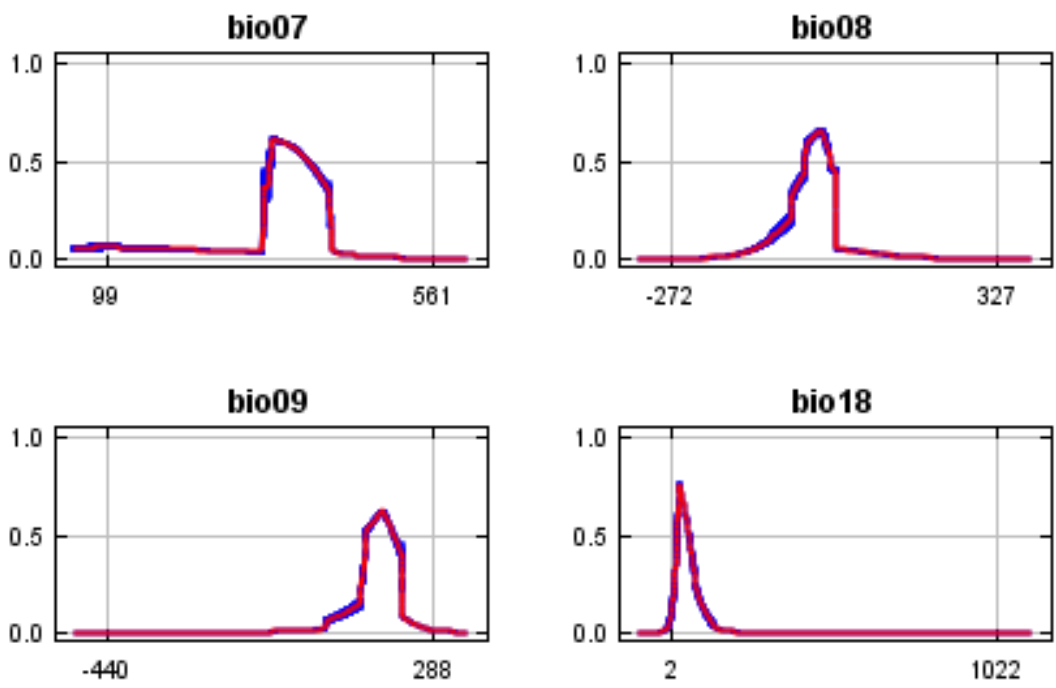

Sylvilagus nuttallii pinetis

Figure F24
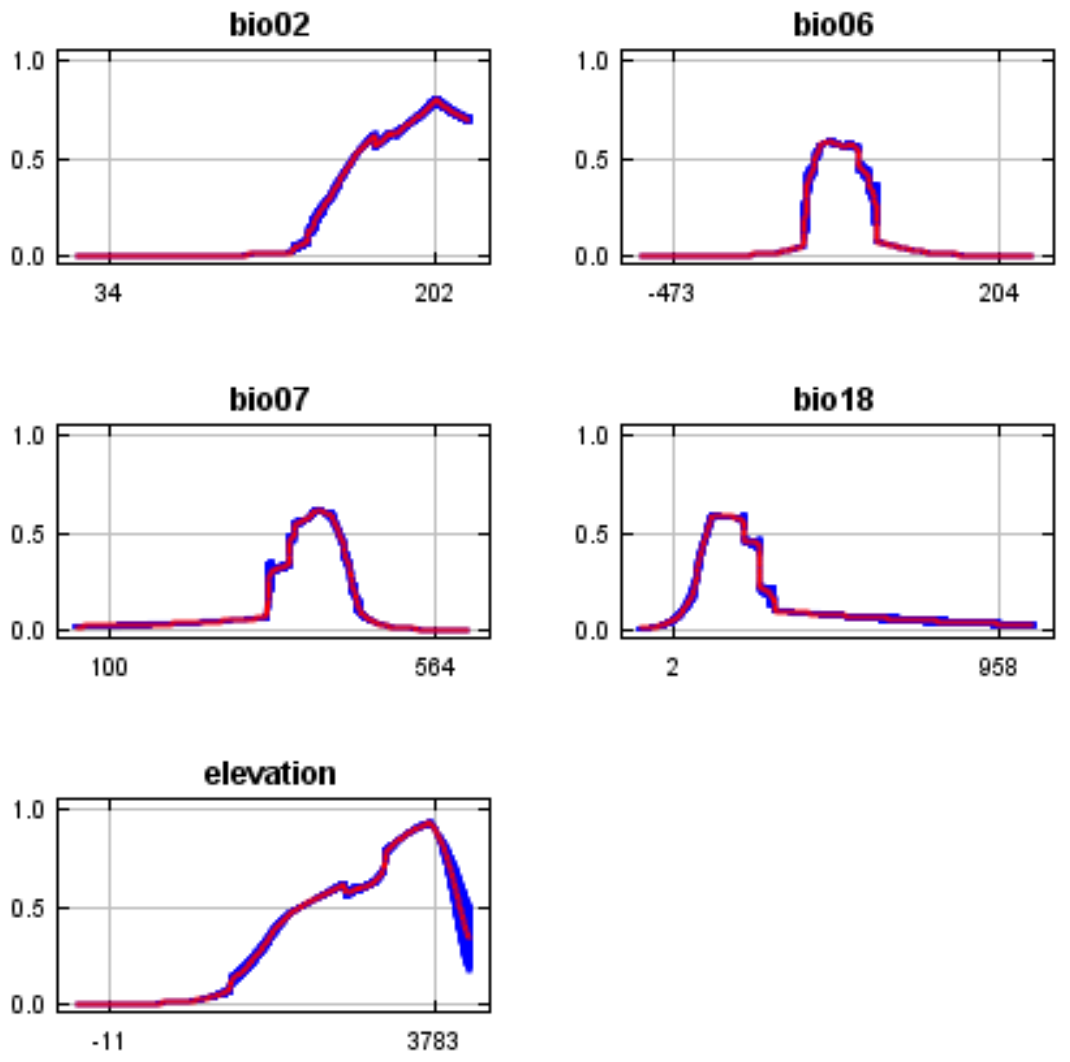
Analysis of variable contributions

The following table gives estimates of relative contributions of the environmental variables to the Maxent model. To determine the first estimate, in each iteration of the training algorithm, the increase in regularized gain is added to the contribution of the corresponding variable, or subtracted from it if the change to the absolute value of lambda is negative. For the second estimate, for each environmental variable in turn, the values of that variable on training presence and background data are randomly permuted. The model is reevaluated on the permuted data, and the resulting drop in training AUC is shown in the table, normalized to percentages. As with the variable jackknife, variable contributions should be interpreted with caution when the predictor variables are correlated. Values shown are averages over replicate runs.

Sylvilagus nuttallii grangeri

Table F1

Variable Percent contribution Permutation importance

$\begin{array}{ccc}\text { bio02 } & 53.7 & 43 \\ \text { bio11 } & 20.5 & 30.8 \\ \text { elevation } & 15.1 & 13.6 \\ \text { bio18 } & 10.8 & 12.6\end{array}$

Sylvilagus nuttallii nuttallii

Table F2

Variable Percent contribution Permutation importance

$\begin{array}{ccc}\text { bio09 } & 53.2 & 71 \\ \text { bio08 } & 25 & 9.2 \\ \text { bio18 } & 18.5 & 18.2 \\ \text { bio07 } & 3.3 & 1.7\end{array}$

Sylvilagus nuttallii pinetis

Table F3

Variable Percent contribution Permutation importance

$\begin{array}{ccc}\text { bio02 } & 45.9 & 1 \\ \text { elevation } & 40.1 & 48.8 \\ \text { bio06 } & 7.8 & 40.4 \\ \text { bio07 } & 3.4 & 7.4 \\ \text { bio18 } & 2.8 & 2.5\end{array}$

The following picture shows the results of the jackknife test of variable importance. The environmental variable with highest gain when used in isolation is bio02, which therefore 
appears to have the most useful information by itself. The environmental variable that decreases the gain the most when it is omitted is bio11, which therefore appears to have the most information that isn't present in the other variables. Values shown are averages over replicate runs.

Figure F25

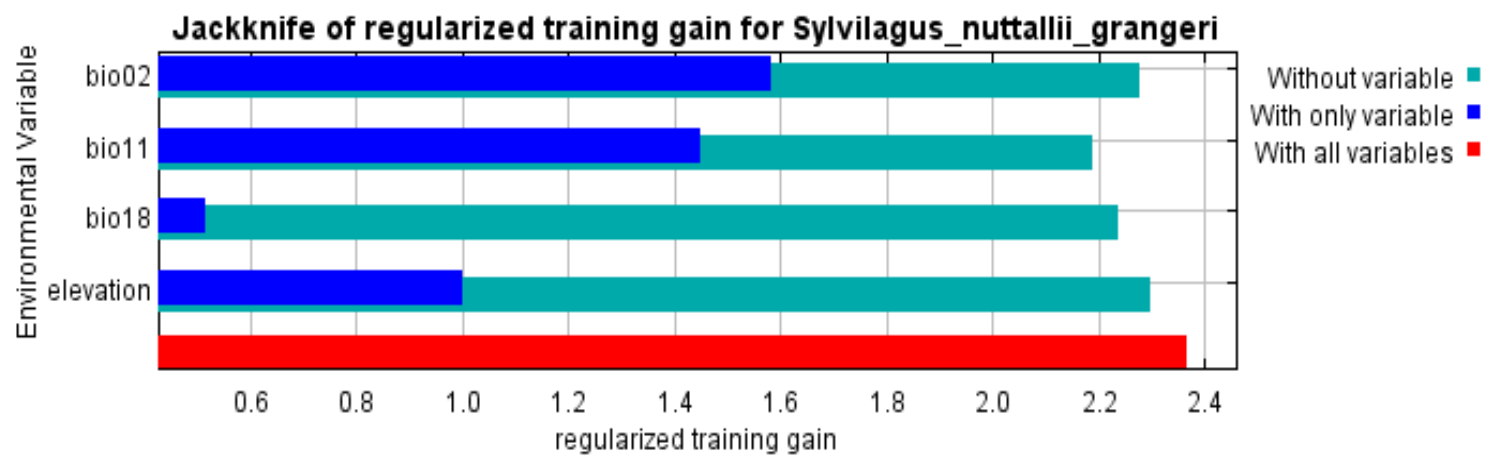

Figure F26

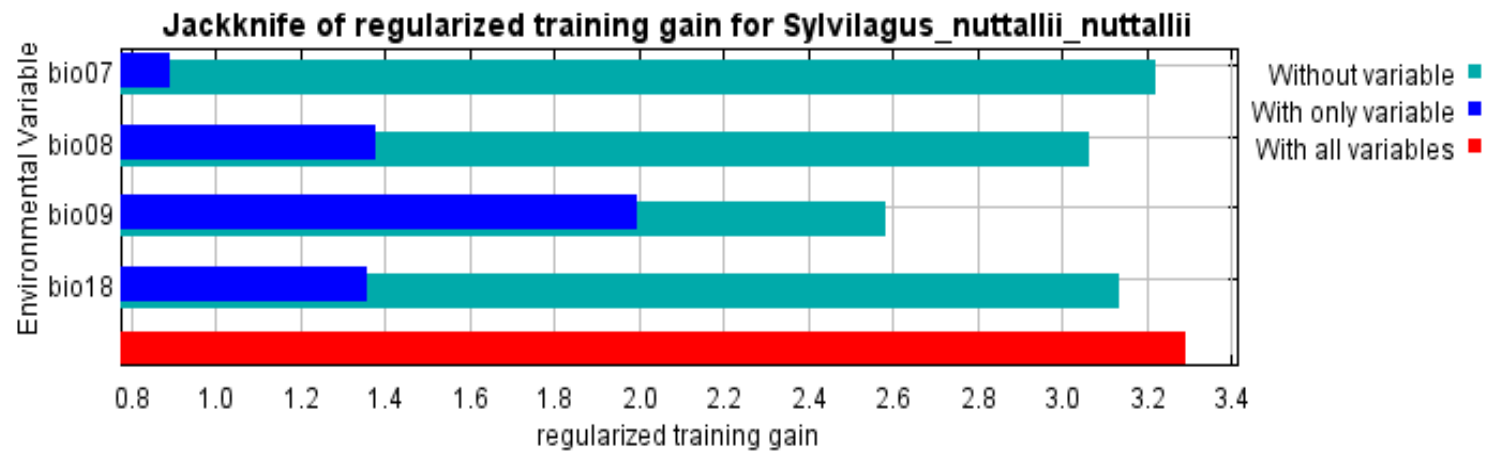

Figure F27

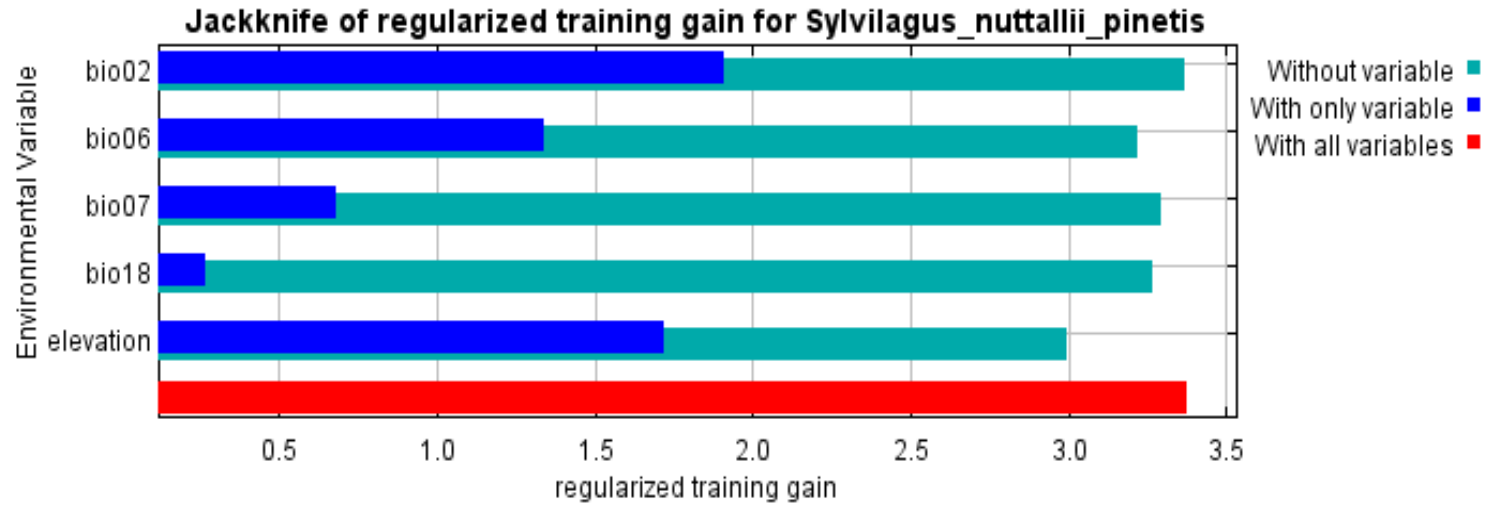

The next picture shows the same jackknife test, using test gain instead of training gain. Note that conclusions about which variables are most important can change, now that we're looking at test data. 
Figure F28

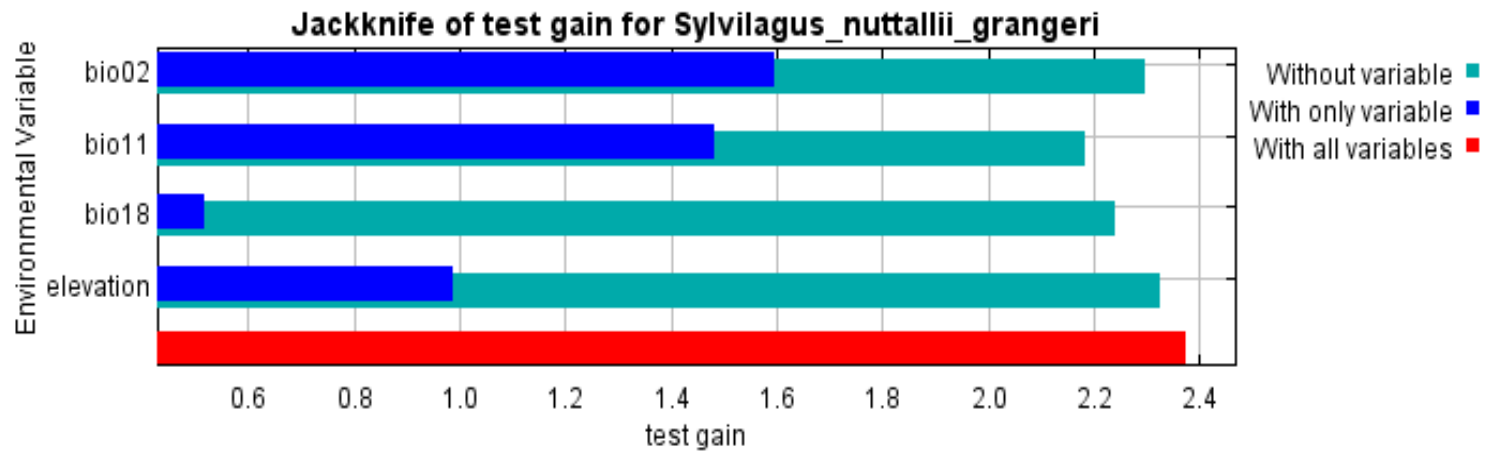

Figure F29

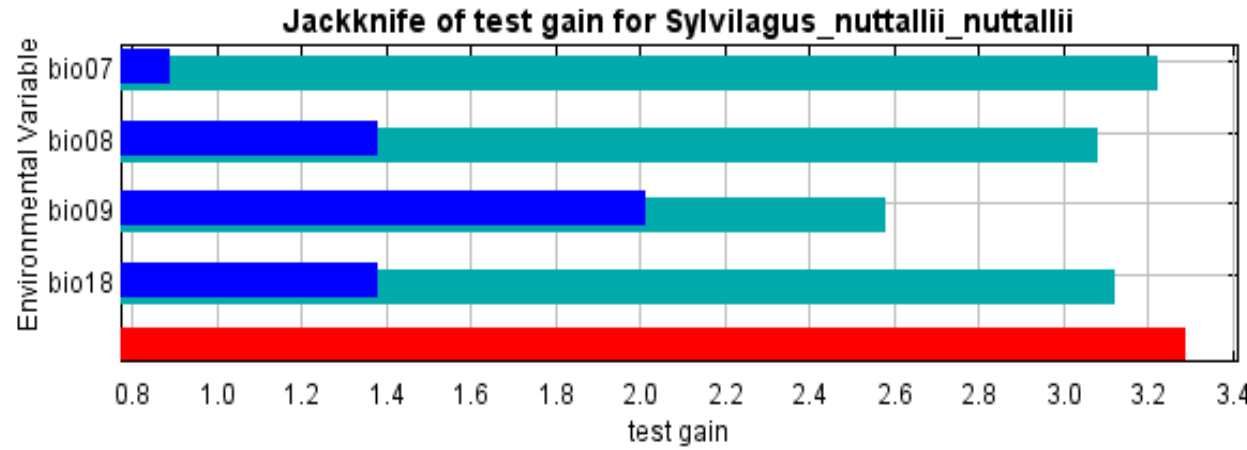

Without variable With only variable With all variables

Figure F30

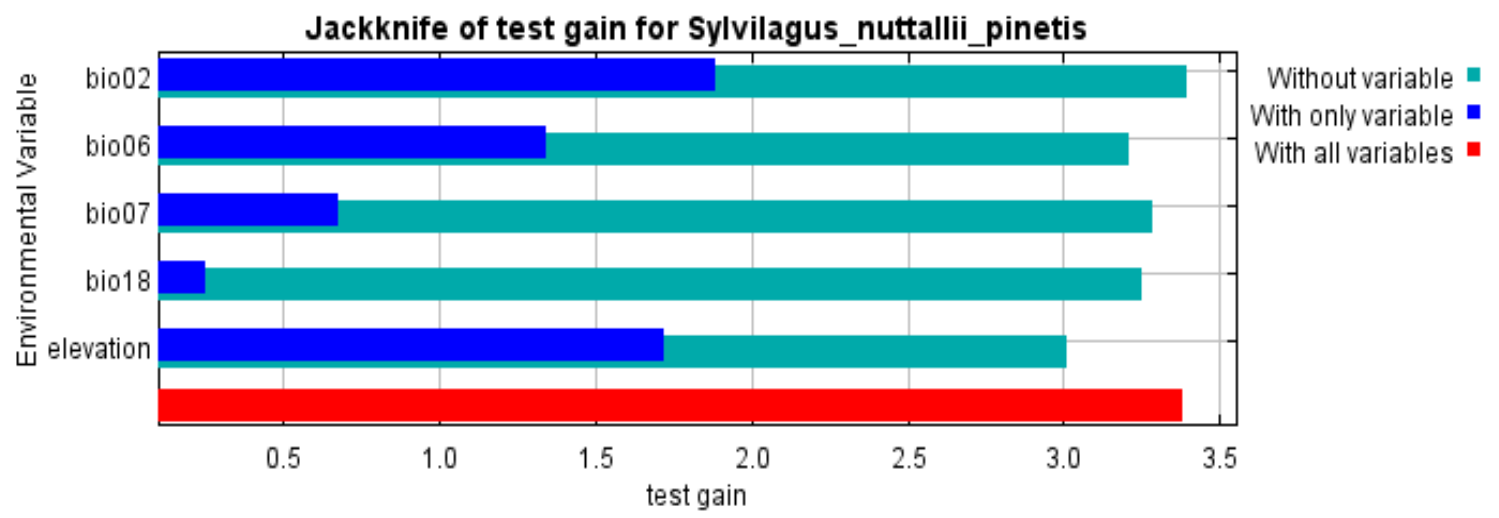


Lastly, we have the same jackknife test, using AUC on test data.

Figure F31

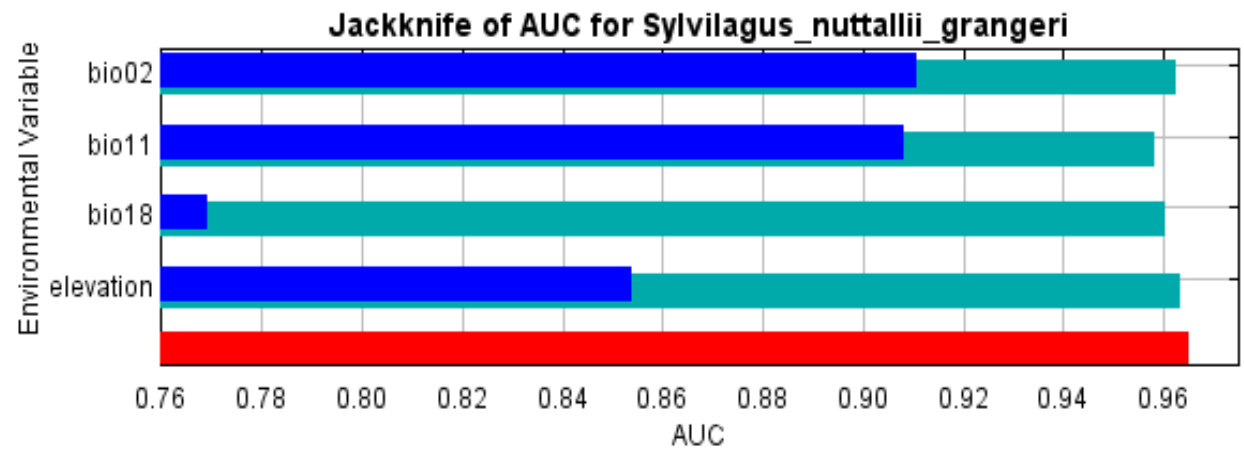

Without variable

With only variable

With all variables

Figure F32

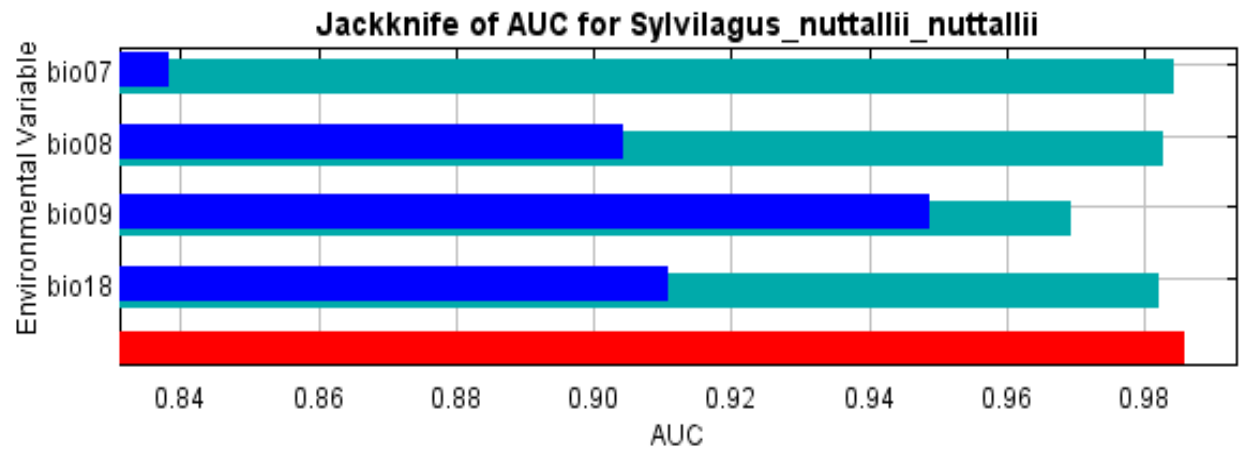

Without variable With only variable With all variables $\mathrm{E}$

Figure F33

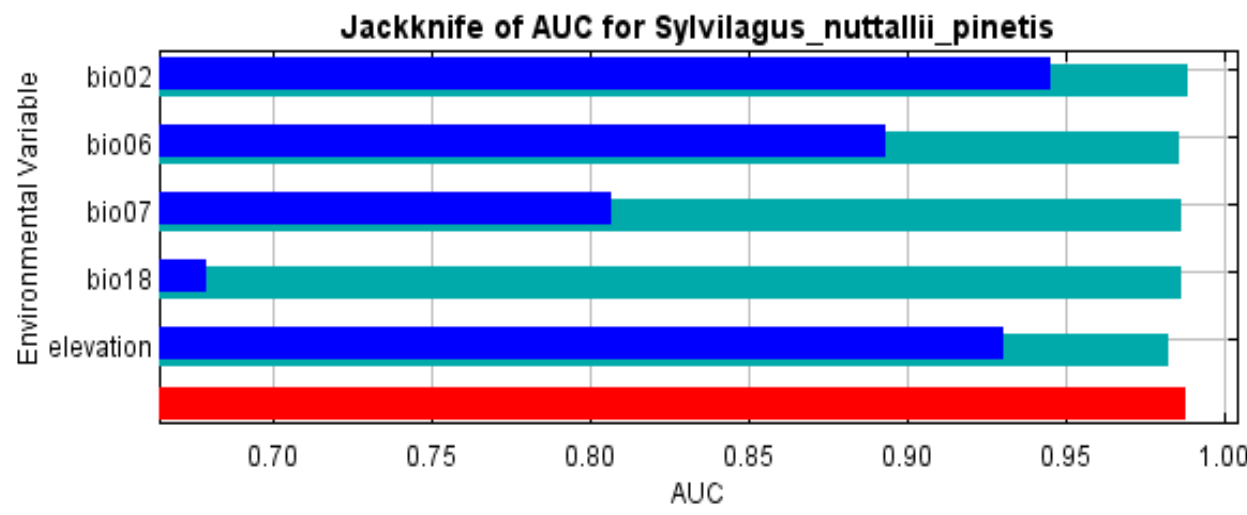

Without variable With only variable With all variables - 


\section{APPENDIX G}

Model output results and figures for the Last Glacial Maximum ( 22KYBP).

Analysis of omission/commission

The following picture shows the test omission rate and predicted area as a function of the cumulative threshold, averaged over the replicate runs. The omission rate should be close to the predicted omission, because of the definition of the cumulative threshold.

Figure G1

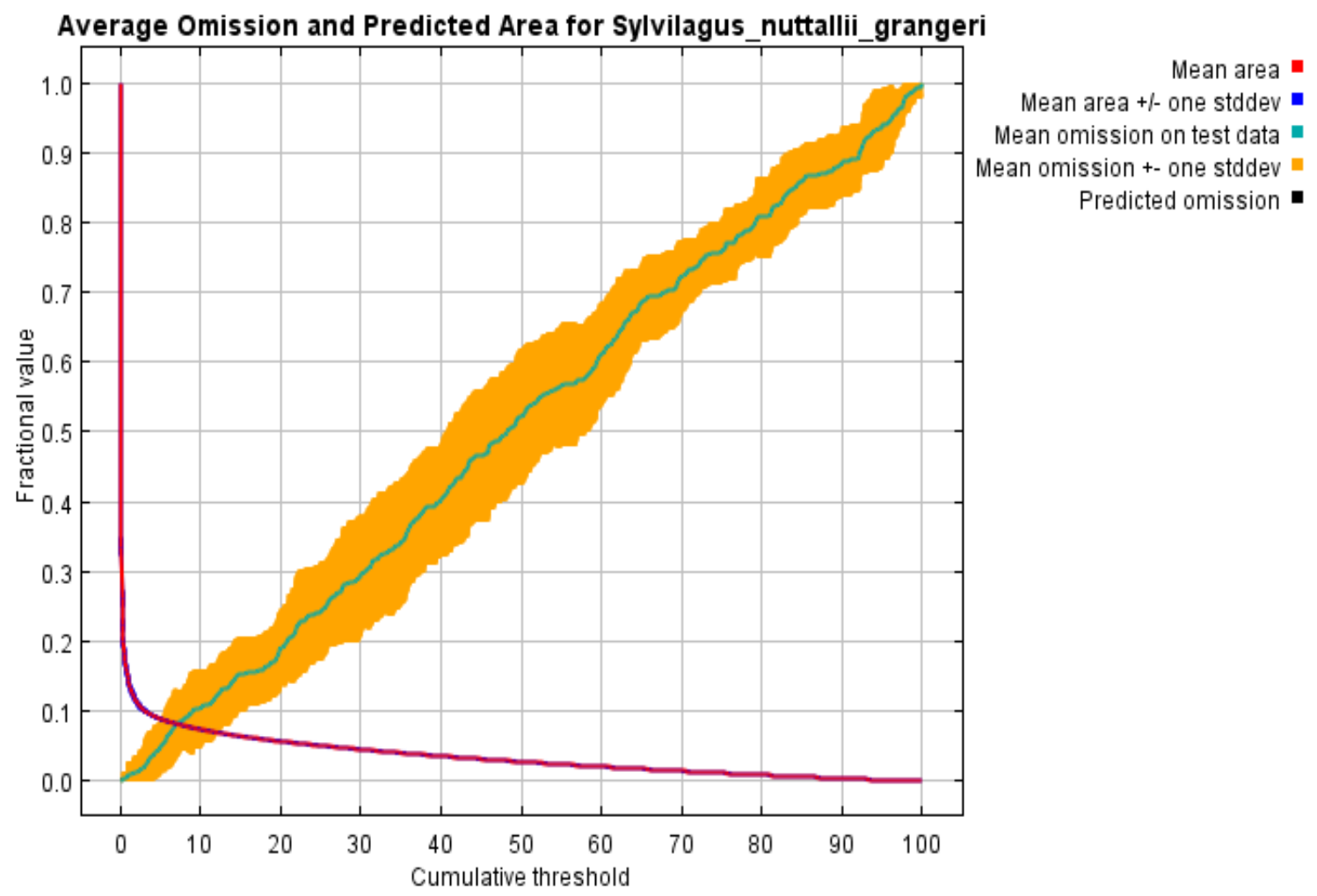


Figure G2

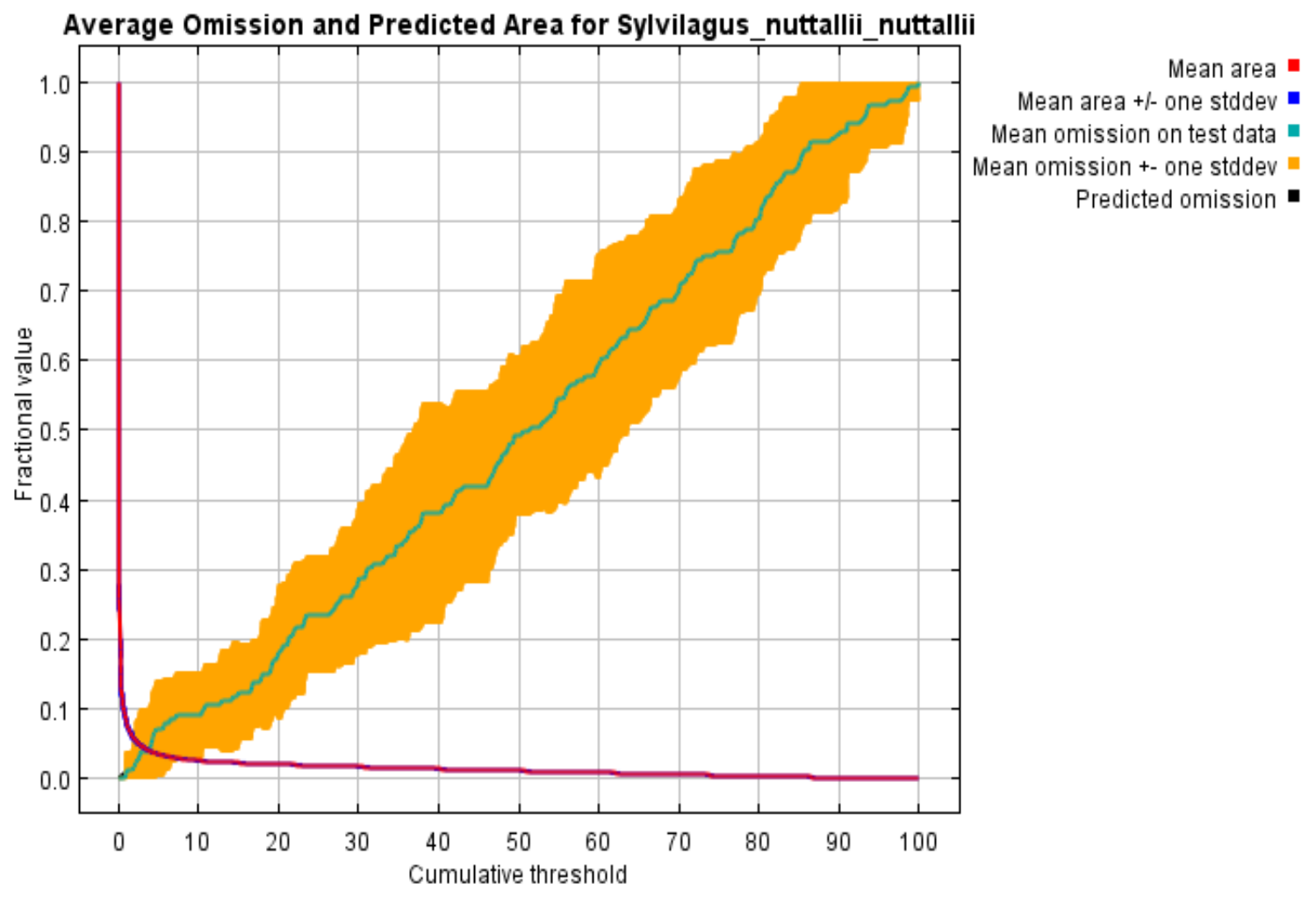


Figure G3

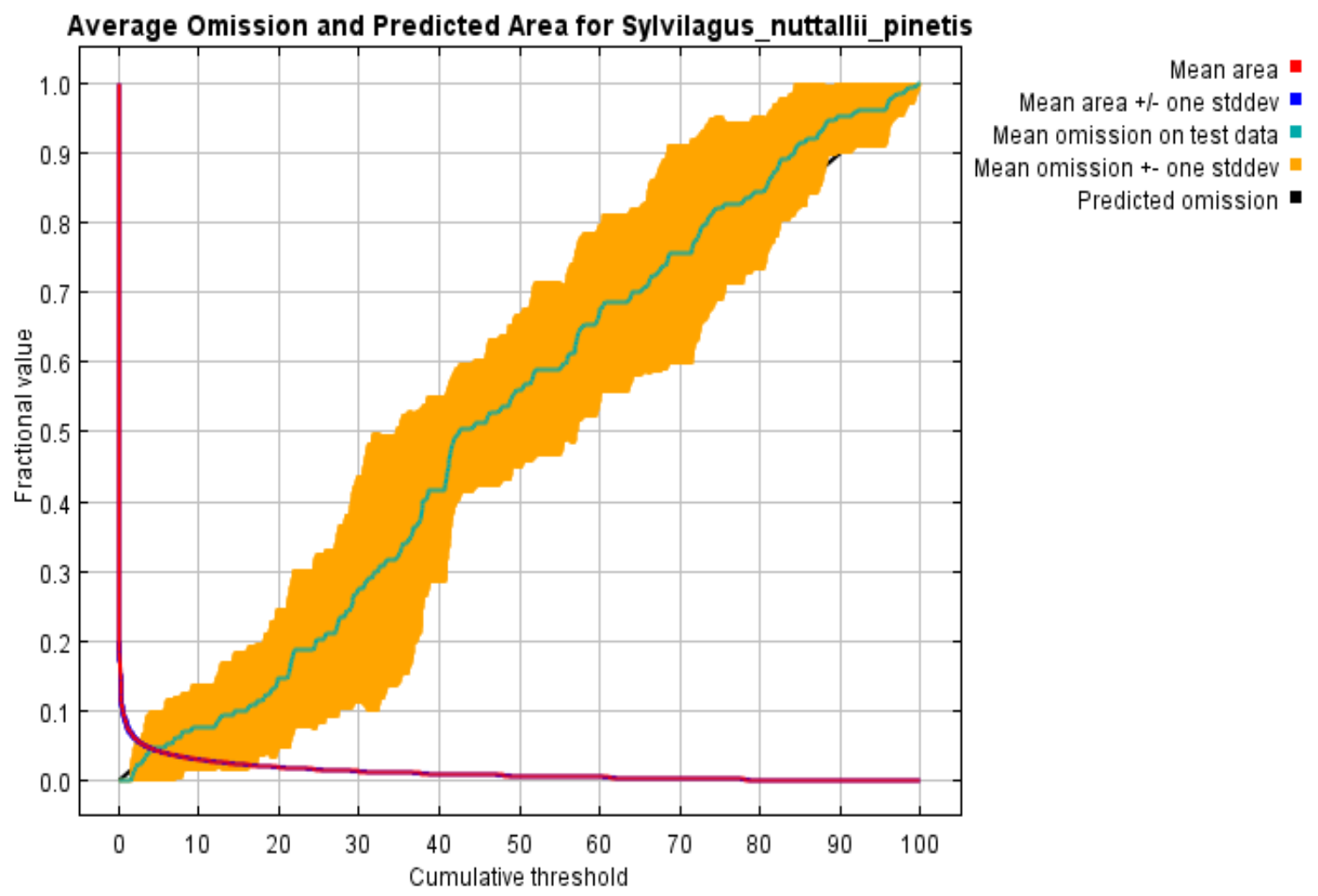

The next picture is the receiver operating characteristic (ROC) curve for the same data, again averaged over the replicate runs. Note that the specificity is defined using predicted area, rather than true commission (see the paper by Phillips, Anderson and Schapire cited for discussion of what this means). The average test AUC for the replicate runs is 0.965 , 0.986 , and 0.988 respectively and the standard deviation is 0.005 . 
Figure G4

Average Sensitivity vs. 1 - Specificity for Sylvilagus_nuttallii_grangeri

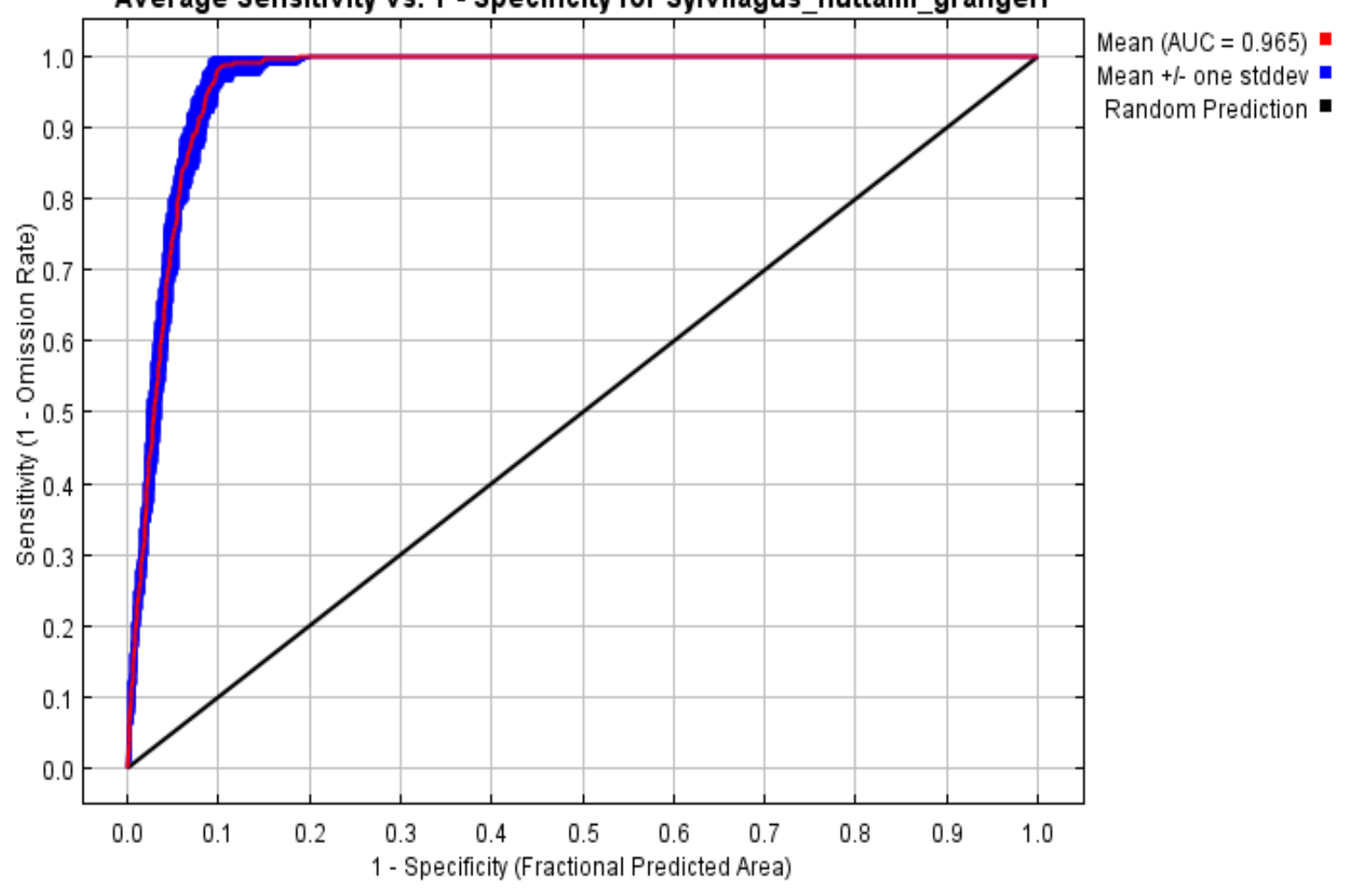


Figure G5

Average Sensitivity vs. 1 - Specificity for Sylvilagus nuttallii nuttallii

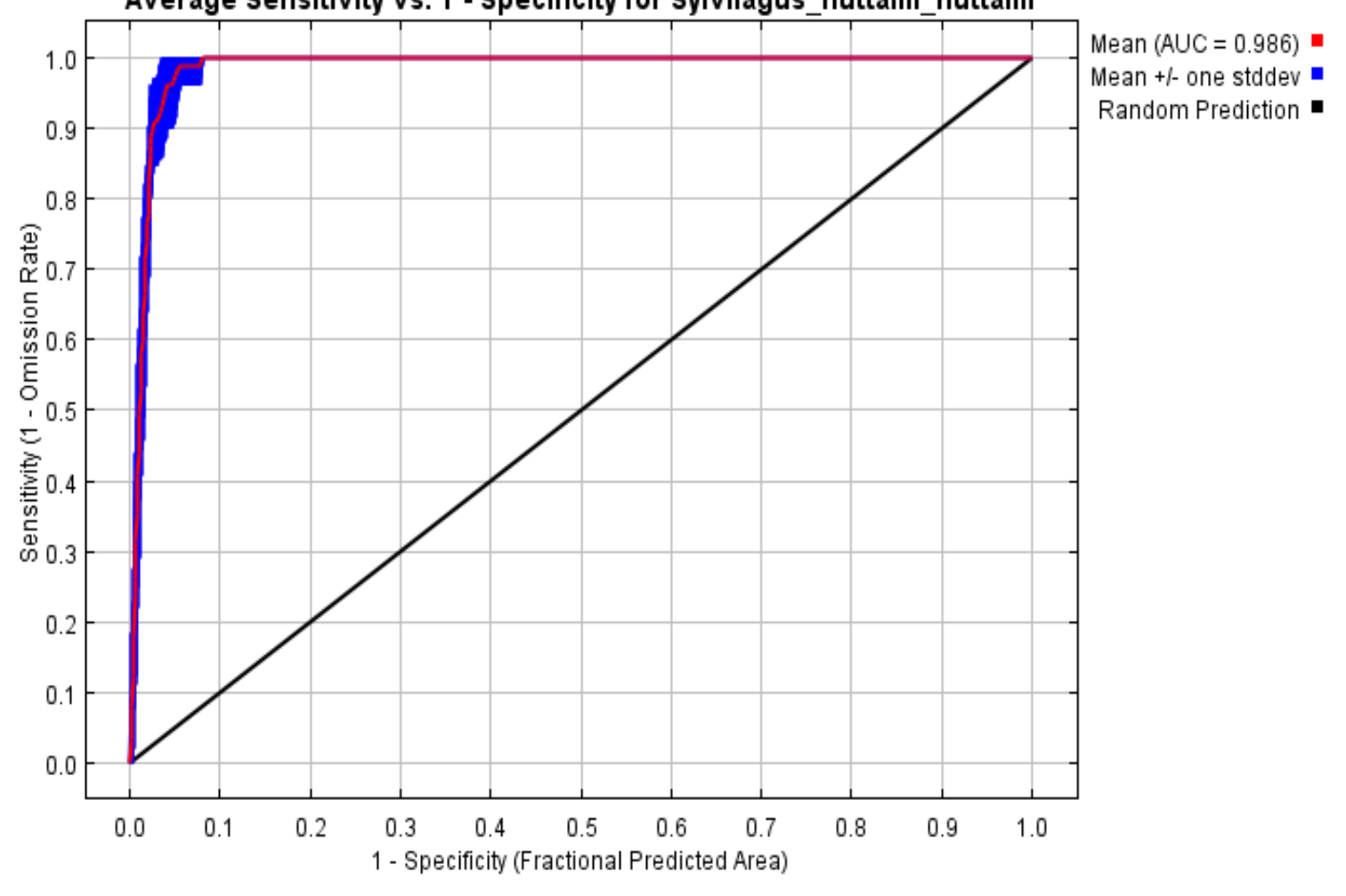


Figure G6

Average Sensitivity vs. 1 - Specificity for Sylvilagus_nuttallii_pinetis

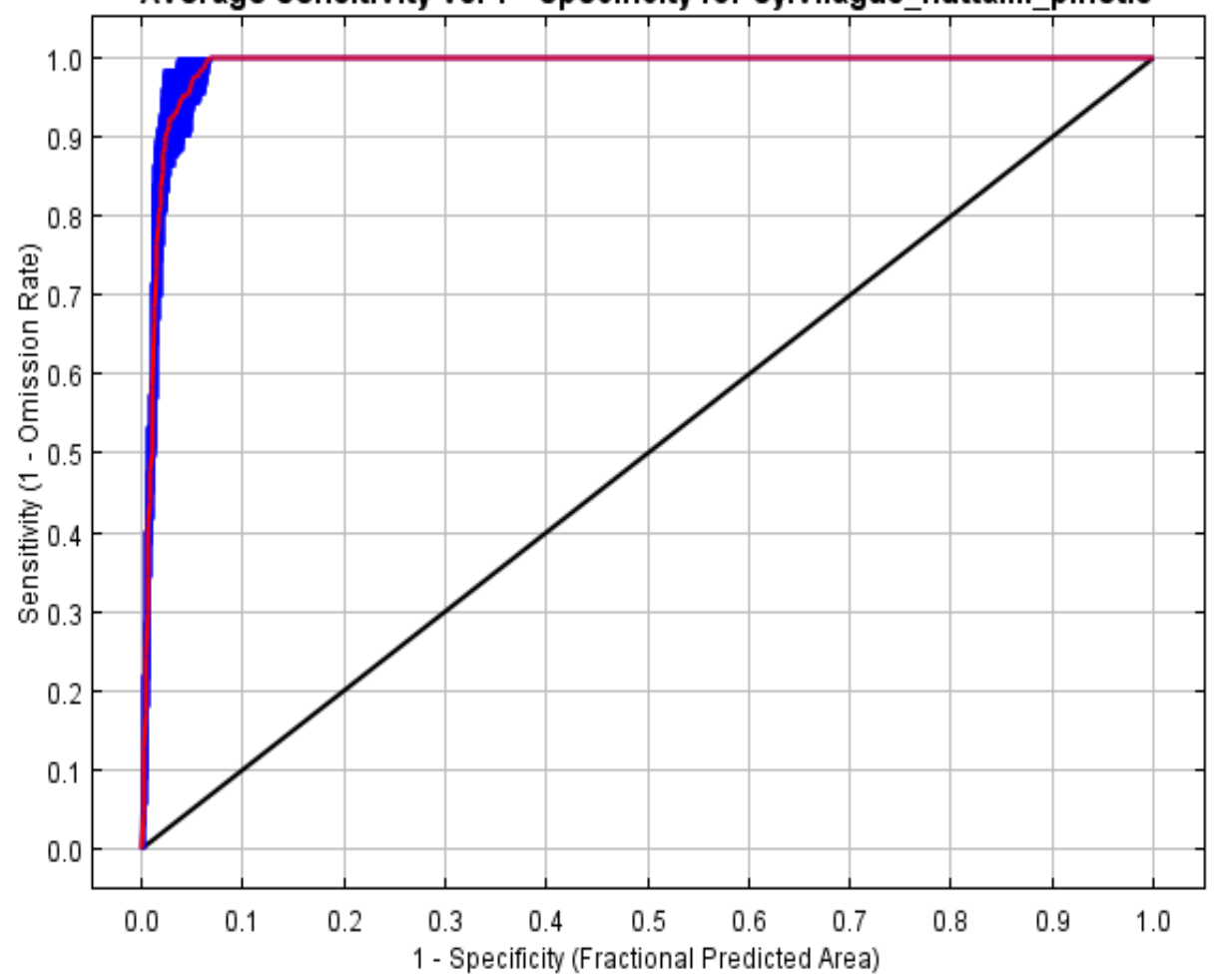

Mean $(\mathrm{AUC}=0.988)$ "

Mean + - one stddev -

Random Prediction -

Pictures of the model

The following pictures show the point-wise mean and standard deviation of the 10 output grids. Other available summary grids are $\underline{\min }, \underline{\max }$ and $\underline{\text { median. }}$.

Sylvilagus nuttallii grangeri:

Figure G7

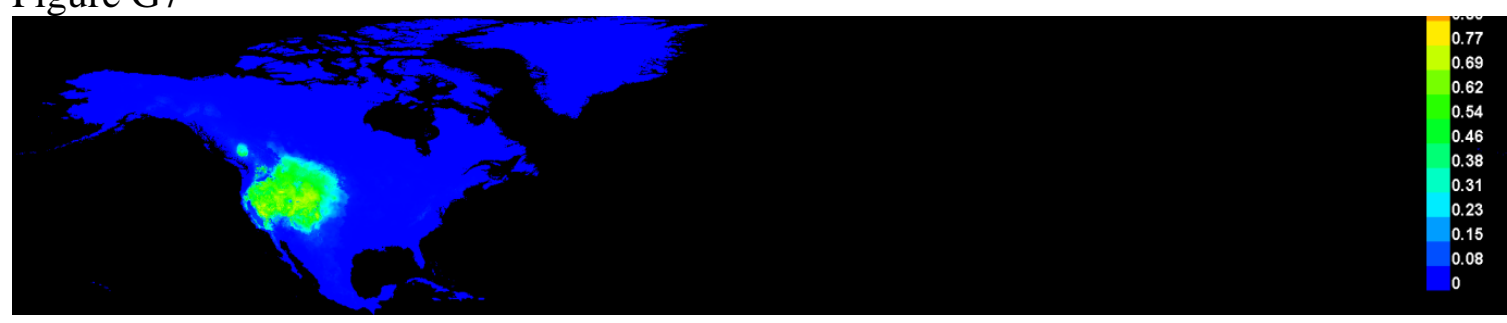

Figure G8

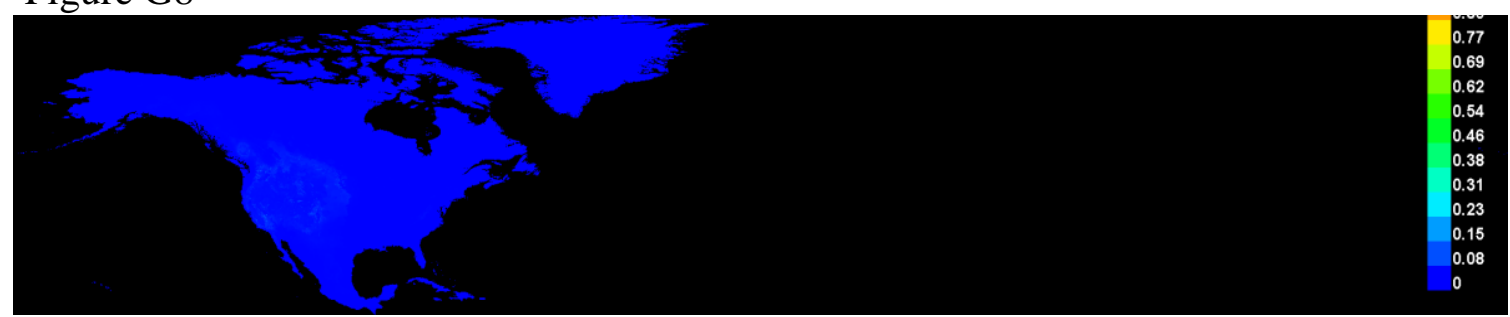


Sylvilagus nuttallii nuttallii:

Figure G9

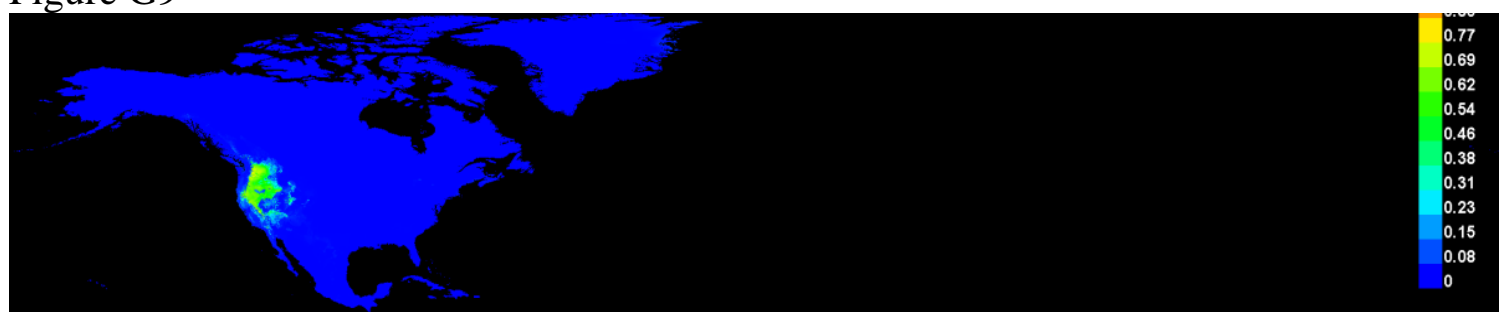

Figure G10

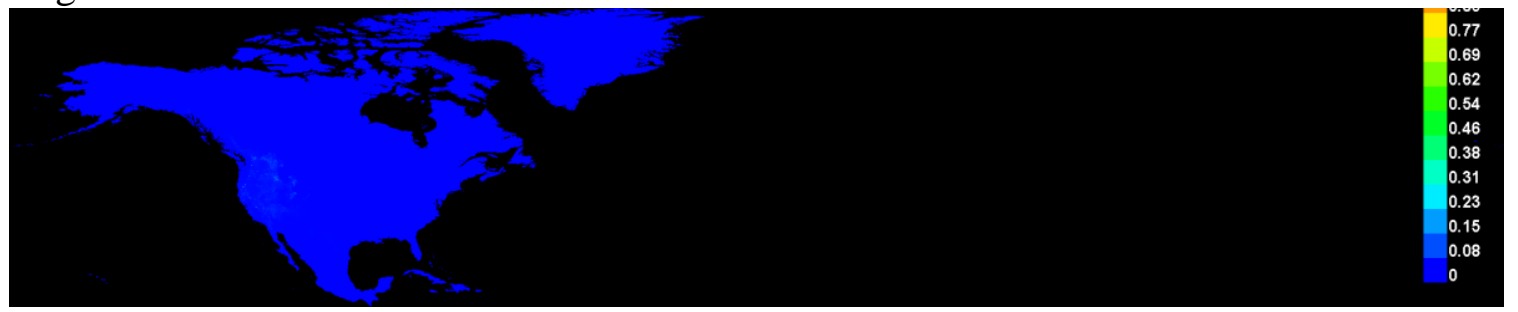

Sylvilagus nuttallii pinetis:

Figure G11

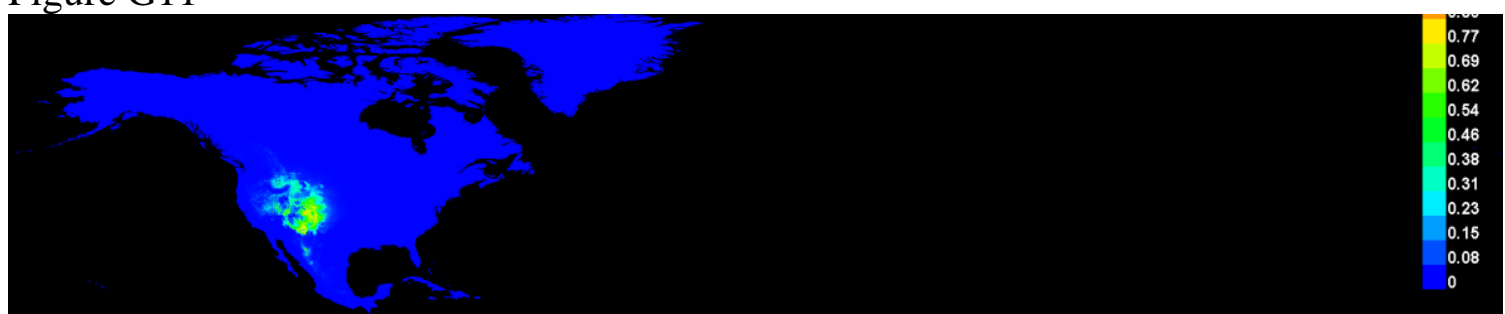

Figure G12

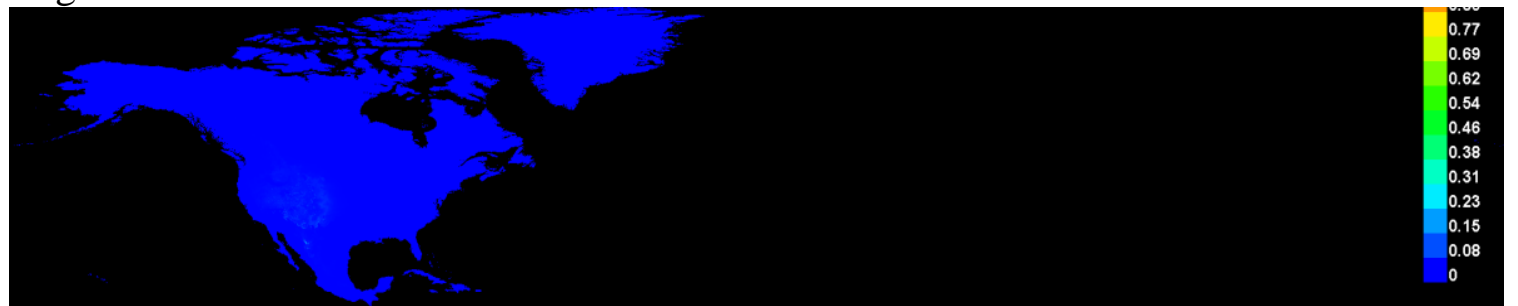

The following pictures show the point-wise mean and standard deviation of the 10 
models applied to the environmental layers in ASCII. Other available summary grids are $\underline{\min }, \underline{\max }$ and $\underline{\text { median. }}$.

Sylvilagus nuttallii grangeri

Figure G13

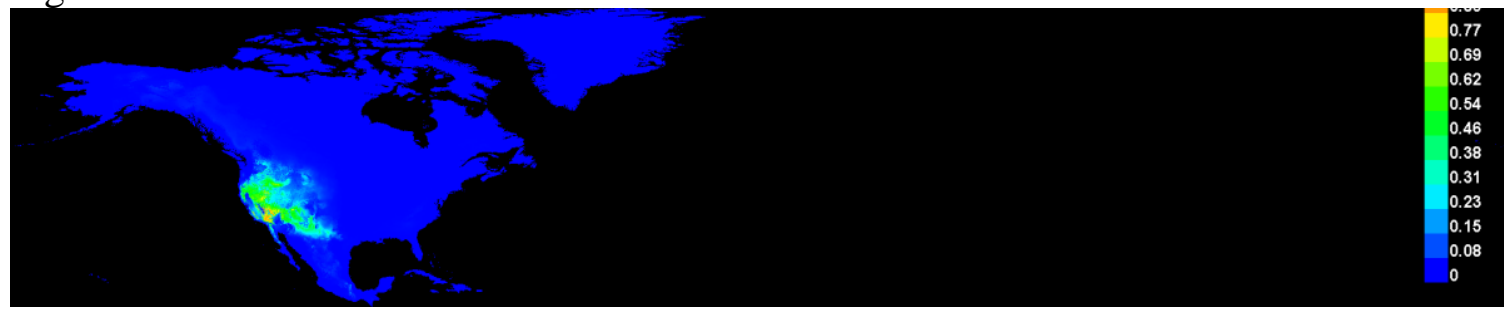

Figure G14

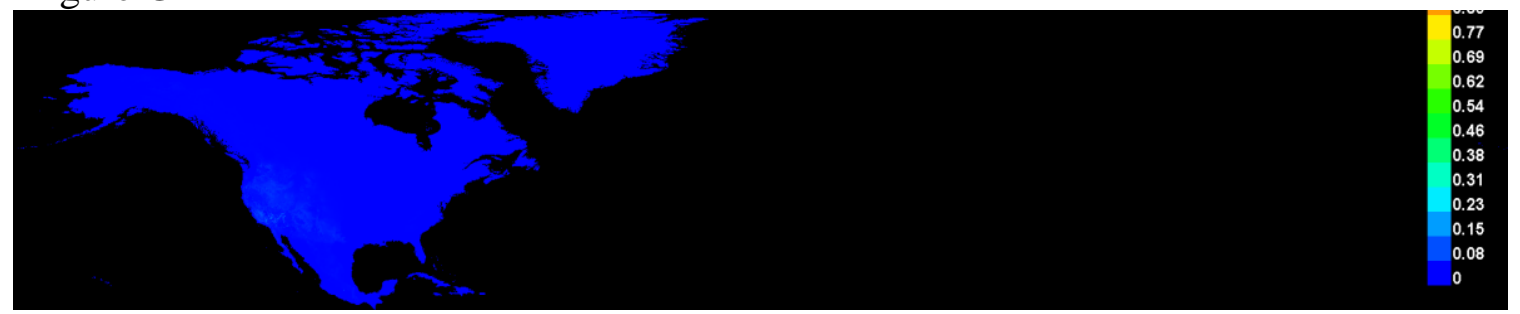

Sylvilagus nuttallii nuttallii:

Figure G15

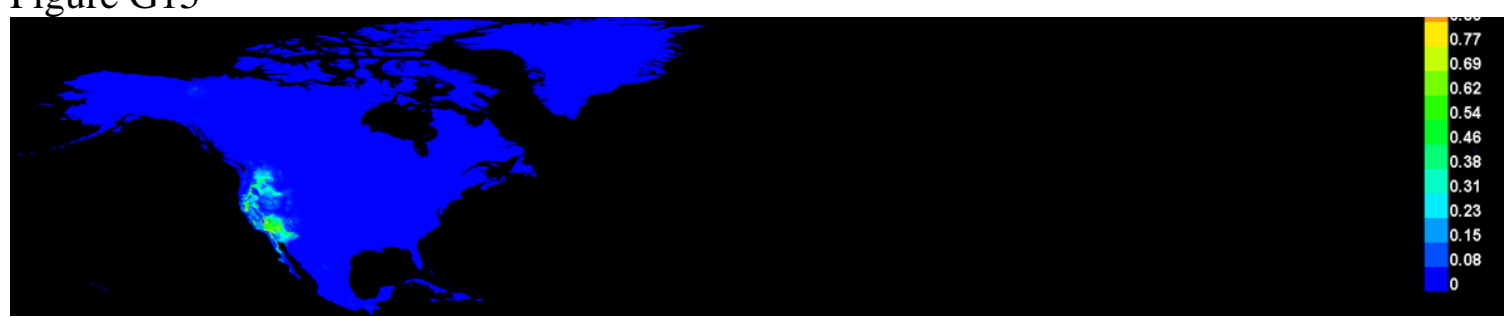

Figure G16

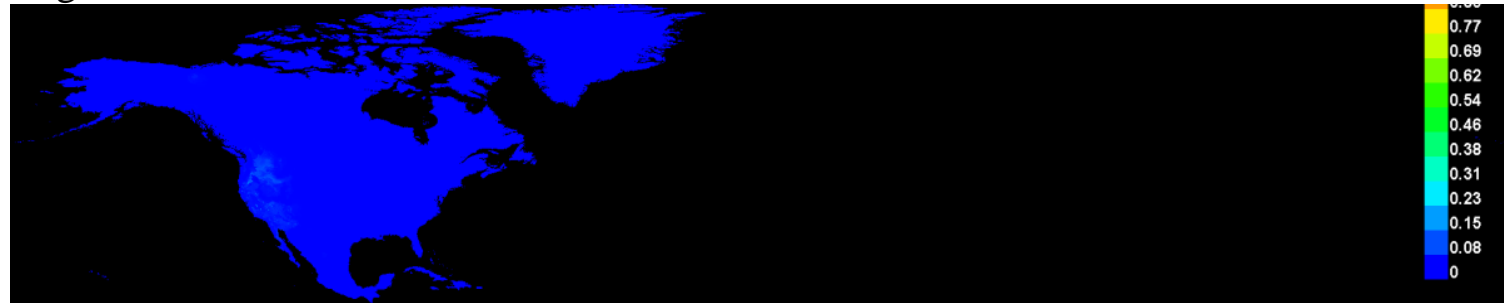


Sylvilagus nuttallii pinetis:

Figure G17

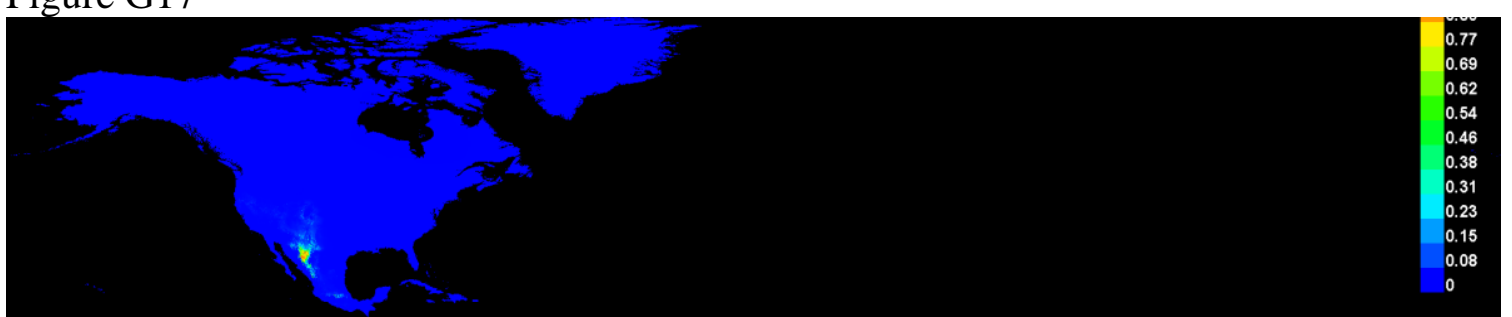

Figure G18

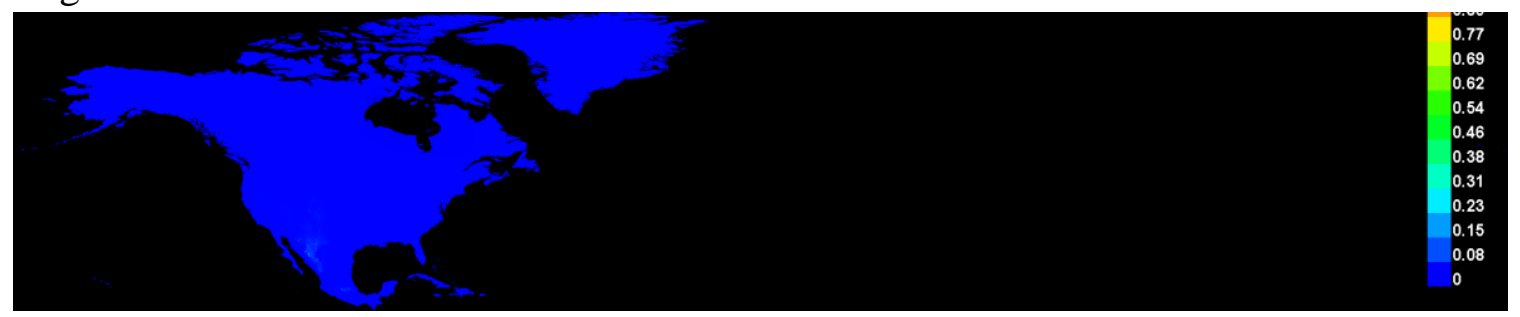




\section{Response curves}

These curves show how each environmental variable affects the Maxent prediction. The curves show how the logistic prediction changes as each environmental variable is varied, keeping all other environmental variables at their average sample value. Click on a response curve to see a larger version. Note that the curves can be hard to interpret if you have strongly correlated variables, as the model may depend on the correlations in ways that are not evident in the curves. In other words, the curves show the marginal effect of changing exactly one variable, whereas the model may take advantage of sets of variables changing together. The curves show the mean response of the 10 replicate Maxent runs (red) and and the mean $+/$ - one standard deviation (blue, two shades for categorical variables).

Sylvilagus nuttallii grangeri

Figure G19
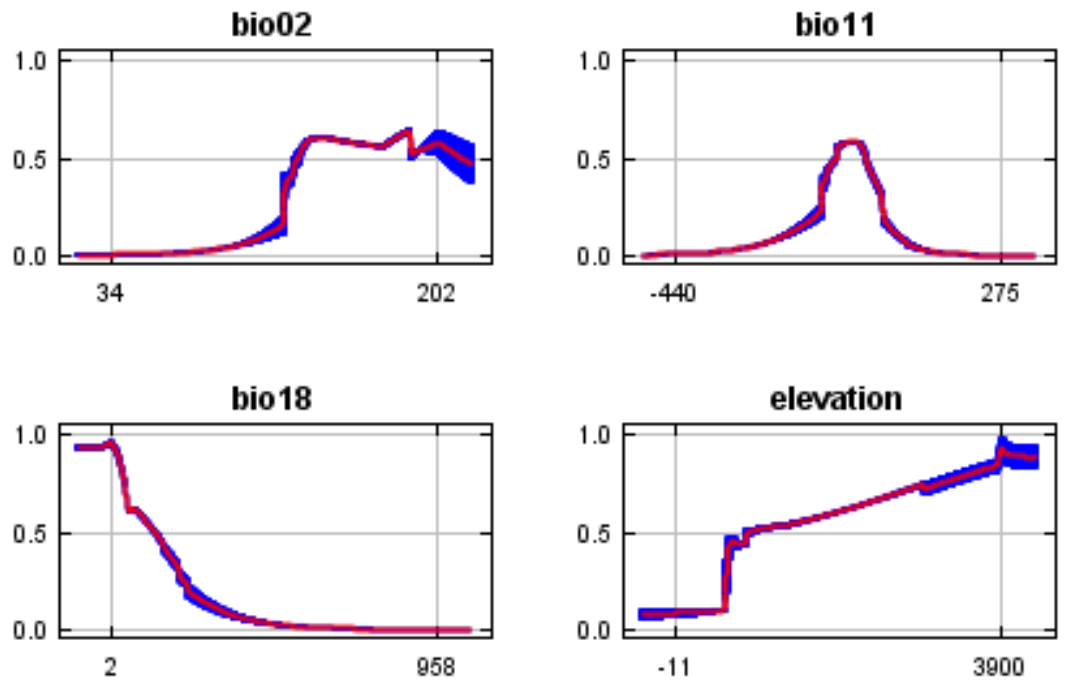
Sylvilagus nuttallii nuttallii

Figure G20
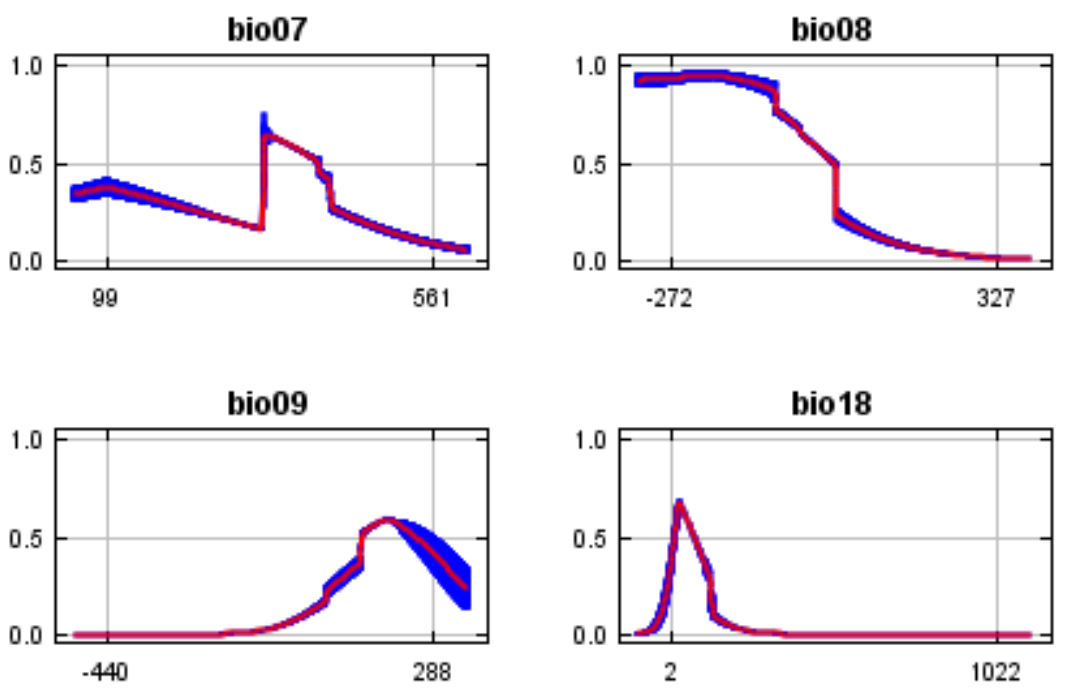

Sylvilagus nuttallii pinetis

Figure G21
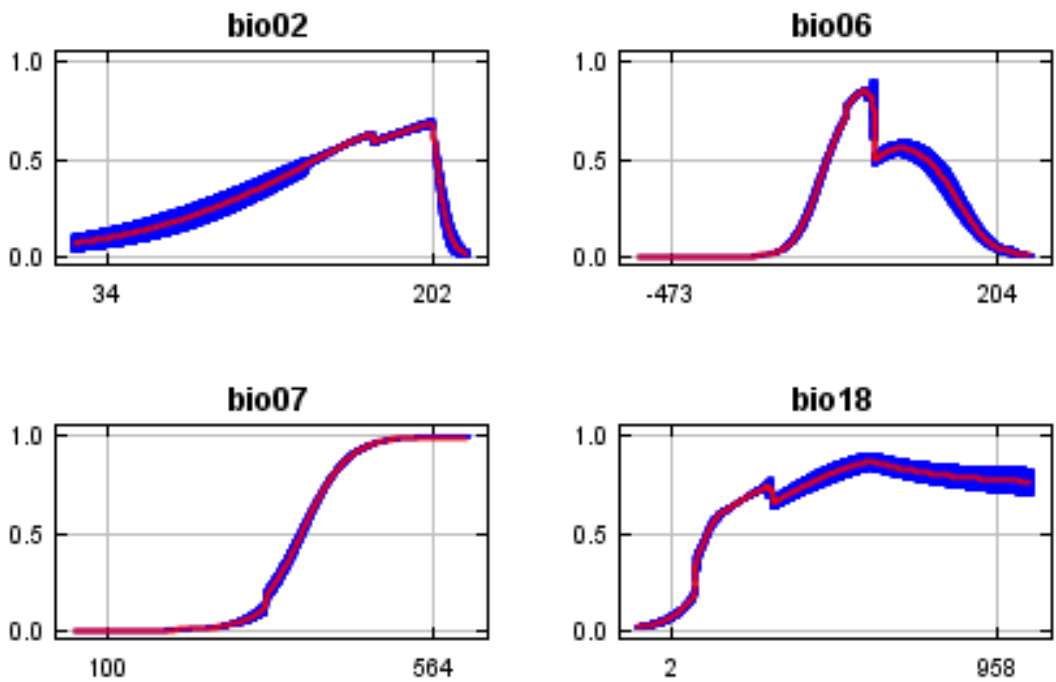


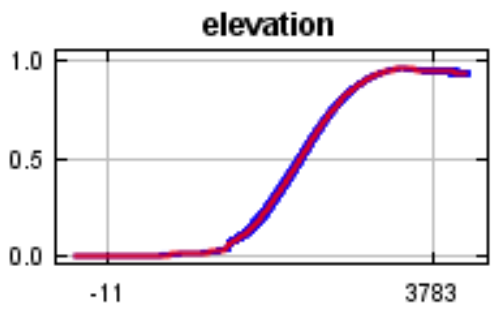

In contrast to the above marginal response curves, each of the following curves represents a different model, namely, a Maxent model created using only the corresponding variable. These plots reflect the dependence of predicted suitability both on the selected variable and on dependencies induced by correlations between the selected variable and other variables. They may be easier to interpret if there are strong correlations between variables.

Sylvilagus nuttallii grangeri

Figure G22
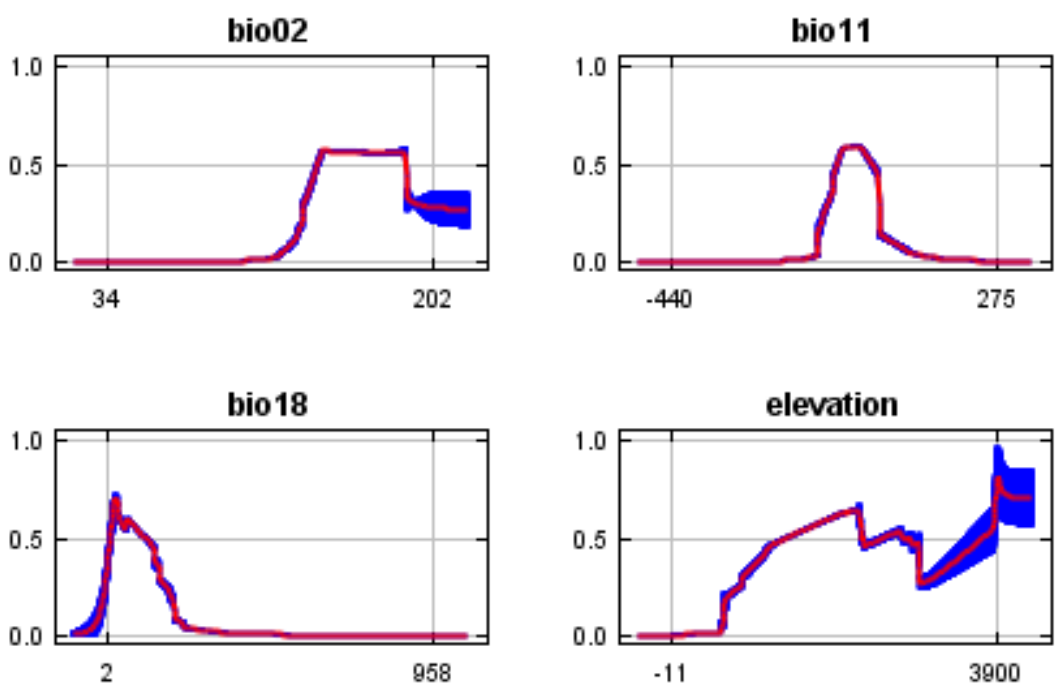

Sylvilagus nuttallii nuttallii

Figure G23 
Sylvilagus nuttallii nuttallii

Figure G23
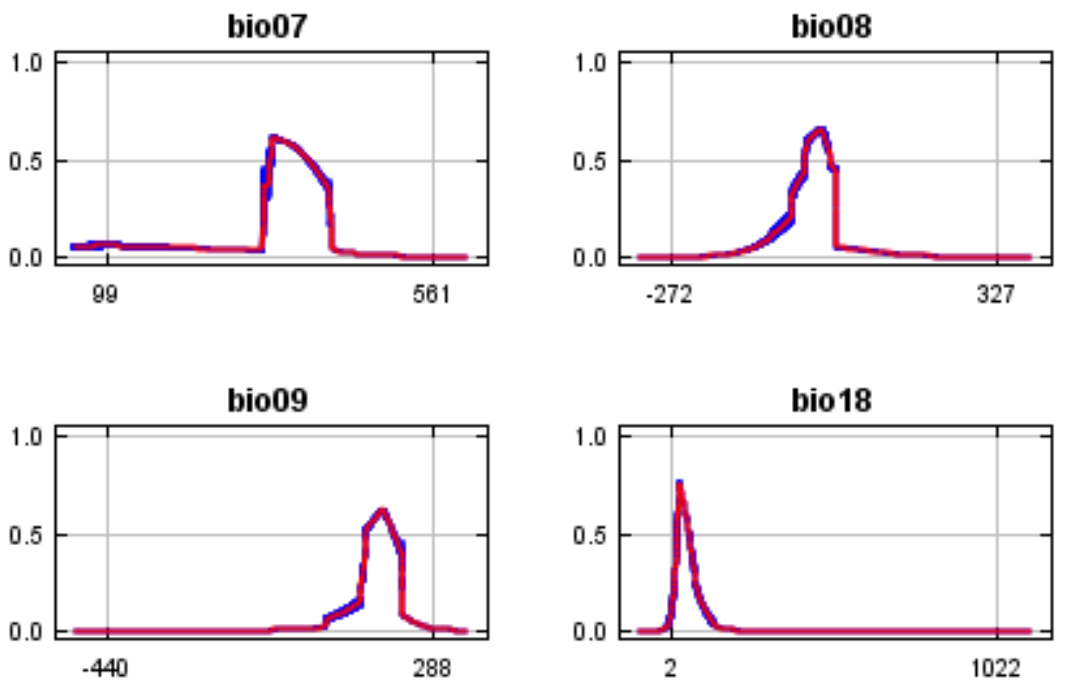

Sylvilagus nuttallii pinetis

Figure G24
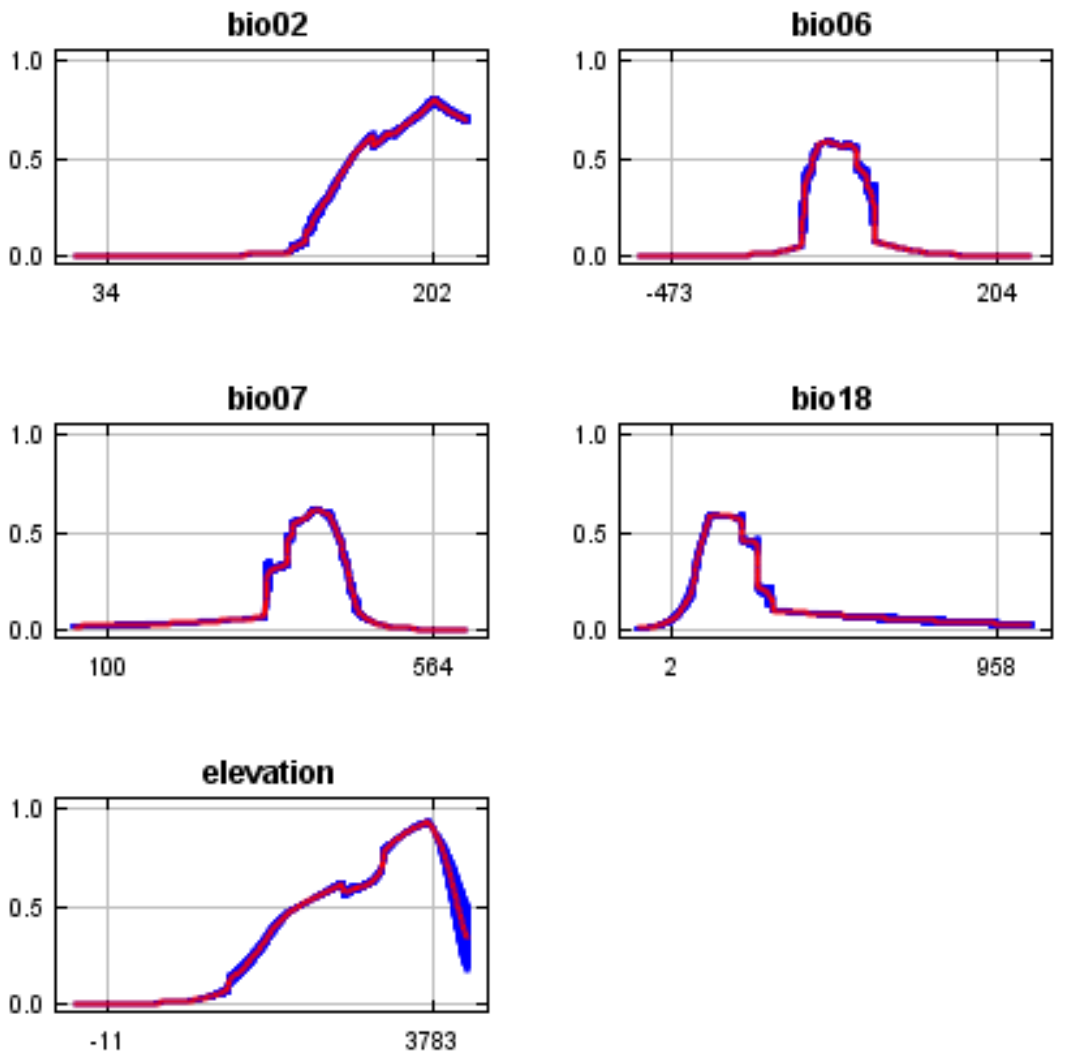

Analysis of variable contributions 
The following table gives estimates of relative contributions of the environmental variables to the Maxent model. To determine the first estimate, in each iteration of the training algorithm, the increase in regularized gain is added to the contribution of the corresponding variable, or subtracted from it if the change to the absolute value of lambda is negative. For the second estimate, for each environmental variable in turn, the values of that variable on training presence and background data are randomly permuted. The model is reevaluated on the permuted data, and the resulting drop in training AUC is shown in the table, normalized to percentages. As with the variable jackknife, variable contributions should be interpreted with caution when the predictor variables are correlated. Values shown are averages over replicate runs.

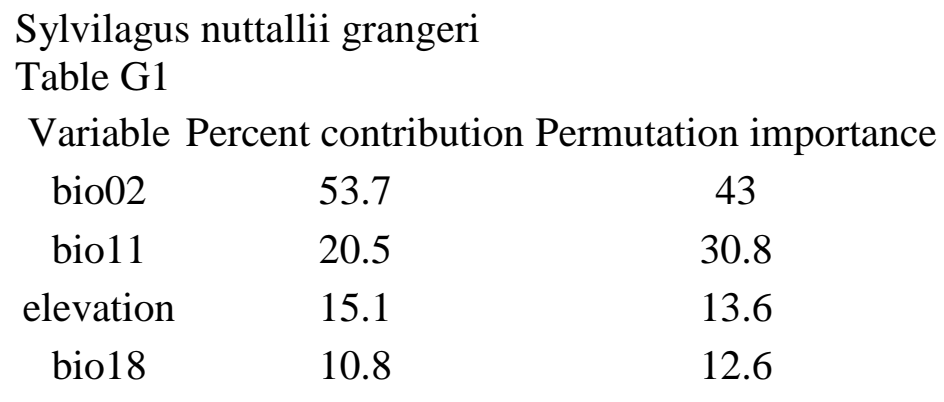

Sylvilagus nuttallii nuttallii

Table G2

Variable Percent contribution Permutation importance

$\begin{array}{ccc}\text { bio09 } & 53.2 & 71 \\ \text { bio08 } & 25 & 9.2 \\ \text { bio18 } & 18.5 & 18.2 \\ \text { bio07 } & 3.3 & 1.7\end{array}$

Sylvilagus nuttallii pinetis

Table G3

Variable Percent contribution Permutation importance

$\begin{array}{ccc}\text { bio02 } & 45.9 & 1 \\ \text { elevation } & 40.1 & 48.8 \\ \text { bio06 } & 7.8 & 40.4 \\ \text { bio07 } & 3.4 & 7.4 \\ \text { bio18 } & 2.8 & 2.5\end{array}$

The following picture shows the results of the jackknife test of variable importance. The environmental variable with highest gain when used in isolation is bio02, which therefore appears to have the most useful information by itself. The environmental variable that 
decreases the gain the most when it is omitted is bio11, which therefore appears to have the most information that isn't present in the other variables. Values shown are averages over replicate runs.

Figure G25

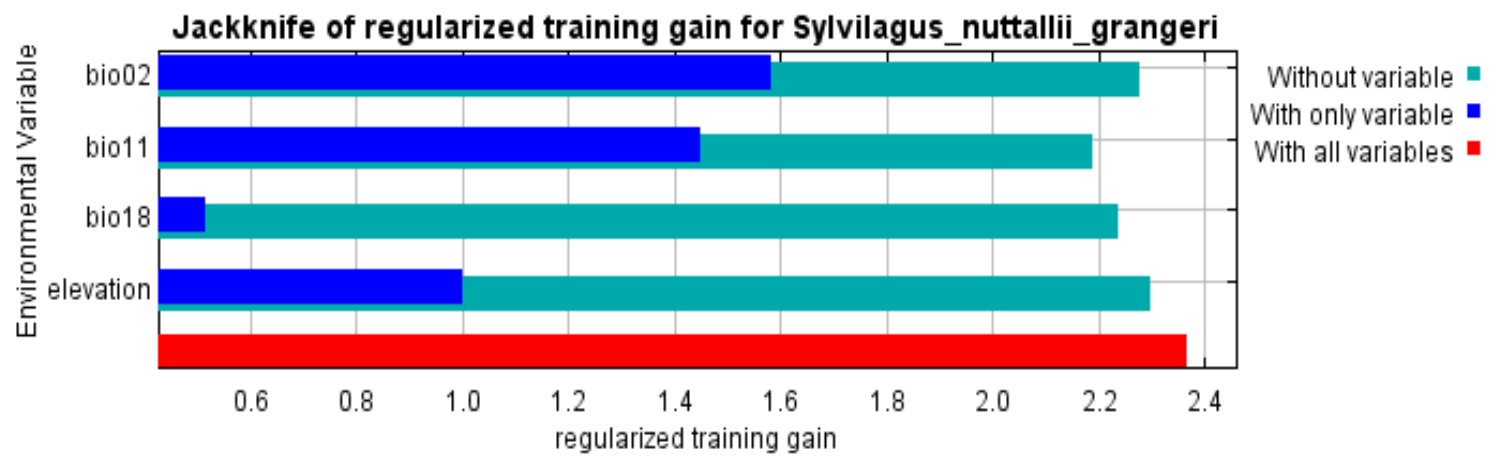

Figure G26

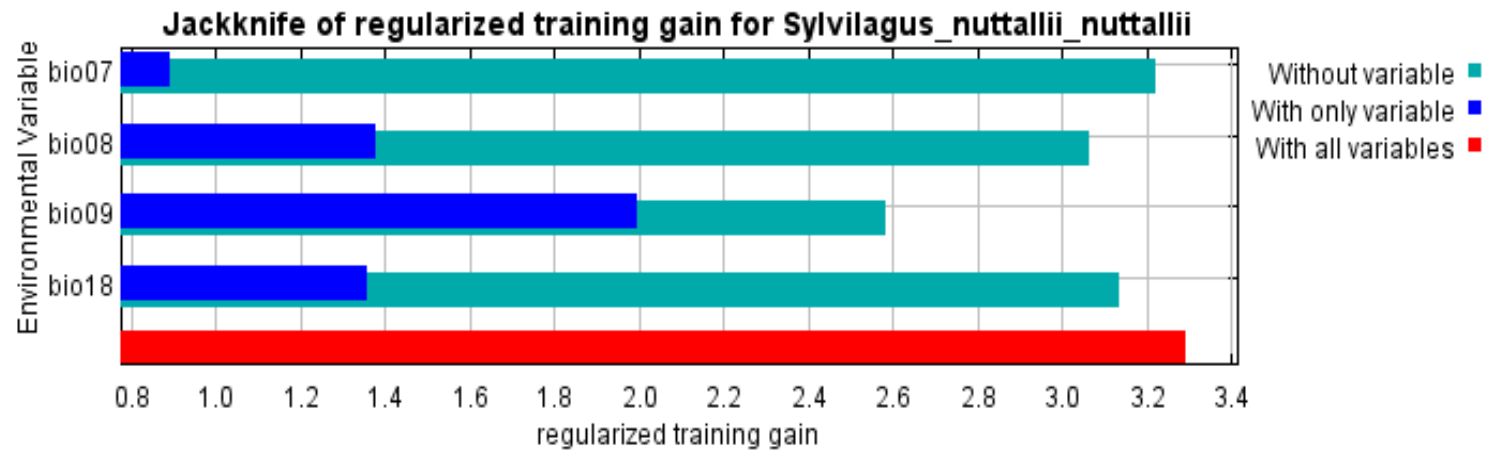

Figure G27

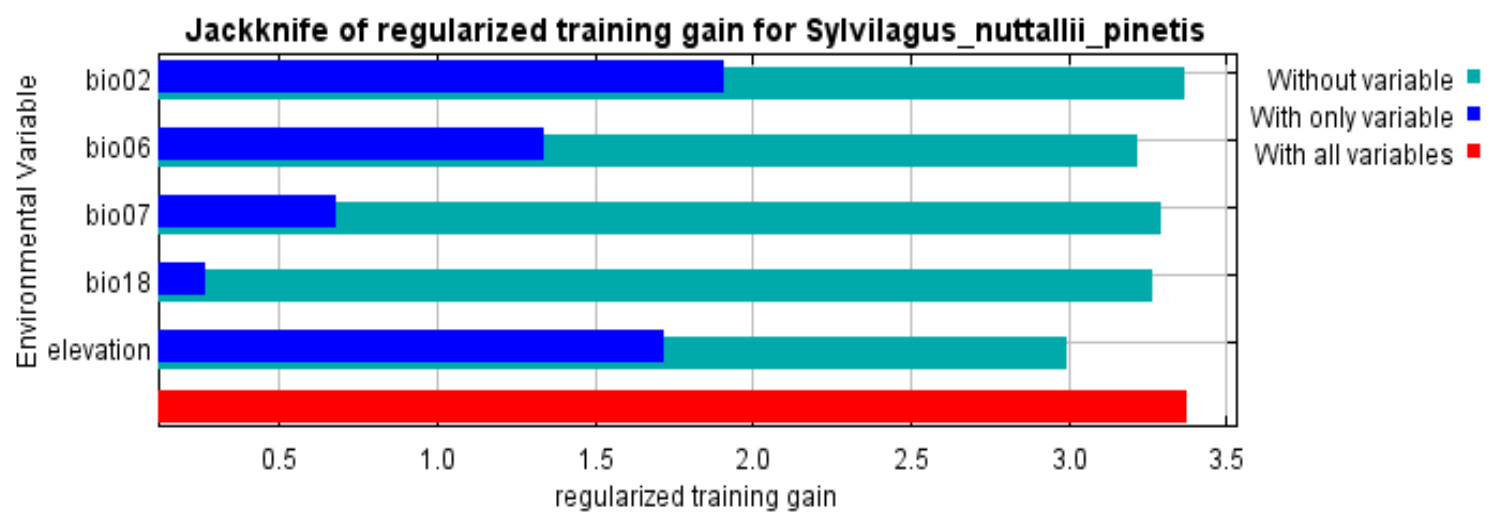

The next picture shows the same jackknife test, using test gain instead of training gain. Note that conclusions about which variables are most important can change, now that we're looking at test data. 
Figure G28

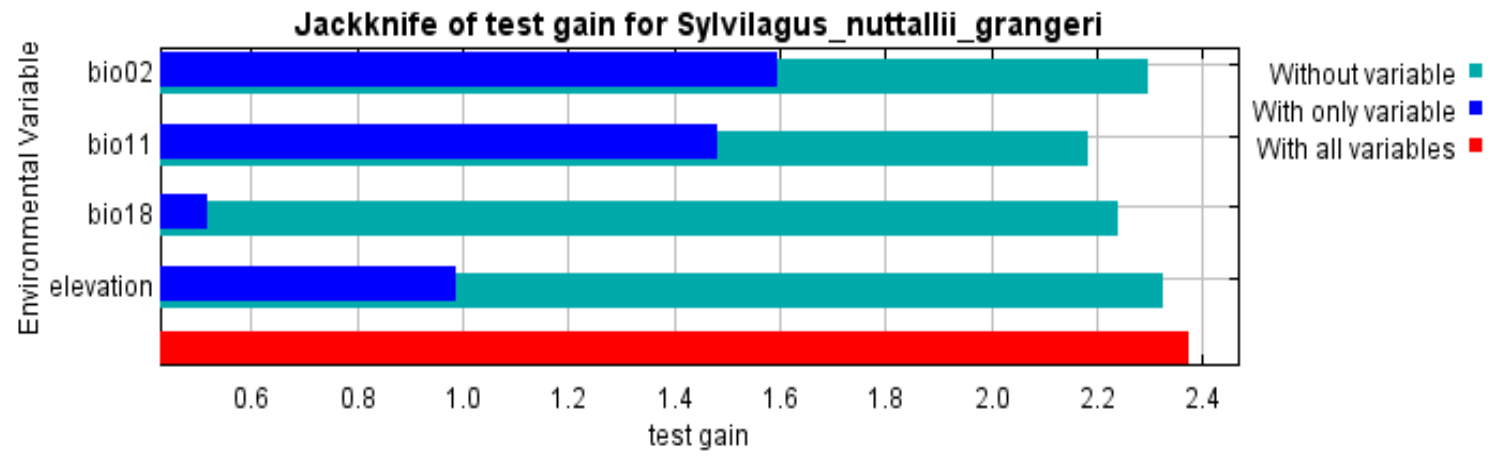

Figure G29

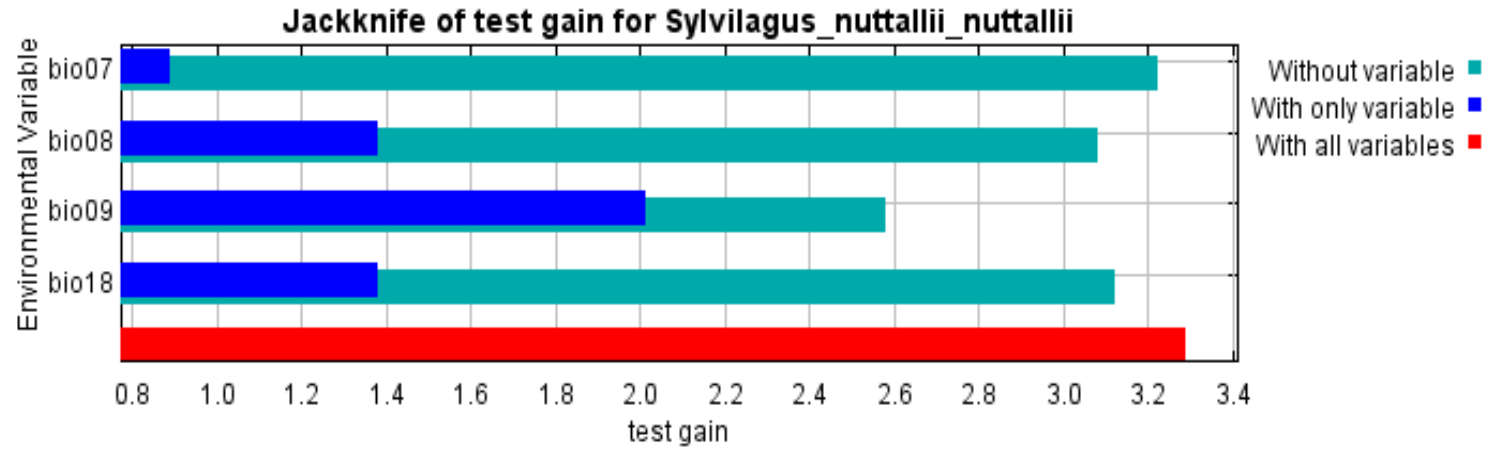

Figure G30

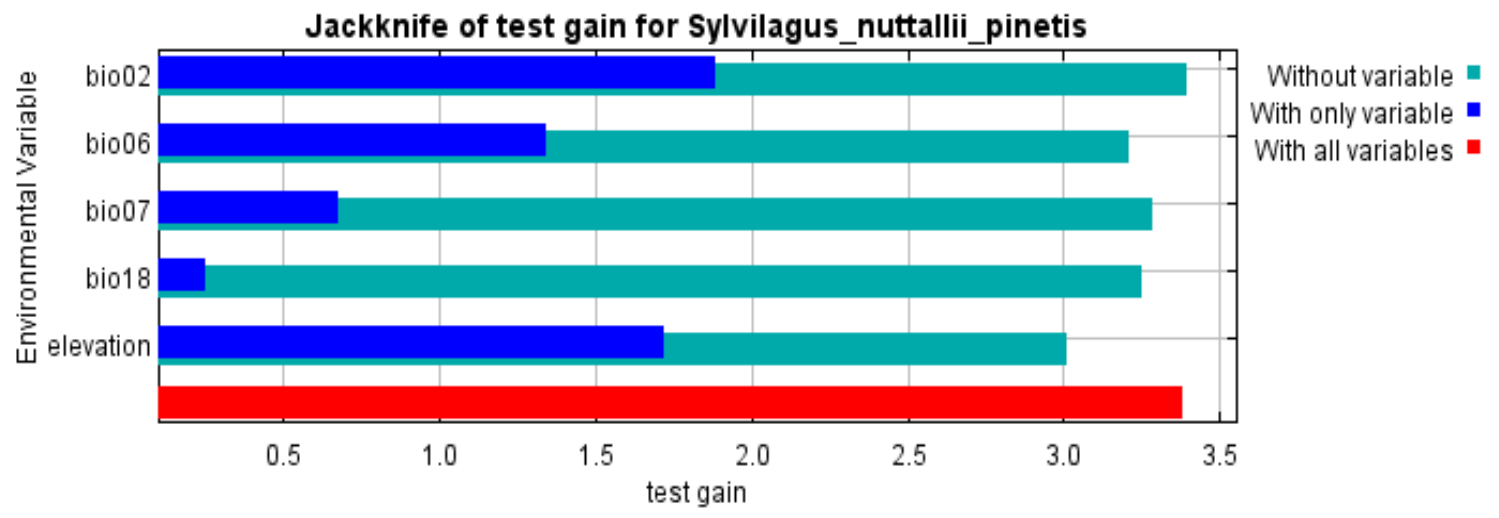

Lastly, we have the same jackknife test, using AUC on test data. 
Figure G31

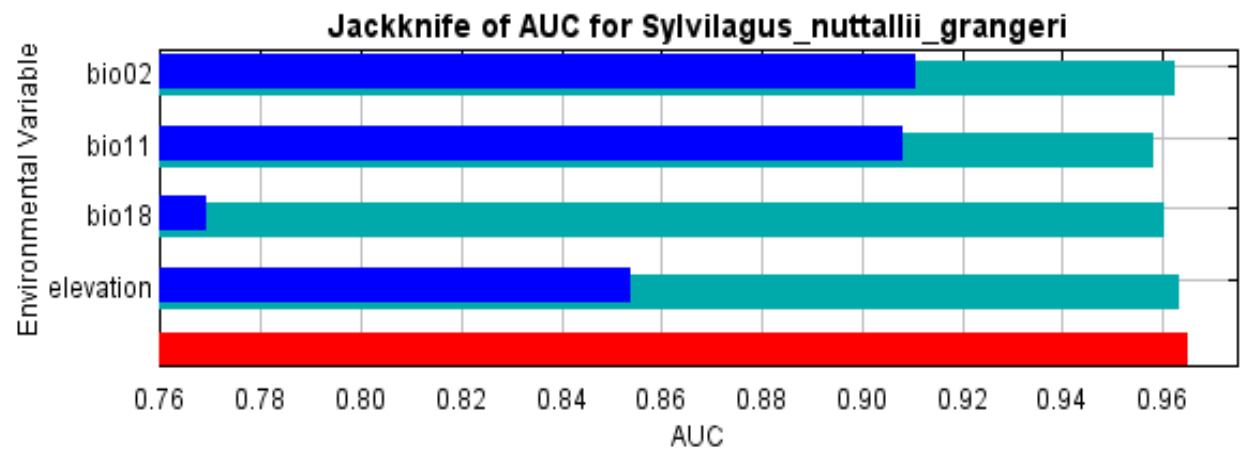

Without variable With only variable With all variables

Figure G32

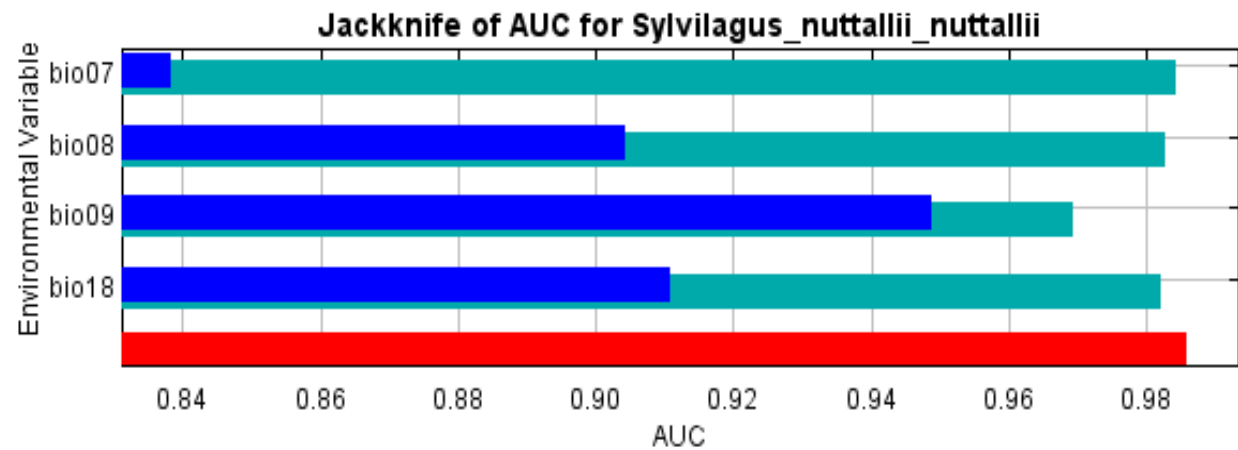

Without variable With only variable With all variables

Figure G33

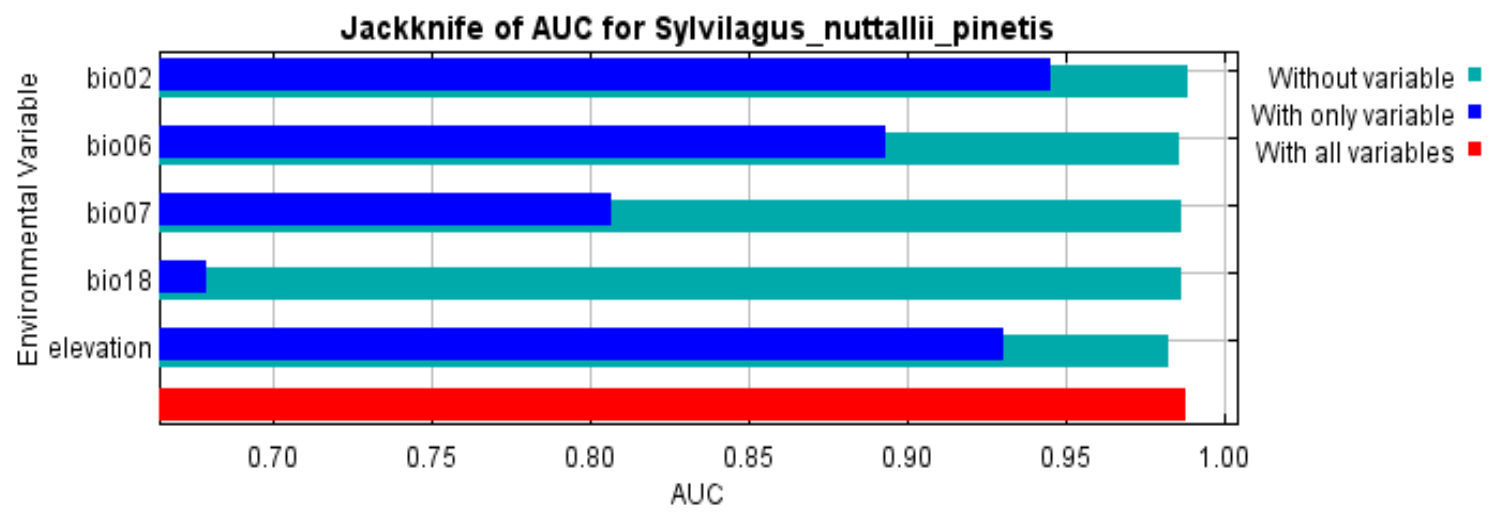




\section{APPENDIX H}

Model output results and figures for the mid-Holocene period ( 6KYBP).

\section{Analysis of omission/commission}

The following picture shows the test omission rate and predicted area as a function of the cumulative threshold, averaged over the replicate runs. The omission rate should be close to the predicted omission, because of the definition of the cumulative threshold.

Figure H1

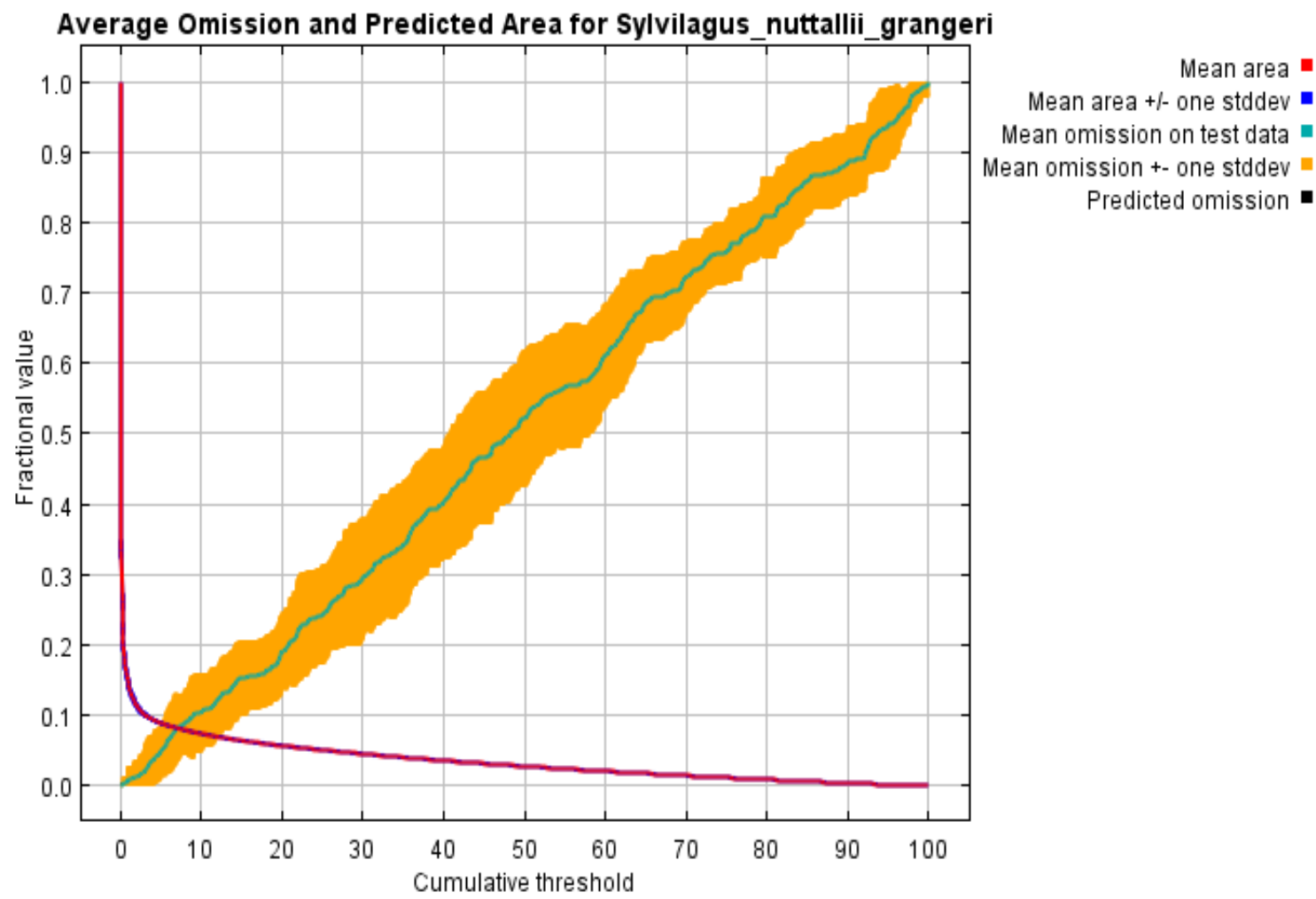


Figure H2

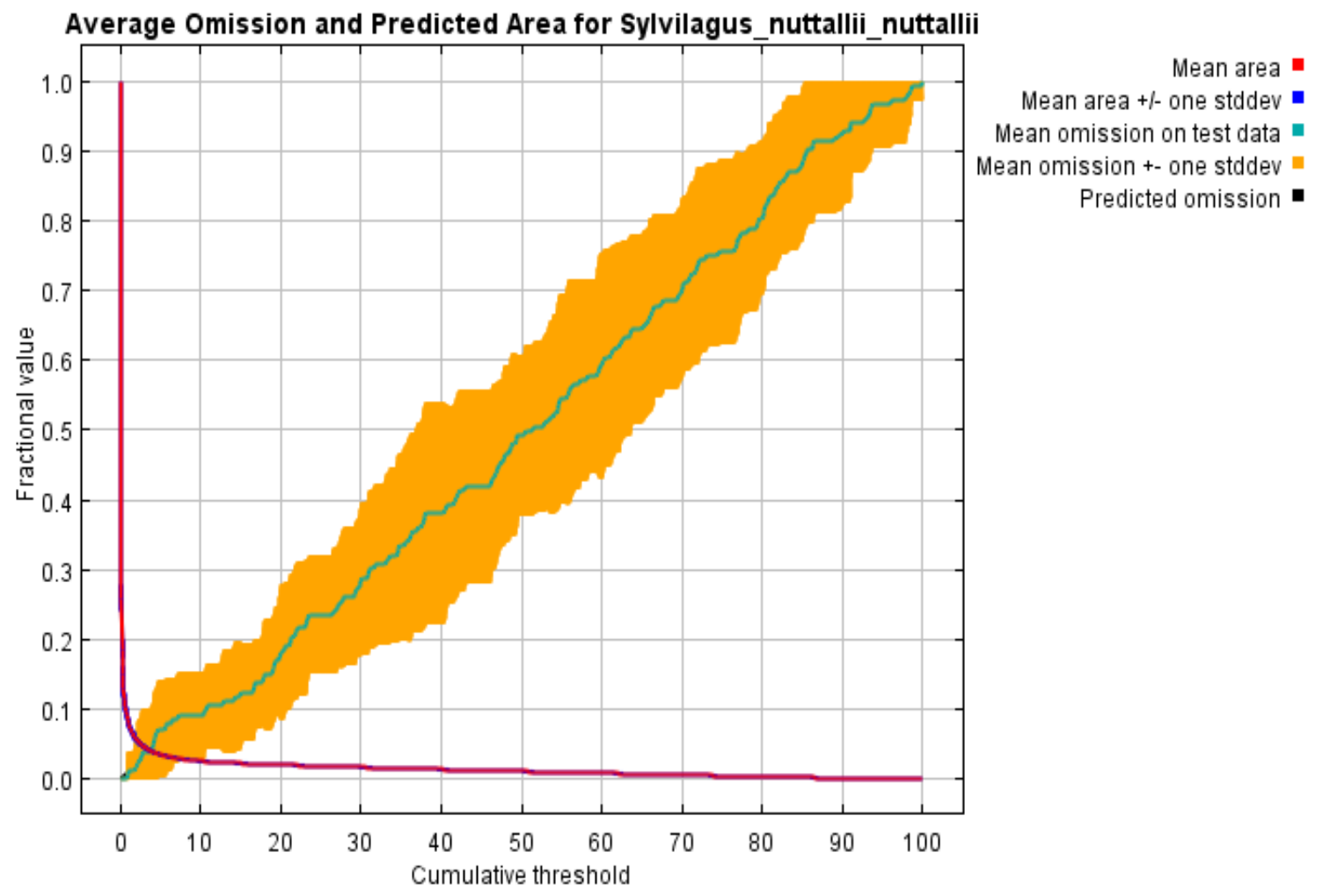


Figure $\mathrm{H} 3$

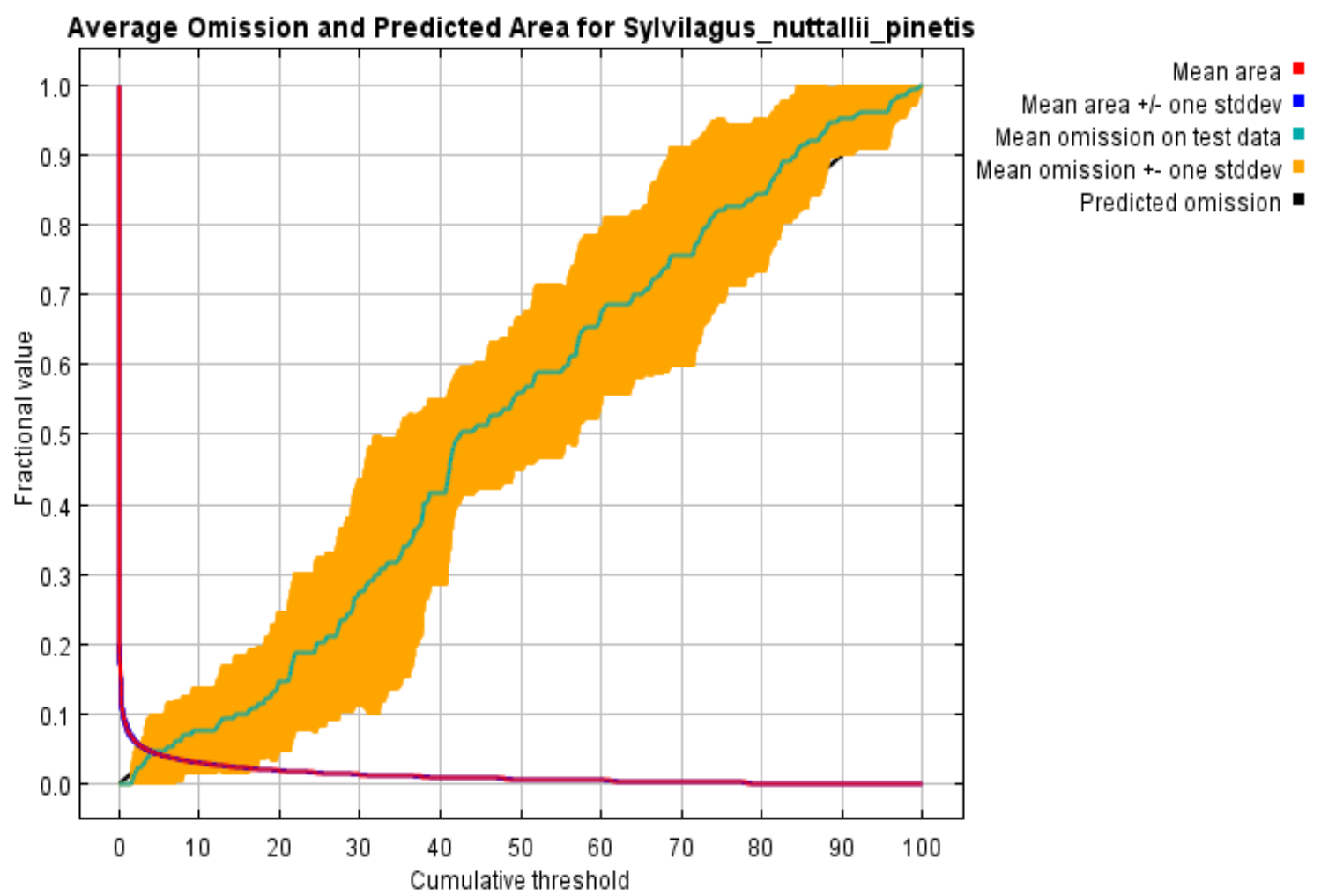

The next picture is the receiver operating characteristic (ROC) curve for the same data, again averaged over the replicate runs. Note that the specificity is defined using predicted area, rather than true commission (see the paper by Phillips, Anderson and Schapire cited for discussion of what this means). The average test AUC for the replicate runs is 0.965 , 0.986 , and 0.988 respectively and the standard deviation is 0.005 . 
Figure H4

Average Sensitivity vs. 1 - Specificity for Sylvilagus_nuttallii_grangeri

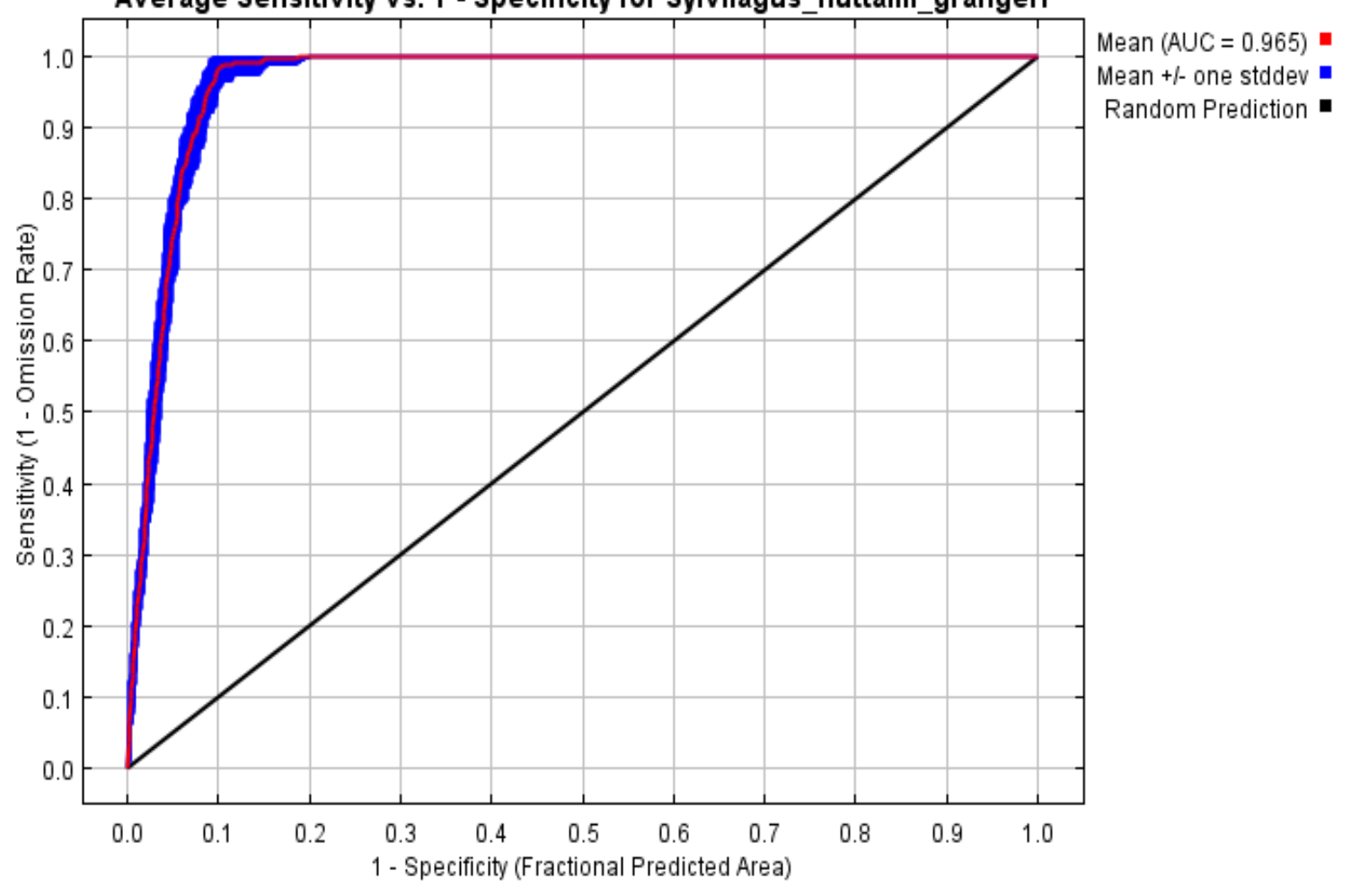


Figure H5

Average Sensitivity vs. 1 - Specificity for Sylvilagus nuttallii nuttallii

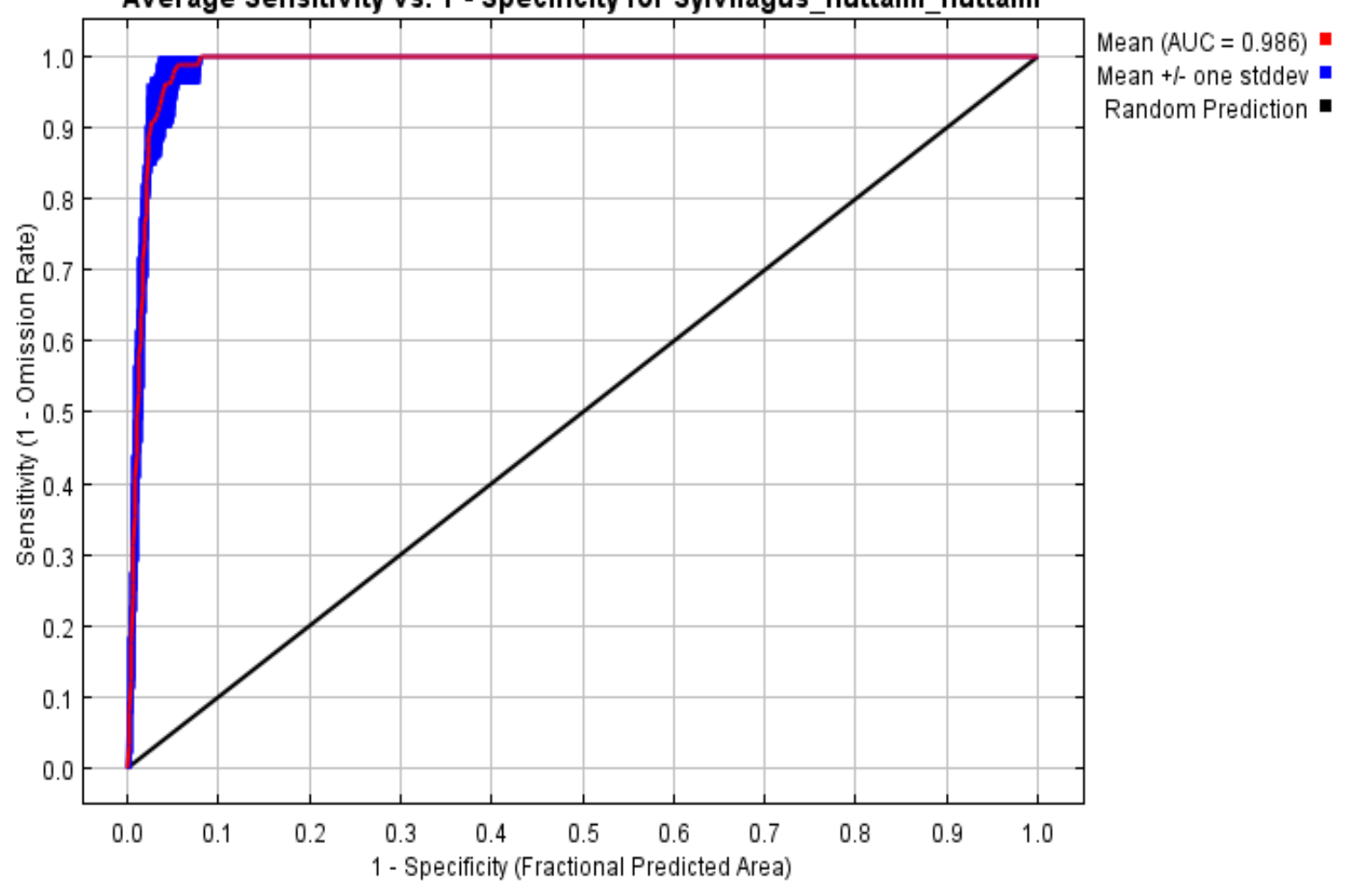


Figure H6

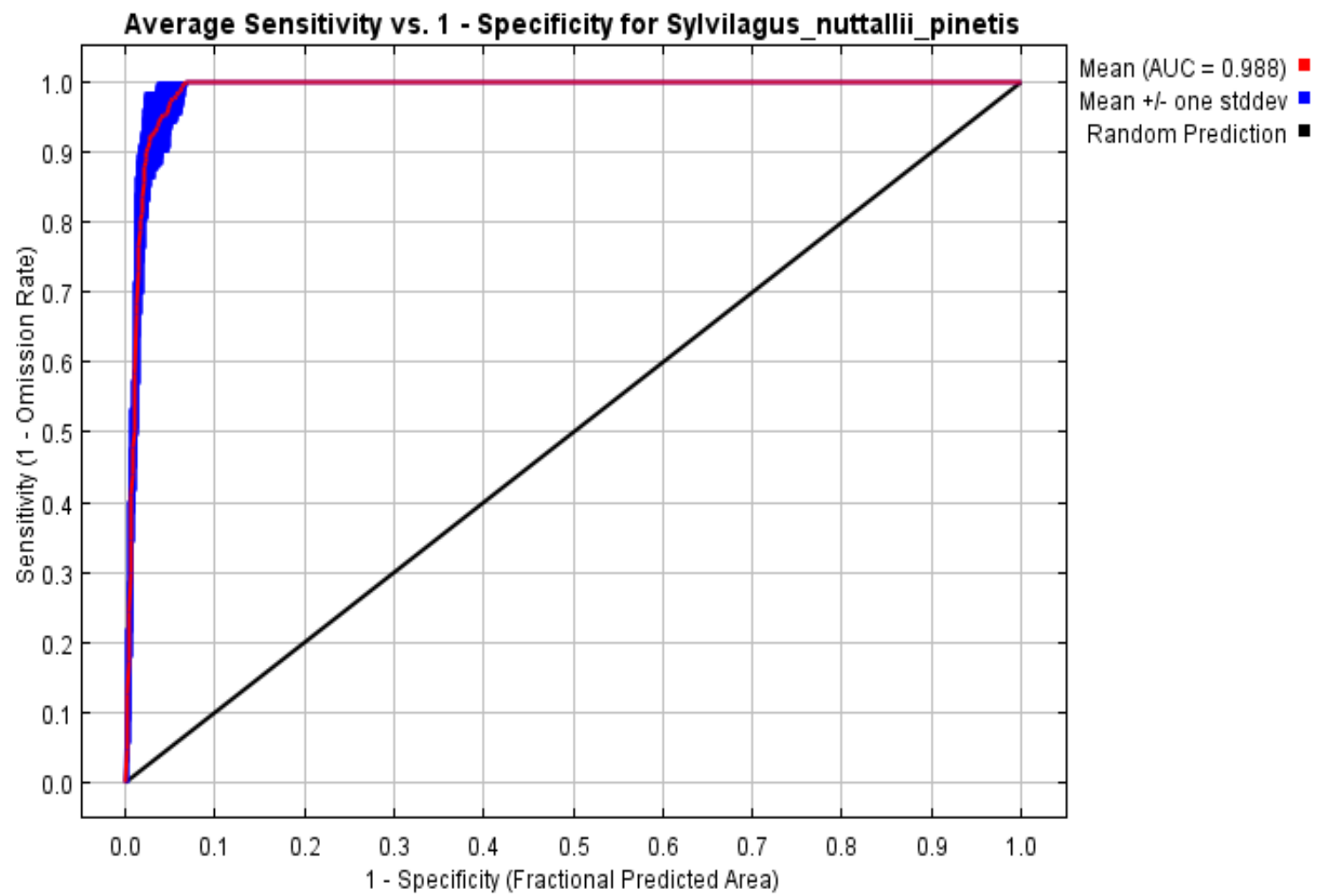

Pictures of the model

The following pictures show the point-wise mean and standard deviation of the 10 output grids. Other available summary grids are $\underline{\min }, \underline{\max }$ and $\underline{\text { median. }}$.

Sylvilagus nuttallii grangeri:

Figure H7

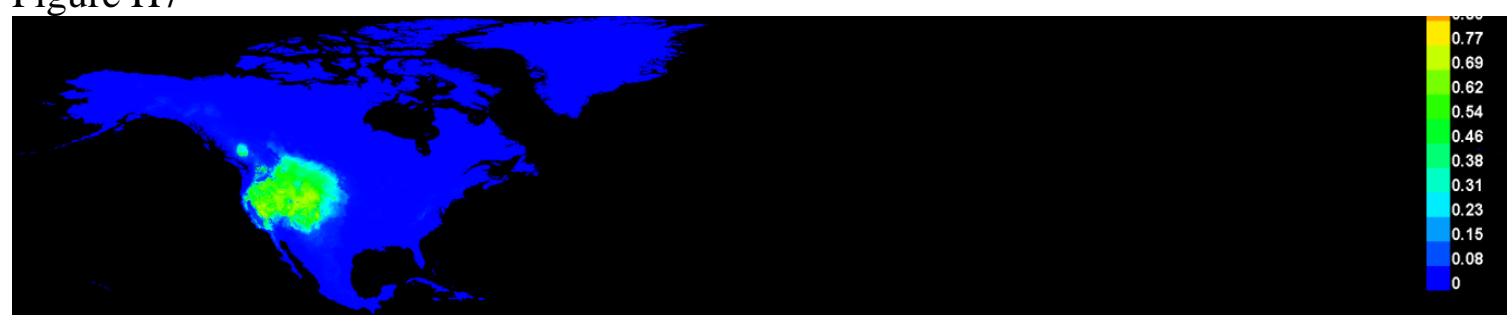

Figure H8

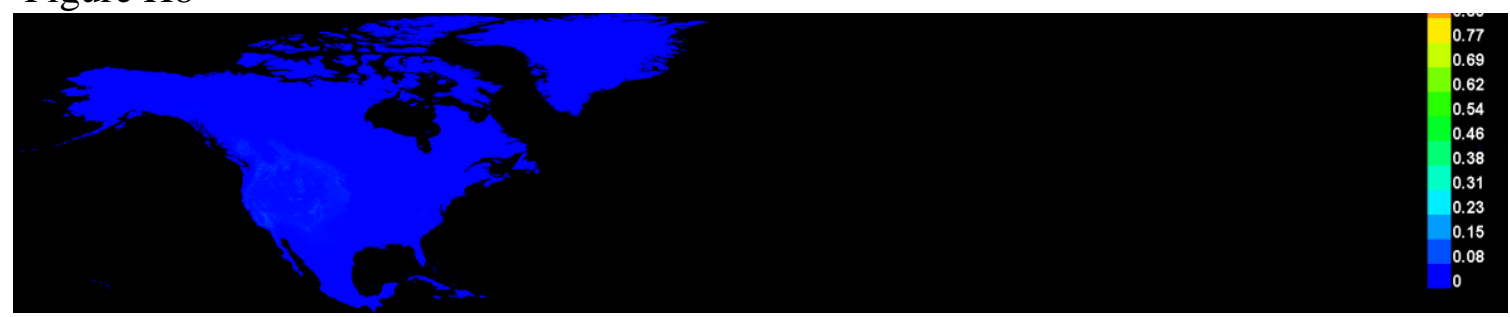


Sylvilagus nuttallii nuttallii:

Figure H9

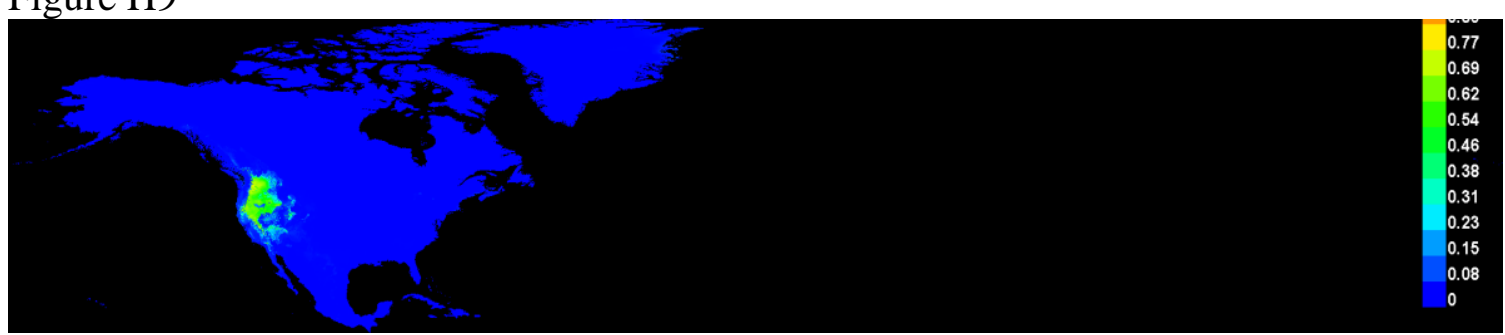

Figure $\mathrm{H} 10$

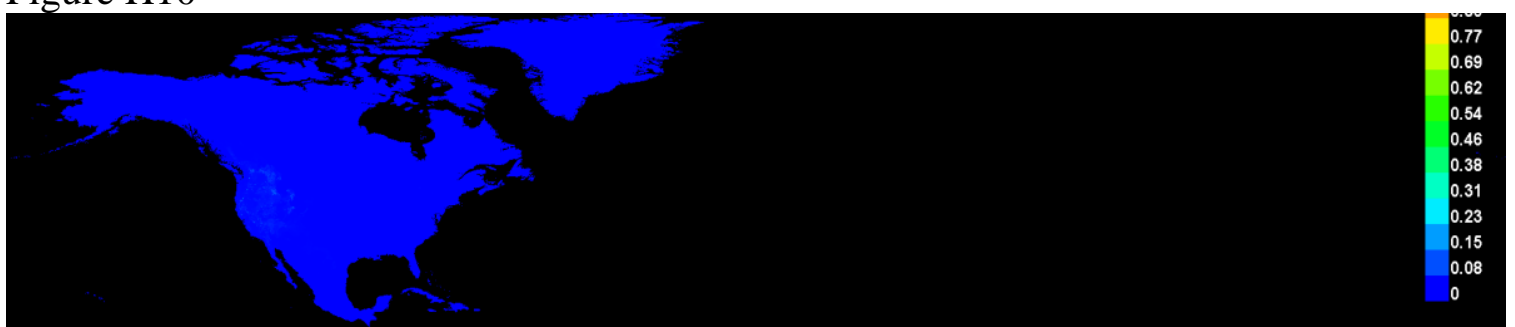

Sylvilagus nuttallii pinetis:

Figure H11

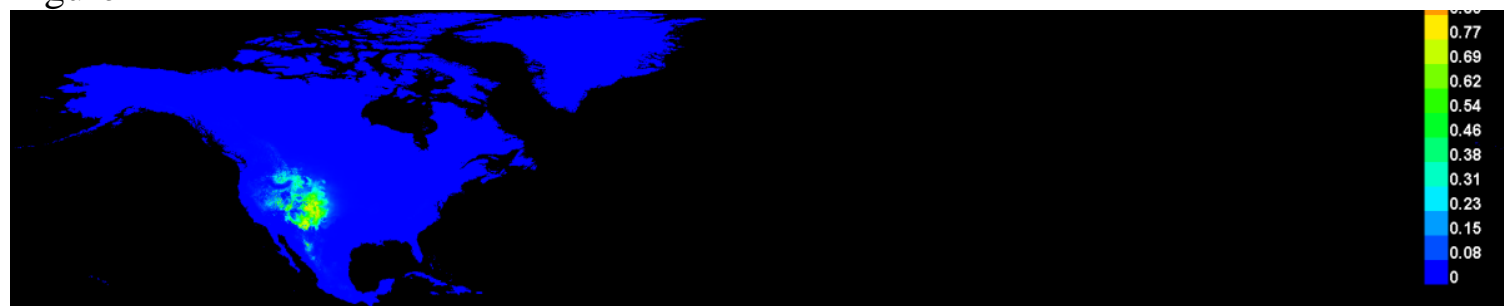

Figure $\mathrm{H} 12$

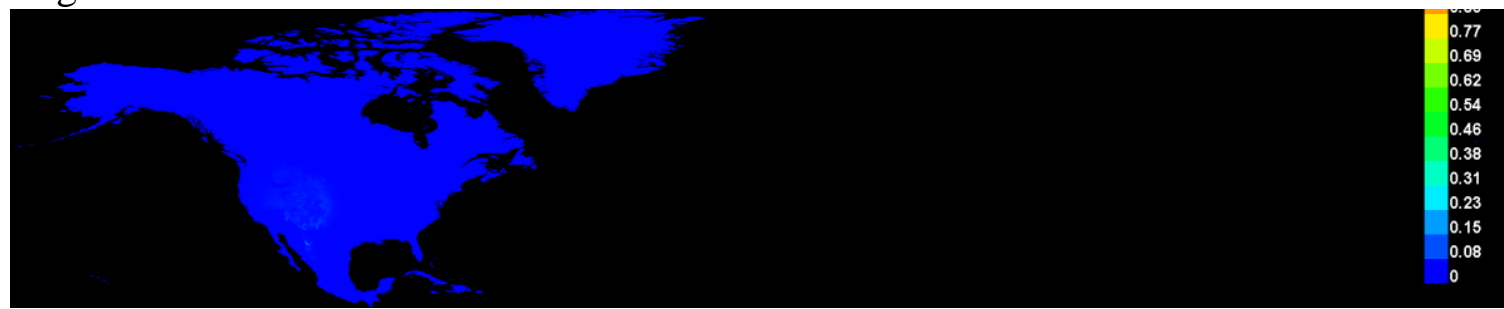

The following pictures show the point-wise mean and standard deviation of the 10 models applied to the environmental layers in ASCII. Other available summary grids are $\underline{\min }, \underline{\max }$ and median. 
Sylvilagus nuttallii grangeri

Figure H13

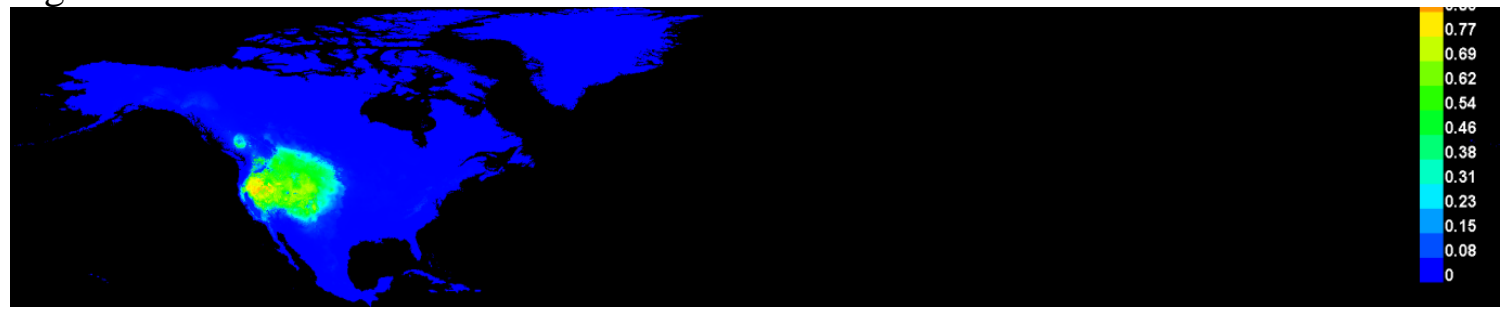

Figure H14

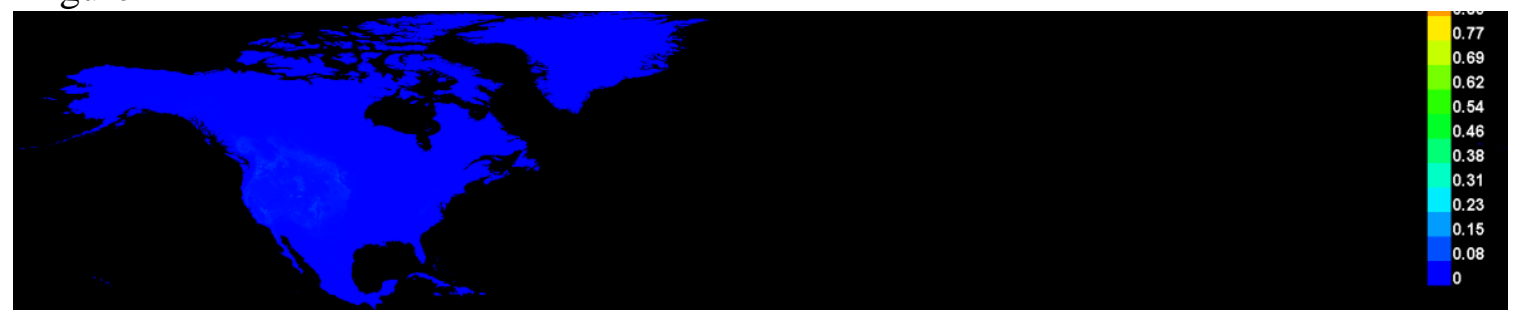

Sylvilagus nuttallii nuttallii:

Figure H15

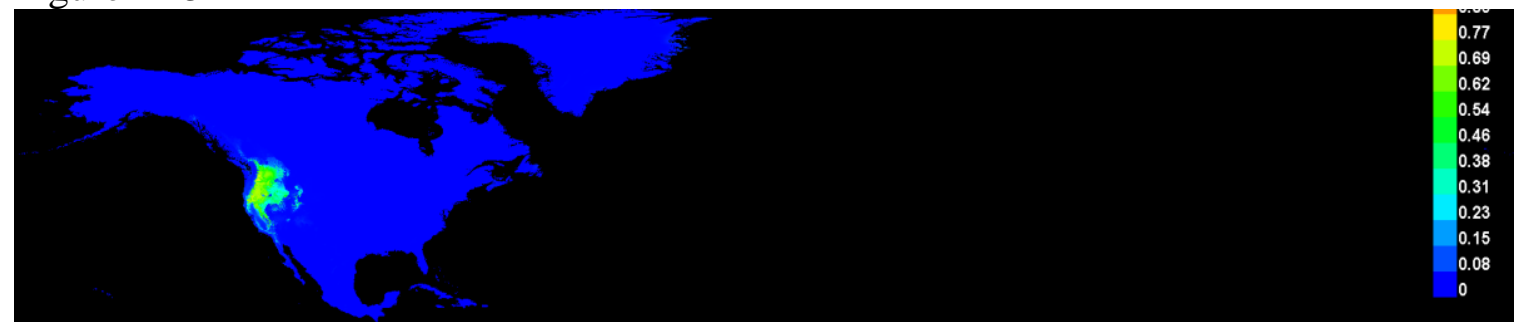

Figure H16

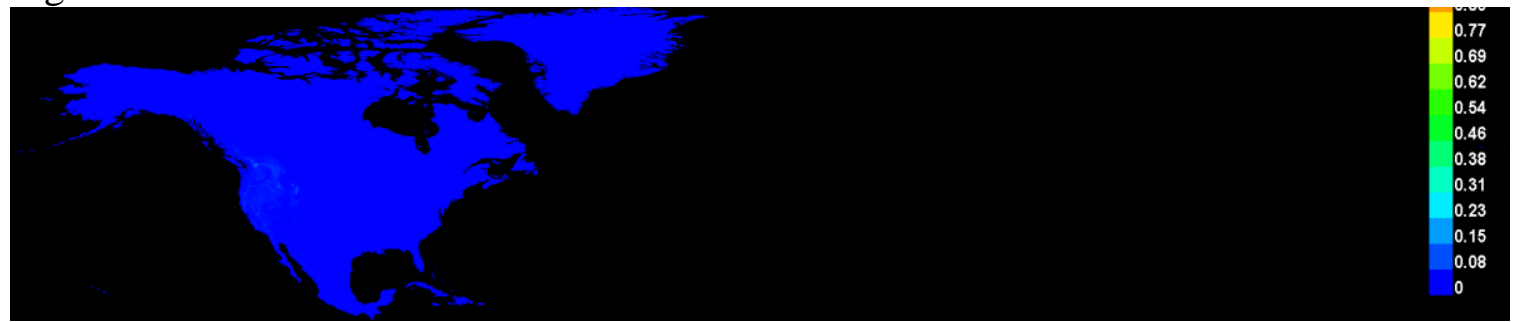

Sylvilagus nuttallii pinetis:

Figure H17

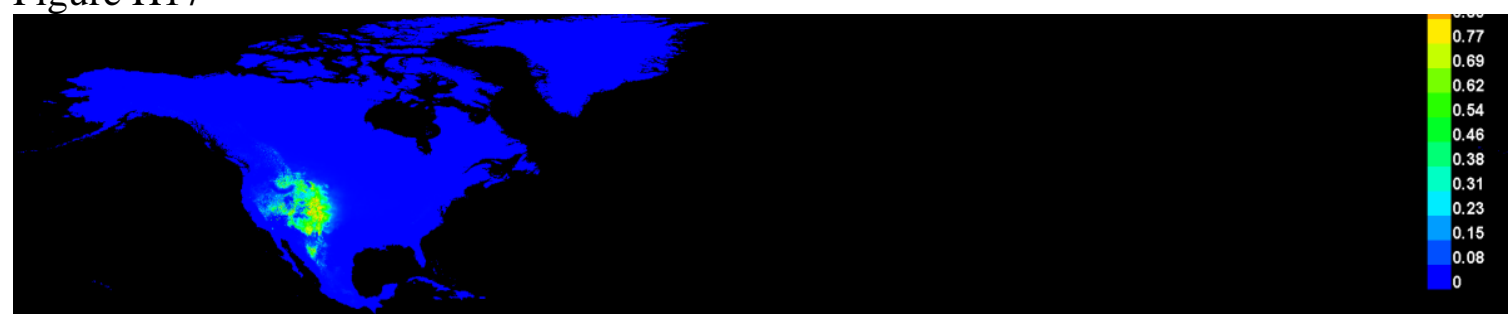


Figure H18

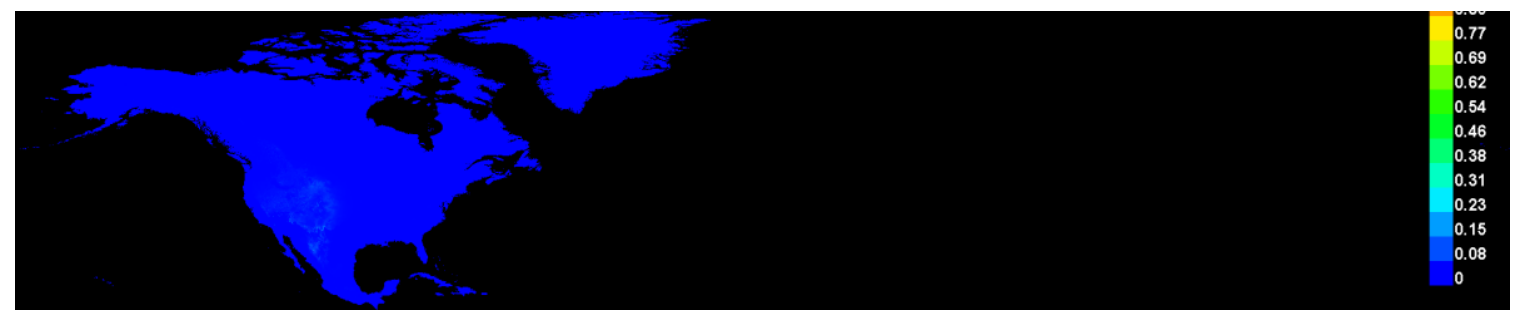




\section{Response curves}

These curves show how each environmental variable affects the Maxent prediction. The curves show how the logistic prediction changes as each environmental variable is varied, keeping all other environmental variables at their average sample value. Click on a response curve to see a larger version. Note that the curves can be hard to interpret if you have strongly correlated variables, as the model may depend on the correlations in ways that are not evident in the curves. In other words, the curves show the marginal effect of changing exactly one variable, whereas the model may take advantage of sets of variables changing together. The curves show the mean response of the 10 replicate Maxent runs (red) and and the mean $+/$ - one standard deviation (blue, two shades for categorical variables).

Sylvilagus nuttallii grangeri

Figure H19
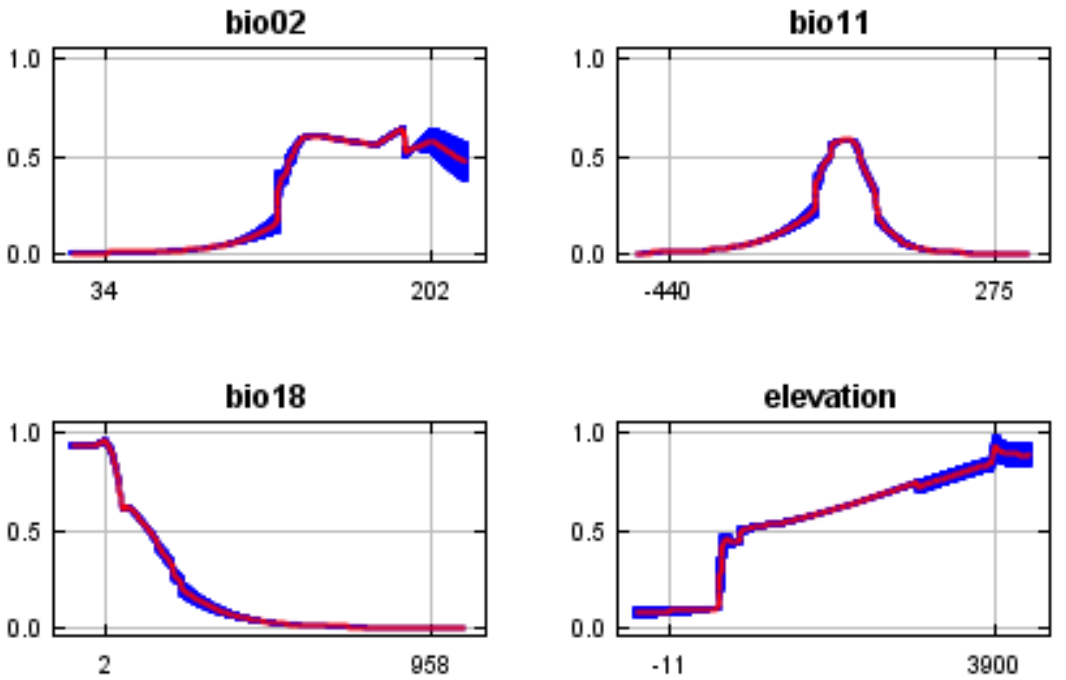
Sylvilagus nuttallii nuttallii

Figure H20
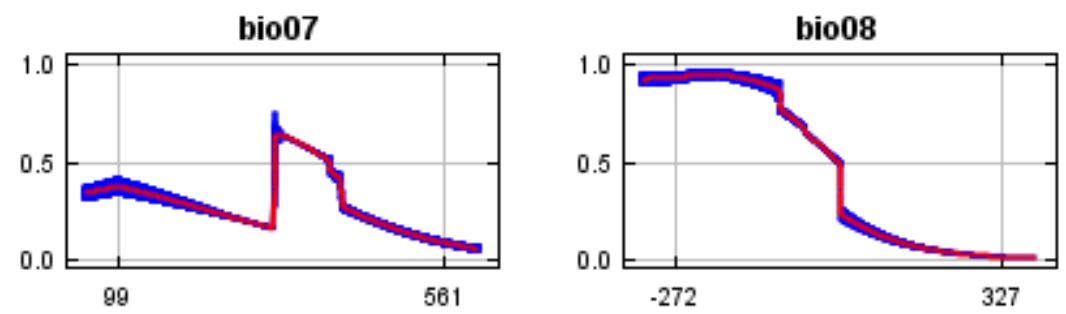

bio09

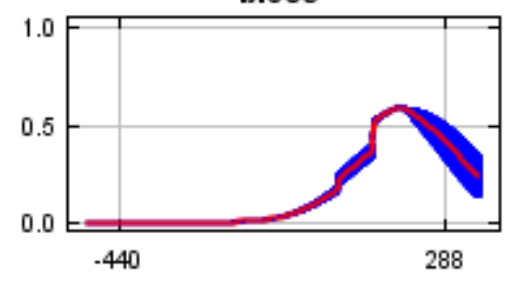

bio 18

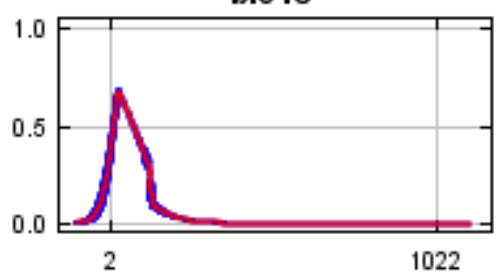

Sylvilagus nuttallii pinetis

Figure H21
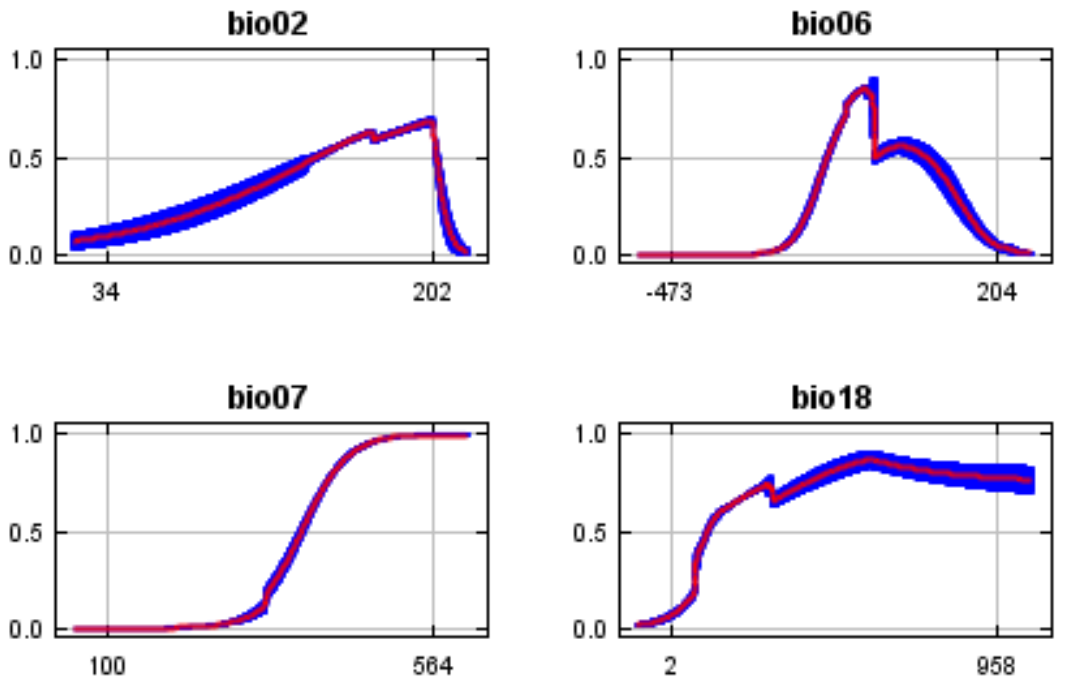


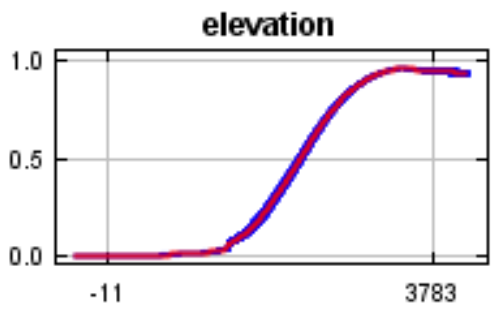

In contrast to the above marginal response curves, each of the following curves represents a different model, namely, a Maxent model created using only the corresponding variable. These plots reflect the dependence of predicted suitability both on the selected variable and on dependencies induced by correlations between the selected variable and other variables. They may be easier to interpret if there are strong correlations between variables.

Sylvilagus nuttallii grangeri

Figure H22
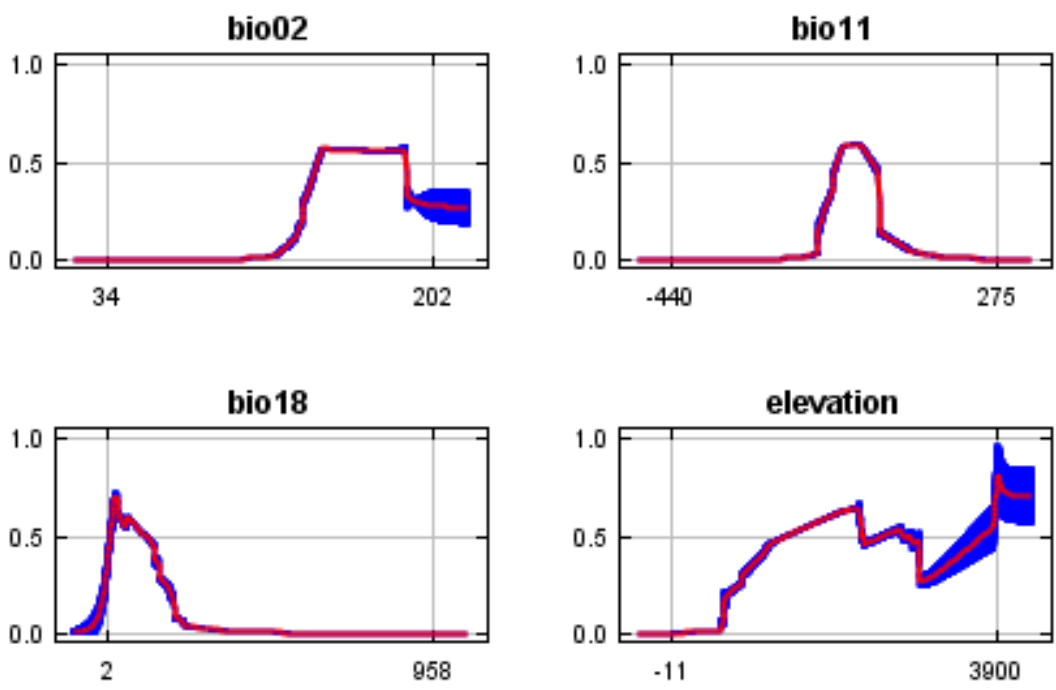
Sylvilagus nuttallii nuttallii

Figure H23
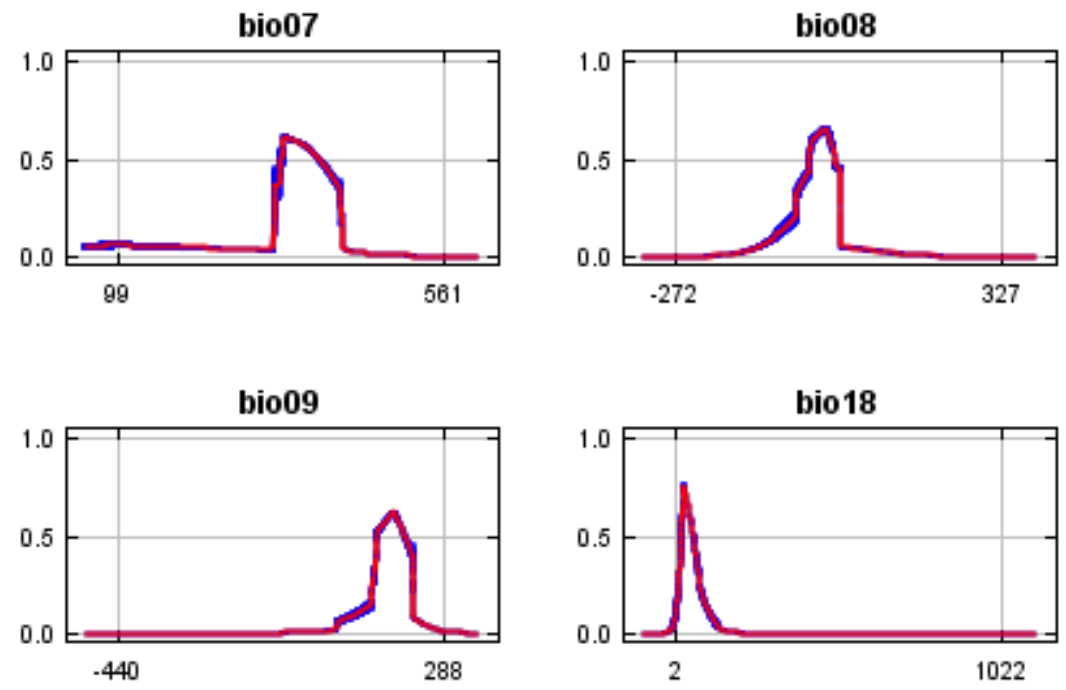

Sylvilagus nuttallii pinetis

Figure H24
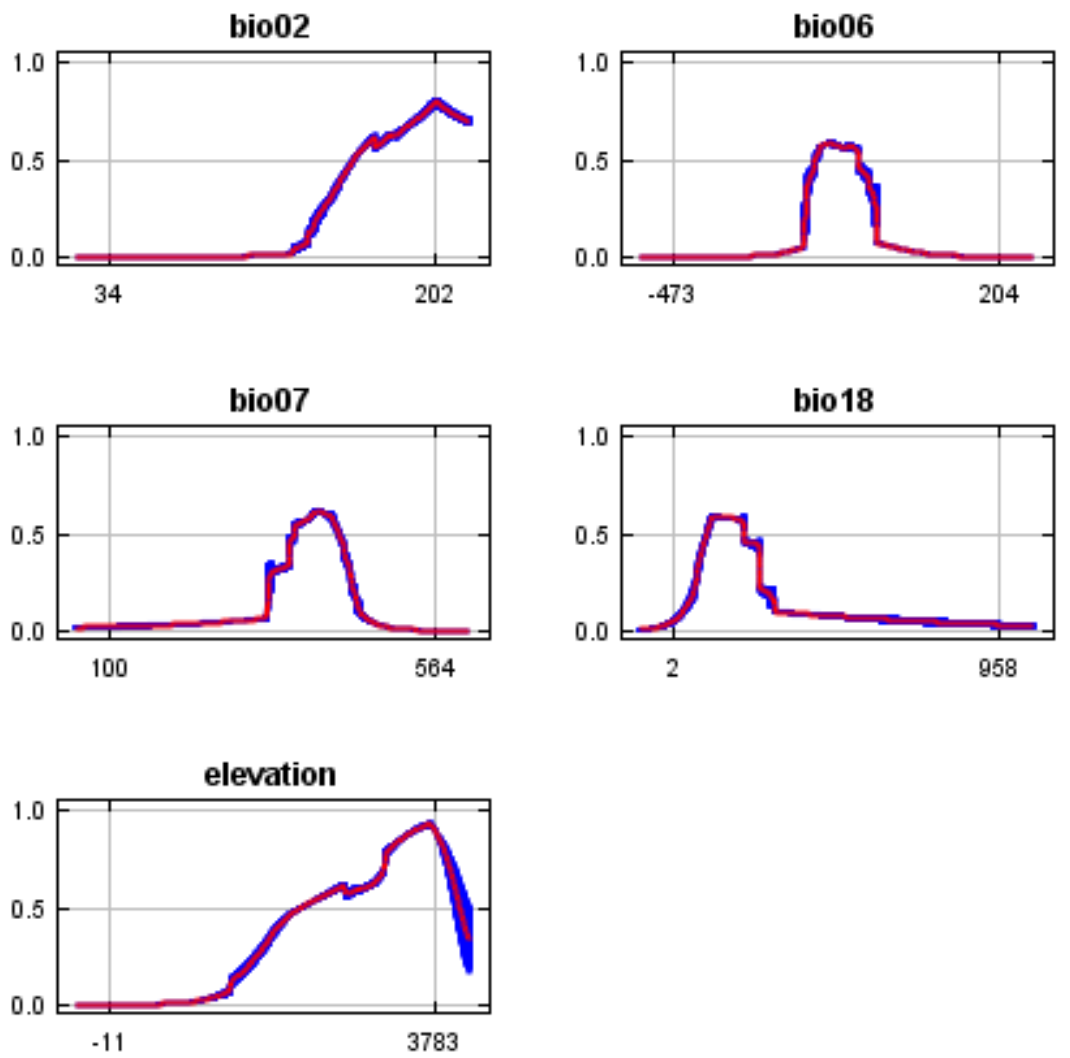
Analysis of variable contributions

The following table gives estimates of relative contributions of the environmental variables to the Maxent model. To determine the first estimate, in each iteration of the training algorithm, the increase in regularized gain is added to the contribution of the corresponding variable, or subtracted from it if the change to the absolute value of lambda is negative. For the second estimate, for each environmental variable in turn, the values of that variable on training presence and background data are randomly permuted. The model is reevaluated on the permuted data, and the resulting drop in training AUC is shown in the table, normalized to percentages. As with the variable jackknife, variable contributions should be interpreted with caution when the predictor variables are correlated. Values shown are averages over replicate runs.

Sylvilagus nuttallii grangeri

Table H1

Variable Percent contribution Permutation importance

$\begin{array}{ccc}\text { bio02 } & 53.7 & 43 \\ \text { bio11 } & 20.5 & 30.8 \\ \text { elevation } & 15.1 & 13.6 \\ \text { bio18 } & 10.8 & 12.6\end{array}$

Sylvilagus nuttallii nuttallii

Table H2

Variable Percent contribution Permutation importance

$\begin{array}{ccc}\text { bio09 } & 53.2 & 71 \\ \text { bio08 } & 25 & 9.2 \\ \text { bio18 } & 18.5 & 18.2 \\ \text { bio07 } & 3.3 & 1.7\end{array}$

Sylvilagus nuttallii pinetis

Table H3

Variable Percent contribution Permutation importance

$\begin{array}{lll}\text { bio02 } & 45.9 & 1\end{array}$

$\begin{array}{lll}\text { elevation } \quad 40.1 & 48.8\end{array}$

$\begin{array}{lll}\text { bio06 } & 7.8 & 40.4\end{array}$

$\begin{array}{lll}\text { bio07 } & 3.4 & 7.4\end{array}$

$\begin{array}{lll}\text { bio18 } 2.8 & 2.5\end{array}$ 
The following picture shows the results of the jackknife test of variable importance. The environmental variable with highest gain when used in isolation is bio02, which therefore appears to have the most useful information by itself. The environmental variable that decreases the gain the most when it is omitted is bio11, which therefore appears to have the most information that isn't present in the other variables. Values shown are averages over replicate runs.

Figure $\mathrm{H} 25$

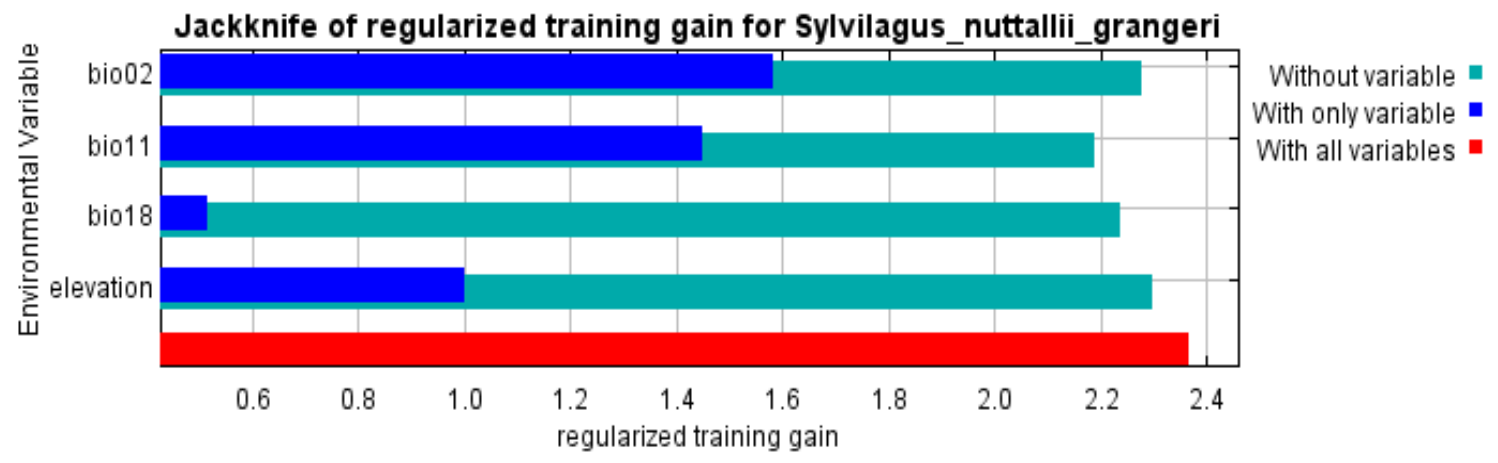

Figure H26

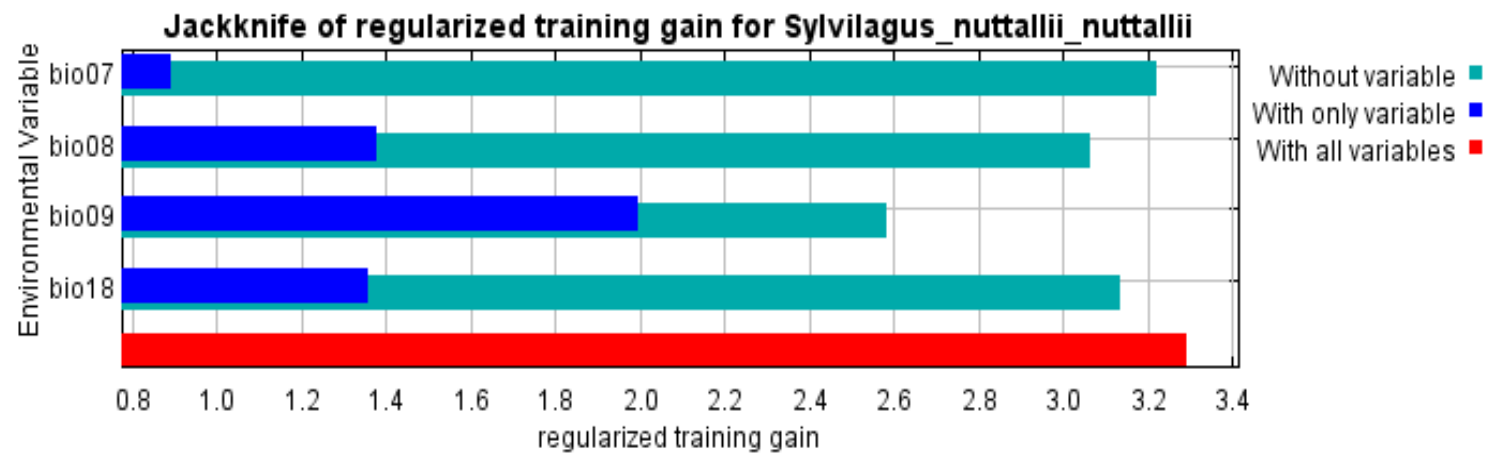

Figure $\mathrm{H} 27$

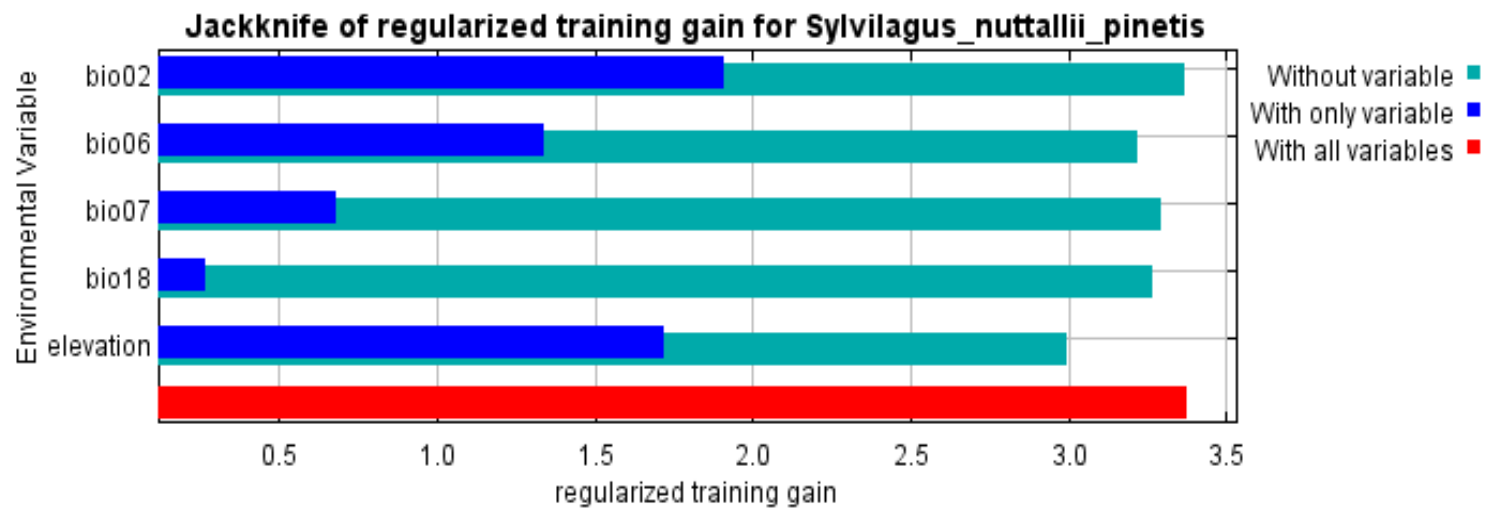

The next picture shows the same jackknife test, using test gain instead of training gain. 
Note that conclusions about which variables are most important can change, now that we're looking at test data.

Figure $\mathrm{H} 28$

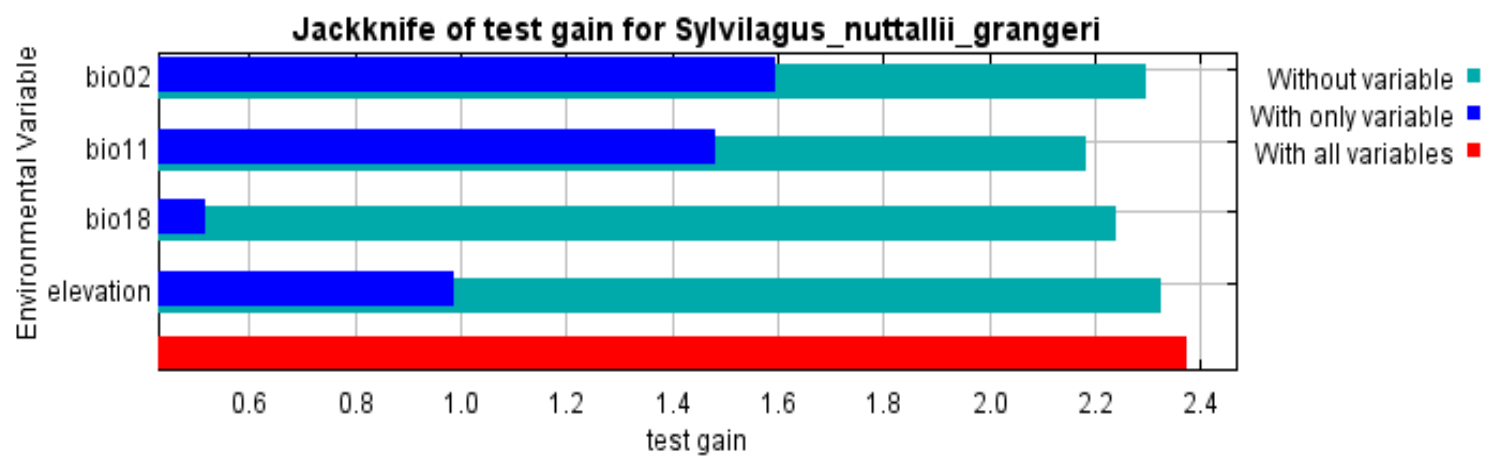

Figure H29

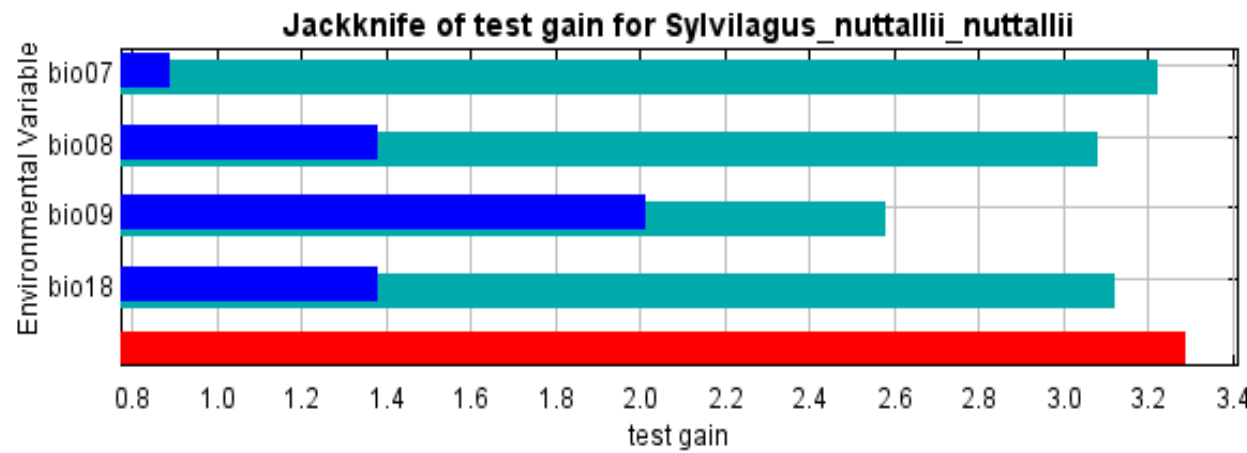

Without variable With only variable With all variables

Figure H30

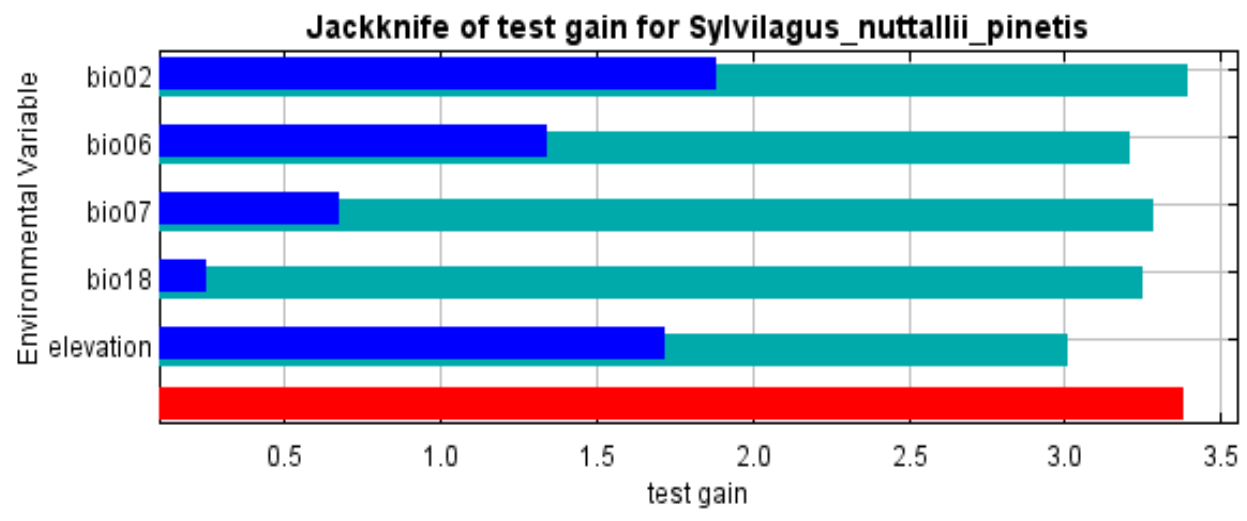

Without variable With only variable With all variables

Lastly, we have the same jackknife test, using AUC on test data. 
Figure H31

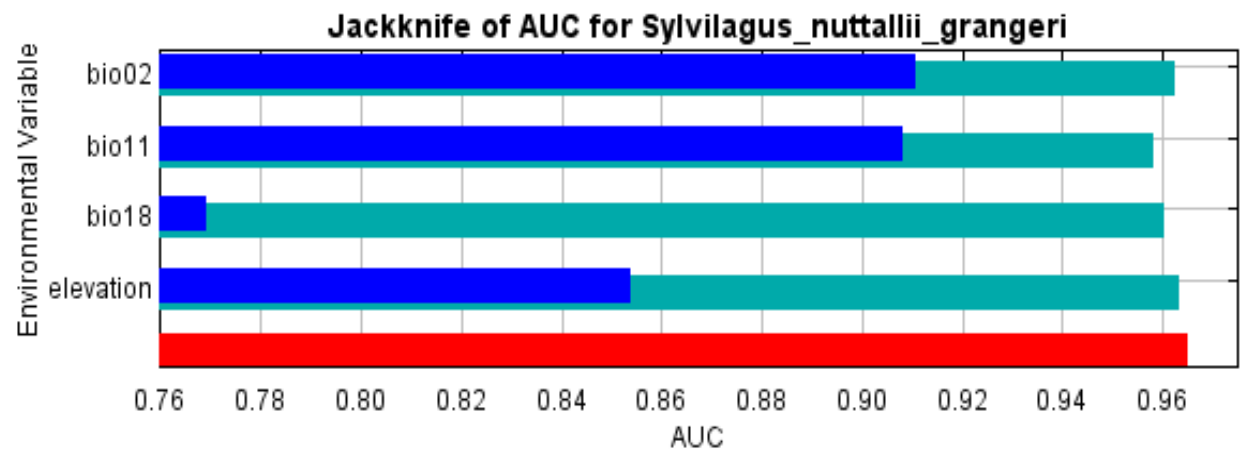

Without variable With only variable With all variables

Figure H32

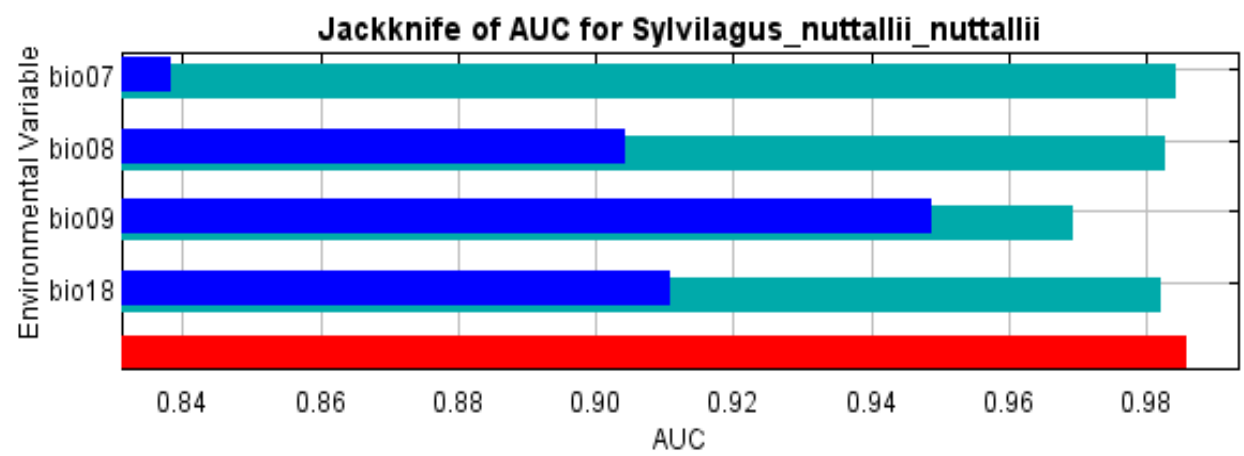

Without variable With only variable With all variables

Figure H33

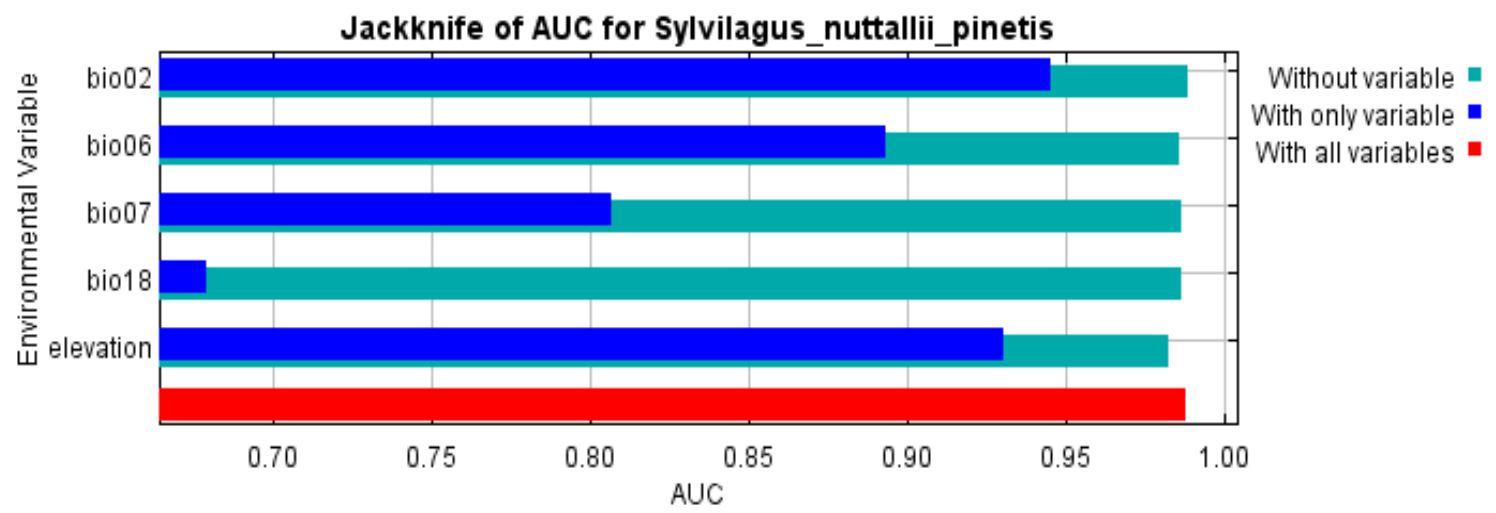




\section{APPENDIX I}

Holotype and topotype cranial measurements

Cranial measurements used in Chapter 2. All measurements were recorded in millimeters. Figures show skull measurements and descriptions of skull elements.

Table I1

\begin{tabular}{|c|c|c|c|c|c|c|c|c|c|c|c|c|c|c|c|c|c|}
\hline & 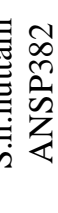 & & 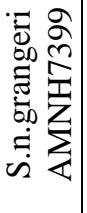 & 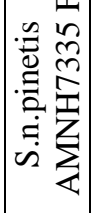 & 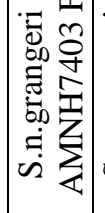 & 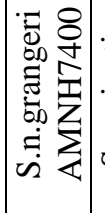 & 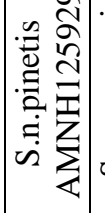 & 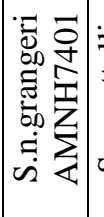 & 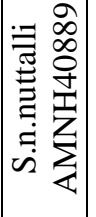 & 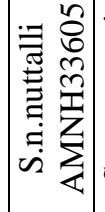 & 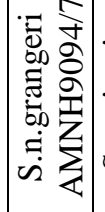 & 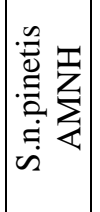 & 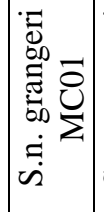 & 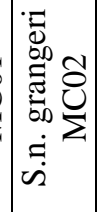 & 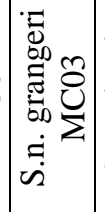 & 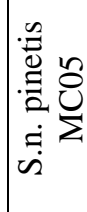 & \\
\hline 恣 & $\begin{array}{l}\vec{J} \\
\infty \\
\infty \\
\infty\end{array}$ & $\hat{\sigma}$ & $\begin{array}{l}\stackrel{m}{b} \\
\dot{b}\end{array}$ & ㄱ. & $\begin{array}{l}7 \\
0 \\
0\end{array}$ & 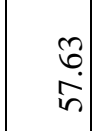 & 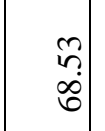 & $\begin{array}{l}\bar{n} \\
\stackrel{y}{y}\end{array}$ & 竎 & 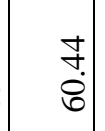 & | & 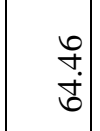 & 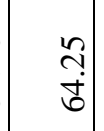 & 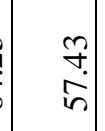 & $\begin{array}{l}n \\
\hat{n} \\
\hat{n}\end{array}$ & $\begin{array}{l}8 \\
\text { İ }\end{array}$ & : \\
\hline 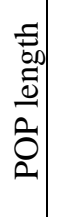 & $\stackrel{\vec{r}}{\mathrm{r}}$ & 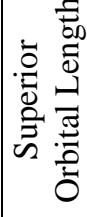 & 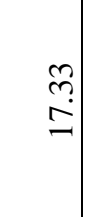 & $\begin{array}{l}\bar{f} \\
\dot{\Delta}\end{array}$ & 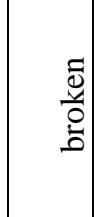 & 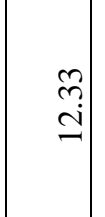 & $\vec{m}$ & $\stackrel{\bullet}{\ominus}$ & 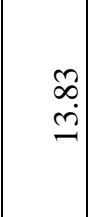 & 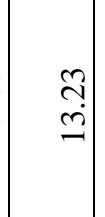 & $\begin{array}{l}\hat{\imath} \\
\underline{\imath}\end{array}$ & 资 & 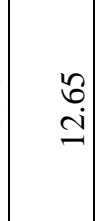 & $\begin{array}{l}\stackrel{t}{ \pm} \\
\stackrel{\Xi}{=}\end{array}$ & 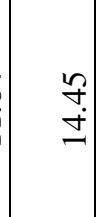 & 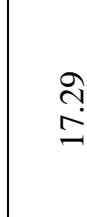 & ป \\
\hline : & 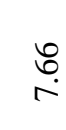 & 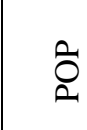 & $\begin{array}{l}0 \\
\stackrel{0}{0} \\
\stackrel{0}{0}\end{array}$ & $\begin{array}{l}\tilde{n} \\
\stackrel{0}{=}\end{array}$ & 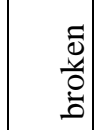 & $\begin{array}{l}\infty \\
\infty \\
\substack{0 \\
0}\end{array}$ & 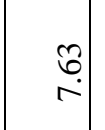 & స్ర & 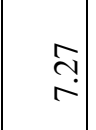 & $\begin{array}{l}\infty \\
\infty \\
0 \\
0\end{array} \mid$ & $\begin{array}{c}m \\
\infty\end{array}$ & $\stackrel{m}{\infty}$ & ज़ & $\stackrel{n}{\stackrel{n}{-}}$ & 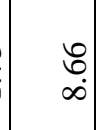 & $\stackrel{\circ}{9}$ & i \\
\hline 馬 & $\begin{array}{l}\stackrel{\circ}{\infty} \\
\stackrel{0}{0}\end{array}$ & 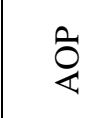 & $\begin{array}{l}\text { f. } \\
\text { i }\end{array}$ & $\begin{array}{c}\overrightarrow{\vec{v}} \\
\overrightarrow{0} \\
\vec{\omega}\end{array}$ & $\stackrel{+}{-}$ & $\stackrel{\leftrightarrow}{\rightarrow}$ & 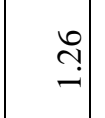 & in & $\stackrel{I}{i}$ & $\stackrel{\infty}{\rightarrow}$ & 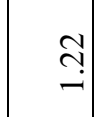 & $\Rightarrow$ & 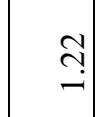 & 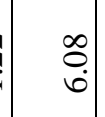 & 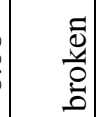 & f & 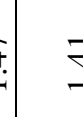 \\
\hline $\begin{array}{l}\overline{\bar{v}} \\
3 \\
3\end{array}$ & $\stackrel{2}{r}$ & 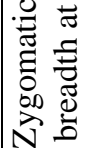 & $\stackrel{\infty}{\stackrel{m}{m}}$ & $\begin{array}{c}\hat{\delta} \\
\dot{j} \\
\end{array}$ & $\left|\begin{array}{l}\tau \\
0 \\
0 \\
i\end{array}\right|$ & 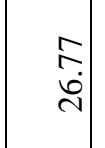 & 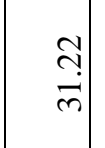 & $\begin{array}{l}\overrightarrow{\mathrm{N}} \\
\stackrel{\mathrm{d}}{ }\end{array}$ & in & $\begin{array}{l}0 \\
\stackrel{\sim}{0} \\
\stackrel{\sim}{\sim}\end{array}$ & $\begin{array}{l}\vec{a} \\
\stackrel{\rho}{d}\end{array} \mid$ & 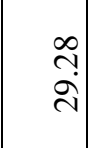 & î̀े & $\begin{array}{l}n \\
\stackrel{n}{a} \\
\stackrel{\sim}{n}\end{array}$ & {$\left[\begin{array}{c}n \\
\infty \\
i\end{array}\right]$} & $\stackrel{m}{m}$ & ?. \\
\hline है & $\stackrel{n}{=}$ & 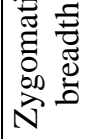 & $\begin{array}{l}\mathcal{F} \\
\dot{m} \\
\dot{m}\end{array}$ & $\begin{array}{l}n \\
\dot{b} \\
\dot{m}\end{array}$ & $\mid \begin{array}{c}5 \\
\dot{m}\end{array}$ & $\begin{array}{l}\tilde{N} \\
\text { } \\
\text {. }\end{array}$ & $\stackrel{\infty}{\stackrel{\infty}{+}}$ & $\stackrel{\infty}{\stackrel{\sim}{\Delta}}$ & $\begin{array}{l}\stackrel{+}{ } \\
\text { i. } \\
\text { mे }\end{array}$ & $\begin{array}{c}\infty \\
\stackrel{n}{m}\end{array}$ & $\stackrel{\sim}{m}$ & $\overrightarrow{\tilde{n}}$ & $\stackrel{n}{n}$ & $\stackrel{9}{\vec{m}}$ & $\mid \begin{array}{l}0 \\
i \\
m\end{array}$ & ते & \\
\hline
\end{tabular}




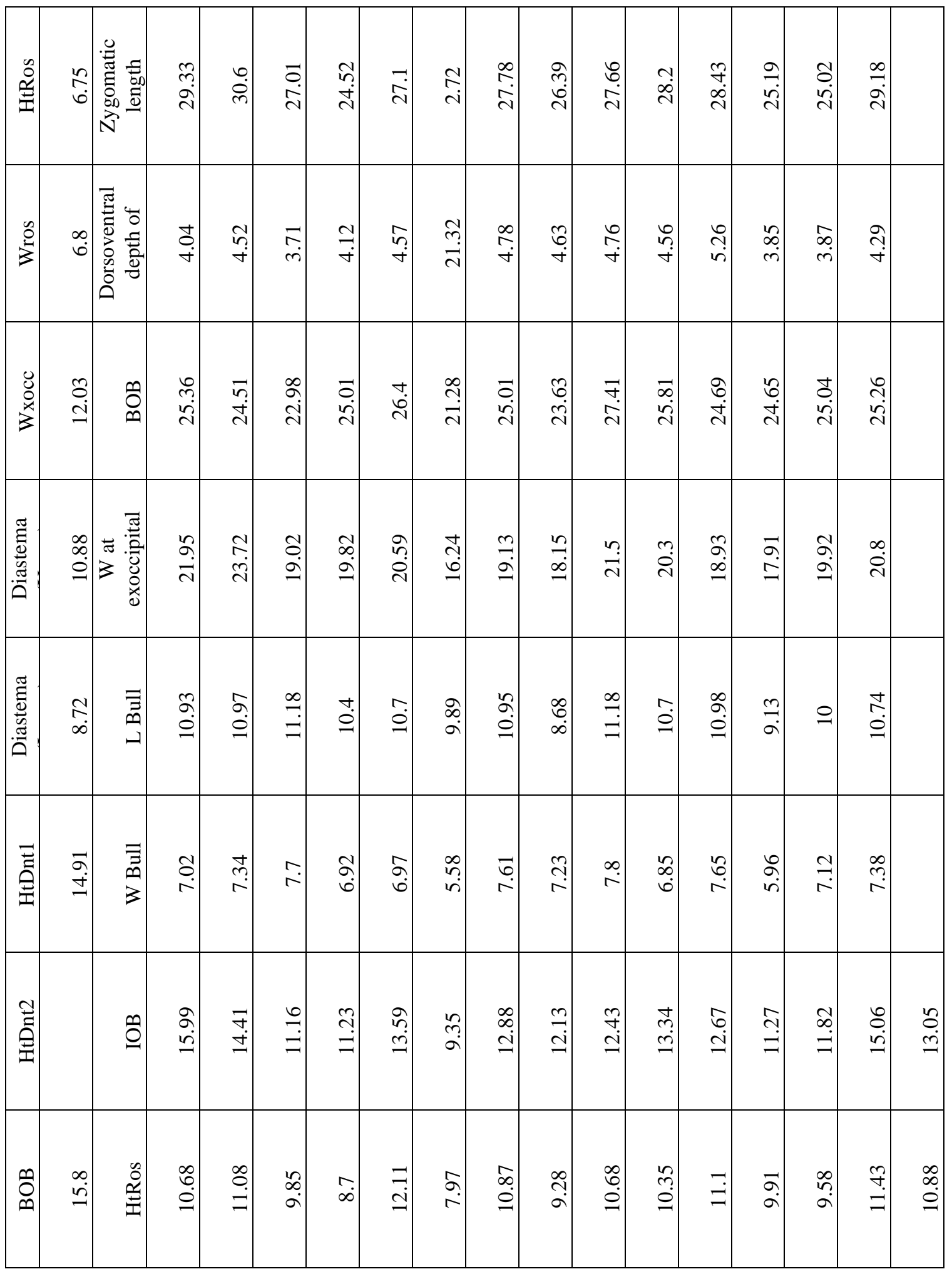




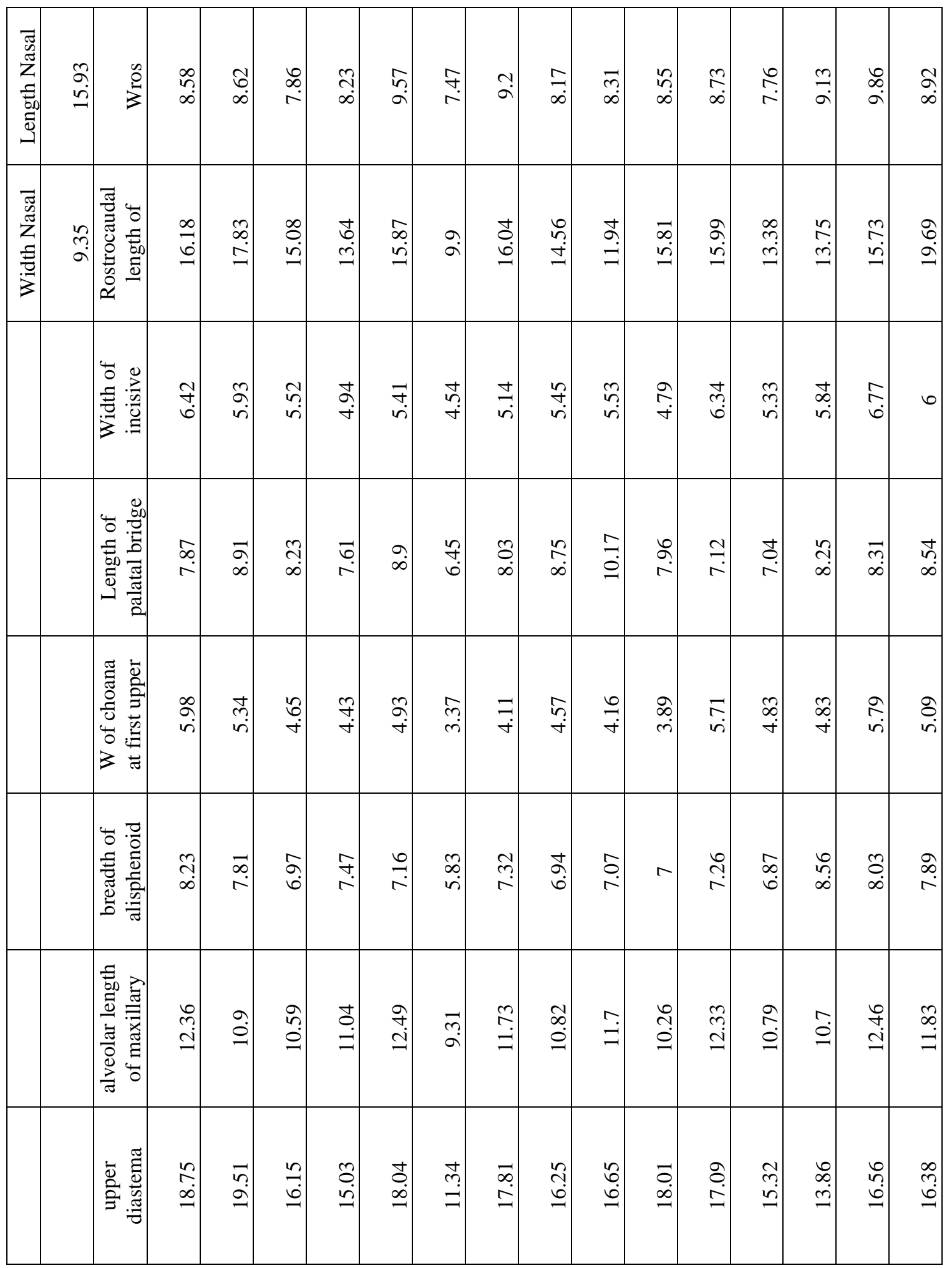




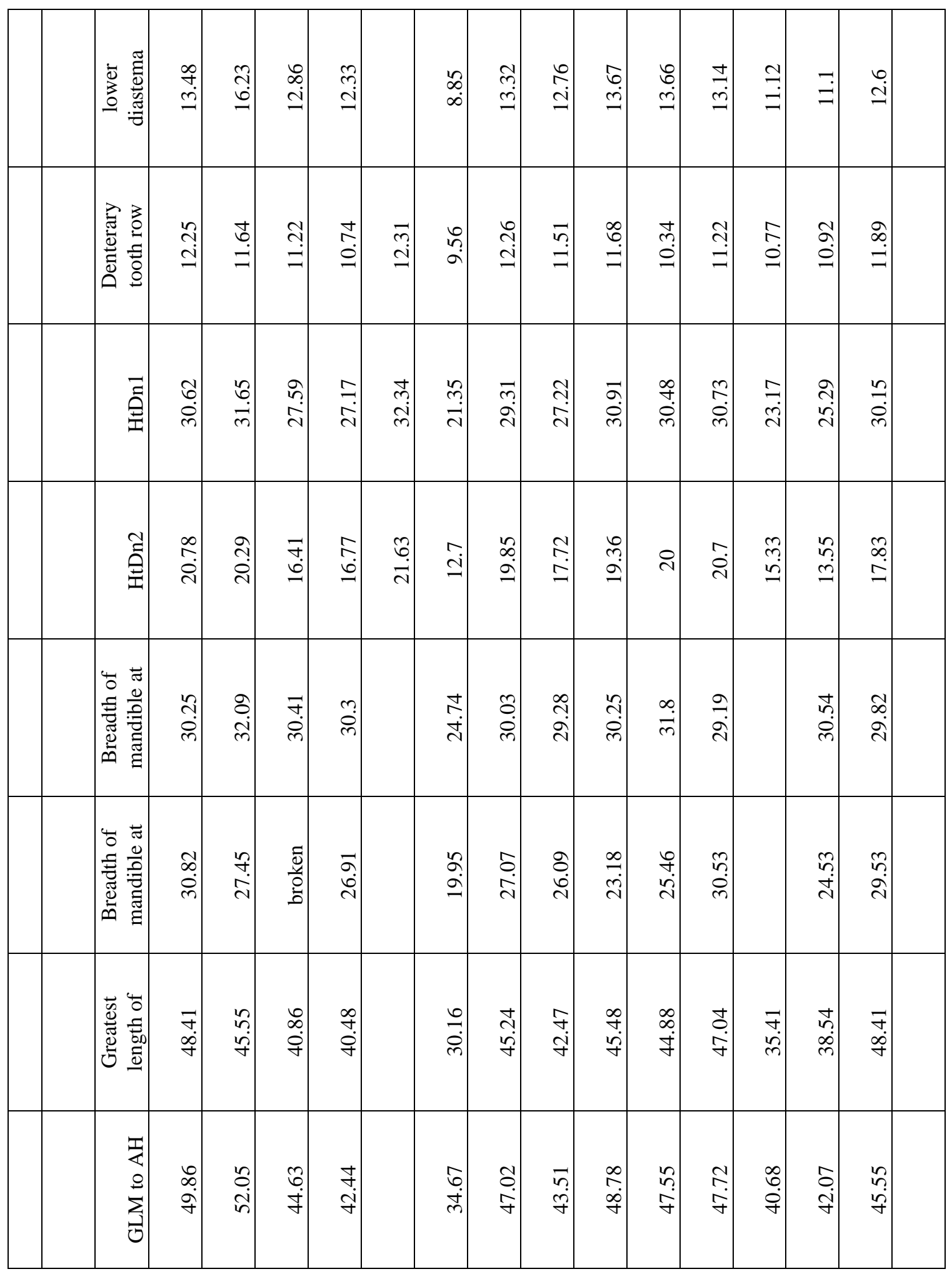




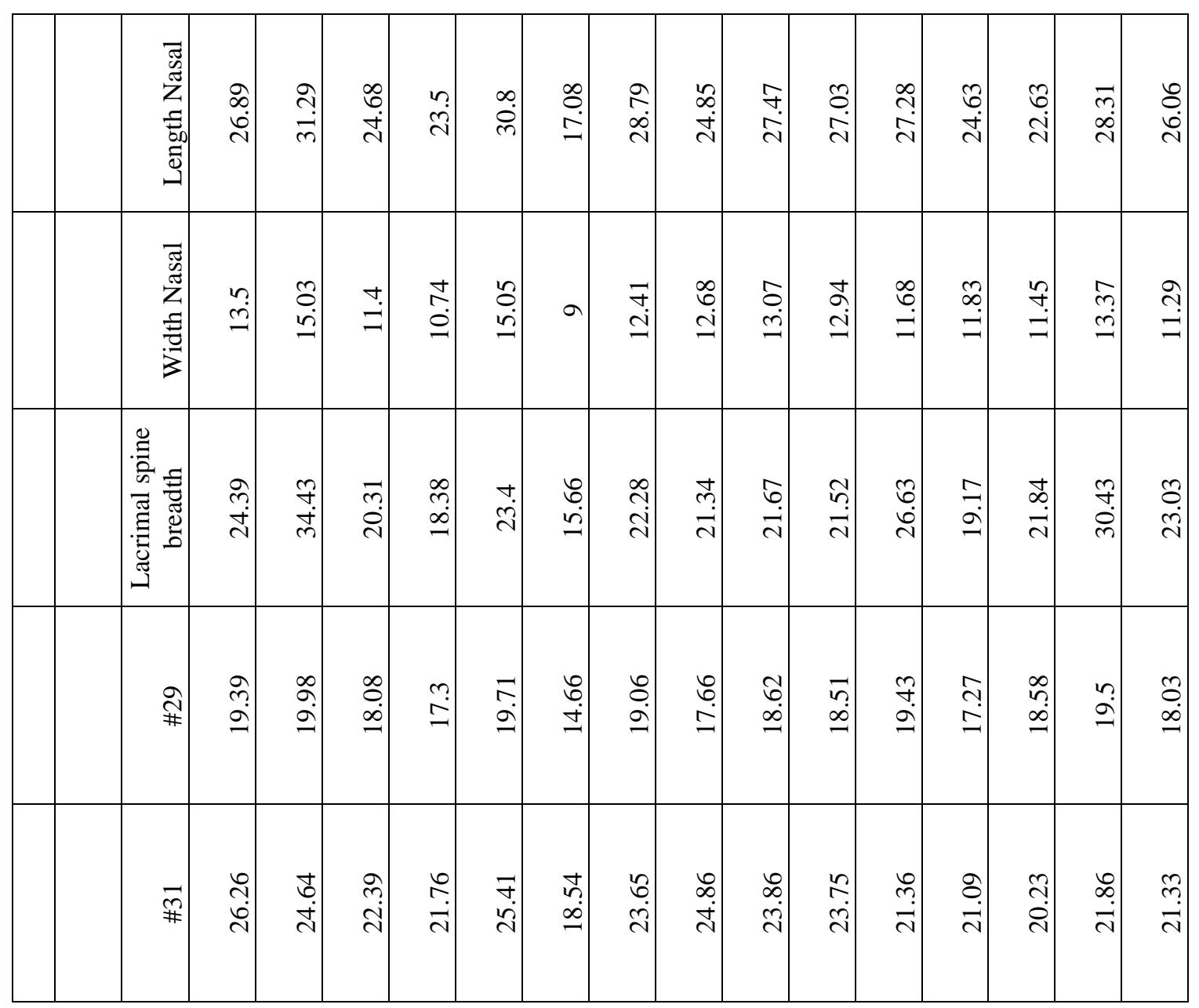


Figure I1

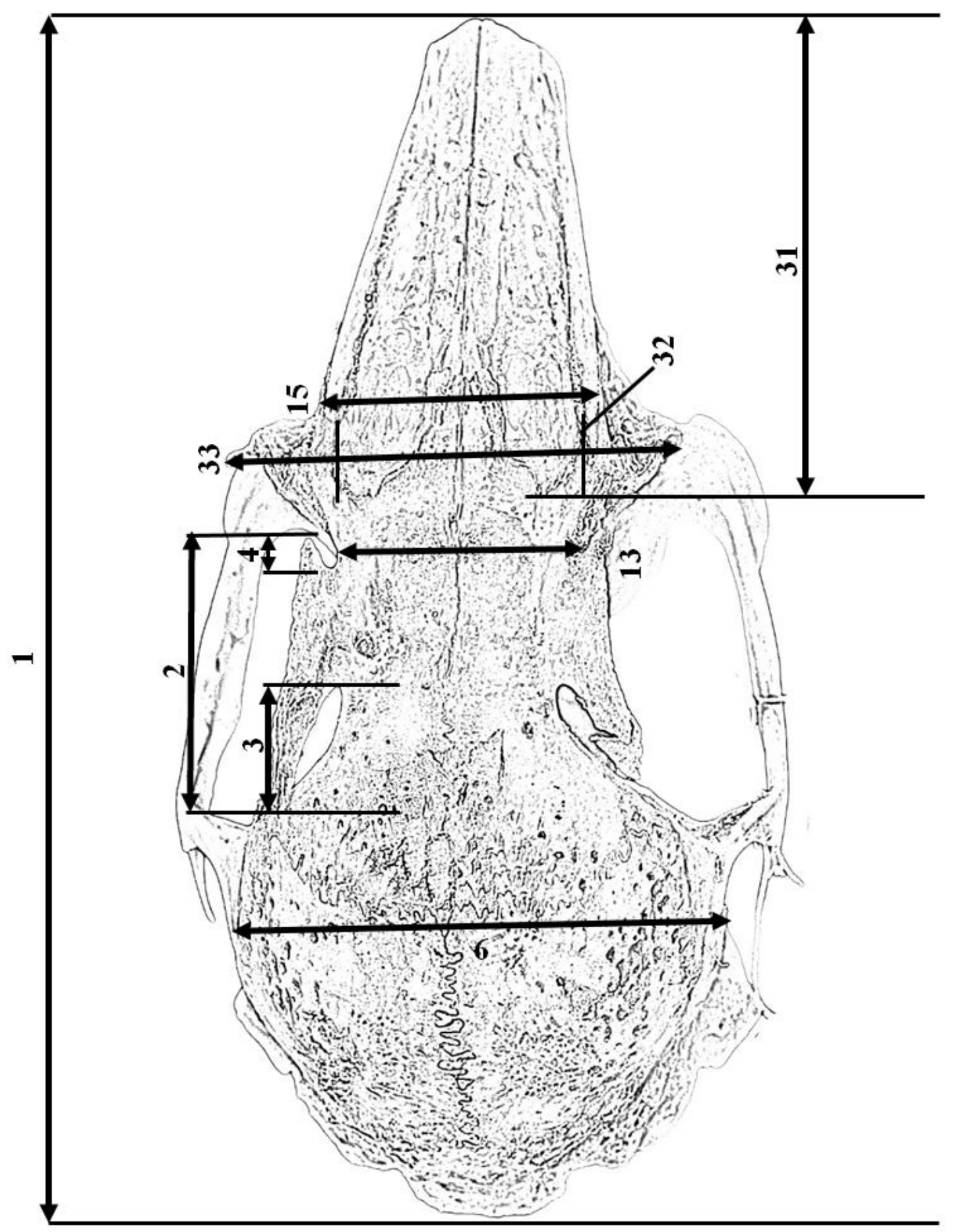


Figure I2

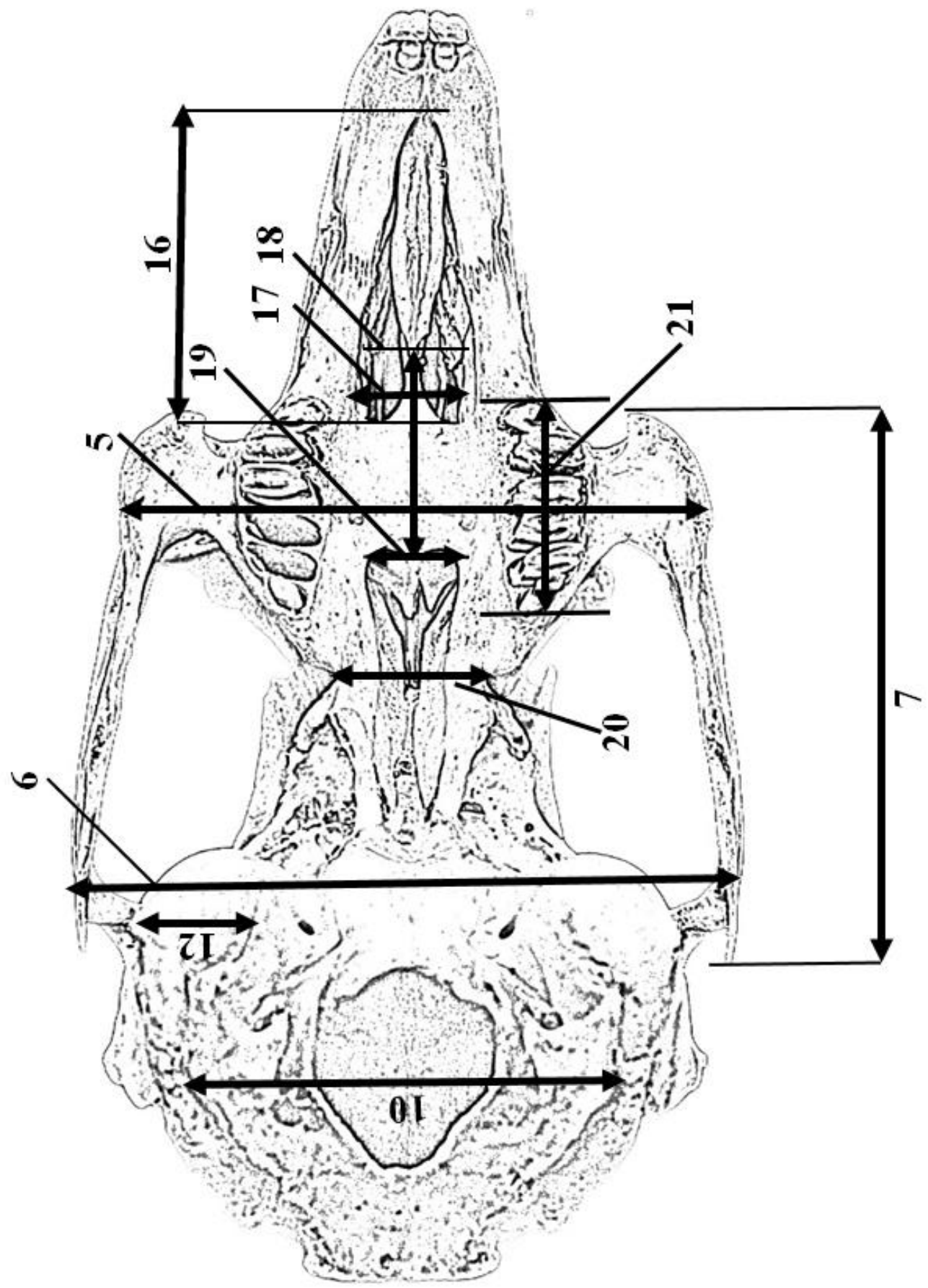


Figure I3

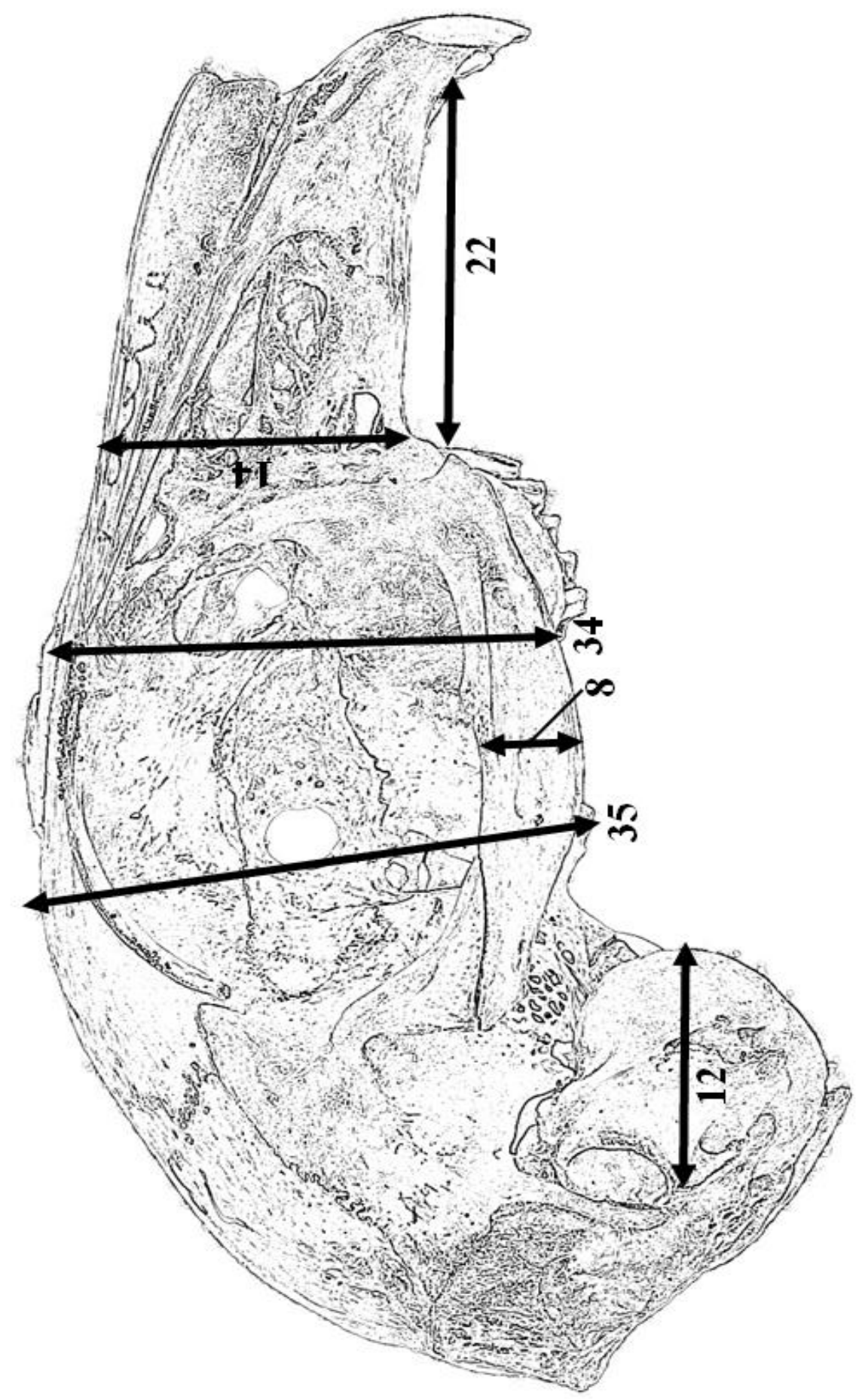


Figure I4

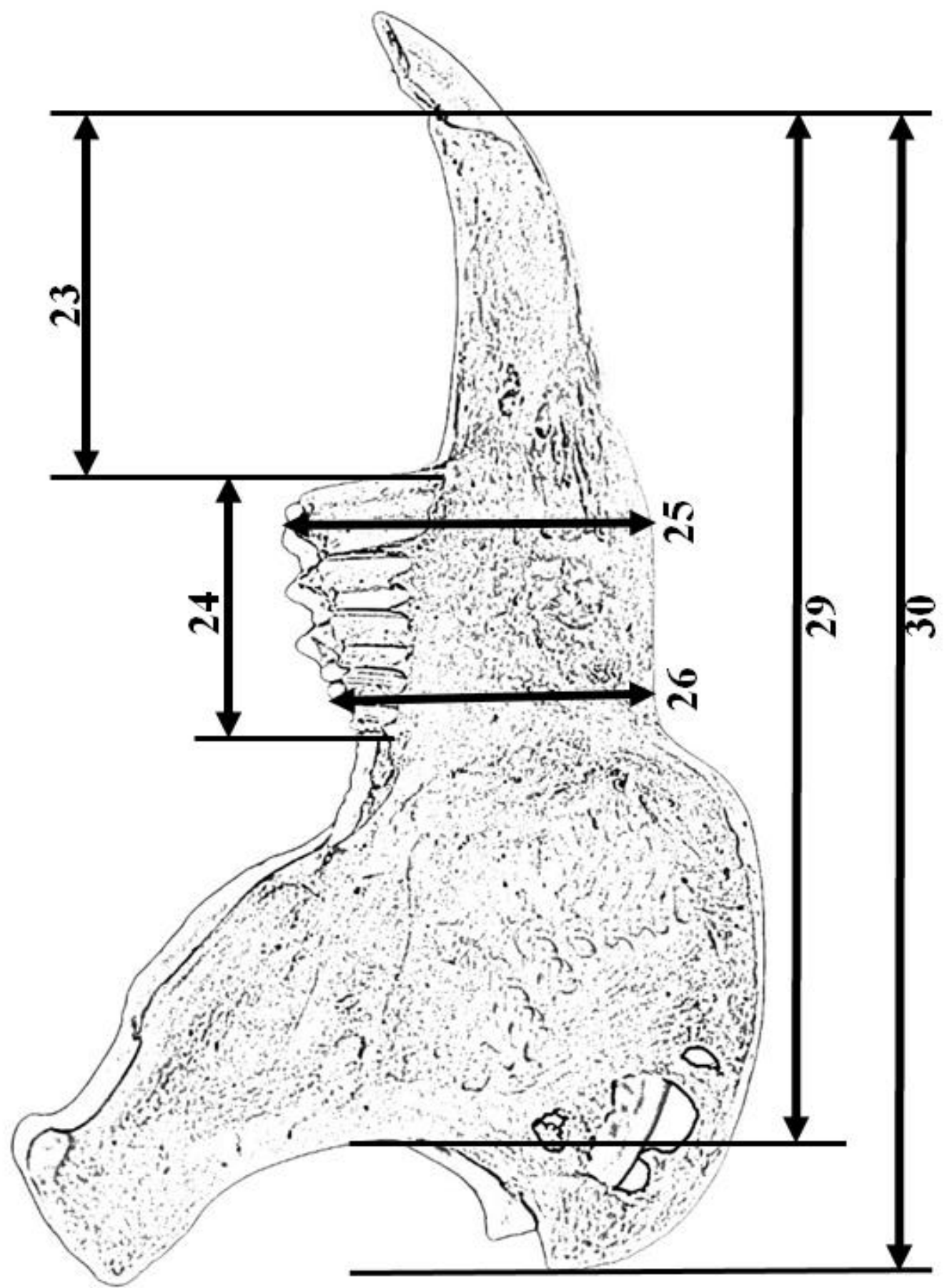


Measurements corresponding to Figures I1-I4.

Table I2

1. Greatest length of skull

2. Superior Orbital Length

3. Posterior orbital process

4. Anterior orbital process

5. Zygomatic breadth at spine

6. Zygomatic breadth

7. Zygomatic length

8. Dorsoventral depth of zygomatic arch

9. Breadth of braincase

10. Width at exoccipital bones

11. Length of auditory bulla

12. Width of auditory bulla

13. Interorbital breadth

14. Height of rostrum

15 . Width of rostrum

16. Rostrocaudal length of incisive foramina

17. Width of incisive foramina

18. Length of palatal bridge

19. Width of choana at first upper molar

20. breadth of alisphenoid constriction

21. alveolar length of maxillary tooth row

22. upper diastema

23. lower diastema

24. Dentary tooth row length

25. Maximum height of dentary tooth row

26. Minimum height of dentary tooth row

27. Breadth of mandible at AH

28. Breadth of mandible at masseteric line

29. Greatest length of mandible (incisor to ptt)

30. Greatest length of mandible to $\mathrm{AH}$

31. Length of Nasals

32. Width of Nasals

33. Lacrimal spine breadth

34. Skull height at brow

35. Maximum skull height 